\title{
Cellulosic Substrates for Removal of Pollutants from Aqueous Systems: A Review. Part 4. Dissolved Petrochemical Compounds
}

\author{
Martin A. Hubbe, * Junyeong Park, and Sunkyu Park \\ Dissolved petroleum-based compounds, e.g. solvents, pesticides, and \\ chemical reagents such as phenolic compounds, can pose significant \\ hazards to the health of humans and ecosystems when they are released \\ to the environment. This review article considers research progress \\ related to the biosorption and removal of such contaminants from water \\ using cellulose-derived materials. The fact that cellulosic materials show \\ promise in removing such sparingly soluble materials from water lends \\ support to a hypothesis that lignocellulosic materials can be broad- \\ spectrum adsorbents. Also, the hydrophobic character and sorption \\ capabilities can be increased through thermal treatment and the \\ preparation of activated carbons. As shown in many studies, the efficiency \\ of uptake of various petrochemical products from water also can be \\ increased by chemical treatments of the adsorbent. It appears that more \\ widespread adoption of biosorption as a means of removing petroleum- \\ based products from water has been limited by concerns about the used, \\ loaded biosorbent. Disposal or regeneration options that need to be \\ considered more in future research include enzymatic and biological \\ treatments, taking advantage of the fact that the biosorbent material is able \\ to collect, immobilize, and concentrate various contaminants in forms that \\ are suited for a number of packed bed or batch-type degradative treatment \\ systems.
}

Keywords: Cellulose; Biomass; Biosorption; Remediation; Pollutants; Adsorption; Petroleum;

Organic chemicals; Solvents; Pesticides; Wastewater treatment

Contact information: Department of Forest Biomaterials, College of Natural Resources, North Carolina State University, Campus Box 8005, Raleigh, NC 27695-8005; *Corresponding author: hubbe@ncsu.edu

\section{CONTENTS}

Introduction ................. 7783

Experimental Findings .............. 7784

Source materials ........... $\quad 7784$

Modification of the sorbent . . . . . . . 7787

Attributes of the sorbent . . . . . . . . 7792

Attributes of the sorbate . . . . . . $\quad 7799$

Aqueous conditions . . . . . . . . . . 7801

Theoretical Aspects . . . . . . . . . . . . . $\quad 7806$

Life Cycle Issues . . . . . . . . . . . . $\quad 7829$

Concluding Remarks. . . . . . . . . . . . . $\quad 7835$

Literature Citations . . . . . . . . . . . . . . . . . . . 7837

Table A (Appendix) . . . . . . . . . . . . . . 7881 


\section{INTRODUCTION}

The water-soluble components of various petrochemical products, such as pesticides, solvents, plasticizers, and pharmaceuticals, pose hazards to people and to nature (Keith and Telliard 1979). The toxic nature of many petroleum-derived organic compounds has been well documented (Augulyte et al. 2008). Substances capable of disrupting the endocrine systems of people and animals are of particular concern (Sethunathan et al. 2004; Yu et al. 2008; Kumar et al. 2009a; Rossner et al. 2009; Chang et al. 2012; Jung et al. 2013; Ye et al. 2013; Soni and Padmaja 2014). Phenolic compounds, despite their limited aqueous solubility, are serious water pollutants, especially in the case of chlorinated phenolics (Igbinosa et al. 2013; Tsai 2013).

Alternative measures for removal of organic pollutants from water solution have been reviewed (Franklin 1991; Dvorak et al. 1993; Droste 1997; Özbelge et al. 2002; Demirev 2008; Thuy et al. 2008; Musteret et al. 2010; Pratarn et al. 2011; Margot et al. 2013). In particular, conventional wastewater treatment, using either activated sludge or various types of bioreactors, can induce biodegradation of many petrochemical products, at least in part (Juhasz and Naidu 2000a; Farhadian et al. 2008; Marin et al. 2010; Kwon et al. 2011; Al-Khalid and El-Naas 2012; Krastanov et al. 2013; Niti et al. 2013).

Adsorption onto suspended particles has been proposed for many years as a promising route to remove petrochemical pollutants from dilute aqueous solutions (Morris and Weber 1962; Weber and Morris 1963). The general topic of biosorption also has been reviewed (Mattson and Mark 1971; Dobbs and Cohen 1980; Perrich 1981; Pollard et al. 1992; Vrana et al. 1998; Moreno-Castilla 2004; Aksu 2005; Dąbrowski et al. 2005; Mathialagan and Viraraghavan 2008; Gadd 2009; Lin and Juang 2009; Bhatnagar et al. 2010; Capasso and De Martino 2010; Zolgharnein et al. 2011; Delgado et al. 2012; Julinová and Slavík 2012; Pintor et al. 2012; Gupta and Saleh 2013; Liu et al. 2013; Michalak et al. 2013; Fomina and Gadd 2014). In the present discussion the term "biosorption" will be taken to include adsorption of pollutants on any sorbent material derived from plant matter. Activated carbons will be included, with emphasis placed on such products prepared from cellulosic raw materials. A recent article by Chowdhury et al. (2013) provides a thorough review and discussion of carbonization and carbon activation procedures, making it unnecessary to cover those aspects in as great detail in the present article. This article focuses on progress that has been made in the use of lignocellulosic materials, as well as its derivative products, for the removal of solubilized petrochemical products from water.

A subtheme of this article will be the extent to which cellulose-derived products can act as broad-spectrum absorbents. The earlier review articles in this series also showed that cellulose-based materials can be effective for the removal of heavy metals, dyes, and liquid or emulsified oils from water (Hubbe et al. 2011, 2012, 2013). It is notable that cellulosic products can be effective for the remediation of aqueous spills of oil-like substances, a capability that is not obvious based on the hydrophilic nature of the sugar units that make up cellulose. The scope of the third of the listed review articles was intentionally incomplete, since it did not deal with uptake of the dissolved portions of those oils. Thus, the present article completes the analysis for petroleum-derived products as a whole. Also it should be noted that, strictly speaking, the dyes reviewed in Part 2 of the 
series can be considered as petrochemical products. So there will naturally be frequent references to aspects already covered in Part 2 (Hubbe et al. 2012).

The motivation to seek broad-spectrum absorbency stems from the nature of pollution. Only seldom does it happen that the material one wishes to remove from water is highly pure and highly characterized. It is far more common for polluted water to contain many substances that have not been identified. For instance, it is reasonable to expect that petrochemical-based compounds in samples of contaminated water may span the ranges between aliphatic and aromatic, hydrophilic to very sparingly soluble, and nonionic to highly charged, with huge ranges of molecular mass and volatility. In light of this diversity of potential sorbates, this review article will begin with consideration of diverse types of cellulosic materials - as well as transformed products such as torrefied wood and activated carbons - relative to the uptake of petroleum-based sorbates from water. As will be shown, while cellulosic biomass in general has a rather broad affinity for a wide range of petroleum-based substances, the affinity can be increased by various treatments. Also, one should not rule out the possible use of mixed sorbents, such as combinations of raw and torrefied biomass or sawdust together with fungal biomass, etc. Subsequent sections of the article will deal with attributes of common petroleum-derived contaminants that may be present in water samples, aspects of aqueous composition found to affect sorption, theoretical aspects, and life cycle issues.

\section{EXPERIMENTAL FINDINGS}

\section{Overview}

Research studies devoted to the removal of petrochemical-based substances from water by use of cellulose-derived sorbents have been both numerous and diverse, especially during the most recent decade. Key findings from articles considered in the present review are listed in Table A, which due to its length is placed in the Appendix. The table lists the information according to the categories of pollutant, adsorbent (including drying conditions and treatments), adsorption isotherms that best fit the data, adsorption capacities, the rate laws that best fit to data, and the main thermodynamic information whether adsorption is exothermic or endothermic. Additional information of note appears in a column headed by "Key Findings". The headings of the table correspond, in a rough sense, to the progression of topics in sections that follow.

\section{Sorbent Source Materials}

Though just about every imaginable plant-based material has been studied relative to its potential use in adsorbing synthetic organic compounds, inspection of the second column in Table A reveals a preponderance of interest in the use of activated carbon sorbents. Results of such work will be summarized later in this section. The reason why activated carbon products receive so much attention can be attributed to a favorable combination of a hydrophobic nature, a high surface area, and a potentially favorable pore size distribution that can be changed depending on the conditions of preparation. But, as will be described, the conditions used in the preparation of activated carbons make such sorbents inherently more expensive than many other cellulosic materials due to the significant weight loss, energy usage, and chemical usage, especially in cases where the 
raw material can be obtained as an underutilized byproduct. So, one of the important questions to consider is whether and when it may make sense to favor the use of different kinds of sorbent materials.

\section{Wood}

Adsorption tests of monoaromatic hydrocarbons onto unmodified softwood chips have been reported by Mackay and Gschwend (2000). Adsorption kinetics were found to be favorably affected by lignin content in the wood. But one of the key findings was that the rate of uptake into the wood was very slow, at least when it is utilized in the form of chips rather than fibers.

Huang et al. (2006) found that the adsorption characteristics of aspen wood fibers could be altered by bleaching and hydrolysis. An oxidative bleaching treatment removed the lignin, rendering the fibers more hydrophilic and more porous. Hydrolysis, with use of strong acid, mainly removed hemicellulose, thus yielding fibers having a higher aromatic character and lower polarity. In general, the bleaching treatment decreased the sorption capacity for phenanthrene and pyrene, whereas the hydrolysis treatment increased adsorption of both of the sparingly soluble compounds from aqueous solution.

The lignin component of wood is sometimes viewed as a potential sorbent for sparingly soluble organic pollutants due to its generally hydrophobic character. Lignin's capability for biosorption of phenolic substances was evaluated by Allen et al. (2005). Cuhha et al. (2010) showed that humins, which can be considered to be a product of the natural decomposition of lignin, can be used to adsorb trihalomethanes. Rodriguez-Cruz et al. (2007) compared the adsorption capacities for pesticides onto nine types of woods having a wide range of lignin content. There was a strong correlation between increasing lignin content and increasing sorption capacity. These results are consistent with the findings of Severtson and Banerjee (1996), as shown in Fig. 1.

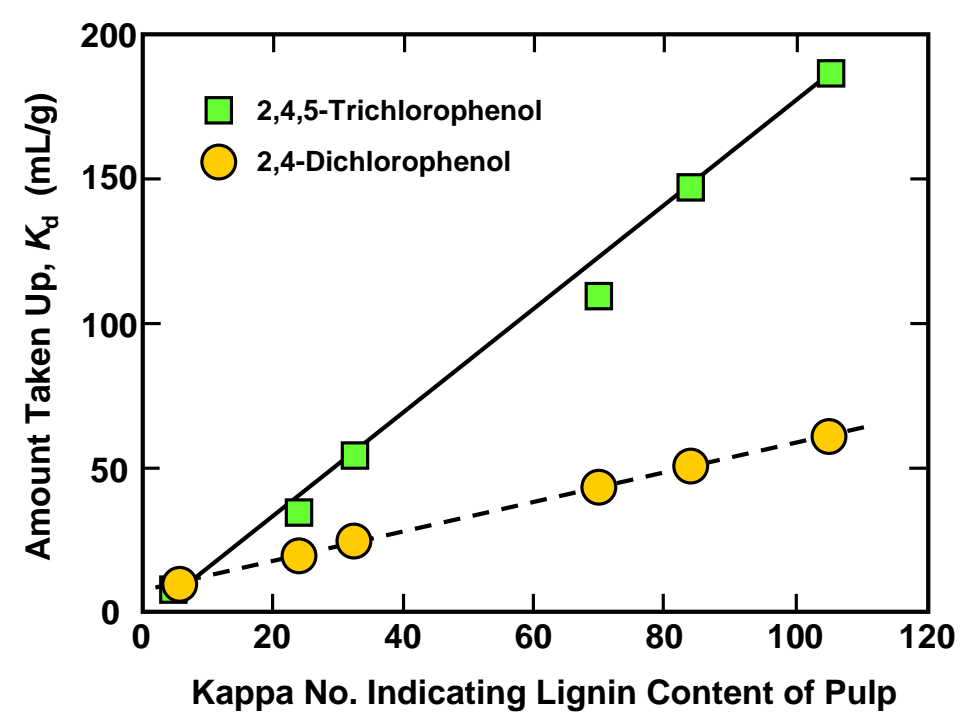

Fig. 1. Dependency of two phenolic compounds onto cellulosic fibers vs. kappa number, which linearly correlates with lignin content. Data at near-zero kappa correspond to cotton. Other points were for softwood kraft fibers over a wide range of pulping and bleaching conditions. Uptake includes the amount contained in water solution that is within the pores and lumens of the fibers. Figure redrawn based on data from Severtson and Banerjee (1996). 
Severtson and Banerjee (1996) studied sorption of chlorophenols onto pulped softwood kraft fibers having different extents of delignification. As indicated in Fig. 1, very little of the pollutants were adsorbed onto cotton cellulose (data points near to zero kappa number), whereas there was a very strong correlation between chlorophenol adsorption and the kappa number of the kraft pulps, the value of which is reflective of the relative amount of lignin remaining in the fiber.

Bark is another tree-derived material that has been considered as a potential biosorbent. Kumar and Min (2011a) and Kumar et al. (2012) showed that Acacia leucocephala bark could be used to remove chlorophenols. Related work with pine bark was reported by Kumar et al. (2014). Rotala et al. (2003) showed that pine bark can be used to remove the pesticides lindane and heptachlor from solution. A study by Li et al. (2010a) showed that pine bark contains substantial amounts of waxy substances, in addition to polysaccharides and lignin.

\section{Fungal sorbent material}

Relative to wood, fungal products have some key attributes that make them promising candidates for biosorption (Aksu 2005): The material tends to be less dense, making it reasonable to expect easier accessibility of various molecules into the fine pore structure. Also, much of the available fungal material is produced as a byproduct of other processes, such as fermentation, which are carried out at centralized locations. As shown by Kumar and Min (2011b), fungal biomass may contain significant amounts of nitrogen in the form of amines and amides; this is attributable to the presence of protein. Various researchers have evaluated fungal material relative to the uptake of phenols and other synthetic organic compounds from solution (Young and Banks 1998; Rao and Viraraghavan 2002; Denizli et al. 2005; Wu and Yu 2006b; Kumar et al. 2009b; Pernyeszi et al. 2009; Huang et al. 2010; Kumar and Min 2011b; Zhang et al. 2011c; Farkas et al. 2013). Rao and Viraraghavan (2002) found the highest uptake following pretreatment of Aspergillus niger with sulfuric acid.

\section{Bacterial sorbent material}

$\mathrm{Ju}$ et al. (1997) compared the adsorption of lindane onto Gram-positive and Gramnegative bacteria. Seo et al. (1997) explored the use of seeding micro-organisms into a membrane filtration system, in combination with activated carbon. The inoculated systems were found to be four times as effective in removing various hard-to-decompose organic substances from water. Though such studies involving bacteria have been relatively scarce, they can help contribute to an understanding of activated sludge systems for water treatment (Bell and Tsezos 1988; Aksu and Yener 1998, 2001; Vrana et al. 1998; Stringfellow and Alvarez-Cohen 1999; Aksu and Gönen 2004; Arslan and Dursun 2008; Augulyte et al. 2008; Pan et al. 2010; Yu and Hu 2011; Hai et al. 2012; Julinová and Slavík 2012; Khalaf et al. 2013). Thus, it is likely that biosorption can explain at least part of the ability of activated sludge-based wastewater treatment systems to remove various sparingly soluble pollutants from water (Tsezos and Bell 1988, 1989, 1991; Tsezos and Wang 1991). 


\section{Living or dead microbial matter}

One key difference between a conventional activated sludge wastewater treatment system and most studies that have considered use of microbial matter as a biosorbent concerns whether the cells are alive or dead. Several studies have confronted this issue directly, using various means to optionally kill the microbes and find out any effects of such treatment on biosorption (Tsezos and Bell 1989). In some cases the extent of removal of pollutants from water was about the same, when comparing live vs. dead cells (Yan and Allen 1994; Johasz et al. 2002; Lei et al 2002; Chen et al. 2010; Ding et al. 2013). There was evidence in some of the studies that adsorption onto microbial material may tend to protect the target compounds from enzyme-induced decomposition (Chen et al. 2010). On the other hand, increased adsorption of petrochemicals after autoclaving of microbial biomass to kill the cells has been observed in some cases (Wang and Grady 1994; Lang et al. 2009).

\section{Modification of Sorbent Materials}

Biomaterials have been modified physically, chemically, and by pyrolysis with an aim to determine the most suitable processing conditions to enhance adsorption capacities or other attributes of sorbents.

\section{Drying}

As was noted in earlier review articles concerned with biosorption of heavy metal ions and dyes (Hubbe et al. 2011, 2012), a majority of researchers have begun their analyses either with pre-dried cellulosic materials or by imposing a controlled drying step, using an oven (see Table A). Such procedures possibly can be justified in terms of better storage stability of the dried material. Also, the heat treatment can help to define the starting condition for testing. But the question of whether or not such drying may affect adsorption outcomes has been studied less frequently. Choi and Huber (2009) observed that the sorption of 1-methylcyclopropene from the atmosphere to fruit and vegetable materials was markedly reduced by drying. In that case, much of the adsorptive capability was restored when the material was rehydrated by a minute of wetting with distilled water. But other researchers have documented irreversible losses in the water-absorbing ability of cellulosic materials when they are dried (Stone and Scallan 1966; Weise 1998). The phenomenon is often called hornification (Jayme and Büttel 1968). Thus, there is a critical need for further research, especially in the case of phenolics and other potentially toxic organic compounds in water adsorbing onto plant material that is either never-dried, dried by exposure to different heating regimes, or rehydrated under different aqueous conditions (e.g. temperature, $\mathrm{pH}$, and duration) to determine reversibility of the drying effect.

\section{Grinding of plant material}

A great many studies of biosorption begin with the grinding of dried plant-derived material into a fine powder (Table A). However, in the cited cases the authors generally did not run control tests to find out whether such grinding will affect biosorption results. Thus, again, there is a critical need for research in that area. The topic of "particle size" will be considered later. 


\section{Chemical pretreatments or extraction}

Certain studies have shown clear effects on biosorption after treating the plantderived sorbent with acids, bases, or various solvents. For instance, Juhasz and Naidu (2006b) observed very significant increases in uptake of DDT and related pesticide compounds onto fungal mycelia after treatment with concentrated $\mathrm{HCl}$. Chen et al. (2005) found that when plant cuticle material was solvent-fractionated into components having different polarity, such components differed greatly in their ability to take up polar and nonpolar organic compounds. Li et al. (2010a) showed that relatively severe extraction, using a Soxhlet device, as well as treatments with strong acid or base, were able to partition pine bark into components that differed greatly in their ability to adsorb polycyclic aromatic compounds. El-Sheikh et al. (2013) found surprisingly that washing of olive wood with various solvents made it more effective as an adsorbent for various phenolics. Presumably such an effect can be understood as a removal of hydrophobic materials from pore spaces, thereby making those spaces available for removal other hydrophobic substances from water. However, the cited observation can be considered surprising because one might expect that removal of hydrophobic components from lignocellulosic material would render it more hydrophilic and less oleophilic.

\section{Chemical derivatization and grafting}

The adsorptive characteristics of plant-derived materials clearly can be changed by reactions that place new functional groups on the solid surfaces. Maurin et al. (1999) treated sawdust with fatty acids and demonstrated increased removal of fats from water. Vismara et al. (2009) and Sokker et al. (2009) grafted glycidyl methacrylate (GMA) onto cotton, which in its untreated state was ineffective for adsorption of phenol. The derivatized cotton, depending on the detailed structure of the functional groups, was highly effective as an adsorbent. Hsu and Pan (2007) and Hsu et al. (2009) showed that grafting of methacrylic acid onto rice husk greatly enhanced its ability to take up paraquat.

For high-end applications, such as purification of petrochemical compounds present in aqueous solution, it has been shown feasible to chemically "imprint" a polymeric adsorbent, using the target molecule as a template (Shaikh et al. 2012). The cited authors showed that such a system could be used to bind and enrich an endocrine disruptor molecule, thus amplifying and simplifying subsequent chromatographic analysis. Such a concept has potential to be incorporated into a system for biosorption of specific molecules, using cellulosic materials as a support.

\section{Torrefaction of cellulosic matter}

The word torrefaction can be defined as the applications of mild thermal treatment in the range of about 200 to $300{ }^{\circ} \mathrm{C}$ in the partial or complete absence of oxygen (van der Stelt et al. 2011). Such treatment can significantly change the composition and behavior of woody material. Torrefaction has been shown to cause chemical changes due to the loss of volatile components and hemicelluloses. In addition, the changes in lignin structure (e.g. the amount of non-protonated carbon characterized by solid-state NMR) has been reported in this temperature range (Park et al. 2013). There has been a lot of attention directed to the topic of torrefaction in the most recent decade as a promising means to upgrade the energy-density and burning characteristics of pellets and briquettes (van der Stelt et al. 2011; Giudicianni et al. 2013; Ibrahim et al. 2013). But some other changes 
brought about by torrefaction of wood suggest potential applications in the adsorption of oleophilic species from water. For example, various studies have shown that torrefaction tends to make the treated material more hydrophobic (Ibrahim et al. 2013). Penmetsa and Steele (2012) took this approach one step further by adding a binder, before torrefaction, such that the final product was sufficiently hydrophobic to resist moisture when shipped in open containers. In none of the cited studies was there any attempt to evaluate the uptake of petrochemicals from water; thus research in this area is critically needed.

\section{Biochars and carbonation}

The term "biochars" can denote a broad range of cellulose-derived products that have been pyrolyzed to various degrees sufficient to cause at least partial carbonation, i.e. the conversion of polysaccharides and/or lignin to such carbon species as graphite (Reed and Williams 2004; Anderson et al. 2013; Giudicianni et al. 2013). Rutherford et al. (2012) found that aliphatic components tended to be lost, leaving behind material enriched in aromatic content. Various studies have shown that biochars can be used as biosorbents to remove petrochemicals from water (Edgehill and Lu 1998; Jonkers and Koelmans 2002; James et al. 2005; Chen and Chen 2008, 2009; Zheng et al. 2010; Kong et al. 2011b; Ni et al. 2011; Ahmad et al. 2012, 2013; Chen et al. 2012b; Denyes et al. 2012; Mubarik et al. 2012; Das et al. 2013; Hao et al. 2013; Zheng et al. 2013; Mohan et al. 2014). Ahmad et al. (2012) attributed increased adsorption of trichloroethylene after pyrolysis to a combination of increased hydrophobicity and surface area. Also, the aromatic character of the surface tends to be increased (Hao et al. 2013). Karakoyun et al. (2011) showed that effective biosorption of organic contaminants could be achieved with a composite prepared from a hydrogel and biochar.

One of the potential advantages of biochars prepared under intermediate thermal conditions is that there might be a high diversity of surface sites. James et al. (2005) found that the heterogeneity of surface sites in biochar depends on both the starting material and the temperature of pyrolysis. Mohan et al. (2014), who reviewed the topic of adsorption of contaminants onto biochar, noted that such sorbents typically have much higher oxygen, hydrogen, and ash content in comparison to typical activated carbons. The cited article showed very wide ranges in the reported adsorption capacities of different biochars for a range of metal ions; presumably much of the differences might be attributable to differences in conditions of charring, e.g. temperature, time, and atmosphere. Biochars also have to potential for lower cost than the available activated carbons, though as Mohan et al. (2014) point out, such an advantage may slip away as soon as one attempts to upgrade the material to improve its adsorption capacity or other performance issues.

Biochars have been often suggested as playing a key role in carbon sequestration, since biochar added to soils can be expected to persist for many decades (Rutherford et al. 2012). But in addition, such biochar can be expected to play a role in binding sparingly soluble organic contaminants that may be present in the soil (Lou et al. 2011; Deneys et al. 2012; Hao et al. 2013; Li et al. 2013a). One potentially problematic aspect of biochar addition to soils is the fact that some polycyclic aromatic hydrocarbons (PACs), which can be considered as pollutants, may come from the biochar itself (Fabbri et al. 2013; Quilliam et al. 2013). A slow pyrolysis process was recommended by Fabbri et al. (2013) in order to minimize the level of the PACs that originate from the biomass or from its conversion into char. 


\section{Activation of carbon}

The term "activated carbon" implies a material that has been pyrolyzed under conditions leading to very high internal surface area. Though substantial quantities of carbon products are prepared from fossil resources such as coal (Dumanli and Windle 2012), there is increasing interest in preparation of activated carbons from a variety of biomass sources (Choudhury et al. 2013). In particular, coconut shell is a major source for the production of activated carbons. Activated carbon products have a complex, interconnecting pore nanostructure that can be influenced by the treatment conditions. The subject of activated carbons, including strategies and theories related to their optimization, has been described in greater detail elsewhere (Dias et al. 2007; Suhas et al. 2007; Chowdhury et al. 2013). Briefly stated, the production of activated carbons typically entails treatment at temperatures in the range of 600 to $1200{ }^{\circ} \mathrm{C}$. But mere carbonizing of the plant-derived material in an oxygen-poor environment generally would not succeed in production of a high surface area material with a favorable balance between micropores (less than $2 \mathrm{~nm}$ ) and mesopores (2 to $50 \mathrm{~nm}$ ) (Rouquerol et al. 1994). One approach to achieving such objectives entails adding such reagents as $\mathrm{KOH}, \mathrm{NaOH}, \mathrm{H}_{3} \mathrm{PO}_{4}$, or $\mathrm{H}_{2} \mathrm{SO}_{4}$ before the final stage of pyrolysis (see Table A). Another approach is to treat the system with steam during pyrolysis (see later).

Various studies have shown favorable effects of activation treatments on the uptake of petrochemicals from aqueous systems. Such studies can be identified in Table A by the letters "AC" (for "activated carbon") in the third column. As is evident from many of the values shown in the $6^{\text {th }}$ column, activated carbons typically exhibit high adsorption capacities in comparison to most other types of sorbents.

Because of the profoundness of the changes brought about by pyrolysis and activation, it appears that details of the starting cellulosic material can become unimportant. For example, Klasson et al. (2010) found no significant differences between activated carbons prepared from different batches of nut shells. As long as the material was relatively uniform it was possible to prepare activated carbon of high quality and effectiveness. More prominent effects related to the source material were reported by Yeganeh et al. (2006), who compared a much more diverse set of biomass types.

\section{Activating compound}

The performance of carbon-based absorbents can be greatly enhanced by treatment of the carbon with certain chemicals, either initially or before a final activation stage. Potassium hydroxide is one of the most widely studied activating agents (Wu et al. 2005; Radhika and Palanivelu 2006; Tan et al. 2008; Kilic et al. 2011; Wu et al. 2011, 2012b; Kong et al. 2012). Radhika and Palanivelu (2006) found that $\mathrm{KOH}$-activated carbon outperformed products that they prepared from five other activating systems relative to sorption of chlorophenol. Wu and Tseng (2006) and Tan et al. (2008) described the action of $\mathrm{KOH}$ as "etching", a treatment that renders the carbon susceptible to the generation of pores. The cited authors showed that a combination of $\mathrm{KOH}$ activation followed by pyrolytic treatment with $\mathrm{CO}_{2}$ had a promising effect on phenol sorption. Chen et al. (2012a) employed the unique approach; instead of adding $\mathrm{KOH}$ they selected a biomass source inherently rich in potassium. After pyrolysis the material had a well-developed mesoporous structure and exhibited a high ability to adsorb phenol from water. 
Phosphoric acid is another of the most widely reported activating compounds for preparation of activated carbons (Toles et al. 1997, 1998; Daifullah and Girgis 1998, 2003; Kennedy et al. 2007; Aber et al. 2009; Anirudhan et al. 2009; Klasson et al. 2009; BelloHuitle et al. 2010; Timur et al. 2010; Moreno-Pirajan et al. 2011). Kennedy et al. (2007) found that a two-stage process, with an initial carbonation stage followed by addition of the activating agent $\left(\mathrm{H}_{3} \mathrm{PO}_{4}\right)$ and further pyrolysis, yielded a favorable combination of micropores and mesopores - offering both high sorption capacity and relatively quick equilibration.

Other activating agents that have been considered to improve the adsorption of petrochemicals from water include zinc chloride (Mohanty et al. 2005; Nath et al. 2008; Subha and Namasivayam 2009, 2010; Timur et al. 2010; Aravindhan et al. 2011), carbon dioxide (Ferro-Garcia et al. 1996; Toles et al. 1997; Teng and Hseih 1999; Wu and Tseng 2006; Hameed et al. 2009; Zhong et al. 2012), sodium hydroxide (Tseng et al. 2010, 2011; Fierro et al. 2008), potassium carbonate (Mestre et al. 2007; Kilic et al 2011), and nitric acid (Nabais et al. 2009; Mourão et al. 2011). Sulfuric acid, when used as an activating agent, has been said to help dehydrate the raw material and to aid in formation of a porous texture (Cuerda-Correa et al. 2006). Iniesta et al. (2001) reported that sulfuric acid also can result in lower ash content. Because some of the ash may have a catalytic effect, the removal of mineral content may affect char reactivity.

\section{Steam activation}

Several investigators have reported that steam activation of carbon can be effective to increase the sorption capacity for hydrophobic organic compounds ( $\mathrm{Ng}$ et al. 2000; Juang et al. 2001; Galiatsatou et al. 2002; Vinod and Anirudhan 2002; Tseng et al. 2003; Reed and Williams 2004; Kumar et al. 2006; Mestre et al. 2007; Klasson et al. 2009, 2010; Anderson et al. 2013; Bai et al. 2013). Ahmedna et al. (2004) found that steam-activated carbon outperformed acid-activated carbon for the sorption of chlorination byproducts from drinking water. Bansode et al. (2003) likewise found that activation with either steam or $\mathrm{CO}_{2}$ was more effective than other activation systems considered for enhancing the uptake of volatile organic compounds.

\section{Post-treatments of activated carbons}

Various authors have described enhancement procedures for activated carbons that might be called "post-treatments". It appears that the general goal of such treatments has been to modify the nature of surface sites on the material, while attempting to avoid too much damage to the pore size distribution and surface area attributes achieved in previous steps. Alvarez et al. (2005) treated activated carbons with ozone and showed evidence of an increased level of acidic functional groups on the surface. Nevskaia and Guerrero-Ruiz (2001) showed that post-treatment with nitric acid was another way to increase the content of oxygen-containing groups at the surface of activated carbon. Qu et al. (2013) showed that by post-treatment with nitrogen plasma it was possible to reduce the frequency of oxygen-containing groups in activated carbon, together with a loss of surface area; by contrast, treatment with an oxygen plasma increased both oxygen content and specific surface area. Mahajan et al. (1980) had shown earlier that post-treatment with a nitrogen atmosphere increased the adsorption capacity for phenol. Leng and Pinto (1997) considered the effects of oxygenation, de-oxygenation, and HCl-washing. Mild oxidation 
showed promise for extending the service life of regenerated activated carbon. Quinlivan et al. (2005) showed that the surface chemistry of active carbon could be modified by acid washing, oxidation, hydrogen treatment, or ammonia treatment, and such changes affected the adsorption of methyl tetra-butyl ether and trichloroethene.

Post-treatment can be used as a way to change the surface composition and make an activated carbon product more effective for specific applications. Thus, Radovic et al. (1997) found that an increase in acidic groups on the sorbent surface increased the uptake of analine, a basic material, whereas an increase in graphene content favored uptake of the neutral, hydrophobic compound nitrobenzene. Stavropoulos et al. (2008) post-treated active carbon to introduce acidic or basic properties using partial oxygen gasification, nitric acid, or urea followed by pyrolysis. The urea treatment resulted in higher nitrogen content of the sorbent and led to the greatest increase in uptake of phenol. Tessmer et al. (1997) observed that adsorption of phenolic compounds was favored by carrying out the final pyrolysis in the absence of oxygen, thus lowering the content of acidic groups at the surface of the sorbent.

\section{Attributes of Sorbent Materials}

The goal of this section is to discuss evidence, provided in the literature, to support the hypothesis that the ability of cellulose-based materials to take up sparingly soluble synthetic organic materials from water is somehow related to either the physical structure or the chemical nature of the solid surfaces. Attributes related to physical structure will be considered first.

\section{Particle size of the cellulose-based sorbent}

If one starts with a simple model in which sorbate molecules are envisioned as adsorbing mainly onto outer surfaces of the sorbent material, then it would follow that adsorption capacity, or at least the initial rate of uptake, ought to increase with decreasing particle size. A number of publications that have provided information that permit some testing of such idealized models will be considered here.

Several studies reported strongly rising adsorption capability with decreasing particle size of the adsorbent (Munaf et al. 1997; Brás et al. 1999, 2005; Garcia-Mendieta et al. 2003; Boussahel et al. 2009). For adsorption of DDT from aqueous solution onto sawdust or cork powders, Boussahel et al. (2009) observed a five to ten times higher initial rate of adsorption onto $0.2 \mathrm{~mm}$ particles compared to $0.5 \mathrm{~mm}$ particles. Brás et al. (1999, 2005) found a similar relationship for the adsorption capacity of organochlorine compounds on pine bark. One common feature that may help account for the findings cited above is that the mentioned sorbent materials tended to be relatively dense or limited in porosity.

Some other studies have shown little or no relationship between adsorption capacities and particle size of the adsorbent (Garcia-Mendieta et al. 2003). Presumably in such cases the diffusion of the adsorbate was sufficiently rapid that particle size did not matter very much, at least within the time scales considered in the cited studies. This is especially true in the case of activated carbons, which are generally known for their high porosity. Also, many activated carbons have been optimized to have a high content of mesopores, which are large enough to promote relatively rapid transport of adsorbates into interior spaces. Koumanova et al. (2003) found higher initial adsorption rates onto smaller 
particles even in the case activated carbon, an effect that might be at least partly attributed to relatively slow diffusion into the interior of particles. Zheng et al. (2010) found that less time was required to reach equilibrium adsorption of triazine pesticides onto smaller particles of biochar. Leyva-Ramos et al. (1999) reported increased adsorption capacity of smaller activated carbon particles when adsorbing phenol from aqueous solution; no effect of particle size was found when the adsorption was from cyclohexane solution. Kao et al. (2000) surprisingly observed higher adsorption capacity for chlorophenols in the case of larger fly ash particles than smaller particles. This unusual effect was attributed to a different chemical composition of the bigger particles compared to the smaller ones. The bigger particles were found to have a higher carbon content, which apparently contributed to a higher sorption capacity.

\section{Surface area of the cellulose-based sorbent}

Taking a somewhat more sophisticated approach, several studies have attempted to correlate adsorption capacities to the measured surface areas of sorbent materials. Positive correlations between the surfaces areas (usually determined by nitrogen adsorption at very low temperature in a near-vacuum) and the amount of petrochemical adsorbed from aqueous solution have been reported by several groups (Moreno-Castilla et al. 1995b; Teng and Hseigh 1999; Kao et al. 2000; Hao et al. 2013). Figure 2 shows results obtained by Kao et al. (2000) for adsorption of 2-chlorophenol onto fly ash samples having different specific surface area. Further demonstration of the importance of porosity has been evident in the unusually low sorption capacities sometimes reported for adsorption onto cork, which tends to be rather impervious (Domingues et al. 2005).

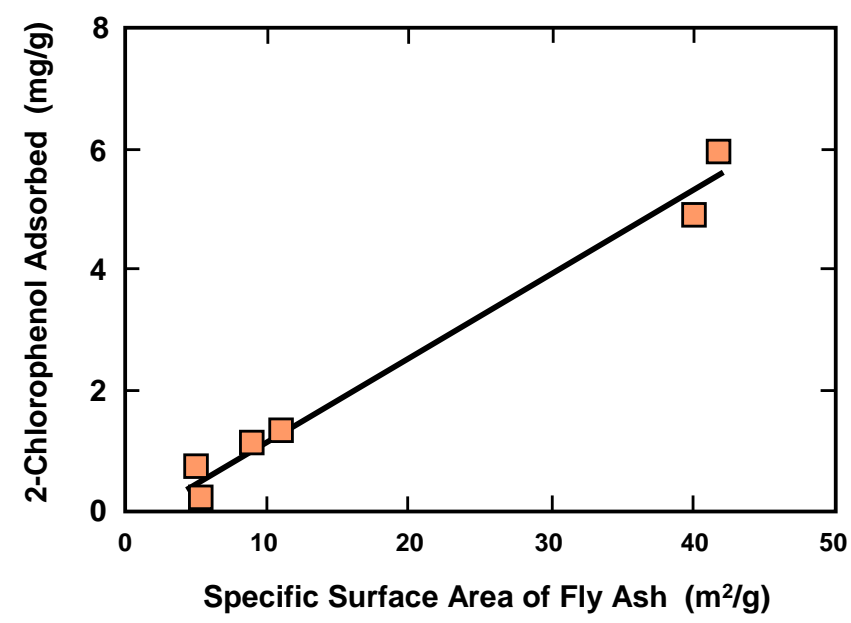

Fig. 2. Relationship between adsorbed amount of 2-chlorophenol and the specific surface area of fly ash fractions. Data from Kao et al. (2000) were replotted.

Not all publications support a hypothesis that adsorption increases with increasing surface area. For instance, Brás et al. (2004) reported that pine bark is "an encouraging sorbent for cheap water remediation solutions" despite the fact that is was found to have a low specific surface area. Unpublished findings by the authors suggest that although the adsorbed amount generally may increase with increasing surface area, the experimental 
results can be highly dependent on experimental conditions such as the manner of washing and the flow rate.

\section{Pore volume}

Chiu et al. (2003) found that it was the pore volume of the micropore structure, rather than the surface area, that seemed to control the sorption of toluene vapor onto natural organic materials. Pore volumes based on analysis of nitrogen adsorption in a nearvacuum at very cold temperature correlated well with the uptake of the toluene vapor at ambient temperature. Likewise, Ran et al. (2013) concluded that it was the void volume rather than the surface area that determined the amounts of nonpolar organic contaminants adsorbing on natural organic solids. Their data are shown replotted in Fig. 3. Note that the plotted line represents a slope of exactly one (unlike the lines plotted in the original publication). It is remarkable how closely the adsorption of the pollutants agreed with the pore volume determined separately by adsorption of carbon dioxide. Garcia-Mendieta et al. (2003) reached similar conclusions when comparing adsorption of phenols onto activated carbon products. Rivera-Utrilla et al. (1991) found that the pore volume accessible to water was a good indicator of adsorption capacity of activated carbons for removal of chlorophenols from water.

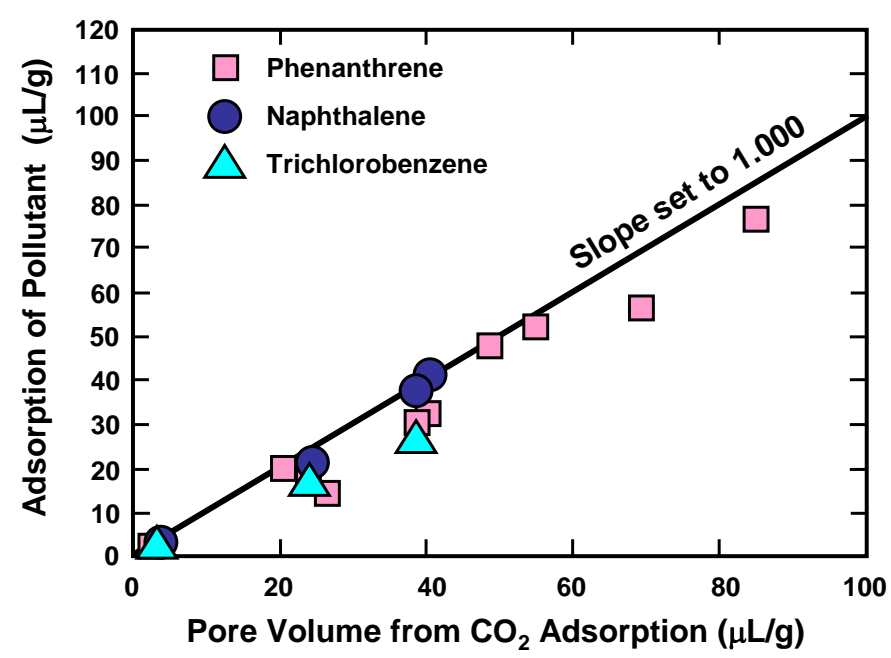

Fig. 3. Adsorption of phenanthrene, naphthalene, and trichlorobenzene onto eleven samples of natural organic matter relative to the pore volume determined by carbon dioxide adsorption. Data from Ran et al. (2013) replotted.

Pore size

Several research teams concluded that it is not the pore volume per se that governs the adsorption capacity of activated carbon products, but rather the net volume of pores in the micropore range (formally less than $2 \mathrm{~nm}$ in diameter). Juang et al. (2001) found a strong correlation between the microporosity of activated carbons and their sorption capacities for phenols. Fierro et al. (2008) found good agreement between the net volume of micropores in activated carbons and the adsorption of phenol, with additional influences due to chemical factors. Karanfil and Dastgheib (2004) concluded that the pore volume 
associated with micropores governed the capacity of granulated carbon for adsorption of trichloroethylene from water. Kumagai et al. (2009) reached a similar conclusion for adsorption of dibenzothiophenes from kerosene onto activated carbons; the mesopores were regarded by those authors as mainly a way to conduct the sorbate to the smallest category of pores. Presumably the adsorbate has a strong tendency to completely fill pores if they are smaller than a critical dimension, whereas adsorbate merely coats the surface of larger pores.

\section{Pore size distribution}

More complex relationships have been reported by investigators who considered somewhat larger sorbate molecules (Li et al. 2002; Newcombe et al. 2002a; Karanfil et al. 2006; Yang et al. 2006a,b). In principle, for each size of sorbate molecule, there must be an optimal size of pore that is large enough to accommodate that sorbate with high affinity. Thus, Hsieh and Teng (2000) proposed that sorbents having a range of pore size will have a consequent range of adsorption energies, such that smaller pores, still able to accommodate the sorbate, exhibit higher energies of adsorption. If pores are too small, then either the adsorption will be unfavored (due to restricted molecular motions) or impossible (because the sorbate molecule simply does not fit). In consideration of such factors, Quilivan et al. (2005) proposed an ideal pore size of 1.5 times the kinetic diameter of the target adsorbate.

Micropores, i.e. those having diameter below $2 \mathrm{~nm}$, often account for the largest component of surface area in activated carbon products (Urano et al. 1991; Aber et al. 2009). The following studies reported cases in which the finest pores were too small to accommodate one or more adsorbates (Li et al. 2002; Ali et al. 2012). Furthermore, very narrow pores are more prone to clogging (Amstaetter et al. 2012). However, in other cases, the adsorption of the target pollutant was increased by increased microporosity of activated carbon (Bai et al. 2013). Galiatsatou et al. (2002) found a correlation between mesoporosity and adsorption of phenols, whereas other sorbates appeared to be mainly influenced by the extent of microporosity. Ji et al. (2010) found evidence that humic acid molecules, which are relatively large, may fail to fill micropores in activated carbon; such exclusion was proposed as a mechanism to account for the non-competition between the humic acids and tetracycline on graphite and carbon nanotubes. Martín-Gullón and Font (2001) attributed high removal of pesticide from water to the presence of "low size mesopores", i.e. a class of pores that provided a good balance between rapid diffusion and fairly high surface area.

Caturla et al. (1988) proposed that if the pore size distribution of activated carbon is sufficiently broad, thus presenting few barriers to adsorption, then the adsorption process ought to become more influenced by factors such as chemical affinity. Indeed, Seredych and Bandosz (2011) documented cases in which sulfur-to-sulfur affinity was strong enough to promote significant adsorption within mesopores in addition to the micropores. Chen et al. $(2005,2008)$ proposed that adsorption can be "porosity-selective" within a certain size range of pores, whereas adsorption can be "polarity-selective" in some other cases. It is worth noting that the broad pore-size distributions present in many well-designed activated carbon products are in contrast to the extremely uniform microporosity inherent in zeolite materials (Rossner et al 2009). Sakoda et al. (1987) argued that a combination of 
microporosity (offering a high surface area) and mesoporosity (offering a shorter diffusion path and more rapid equilibration) is likely to give the best overall performance.

\section{Sorbent chemical composition}

The sorbent's chemical composition, and in particular the chemistry of the surface, can be expected to play a major role in determining the ability to bind various species from solution. For instance it makes sense to expect that cork, which has a chemical composition quite different from most other plant materials (Olivella et al. 2013), might have a quite different affinity for hydrocarbons. The suberin component, which is generally understood to provide the impervious nature of cork, is not found in most other plant materials. However, in the cited study, the content of aromatic groups in the cork had a bigger contribution to adsorption of polycyclic aromatic hydrocarbons.

\section{Oxygen content of the surface}

Several studies have considered the extent to which the oxygen content of the surface of cellulose-based sorbents - especially activated carbon products - has an influence on the uptake of various petrochemical compounds from solution (Franz et al. 2000; Galiatsatou et al. 2002; Alvarez et al. 2005; László et al. 2006; Fierro et al. 2008). In many such studies, the adsorbed amounts were found to decrease as the oxygen content of the adsorbent surfaces became higher (Coughlin et al. 1968; Mahajan et al. 1980; Tessmer et al. 1997; Franz et al. 2000; Nevskaia and Guerrero-Ruiz 2001; Li et al. 2002; Salame and Bandosz 2003; Dąbrowski et al. 2005; Mestre et al. 2007; Okawa et al. 2007; Stavropoulos et al. 2008; Blanco-Martínez et al. 2009; Leyva-Ramos et al. 2009b; Kong et al. 2011a; Sun et al. 2012b; Das et al. 2013; Olivella et al. 2013).

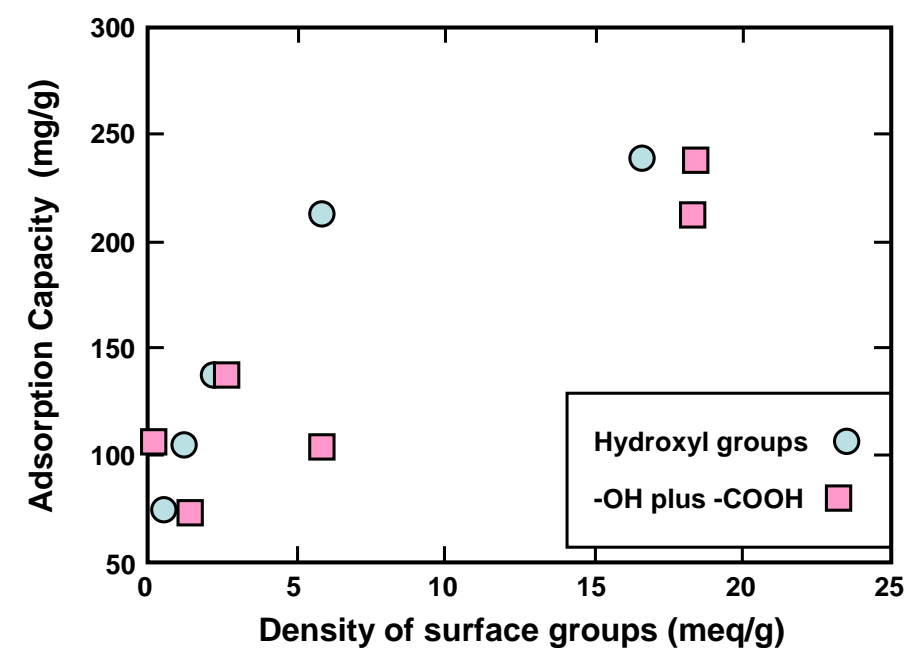

Fig. 4. Phenol adsorption onto activated carbons as a function of the amounts of oxygen-containing groups (hydroxyls or the sum of hydroxyls and carboxyls). Data from Fierro et al. (2008) were replotted.

In other cases there was little observed effect when comparing adsorbents having different levels of surface oxygen groups (Coughlin and Ezra 1968; Haydar et al. 2003). Higher uptake with increasing oxygen content of the adsorbent was observed for the 
adsorption of ethanol (Bai et al. 2013), phenol (Leng and Pinto 1997; Podkościelny et al. 2003; Fierro et al. 2008), polyaromatic compounds (Gotovac et al. 2007b), trihalomethanes (Lu et al. 2005), and fluorinated herbicides (Sun et al. 2011a). Figure 4 shows data from Fierro et al. (2008), which suggests a positive influence of oxygen-containing groups on the adsorption of phenol onto activated carbons that had been modified in different ways.

One aspect that needs to be borne in mind, when considering such findings, is that treatments capable of changing the oxygen content of the surface of activated carbons can be expected to also affect the surface area and distribution of pore sizes. Thus, Teng and Hseih (1999) attributed the greater adsorption of phenol onto carbons with higher oxygen content to the larger surface areas of such adsorbents. Dąbrowski et al. (2005) proposed, based on their study of the literature, that phenols mainly are bound to oxygen-free sites at the edges of graphene sheets in the carbonized material.

\section{Nitrogen content of the surface}

Stavropoulos et al. (2008) correlated the presence of nitrogen at activated carbon surfaces with increased affinity for phenol. Likewise, Wu et al. (2012b) prepared activated carbon with a high nitrogen content and found a high capacity for phenol adsorption. Sun et al. (2012b) found a positive relationship between $\mathrm{N}$ content and adsorption of phthalic esters; the effects was attributed to the hydrogen bonding capability of the nitrogencontaining groups. Zhang et al. (2013) found a similar relationship in the case of phenanthrene. Yaghmaeian et al. (2014) found that activation of carbon in the presence of $\mathrm{NH}_{4} \mathrm{Cl}$ yielded more effective uptake of amoxicillin, presumably due to the interaction between the carboxylate group of the antibiotic and the basic nitrogens ending up on the activated carbon.

But increased nitrogen content may not be a suitable approach for sorption of more hydrophobic species. As in the case of oxygen, the presence of nitrogen at the surface of activated carbon contributes to a hydrophilic character; with this in mind, Li et al. (2002) suggested that nitrogen content should be kept low when designing activated carbon products for adsorption of organic contaminants.

\section{Polar character of the absorbent surface}

Several authors have postulated that the polar character of sites at the absorbent surface contribute to adsorption, especially in the case of phenolic adsorbates (Aksu and Yener 2001; Chen et al. 2005; Akhtar et al. 2006). Other researchers have found higher adsorption of nonpolar sorbate species when the adsorbent surface was less polar (Huang et al. 2006; Chen et al. 2008; Olivella et al. 2013; Zhang et al. 2013). Haghseresht et al. (2002b) proposed that different mechanisms can be important for adsorption when one compares effects of hydrophilic $v s$. hydrophobic types of activated carbons.

Though it might be argued the "hydrophobic" is merely another way of saying "non-polar," several authors have suggested the content of specific hydrophobic compounds already present in adsorbents can account for the differing abilities of activated carbon surfaces to take up various petrochemical compounds (Li et al. 2002; Karanfil and Dastgheib 2004; Quinlivan et al. 2005; Li et al. 2010a; Hao et al. 2013). Thus, Barbour et al. (2005) found that lipids, a hydrophobic component of plant tissues, were primarily responsible for uptake of aromatic organic pollutants from water. Likewise, Boucher et al. (2007) found that residual oils in press-cake from oilseed processing had a high affinity for 
adsorption of the pesticides carbaryl, atrazine, and parathion. Chen and Li (2007) found that removal of wax from plant cuticles made them less effective for the adsorption of naphthol. Lin et al. (2007) found that the adsorption of hydrophobic organic compounds onto tea leaf powders increased with the content of aliphatic carbons; Sun et al. (2012a) reached similar conclusions in the case of herbicide adsorption by biochars. Likewise, Salloum et al. (2002) found that the aliphatic carbons in organic matter were largely responsible for adsorption of phenanthrene. Chen and Schnoor (2009) found that removal of the hydrophobic suberin from root tissue rendered the adsorbent material less effective for phenanthrene. Similarly, Ghosh et al. (2009) found that removal of lipids from Rhizopus oryzae biomass decreased the ability of the adsorbent to take up lindane. Choi and Huber (2009) attributed higher adsorption of 1-methylcyclopropene to certain plant materials to the greater hydrophobicity of lignin. Li et al. (2012) correlated the adsorption of chlorophenols onto fruit cuticles and potato periderm factions to the content of hydrophobic components such as waxes and cutin.

The influence of the polarity of the sorbate material in illustrated in Fig. 5, which is based on data from Li et al. (2010b). Different fractions of material derived from pine bark were used to adsorb pyrene and phenanthrene from aqueous solution. The uptake showed a very high dependency on the ratio of the sum of the nitrogen and oxygen elements to the amount of carbon element. As shown, each of the target chemicals was adsorbed at much higher efficiency if the polarity was very low, i.e. as little as possible of nitrogen and oxygen in the component obtained from pine bark.

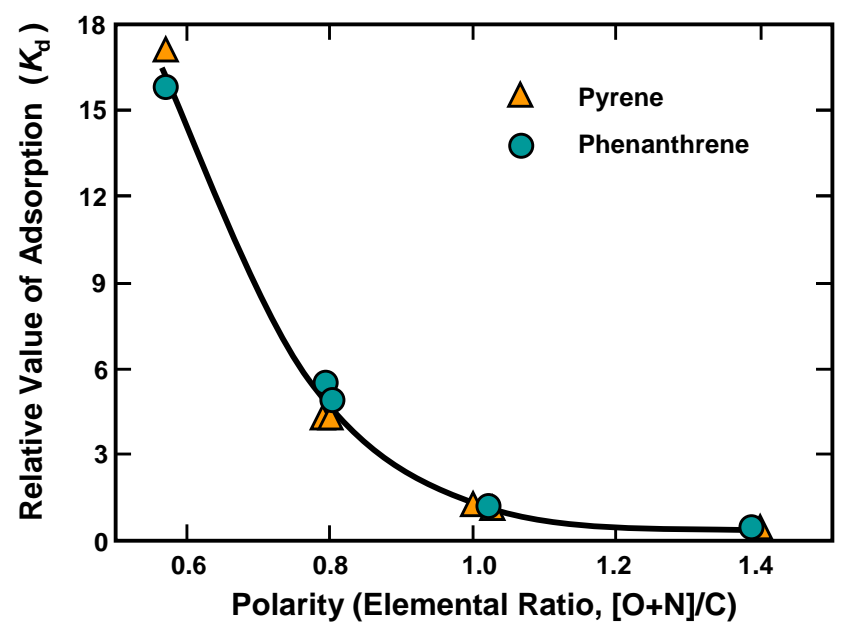

Fig. 5. Dependency of adsorption capacity of different extracted components from pine bark on the $[\mathrm{O}+\mathrm{N}] / \mathrm{C}$ ratio (Figure replotted from the data of $\mathrm{Li}$ et al. 2010b).

\section{Acid/base character of the absorbent surface}

Some of the effects just described, involving relative contents of oxygen and nitrogen at adsorbent surfaces, might be explained in terms of the acidic or basic character of the surfaces. That is because oxygen at a carbon-rich surface is often in the form of carboxylic acids, whereas nitrogen is often present as basic amine groups. The following studies provided support for the idea that acidic or basic groups on an adsorbent surface were favorable for adsorption of certain species from solution (Fierro et al. 2008; Stavropoulos et al. 2008). Similarly, Mattson et al. (1969) used the term "charge-transfer" 
to explain the preferential adsorption of adsorbate molecules based on the electron-density of surface sites. However, given the importance of acidic or basic character in many branches of technology, it is striking how few studies have emphasized such issues among those surveyed in the present work.

\section{Diversity of adsorption sites}

In view of the fact that most contaminated waters contain a wide variety of pollutants, there may be a preference for "broad-spectrum" adsorbents having the capability of removing many contrasting compounds. Heterogeneity of adsorption sites has been noted as an important attribute (Snoeyink et al. 1969; Podkościelny et al. 2003; Pan and Xing 2008; Rossner et al. 2009; Sun et al. 2011b). One of the ways in which a substrate can be heterogeneous can involve ionically charged groups (Müller et al. 1980). Thus, László et al. (2003, 2006) and Dąbrowski et al. (2005) point out that the charge heterogeneity of a sorbent, which might be called its amphoteric character, tends to be greater at intermediate $\mathrm{pH}$ values where both amines and carboxylic acids can be present in their charged forms. Sun et al. (2011b) suggested that hydrothermal biochars may be superior to thermally-produced biochars in terms of the chemical diversity of the surface sites. Another aspect of heterogeneity, as described by Hseigh and Teng (2000) and Rossner et al. (2009), is due to the different sizes of pores, offering capability to take up a spectrum of different adsorbates having different attributes (see next section).

\section{Attributes of the Sorbate}

Petrochemical compounds present in water can vary over large ranges with respect to many attributes, including molecular weight (i.e. molecular size), shape, solubility in water (or polarity), aromatic character, and ionic charge. Specific functional groups might also be important in some cases. This section considers published findings that help to address the hypothesis that such differences in the sorbate can have an important influence on their removal from aqueous solution by adsorption.

\section{Molecular weight of the adsorbate}

The importance of molecular size of the sorbate molecules already was mentioned in the earlier discussion of findings related to the pore size distributions of adsorbents. Thus, studies have identified cases in which the dissolved compounds were too large to be efficiently adsorbed within micropores (Yang et al. 2006a,b; Ali et al. 2012). Correa (2009) explained similar findings based on kinetics, noting that increasing numbers of chlorine substituent atoms imply larger size of chlorophenol molecules; the larger molecules can be expected to exhibit slower rates of diffusion into the fine pore structure of a cellulose-based adsorbent. As was noted earlier, one can expect there to be an optimum pore size, estimated to be 1.3 to 1.8 times larger than the kinetic diameter of the sorbate, which will give the greatest uptake (Li et al. 2002). In principle the free energy of adsorption will be maximized when there is a suitable balance between such factors as (a) favorable surface interactions (enthalpy term), and (b) sufficient space for the molecules to move around (entropy term) (Maginn et al. 1995; Jaroniec and Choma 1997; Adolphs 2007). In other cases the size of a sorbate molecule appears to play an underlying role relative to its affinity to the adsorbent surface (Nouri et al. 2002a). Higher molecular mass often implies a greater tendency to adsorb (Haghseresht et al. 2002a; Choi et al. 2003; 
Boving and Zhang 2004; Gao and Wang 2007; Hansen et al. 2010; Julinová and Slavík 2012; Kusmierek et al. 2013). Larger molecules in general would be expected to have higher free energy of adsorption, per unit molecule.

\section{Molecular shape of the adsorbate molecule}

The topic of molecular shape seems to have been considered in only a few cases. Thus, Karanfil and Dastgheib (2004) found that trichloroethylene molecules were able to access the interior regions of microporous activated carbons; this ability was attributed to a flat molecular shape. There was no demonstration, however, of whether different results would be obtained with a different molecular shape, all things being equal. Likewise, Jonker and Koelmans (2002) observed preferential adsorption of planar molecules. The work of Ozdemir et al. (2012) includes a suggestion that maybe some of the observed differences in adsorption behavior of chlorophenoxy acid derivatives might be related to the presence or absence of chirality. Such ideas might be the subject of future studies, especially if the concepts can be backed up by molecular dynamics simulations or other support. Dargaville et al. (1996) found that ortho-linked oligomers of phenol were adsorbed more from an ethanol solution than the corresponding para-linked phenol oligomers. The difference was explainable by the greater ethanol-solubility of the paralinked compounds. Related findings are discussed in the next section.

\section{Solubility of the sorbate molecules in water}

Several studies have found correlations between adsorption capacity and decreasing water-solubility of the sorbate (Daifullah and Girgis 1998, 2003; Nouri et al. 2002b; Dąbrowski et al. 2005; Wu and Yu 2006a; Aktar et al. 2007a; Hamdaoui and Naffrechoux 2007a; Thuy et al. 2008; Navarro et al. 2009; Hansen 2010; Zhang et al. 2011c). An example is shown in Fig. 6, which is from the data of Thuy et al. (2008). As shown, there was a log-log relationship between the adsorption tendencies (Freundlich main coefficient) and the partition coefficient of the four pesticides between water and octanol.

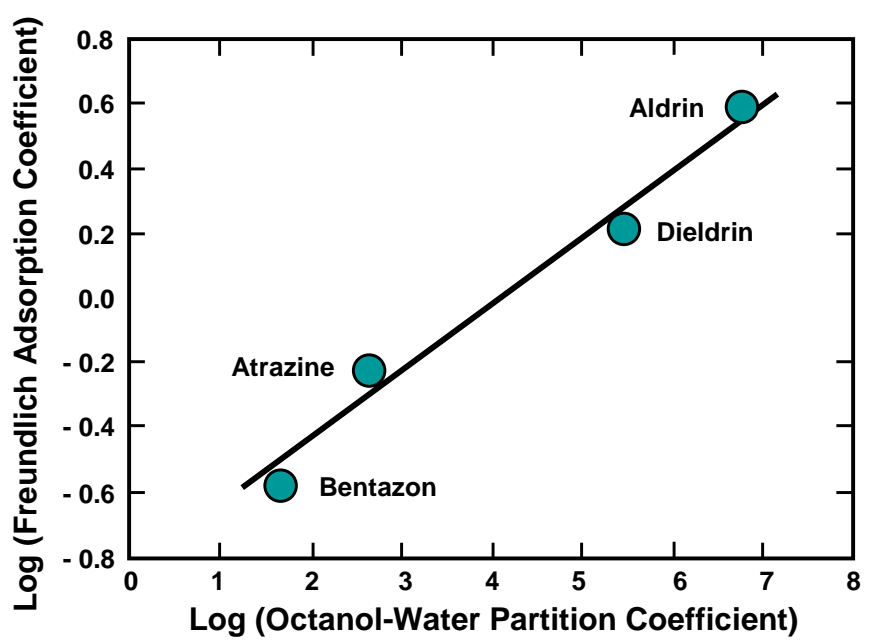

Fig. 6. Log-log (base ten) relationship between the Freundlich " $K$ " coefficient and the octanol-water partition coefficient for four pesticides adsorbing from water onto natural organic matter present in river water. Data replotted from the study of Thuy et al. (2008). 
Similarly, Boving and Zhang (2004) showed that the rate at which aromatic hydrocarbons desorbed from aspen wood fibers was proportional to their water-solubility. Thus, the interaction between the sorbate molecules and water may often play a major role in determining the degree of success of adsorption as a procedure to remove a contaminant from water. Whightman and Fein (1999) identified the molecular characteristics governing the water-solubilities of chlorinated phenols. Findings of increased adsorption with decreasing water-solubility are sometimes explained in terms of a partitioning of the sorbate between the solubilized phase and an adsorbed state (Xia and Ball 1999).

Water-solubility does not always predict adsorption of petrochemical compounds in an expected way. For instance, a study by Yu et al. (2008) was notable with respect to its contrary finding that adsorption increased with increasing water-solubility of the three endocrine-disrupting compounds. Vismara et al. (2009) reported that a certain type of activated carbon, modified by polymer grafting, had high affinity for nitrophenols, which are somewhat hydrophilic compared to other phenols. The finding was attributed to the polarity of the polymeric chains grafted onto the adsorbents.

\section{Ionic charge of the adsorbate}

The majority of studies represented in Table A were concerned with sorbate species in their neutral state of charge. However, phenolic compounds are well known to acquire a negative charge if the $\mathrm{pH}$ is raised sufficiently. Thus the $\mathrm{pK}_{\mathrm{a}}$ values (negative logarithms, base 10, of the acid dissociation constants) are generally in the $\mathrm{pH}$ range from about 6 to 10 (Daifullah and Girgis 1998). In addition, various studies have focused on sorbate species bearing strongly dissociated functional groups, such that an ionic charge was expressed over the whole studied range of $\mathrm{pH}$ (Yu et al. 2009; Yu and $\mathrm{Hu}$ 2011). Yu et al. (2009) proposed an ion exchange mechanism to account of the adsorption of perfluorooctane sulfonate and perfluorooctanoate, both of which will be present in dissociated form to give negatively charged surfactant species. Müller et al. (1980) noted that the adsorption of weak electrolytes (those that are not fully dissociated) can be predicted to a large degree by knowing the $\mathrm{pH}$ and the $\mathrm{pK}_{\mathrm{a}}$ values. Li et al. (2012) reported cases in which increasing ionization of weak acid groups (the phenolic groups) resulted in less adsorption of chlorophenols. Such results are consistent with the solubility considerations discussed earlier.

\section{Effects of Aqueous Conditions}

Having considered the influences of adsorbent properties and adsorbate properties, it remains to consider the findings of studies that mainly have investigated the effects of differences in aqueous conditions.

\section{pH of the aqueous solution}

As listed in the "Key Findings" column of Table A, the $\mathrm{pH}$ of the aqueous medium was found to have a significant effect on adsorption in many of the surveyed studies. In particular, $\mathrm{pH}$ appeared to affect the adsorption of phenolic compounds onto cellulosebased materials, including activated carbons. In a majority of cases it was reported that adsorption fell when the $\mathrm{pH}$ was raised to about 10 or above, which is high enough to cause dissociation of phenolic hydrogens (Snoeyink et al. 1969; Moreno-Castilla et al. 1995b; 
Severtson and Banerjee 1996; Kao et al. 2000; László and Szucs 2001; Rengaraj et al. 2002a; Lu and Chang 2005; Nouri and Haghseresht 2005; Ayranci and Duman 2006; DiazFlores et al. 2006; Srivastava et al. 2006; Wang 2007a; Blanco-Martínez et al. 2009; Nabais et al. 2009; Ofomaja and Unuabonah 2011; Rodrigues et al. 2011, 2013; Abdallah 2013). Figure 7, based on data from Severtson and Banerjee (1996), shows typical behavior. Some studies reported a maximum in adsorption at an intermediate $\mathrm{pH}$ (Rao and Viraraghavan 2002; Ahmaruzzaman and Sharma 2005; Ayranci and Duman 2006; Ncibi et al. 2006; Thawornchaisit and Pakulanon 2007; Memon et al. 2008; Bayramoglu et al. 2009; Li et al. 2009; Jamil et al. 2011; Rodrigues et al. 2011; Kumar et al. 2012; Ozdemir et al. 2012; Abdallah 2013; Kumar et al. 2014), though in most of these cases as well, the adsorption dropped off strongly with further increases in $\mathrm{pH}$.

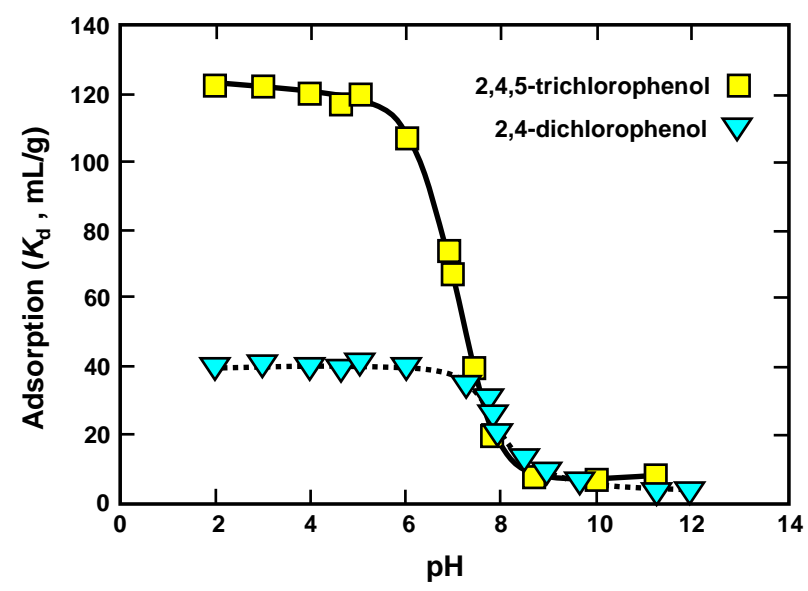

Fig. 7. Effect of $\mathrm{pH}$ on the adsorption of two chlorinated phenols onto softwood fibers having moderately high lignin content (Kappa number 69.8). Data replotted from Severtson and Banerjee (1996).

Other studies reported a general increase in adsorption of phenolic compounds with decreasing pH (Müller et al. 1985a,b; Shimizu et al. 1992; Jacobsen et al. 1996; Brandt et al. 1997; Namasivayam and Kavitha 2003; Nouri and Haghseresht 2004; Villacanas et al. 2006; Gao and Wang 2007; Kennedy et al. 2007; Nath et al. 2008; Correa 2009; Mathialagan and Viraraghavan 2009; Navarro et al. 2009). In yet other cases the best adsorption of phenolic compounds was observed at strongly acidic $\mathrm{pH}$ (Aksu and Yener 2001; Brás et al. 2005; Mohanty et al. 2005; Akhtar et al. 2006; Mestre et al. 2007; Ashour et al. 2008; Pigatto et al. 2013).

All such results, mentioned so far in this subsection, are consistent with increasing repulsion between the generally negative ionic charge of cellulose-based surfaces (due mainly to carboxylic acid groups) and the increasingly negative character of phenols as they are converted to their phenolate form at very high pH (Severtson and Banerjee 1996; Dąbrowski et al. 2005; Nabais et al. 2009). Also, as explained by various researchers (Westall et al. 1985; Wightman and Fein 1999; Moreno-Castilla 2004; Rodrigues et al. 2013), higher $\mathrm{pH}$ conditions that cause dissociation of phenolic groups cause such 
compounds to become more soluble in water and therefore less prone to adsorb, regardless of the nature of the adsorbent.

In rare cases, increasing adsorption of petrochemical compounds with increasing $\mathrm{pH}$ has been reported (Mahvi et al. 2004). Nanseu-Njiki et al. (2010) found that the adsorption of paraquat on sawdust was highest at high $\mathrm{pH}$. Qu et al. (2008) observed increasing adsorption of nitrobenzene onto bacterial surfaces with increasing $\mathrm{pH}$. Navarro et al. (2008) reported maximal adsorption of phenol onto seaweed at $\mathrm{pH}=10$. Notably, many of these reported findings involved non-rigid, swellable cellulose-based materials. Thus increasing adsorption of various sparingly soluble materials with increasing $\mathrm{pH}$ might be attributable to a tendency of the biomaterial to swell and become more accessible under such conditions.

Diverse effects of $\mathrm{pH}$ also have been reported relative to biosorption of certain pesticides. Ju et al. (1997) reported an optimum adsorption of lindane at lower pH onto bacterial biomass. Sathishkumar et al. (2008) reported maximum adsorption of carbaryl onto activated carbon at $\mathrm{pH} 11$. Zheng et al. (2010) found that adsorption of two triazine pesticides on biochar was highest at low $\mathrm{pH}$. However, later work by Zheng et al. (2013) reported increasing adsorption of the antibiotic sulfamethoxazole onto biochars with increasing $\mathrm{pH}$.

\section{Ionic strength}

The effects of ion concentrations in solution also have been studied. Some researchers reported a slight increase in adsorption of sparingly soluble petrochemical compounds onto activated carbons with increasing salt concentration in solution (MorenoCastilla 2004; Anirudhan et al. 2009). Other studies have shown a slight decrease in phenol adsorption with increasing $\mathrm{KCl}$ or $\mathrm{NaCl}$ (Halhouli et al. 1997; Karahoyun et al. 2011). Kilduff et al. (1998) reported similar trends in the case of trichloroethylene onto activated carbon that had been pre-loaded with humic substances. Khan et al. (2010) found that even large concentrations of salt did not interfere with adsorption of dicholoromethane onto activated carbons. Likewise, Liu et al. (2009) found that removal of n-alkanes onto Rhodococcus erythropolis biomass was tolerant of salt conditions corresponding to seawater. Nanseu-Njiki et al. (2010) found somewhat lower adsorption of paraquat onto sawdust in the presence of $\mathrm{NaCl}$. Mathialagan and Viraraghavan (2009) found no effect of salt concentration on the adsorption of pentachlorophenol from aqueous solution onto fungal biomass. To summarize, as noted already by Jacobsen et al. (1996), the effects of ionic strength tend to be minor when compared to those of $\mathrm{pH}$, as described in the previous subsection.

In the case of adsorption of lindane onto bacterial biomass, Ju et al. (1997) found a strongly positive effect of increasing ionic strength. Newcombe and Drikas (1997) reported a similar trend for adsorption of natural organic matter onto activated carbon. Such findings are consistent with screening effects, allowing more charged material to adsorb in adjacent sites on a sorbent surface (Newcombe and Drikas 1997). According to a mechanism described by Westall et al. (1985), charged species such as phenolate ions would be expected to become increasingly compatible with a non-aqueous phase with increasing salt concentration; however, the mechanism has not be strongly supported by more recent work. 
Divalent ions appear to promote adsorption of phenolics onto activated carbon in some cases (Coughlin et al. 1968). Surprisingly, Ni et al. (2011) reported that adsorption of certain aromatic carboxylate species was insensitive to either $\mathrm{Ca}^{2+}$ or $\mathrm{Mg}^{2+}$.

\section{Oxygen content of the aqueous solution}

A number of researchers have found that the adsorption of phenolic compounds onto cellulose-based sorbents, including activated carbons, can be affected by the concentration of oxygen in the solution (Nakhla et al. 1992; Abuzaid and Nakhla 1994; Uranowski et al. 1998). The explanation appears to be that the oxygen can favor an oligomerization reaction at the sorbent surface (Abuzaid and Nakhla 1994). In related work, Alvarez et al. (2009) showed that simultaneous ozonization and adsorption of gallic acid was a promising combined approach to remove it from solution.

\section{Temperature}

Effects of system temperature are shown in Table $\mathrm{A}$ in the column labeled "thermodynamics". A great many studies have included an analysis of whether changes in the temperature of equilibration would either increase or decrease the adsorption capacity of cellulose-based materials for various petrochemical compounds. The label "En", which stands for endothermic, means that heat was taken up when the adsorbate became attached to the surface of the adsorbent. The label "Ex", for exothermic, means that heat was released during the adsorption event. As can be seen from the tabulated findings, both endothermic and exothermic behaviors have been widely reported. One complicating factor is that increased temperature can be expected to increase rates of adsorption, even in cases where there is minimal effect on the adsorption capacity (Chung et al. 2007). Thus, there is some possible difficulty in interpretation in cases where it is not clear whether or not equilibrium conditions of adsorption had been reached.

\section{Agitation}

Increased initial rates of uptake of petrochemical species onto adsorbents in the presence of agitation have been reported in a few cases (Koumanova et al. 2003; Chung et al. 2007; Jamil et al. 2011). Alam et al. (2007) found the best results for adsorption of 2,4dichlorophenol onto activated carbon at an intermediate level of agitation. The fact that so few cases have shown significant effects due to agitation of adsorbent particles suspension suggests that factors other than diffusion to the surface of the adsorbent usually play a more prominent role in affecting adsorption.

\section{Presence of surfactants}

Gotovac et al. (2006) reported that the presence of surfactants affected the rate of adsorption of phenanthrene from ethanol solution onto carbon nanotubes. The sorbent material had been dispersed either with sodium dodecylsulfate or sodium dodecylbenzenesulfonate. The fact that the adsorption isotherms for the two systems were different from each other provides evidence for a strong interaction between the phenanthrene and the surfactant. 


\section{Other solvent media}

Though the focus of this review article is on aqueous media, it can be revealing to consider results from a few studies involving adsorption of petrochemicals from other fluid media. Seredych and Bandosz $(2010,2011)$ studied adsorption of dibenzothiophene and 4,6-dimethyldibenothohphene from simulated diesel fuel onto activated carbon. Results were found to be consistent with the pore size distribution and the size of the sorbate molecules. Zazharov et al. (2010) studied adsorption of phenol from mixtures of water and either dimethylsulfoxide or acetonitrile. Leva-Ramos et al. (1999) compared adsorption of phenol from aqueous and cyclohexane solutions. Greater adsorption was found in the case of the aqueous system. In general, one can expect greater solubility of various petrochemical compounds in non-aqueous media, and this difference may account for reduced adsorption in most of the reported cases.

\section{Competition for adsorption sites}

The topic of competitive adsorption between different petrochemical species will be considered at this point. In other words, one wants to know whether it makes a difference whether the aqueous system contains one adsorbate compound or two. Various articles have set out to answer that question. In many cases it has been reported that the adsorption of one species tended to inhibit the adsorption of another species (Fritz and Schluender 1994; Srivastava and Tyagi 1995a; Ha and Vinitnantharat 2000; Haghseresht et al. 2003; Yang et al. 2006b; Ashour et al. 2008; Li et al. 2010a; Wei and Seo 2010; Kong et al. 2011b; Yu and Hu 2011; Mubarik et al. 2012; Sulaymon et al. 2013). Li et al. (2010b) found competitive effects between pyrene and phenol in the case of one type of activated carbon, but not in the case of a second type of activated carbon. Likewise, Cao et al. (2009) observed strong competition between atrazine and lead for adsorption onto activated carbon, but little competition in the case of biochar. Sometimes the competitive species are already present, due to the source of the adsorbent material (Cabrera et al. 2011). In particular, humic acids and other natural organic matter adsorbed onto biochar or activated carbon has been shown to compete for adsorption sites with various petrochemicals that may be present in soils or effluents (Kilduff et al. 1998; Newcombe et al. 2002b; Quinlivan et al. 2005; Karanfil et al. 2006; Yu et al. 2008; Ji et al. 2010; Li et al. 2010a; Yu and Hu 2011). In other cases minor or no competitive effects were observed (Bell and Tsezos 1998; Barbour et al. 2005; Cao et al. 2009; Chen et al. 2010). Certain of these "no significant competition" cases involved pairs of adsorbates having such different character (e.g. a metal ion and a petrochemical) such that one can easily expect interaction with different classes of surface site (Cao et al. 2009). However, in other cases very different types of sorbate were found to compete with each other for adsorption sites (Kong et al. 2011b). Chen et al. (2010) explained an instance of non-competition by proposing that adsorption was governed by partitioning between an aqueous phase and an oleophilic adsorbed phase having ample capacity.

Some investigators have noted that competition effects can be more pronounced near the beginning of an isotherm, i.e. when the bulk concentration of the adsorbate is very low (Yang et al. 2006b). Such behavior implies that a minority of sites may have higher affinity for the sorbate (Kilduff et al. 1998). As a logical extension, one might expect that competition would be more evident at relatively high levels of coverage if there is unequal 
affinity for different adsorbates on the less-favorable sites (i.e. the last sites to be filled) on the adsorbent surface.

Liu and Pinto (1997) noted that, in a sense, all systems involving adsorption from solution should be considered in terms of competition, since the adsorbate species needs to compete with the solvent molecules, i.e. the water molecules, for adsorption sites. The importance of this effect was observed by Miyake (2003), who studied the adsorption of tricholorethylene from moist air onto activated carbons.

\section{THEORETICAL ASPECTS}

The goal of this section is to review what has been published regarding how to explain various observed adsorption effects in terms of underlying mechanisms and models. Aspects to be considered can be grouped into the areas of molecular-level and colloidal forces, equilibrium aspects of adsorption (including isotherms), kinetic aspects of adsorption, and finally the modeling of semi-continuous "packed bed" systems for removal of petrochemicals from aqueous solutions using cellulose-derived adsorbents. The present discussion builds upon progress as described in previous review articles on the topic (Cookson 1978; Michalak et al. 2013).

\section{Van der Waals Interactions}

The adsorption of hydrocarbons and aromatic compounds is very profoundly influenced by van der Waals forces. The London dispersion component of van der Waals forces results in attraction between all objects in the universe - including both atoms and larger objects (Liang et al. 2007). The range over which these forces are strong extends to about a wavelength of light, and as a consequence, such forces can be very important with respect to interactions between an adsorbate molecule and the adsorbent. Though the London dispersion component of force does not involve fixed electronic charges or polarity, it depends very strongly on the polarizability of electrons in the outer shells of the molecules under consideration (Visser 1972). Thus, somewhat higher London dispersion forces of attraction can be expected in the case of adsorbate molecules and adsorbents that have less strongly held electrons, such as those in the iodine or bromine atom or those associated with aromatic rings. The equations and constants governing such interactions have been well discussed and tabulated elsewhere (Visser 1972; Bowen and Jener 1995).

Because most of the studies considered in the present work involve adsorbates having moderate to strong hydrophobic character, and a majority of the studied compounds were uncharged under the conditions of testing, it is unsurprising that van der Waals forces have been very often proposed as being a key driving force for adsorption onto cellulosederived substrates (Ju et al. 1997; Radobic et al. 1997; Franz et al. 2000; Jung et al. 2001; Haghseresht et al. 2002b; Juhasz et al. 2002; Nouri et al. 2002b; Villacanas et al. 2006). In the cited studies it was generally not possible to attribute adsorption to other likely classes of force, e.g. attraction between opposite charges or hydrogen bonding. One gets a sense that researchers sometimes have relied on a process of elimination in attributing adsorption to van der Waals attractions. Indeed, some of the strongest evidence demonstrating the importance of the London dispersion forces involves systems in which substantial adsorption was observed in spite of there being repulsion between negative 
ionic charges on both the adsorbent and the adsorbate (Haghseresht et al. 2002b; Villacanas et al. 2006). Another form of evidence supporting a prominent role of dispersion forces is the influence of substituent groups on aromatic rings; by affecting the electron density and polarizability of the aromatic structures, the substituent groups of different electronegativity can be expected to change the strength of adsorption (Nouri et al. 2002b).

\section{Hydrophobic interactions}

The term "hydrophobic interactions" has been widely used to account for cases in which the hydrophobic parts of molecules in aqueous solution either self-associate or come out of solution to face towards a hydrophobic solid or air (Widom et al. 2003; Meyer et al. 2006). Thus the term has been used by some researchers to explain aspects of adsorption of petrochemical compounds onto cellulose-derived adsorbents (Ju et al. 1997; Rubin et al. 2006; Pan and Xing 2008; Yu et al. 2009; Pan et al. 2010; Hu et al. 2011; Plazinski and Plazinska 2011; Zhang et al. 2011a,b,c; Kong et al. 2012; Cong et al. 2013; Olivella et al. 2013; Zheng 2013). An important point to bear in mind is that in addition to the London dispersion forces acting between the hydrophobic entities, probably an even greater contribution to observed hydrophobic effects is due to hydrogen bonding and other polar interactions that occur within the aqueous phase. The free energy of the system as a whole is maximized when the hydrophobic groups either self-associate or become involved in adsorption, essentially getting out of the way of the groups capable of hydrogen bonding with each other (Moreno-Castilla 2004). Another important point to bear in mind is that cellulose itself can display substantial hydrophobic character, depending on circumstances, due to the self-integration of most of the hydrogen bondable sites (Medronho et al. 2012). Biochars and activated carbons, due to their greater aromatic nature and lower content of oxygenated groups, can be substantially hydrophobic in character (Ahmad et al. 2012; Ibrahim et al. 2013). As noted by Meyer et al. (2006) certain hydrophobic effects can be amplified and made to appear longer in range if the system contains tiny bubbles of air.

\section{Pi $(\pi)$ Bonding}

The terms $\pi$-bonding and $\pi$-stacking imply that organic compounds arrange themselves with the aromatic groups in a preferred orientation relative to each other. At present there does not appear to be a consensus regarding the origin of these forces, and some researchers have even questioned their existence (Grimme 2008). Three likely explanations for the appearance of strong affinity between aromatic structures include (a) the strength of London dispersion forces that may arise due to the delocalization and polarizability of electrons in aromatic rings, (b) polar interactions between electron-rich and electron-poor parts of molecules, and (c) the hydrophobic effect, as discussed in the previous subsection.

The action of $\pi$-bonding has been used to account for strong adsorption of certain aromatic species to activated carbons and other aromatic-rich plant-derived adsorbents (Jung et al. 2001; Haghserest et al. 2002b; Terzyk 2003a,b; Alvarez et al. 2005; Dąbrowski et al. 2005; Diaz-Flores et al. 2006; Wang et al. 2007a; Nabais et al. 2009; Rodrigues et al. 2011; Zhang et al. 2011b; Fu et al. 2012a; Zheng et al. 2013; Soni and Padmaja 2014). Other authors have noticed a similarly high affinity of aromatic compounds for aromaticcontaining adsorbents but have explained the effect differently, stating that the relatively strong adsorption is due to the fact that flat hydrophobic faces of the "aromatic nuclei" are 
able to interact strongly with adsorbate surfaces (Calace et al. 2002). Certain authors noticed that electron-withdrawing groups tended to decrease adsorption (Salame and Bandosz 2003; Moreno-Castilla 2004; Dąbrowski et al. 2005); this effect was attributed to a decreased electron density in the $\pi$ system, thus decreasing the polarizability of the $\pi$ electrons. Likewise, Diaz-Flores (2006) proposed that the presence of basic sites on the adsorbent made $\pi-\pi$ interactions stronger for the adsorption of pentachlorophenol onto activated carbons. Qu et al. (2008) observed strong adsorption between 1,3-dinitrobenzene and bacterial surfaces and proposed that an acid-base interaction is involved (see later) between deprotonated oxygen of carboxyl groups with the $\pi$ electrons of 1,3dinitrobenzene.

The most serious objection that has been raised relative to the face-to-face $\pi$ stacking model for adsorption of aromatic compounds to activated carbons (Sinnokrot $e t$ al. 2002) appears to be that of Haghseresht et al. (2002a). These authors proposed that the model aromatic compounds that they studied tended to adsorb by their edges, i.e. in a " $T$ " arrangement. For electrostatic reasons the aromatic rings may stack themselves in an offset arrangement, so that the electron-rich regions in the interior of aromatic rings can be adjacent to electron poor hydrogens on neighboring aromatic rings. Also, work has shown that effects very similar - and sometimes stronger - than interaction between adjacent aromatic compounds can be achieved by analogous molecular structures having very similar architecture, but lacking aromaticity (Bloom and Wheeler 2011). In summary, one needs to be quite skeptical of any claims that adsorption of aromatic compounds onto activated carbon or other adsorbents is conclusively attributable to $\pi$-bonding or $\pi$ stacking. More research is needed in order to resolve questions regarding use of the $\pi$ bonding concepts and their possible replacement with other approaches to interpret adsorption phenomena.

\section{Hydrogen Bonding}

It is well known that hydrogen bonds can form in systems where hydrogen is covalently bonded to oxygen, or to a lesser extent to other relatively electronegative atoms such as nitrogen (Jeffrey 1997; Maréchal 2007). Because of the unfair sharing of electrons between the hydrogen and its electronegative partner, the hydrogen takes on part of the character of a bare proton. This unusual circumstance gives rise to hydrogen bond formation between such protons and the lone pairs of electrons on neighboring oxygens in the system. Considering the bonds within cellulose as an example, a typical hydrogen bond has an energy of about $19 \mathrm{~kJ} /$ mole (about 4 to $5 \%$ the energy of a covalent bond between $\mathrm{O}$ and $\mathrm{H}$ ), a distance that can be 2 to 2.5 times the length of a corresponding covalent bond between $\mathrm{O}$ and $\mathrm{H}$ (Li et al. 2011), and an average lifetime of only about 250 picoseconds under ordinary ambient conditions (Belashchenko et al. 2014).

As was briefly suggested in an earlier paragraph dealing with hydrophobic bonding, the most important contributions of hydrogen bonding to the adsorption of substantially oxygen-free compounds onto cellulose-derived substrates may be indirect. That is, the extensive hydrogen bonding within the aqueous phase provides a thermodynamic driving force encouraging the exclusion of molecules or molecular segments that lack hydrogen bonding ability. The high cohesive energy within an aqueous phase $\left(2.30 \mathrm{~kJ} / \mathrm{cm}^{3}\right)$ is considerably larger than that of a typical organic solvent such as heptane $\left(0.23 \mathrm{~kJ} / \mathrm{cm}^{3}\right)$ or 
even benzene $\left(0.35 \mathrm{~kJ} / \mathrm{cm}^{3}\right)$ (Kolker et al. 2005). A sharp contrast between the cohesive forces acting in an aqueous phase and those acting within typical organic solvents is shown in the following table of the Hansen solubility parameters (Hansen 2007).

Table 1. Hansen Solubility Parameters for Three Pure Liquids

\begin{tabular}{|l|c|c|c|}
\hline Liquid type & $\begin{array}{c}\text { Dispersion } \\
\text { forces }\end{array}$ & Polarity & Hydrogen bonding \\
\hline Water & 15.5 & 16.0 & 42.3 \\
\hline Hexane & 14.9 & 0.0 & 0.0 \\
\hline Benzene & 18.4 & 0.0 & 2.0 \\
\hline
\end{tabular}

As shown in Table 1, the non-polar liquids have almost no ability to participate in hydrogen bonding. It follows that the presence of hydrophobic compounds in the aqueous phase is unfavorable in terms of enthalpy, i.e. with respect to the forces of interaction. Random diffusion (i.e. entropy effects) largely accounts for the moderate aqueous solubility of phenols, hydrocarbons, and many other such compounds. Phase separation occurs spontaneously above a certain concentration (Hansen 2007). But the same thermodynamic tendencies leading to phase separation often can promote adsorption of the compounds in question onto suitably hydrophobic substrates.

Another aspect of hydrogen bonding that may potentially have a big effect on the adsorption of petrochemical compounds onto cellulose-derived adsorbents is the local structure of water (Farrell et al. 1999; Joo et al. 2008). Many studies have shown that the presence of a surface or another compound may either increase or decrease the degree of organization, i.e. the ice-like character of the closest layers of water (Park et al. 2007). As noted by Meyers et al. (2006), many researchers have invoked water structure as a contributing factor leading to the self-agglomeration and/or adsorption of hydrophobic compounds originally present in aqueous solution. The idea is that the presence of a nonhydrogen bonding entity causes the adjacent water to become more organized, thus decreasing the entropy of the system. Exclusion of the non-hydrogen-bonding entities from the solution by their adsorption to a surface increases the system's randomness, thus providing a thermodynamic driving force in favor of adsorption, depending on the details of the situation.

Most researchers studying the role of hydrogen bonding in adsorption of petrochemicals from aqueous solution onto cellulose-related adsorbents have focused on hydrogen bonding between the adsorbate and the adsorbents. Several authors reported evidence that hydrogen bonding makes a positive contribution to such adsorption (Franz et al. 2000; Nevskaia and Guerrero-Ruiz 2001; Blackburn et al. 2007; Chen and Li 2007; Navarro et al. 2008; Plazinski and Plazinska 2011; Fu et al. 2012a). Nevskaia and Guerrero-Ruiz (2001) based their attribution regarding hydrogen bonding to the relatively easy thermal desorption of nonylphenol. Franz et al. (2000) cited the thesis work of Leng (1996), who compared the adsorption of phenol from water and from cyclohexane onto oxygenated carbon; increased adsorption from the organic solvent, which cannot form hydrogen bonds, was taken as evidence that the phenolic group was interacting with the surface-bound oxygens. Franz et al. (2000) carried out a similar analysis for a wider variety of adsorbates and reported similar findings. Navarro et al. (2008) argued that strong hydrogen bonding is promoted by the presence of an ionized phenolate group, which can 
interact with available $-\mathrm{OH}$ groups on the adsorbate. The concept was attributed to earlier workers, such as Iqbal et al. (2005). Blackburn et al. (2007) backed up their conclusions with computational chemistry results, which showed the feasibility of Yoshida-type hydrogen bonding between a phenolic $-\mathrm{OH}$ group and the $-\mathrm{OH}$ groups of cellulose. Plazinski and Plazinska (2011) supported their statement by molecular dynamics simulations. By contrast, Zhang et al. (2011a) ruled out hydrogen bonding as being a significant contribution to adsorption of simazine to biochars based on an analysis of Freundlich affinity coefficients (see later). Zheng et al. (2013) used the concept of chargeassisted hydrogen bonding to explain an observation of increased sorption of the antibiotic sulfamethoxazole onto certain biochars. In summary, while researchers have reported a role of hydrogen bonding in the adsorption of petrochemicals, especially in the case of adsorption of phenolic compounds, there is no consensus that such contributions have major importance.

\section{Electrostatic Interactions}

The topic of electrostatic interactions involves several aspects, including not only the attractions and repulsion between ions, but also various acid-base effects that do not involve ionization, as well as issues related to polar compounds. Since the focus of this article is on adsorption from aqueous media, it makes sense to consider the ionic interactions first.

Ionic interactions have been proposed as having a major influence by many researchers who have studied adsorption of petrochemicals onto cellulosic materials and activated carbons (Radobic et al. 1997; Nouri et al. 2002a,b; Ayranci and Dyman 2006; Villacanas et al. 2006; Blackburn et al. 2007; Zhang et al. 2011c; Fu et al. 2012a). Some of the strongest evidence supporting a major role of ionic attractions and repulsions in the adsorption of petrochemical compounds to cellulose-derived substrates comes from studies of $\mathrm{pH}$ effects, as covered in an earlier section (see, for instance, Brandt et al. 1997; Ayranci and Dyman 2006). Also, ionic species can take part in ion-exchange, as a contributing factor in their adsorption (Wu et al. 2003; Yu et al. 2009). Figure 8 represents data from Haghseresht et al. (2002), who studied adsorption of benzoic acid, $p$-cresol, $p$-nitrophenol, and salicylic acid onto three commercial activated carbons. As shown, they found that the results were closely related to the difference between the $\mathrm{pH}$ value and the $\mathrm{pK}_{\mathrm{a}}$ value. When this difference is negative (at the left side of the plot), the phenolic and other weakly acidic compounds were mainly in their uncharged state, and adsorption was strong, despite the negative charge associated with typical activated carbon surfaces at intermediate to alkaline $\mathrm{pH}$ conditions. By contrast, adsorption was strongly reduced under conditions at the right-hand side of the plot, where one would expect both the adsorbate compounds and the adsorbent surface each to bear a negative ionic charge.

A majority of the cited systems that were found to be strongly $\mathrm{pH}$-dependent were those involving phenolic adsorbents; the $\mathrm{pK}_{\mathrm{a}}$ values of various phenols depend on the electronegativity of substituents on the phenol's aromatic ring. The $\mathrm{pK}_{\mathrm{a}}$ value of phenol itself is about 10 (Daifullah and Girgis 1998). But the $\mathrm{pK}_{\mathrm{a}}$ value can range from 5.4 (for 2,4-dinitrophenol), to 10.3 (for $\mathrm{p}$-cresol). A low value of $\mathrm{pK}_{\mathrm{a}}=4.7$ has been reported in the case of pentochlorophenol (Crosby 1981), which is consistent with very strong withdrawal of electron density from the ring, thus stabilizing the anionic phenolate species. MorenoCastilla et al. (1995b) found a rough agreement between such $\mathrm{pK}_{\mathrm{a}}$ values and the influence 
of $\mathrm{pH}$ on the adsorption of two phenols. However, there is a critical need for research that compares a series of different phenols onto a specified adsorbent over a range of $\mathrm{pH}$ values. In principle, adsorption would be expected to fall off under conditions in which the phenols in question spend a high fraction of their time in a negatively charged ionic state, giving rise to electrostatic repulsion with anionic carboxylate groups present on typical cellulosederived adsorbents, including activated carbon products.

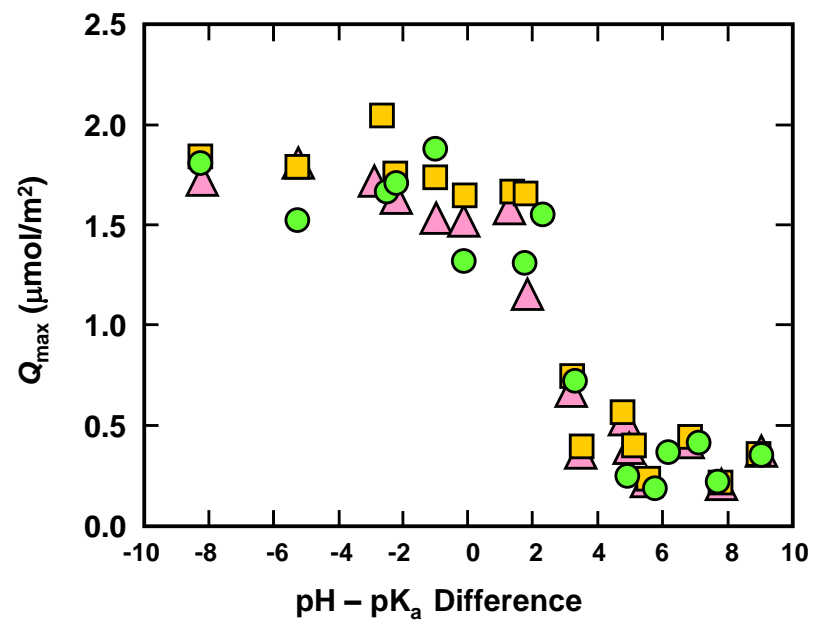

Fig. 8. Dependency of adsorption capacity on the difference between $\mathrm{pH}$ and the $\mathrm{pK}_{\mathrm{a}}$ value of selected weakly acidic compounds having a single aromatic ring. The three symbols correspond to three different commercial activated carbons.

\section{Acid-Base Interactions}

Even in cases where surfaces are not ionized, there still can be important electrostatic contributions to molecular interaction due to Lewis acidity and basicity. The subject of Lewis acids and bases, including explanations of how this type of interaction differs from Brønsted acidity and basicity, has been well described elsewhere (House 2013). While ionic species, i.e. Brønsted acids and bases, are often dominant in aqueous systems, Lewis acidity and basicity can express themselves in non-aqueous environments. The petrochemicals considered in this review article include many quite hydrophobic compounds, and typical activated carbon products are hydrophobic too. It is reasonable to expect, in such cases, that the adsorbing hydrophobic species might force water molecules away from the interface with the adsorbent, creating a local non-aqueous environment.

As noted in review papers by Shen (2009) and Gamelas (2013), lignocellulosic materials typically contain both acidic and basic Lewis sites at their surfaces. Ahmad et al. (2013) noted that the surfaces of activated carbons tend to be dominated by acidic groups after preparation at relatively low temperatures, whereas basic Lewis sites often predominate in carbons pyrolyzed at relatively high temperatures. Strong correlations have been found between Lewis basicity and the content of $-\mathrm{C}=\mathrm{O}$ groups, which are able to contribute electron density (Shen et al. 1998). Furthermore, the Lewis acidic or basic surface character of activated carbon can be affected by post-treatment (Dąbrowski et al. 2005).

Several groups of researchers have proposed that acidic or basic sites play a role in the adsorption of various petrochemical compounds either on lignocellulosic materials or 
on their pyrolyzed forms (Tessmer et al. 1997; Daifullah and Girgis 2003; Terzyk 2003b; Diaz-Flores et al. 2006; Hu et al. 2011; Fu et al. 2012a; Ahmad et al. 2013). According to Dąbrowski et al. (2005), the greater the ratio of acid to basic groups, the lower will be the adsorption of phenol. Franz et al. (2009) concluded that donor-acceptor interactions were not significant in their study of adsorption of various aromatic compounds onto activated carbon. If fact, in none of the studies just cited was there undisputable evidence that it was the Lewis form of acidity or basicity, rather than consequent ionization of the surface, that affected adsorption.

\section{Solubility Concepts Relative to Adsorption}

Another way to attempt to account for different types of contribution to adsorption phenomena is by considering the mutual solubility of the adsorbate in the adsorbent material. Such an approach has become widely applied in order to predict whether a given polymer will dissolve in a given solvent system (Hildebrand 1936; Hansen 2007; Rosenholm 2010). The concept also has been used to predict wetting and adhesion phenomena (Good 1992). To apply a solubility approach to predicting whether or not a given adsorbent will have strong affinity for a given adsorbate surface, one compares certain aspects of each of them, such as the Hildebrand parameter (defined as the squareroot of the cohesive energy density) and the tendency of both the adsorbate and adsorbent to form hydrogen bonds. A mis-match regarding either of these factors implies less compatibility. Browne and Cohen (1990) showed that the Hildebrand solubility parameter could be used to compare the solubilities of different sorbates, therefore helping to explain the relative tendencies of chloroform and trichloroethylene to adsorb onto activated carbon.

One situation in which a solubility approach appears to be especially appropriate is when the substrate contains a portion of solvent-like compounds such as waxes or residual oils (Lin et al. 2007; Li and Chen 2009). Also, solubility considerations such as the partitioning of adsorbate between two phases have been applied when the adsorbate is a soft, swellable material, such as fruit cuticles ( $\mathrm{Li}$ and Chen 2009) or never-dried fungal biomass (Chen et al. 2010, 2011). In some cases the adsorbate may actually become bound to solubilized polymers that are released from a substrate (Choi et al. 2003). Alternatively, it was found that derivatizing the surface of sawdust with fatty acid chains was beneficial for the removal of oleic acid and olive oil from water (Maurin et al. 1999); the cited study provides a clear example of how chemical similarity between the adsorbent's surface and the adsorbate can promote sorption.

Abe et al. (1985) carried out a unique analysis in which they considered the contributions of individual types of atoms toward adsorption of pollutants onto activated carbon. Carbon, bromine, and chlorine atoms on the adsorbent surfaces were found to have a positive effect on adsorption, whereas oxygen atoms negatively affected adsorption, and hydrogen atoms had little influence. As noted earlier, Seredych and Bandosz (2011) found evidence that sulfur atoms on both the adsorbent and adsorbate can promote adsorption.

\section{Free Energy Change on Adsorption}

In principle, by summing all of the interactive force contributions, it should be possible to predict the free energy of adsorption. Polanyi proposed that such an energy term could be used to predict adsorption outcomes (Manes and Hofer 1969). The cited authors used this approach and concluded that findings from gas-phase adsorption can be 
used to predict adsorption from various solvents. Various other researchers have employed aspects of the Polanyi adsorption theory to understand adsorption of petrochemicals onto cellulose-derived adsorbents (Greenbank and Manes 1981; Aytekin 1991). Xia and Ball (1999) found close agreement between their data for adsorption of nine nonpolar compounds onto loam soil; they concluded from such evidence that adsorption involved filling of micropores, which was one of the theoretical predictions (see later). Yang et al. (2006a) likewise found good agreement with the Polanyi theory when studying adsorption of polycyclic aromatic hydrocarbons on various carbon-based adsorbents. Though not much research of this type has been reported, the approach appears well suited for confirmation by molecular dynamics simulation studies (Terzyk et al. 2010; Plazinski and Plazinska 2011). Advances in computing power and simulation programs offer the possibility in future studies of achieving greater quantification of interactive forces, while also taking into account the many possible conformations of adsorbed molecules.

\section{Adsorption Isotherms}

The term "adsorption isotherm" refers to the portrayal of adsorption data obtained under quasi-equilibrium conditions. Either equations or their graphical representation are used in an isotherm to describe the relationship between the amount adsorbed and the concentration in an adjacent bulk solution. As the subject of adsorption isotherms was covered earlier in great detail (Hubbe et al. 2011), the main focus here will be on just the adsorption of petrochemicals onto cellulose-derived adsorbents. Readers who are particularly interested in the mathematical forms of various isotherms may refer to the earlier document. An attempt also will be made in this section to draw connections between the fitting of data to certain types of isotherms $v s$. what is likely to be happening at the molecular and nano-scale levels.

\section{Langmuir isotherm}

As can be seen from the fifth column of Table A (see Appendix), the Langmuir isotherm (Langmuir 1918) has been successfully used by many research groups to represent equilibrium amounts of various petrochemical compounds on various celluloserelated substrates. As was noted earlier (Hubbe et al. 2011), the Langmuir equations can be expressed in nonlinear and linearized forms as follows,

$$
\begin{gathered}
q_{e}=\frac{Q^{o} b C_{e}}{1+b C_{e}} \\
C_{e} / q_{e}=1 / Q^{o} b+C_{e} / Q^{o}
\end{gathered}
$$

where $q_{e}(\mathrm{mg} / \mathrm{g})$ is the amount of adsorbed compound, and $C_{e}(\mathrm{mg} / \mathrm{L})$ is the corresponding concentration in the solution at equilibrium. The quantity $b(\mathrm{~L} / \mathrm{mg})$ is a measure of the affinity of binding sites for the adsorbate, and $Q^{o}(\mathrm{mg} / \mathrm{g})$ is the adsorption capacity, based on a model in which each adsorbate molecule can fill one site and where there are no interactions between molecules adsorbing at adjacent sites.

From several perspectives it can be argued that the Langmuir model provides a superior approach for judging the suitability and performance of different adsorbents for 
removing pollutants from aqueous (or other) solution. A good fit of data to the model yields a single value for the adsorption capacity $Q^{o}$, i.e. how much could the adsorbent material hold when all of the possible sites are filled. This is critically important information when one is judging which of two or more adsorbents would be able to effectively hold onto more of a given pollutant, especially in cases where there is a large amount of material that needs to be removed from the water. On the other hand, the value of $b$ can be a convenient and concise way to judge which of several adsorbents would be likely to perform best in reducing the bulk concentration of a pollutant to a very low level. In addition to these two valuable pieces of information, it can be argued that the mere fact that there is a good fit with the Langmuir model provides evidence that an adsorbent system is well-behaved, providing a predictable capacity and a predictable affinity. In Table A much of the information in the column headed by "Adsorption capac. (mg/g)" comes from fits to the Langmuir model (as indicated by the letter " $\mathrm{L}$ " in the column headed "Isotherm best fits"). In cases where the authors did not report fitting results based on the Langmuir equation, the capacity values shown in the table are estimates based on an inspection of the reported data; in the course of making such estimates it was evident that such systems were often not as "well behaved" in terms of exhibiting a clear adsorption capacity.

Table 2 provides some examples, taken from the surveyed literature, representing the wide ranges in terms of both capacity and affinity, based on Langmuir model fits. As can be readily seen, the two parameters are quite independent. For instance, a system reported by Blanco-Martínez et al. (2009) showed a combination of high adsorption capacity but low affinity. A system reported by Demirak et al. (2011) showed relatively low capacity but high affinity. A study of adsorption of the pesticide cypermethrin on cork showed an especially unpromising combination of low capacity and low affinity (Domingues et al. 2007). And a study by Daifullah and Girgis (1998) showed one of the most promising cases in the published literature, high capacity and very high affinity of phenols onto a certain activated carbon product.

Table 2. Selected Data Representing a Range of Langmuir Fit Coefficients

\begin{tabular}{|l|l|l|l|l|}
\hline Adsorbent & Adsorbate & $\begin{array}{l}Q^{\circ} \\
(\mathrm{mg} / \mathrm{g})\end{array}$ & $\begin{array}{l}b \\
(\mathrm{~L} / \mathrm{\mu g})\end{array}$ & Citation \\
\hline DDD, DDE & Bagasse fly ash & 0.007 & 37 & Gupta \& Ali 2001 \\
\hline Benzene, etc. & Angico sawdust & $0.002-0.011$ & $1-3$ & Costa et al. 2012 \\
\hline Ci-cypermethrin & Cork & $0.1-0.3$ & 0.1 & Domingues et al. 2007 \\
\hline Dichlorophenol & Posidonia ocean. & 1 & 660 & Demirak et al. 2011 \\
\hline Dichlorophenol & Anaerobic sludge & $1-7$ & $6-64$ & Gao et al. 2007 \\
\hline Three pesticides & Date stones & 6 & $1-2$ & El Bakouri et al. 2009 \\
\hline Phenols & Fungal biomass & $42-289$ & $10-40$ & Bayramoglu 2009 \\
\hline Phenol & Activated carbon & $74-238$ & $24-130$ & Fierro et al. 2008 \\
\hline Catechol & Activated carbon & $178-238$ & $4-6$ & Blanco-M. et al. 2009 \\
\hline Phenols & Activated carbon & $232-339$ & $200-600$ & Daifullah \& Girgis 1998 \\
\hline
\end{tabular}

Figure 9 illustrates how different values for the two parameters $Q^{\circ}$ and $b$ can result in quite different graphical output. As shown, a relatively high value of the affinity coefficient $b$ implies that very little of the adsorbed species will remain in the dissolved phase at equilibrium, until the adsorbent material is almost fully saturated. By contrast, a relatively low value of $b$ implies that more of the target compound is expected to remain 
in solution, even though a high proportion of unoccupied sites may be available on the surfaces. As illustrated by the dash-dot curve, if one's main goal is to reduce the bulk concentration to near zero, there may be cases where the value of $b$ is more important than the maximum amount of uptake, i.e. $Q^{\text {o }}$.

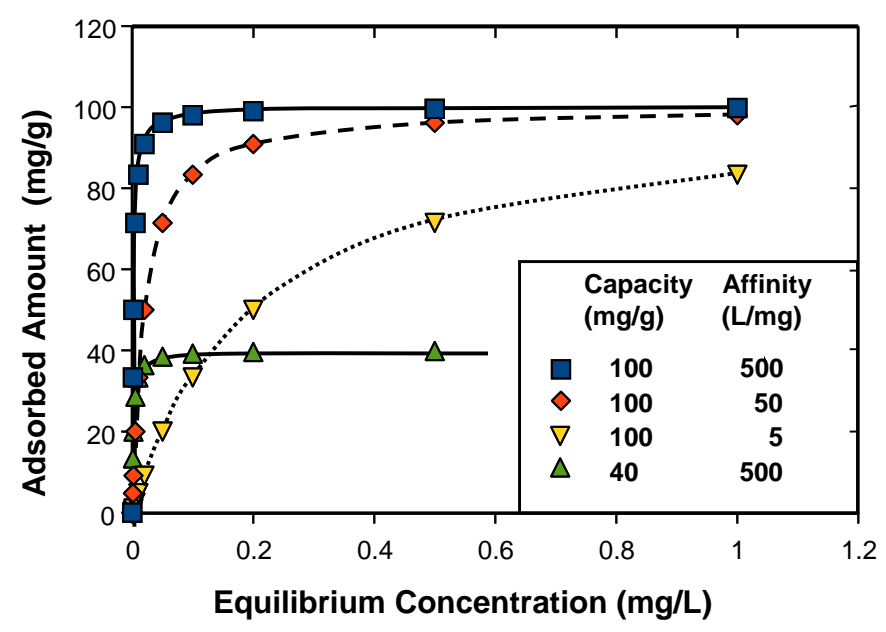

Fig. 9. Calculated values of adsorbed amounts based on the Langmuir model, using selected values of adsorption capacity $Q^{\circ}$ and adsorption affinity $b$

Many sets of adsorption data fail to achieve good fits to the basic form of the Langmuir model. Before abandoning such a promising model in such cases, one of the most practical alternatives to consider is the possibility that the surface has two or more distinct populations of adsorption sites, each of which is consistent with the Langmuir model. Thus, in a particular auspicious case, most of the sites might have moderately high affinity, but there might be a few sites with ultra-high affinity for the adsorbate. Such an adsorbent would have unique capability of being able to "scour" very highly dilute solutions and remove the last vestiges of a pollutant, while also being useful for high levels of removal when used to remove pollutant from more highly contaminated water. For example, Müller et al. (1980) proposed that electrostatic effects could shift local environments at an adsorbate surface, resulting in "patches" that can be represented by different Langmuir parameters. Related approaches have been used when accounting for the adsorption of multiple adsorbates from a mixture (Haghseresht et al. 2002c; Agarwal et al. 2013).

\section{Adsorption to heterogeneous sites}

Several groups of researchers have placed emphasis on the heterogeneity of adsorption sites in the systems that they studied (Snoeyink et al. 1969; Müller et al. 1980; Juang et al. 1996a; Kilduf et al. 1998; Franz et al. 2000; Hsieh and Teng 2000; Nouri et al. 2002a; László et al. 2003, 2006; Podkościelny et al. 2003; Dąbrowski et al. 2005; Abdallah 2013). The empirical Freundlich (1907) isotherm equation is often used as a practical way to summarize adsorption data from such systems. Hsieh and Teng (2000) noted that in the systems they studied the adsorption of phenol was not proportional to the 
determined surface areas of different activated carbons, and they therefore concluded from this observation that the adsorption sites must be heterogeneous. Dąbrowski et al. (2005) argued that both chemical and geometrical factors can account for differences in affinity of an adsorbate for different locations on an adsorbent. Rossner et al. (2009) proposed that some cases in which adsorbents exhibit heterogeneity in adsorption affinity are due to a distribution of pore sizes, with higher affinity associated with the smaller pores. It seems likely that locations within very fine pores can be favored because the tight concave curvature of the solid allows more of the solid surface to be exposed to an individual molecule of adsorbate (Farrell et al. 1999).

Figure 10 provides an example where fits to the Freundlich equation appear to show an important shift in the nature of adsorption phenomena as the temperature of biochar formation is increased (Zhang et al. 2011a). Note that increasing charring temperature changed not only the overall levels of adsorption, but also the slopes of the best-fit lines were changed. Such a shift is consistent with the enrichment of aromatic and hydrophobic surface groups, which offer strong affinity to the simazine pesticide even at very low levels of adsorbed amounts. By contrast, higher slopes were found for samples that had been subjected to lower temperatures of treatment. Such results are consistent with a lower affinity between the pesticide and the surface-bound groups at the lower level of charring. Thus, in those cases there would be a greater importance of self-association of the pesticide molecules with each other as a contributing factor leading to their adsorption.

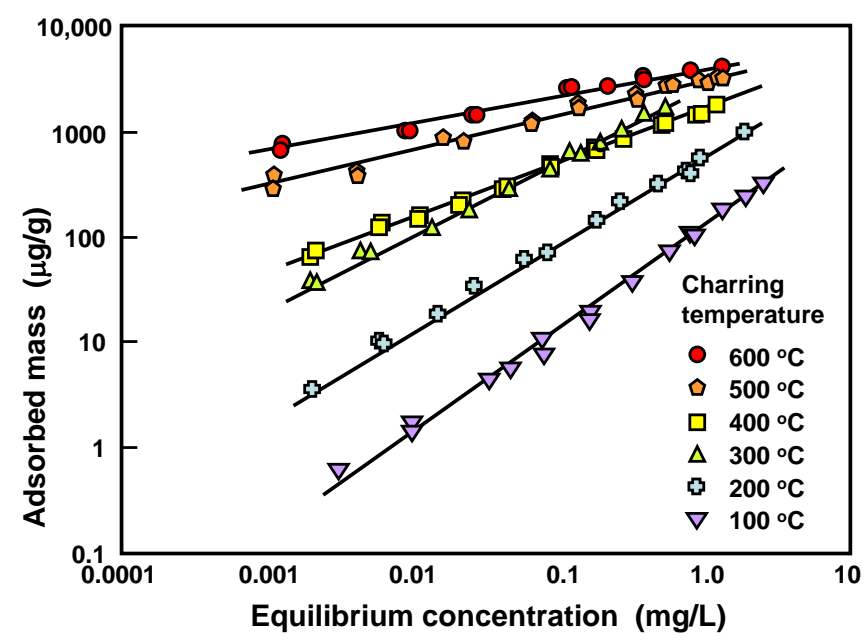

Fig. 10. Freundlich plot of adsorbed amounts of simazine pesticide on biochars prepared from corn straw at various oxygen-limited temperatures. Data replotted from Zhang et al. (2011a)

\section{Other isotherm models}

A wide range of other equations, some empirical and some based on theoretical models, have been used to account for data that do not fit well to the Langmuir model. Some examples are cited in Table 3, which also lists some of the purported advantages or implications of such models. The arrangement of the rows places models that are most similar to the Langmuir model near to the top. Towards the bottom of the table one finds models used to fit data in cases where adsorption did not seem to be related to a definable population of surface sites. 
Table 3. Selected Examples Where Isotherms Models Other than Langmuir Were Used to Account for Adsorption of Petrochemicals onto Cellulose-derived Adsorbents

\begin{tabular}{|c|c|}
\hline Model and its Attributes & Citation \\
\hline $\begin{array}{l}\text { Redlich-Peterson. A heterogeneity factor is used together with an } \\
\text { approach that is otherwise similar to the Langmuir model. The } \\
\text { results converge to the Langmuir equation as the factor approaches } \\
\text { unity. The equation is basically a combination of the Langmuir and } \\
\text { the Freundlich equations. }\end{array}$ & $\begin{array}{l}\text { Redlich \& Peterson } \\
\text { 1959; Aksu and Yener } \\
\text { 2001; Ahmaruzzaman } \\
\text { \& Sharma 2005 }\end{array}$ \\
\hline $\begin{array}{l}\text { Temkin isotherm. The heat of adsorption is assumed to decrease } \\
\text { linearly with filling of adsorption sites. This implies that there is } \\
\text { mutual repulsion between adsorbed molecules and similar dissolved } \\
\text { molecules approaching adjacent adsorption sites. }\end{array}$ & $\begin{array}{l}\text { Temkin 1941; } \\
\text { Hamdaoui \& } \\
\text { Naffrechoux 2007a,b; } \\
\text { Ahmad et al. } 2013\end{array}$ \\
\hline $\begin{array}{l}\text { Dubinin-Astakknov. The cited authors show that this equation has } \\
\text { advantages over the ordinary Langmuir equation to account for } \\
\text { adsorption of phenols on activated carbons. }\end{array}$ & Stoeckli et al. 2001 \\
\hline $\begin{array}{l}\text { Fowler-Guggenheim. The heat of adsorption is assumed to be } \\
\text { varying in a linear manner with increasing adsorption. The model is } \\
\text { consistent with lateral interaction between adsorbate molecules, } \\
\text { which can be either attractive or repulsive. }\end{array}$ & $\begin{array}{l}\text { Fowler \& Guggenheim } \\
\text { 1939; Hamdaoui \& } \\
\text { Naffrechoux 2007a }\end{array}$ \\
\hline $\begin{array}{l}\text { Hill-de Boer. Adsorbate molecules are assumed to be able to } \\
\text { move, and the adsorption sites are assumed to have a range of } \\
\text { adsorption energies. Lateral interaction among the adsorbed } \\
\text { molecules can be positive or negative. }\end{array}$ & $\begin{array}{l}\text { Hill 1946; de Boer } \\
\text { 1953; Hamdaoui \& } \\
\text { Naffrechoux 2007a }\end{array}$ \\
\hline $\begin{array}{l}\text { Kiselev. Adsorption is assumed to take place as localized } \\
\text { monomolecular layers. }\end{array}$ & 1958. \\
\hline $\begin{array}{l}\text { Dubinin-Radushkevich. The model assumes that adsorption is } \\
\text { dominated by the filling of pores, with a strongly increasing energy of } \\
\text { adsorption with decreasing width of slit-like pores. }\end{array}$ & $\begin{array}{l}\text { Dubinin 1975, 1989; } \\
\text { Cal et al. 1994; } \\
\text { Ahmad et al. } 2013\end{array}$ \\
\hline $\begin{array}{l}\text { Elovich. The rate of filling unoccupied sites of adsorption is } \\
\text { assumed to decrease according to an exponential relationship } \\
\text { during the process of adsorption. }\end{array}$ & $\begin{array}{l}\text { Aharoni \& Tompkins } \\
\text { 1970; Tseng \& Juang } \\
\text { 2003; Hamdaoui \& } \\
\text { Naffrechoux 2007a }\end{array}$ \\
\hline $\begin{array}{l}\text { Brunauer, Emmet, and Teller. This model is widely used for } \\
\text { determination of surface areas of solids by adsorption of very cold } \\
\text { nitrogen or argon gases, under the assumption of a detectable } \\
\text { transition from monolayer to multi-layer adsorption. }\end{array}$ & $\begin{array}{l}\text { Brunauer et al. 1938; } \\
\text { Rao \& Viraraghavan } \\
2002\end{array}$ \\
\hline
\end{tabular}

Low affinity adsorption

The scientific literature in general has been shown to reflect a bias in favor of the reporting of successful results (Fanelli 2012). Thus, even when authors report especially low adsorption capacities and feeble affinity, words such as "successfully adsorbed" often appear in the concluding statements. Given this state of affairs, the discerning reader needs to adopt a strategic approach, looking for clues that might reveal inherent problems with certain combinations of adsorbate and adsorbent. Some such clues, which were noted during the current search of the literature, are summarized in Table 4. 


\section{Table 4. Clues to Identify Less-than-Promising Reported Adsorption Results}

\begin{tabular}{|l|l|l|}
\hline Evidence & Problematic Aspects & Examples Cited \\
\hline Log-log plotting of data & $\begin{array}{l}\text { A relatively high solution concentration } \\
\text { may be required to achieve effective } \\
\text { adsorption. }\end{array}$ & $\begin{array}{l}\text { Brown \& Cohen } \\
1990 ; \text { Sun et al. } \\
2011 \mathrm{~b}\end{array}$ \\
\hline $\begin{array}{l}\text { Different models used for low } \\
\text { \& high ends of isotherm }\end{array}$ & $\begin{array}{l}\text { The implications of the different models } \\
\text { may be mutually incompatible. }\end{array}$ & $\begin{array}{l}\text { Dąbrowski } \text { et al. } \\
2005\end{array}$ \\
\hline $\begin{array}{l}\text { Sorption increasing out of } \\
\text { proportion with concentration }\end{array}$ & $\begin{array}{l}\text { This may be a clue that the self-affinity } \\
\text { of the adsorbate drives the process; it } \\
\text { follows that the affinity between the } \\
\text { adsorbate and adsorbent may be low. }\end{array}$ & $\begin{array}{l}\text { Estevinho et al. } \\
2006\end{array}$ \\
\hline $\begin{array}{l}\text { Low value of accessible } \\
\text { surface area }\end{array}$ & $\begin{array}{l}\text { Even if the chemical composition favors } \\
\text { sorption, the capacity may be low. }\end{array}$ & Olivella et al. 2013 \\
\hline $\begin{array}{l}\text { Poor fit to Langmuir } \\
\text { adsorption model }\end{array}$ & $\begin{array}{l}\text { Such lack of fit can be a clue to low } \\
\text { affinity behavior. }\end{array}$ & Chen et al. 2005 \\
\hline $\begin{array}{l}\text { Natural, unmodified plant } \\
\text { material, possibly dried }\end{array}$ & $\begin{array}{l}\text { Some of the lowest reported capacities } \\
\text { were with unmodified biomass. }\end{array}$ & $\begin{array}{l}\text { Estevinho et al. } \\
2006\end{array}$ \\
\hline
\end{tabular}

\section{Bilayer adsorption}

Some experimental situations are best understood by assuming that target substances in the bulk of solution have a strong affinity for similar molecules that are already adsorbed. In the simplest case, the further progress of adsorption results in the gradual formation of a bilayer. Such behavior has been reported in the case of the antimicrobial agent chlorhexidine on cotton (Blackburn et al. 2007). Bilayer adsorption is especially found in the adsorption of cationic surfactants onto negatively charged, hydrophilic surfaces (Speranza et al. 2013). In such systems the cationic headgroups of the first layer face inwards to the negatively charged adsorbent surface, taking advantage of attraction of opposite charges. The second layer involves a favorable tail-to-tail interaction between the hydrophobic parts of the molecules. A third layer of cationic surfactant is not expected in such cases due to the fact that the adsorbed bilayer presents a hydrophilic, cationic layer towards the bulk of solution, and such a surface is unfavorable for adsorption of additional cationic surfactant molecules.

\section{Multilayer adsorption.}

Noting that cationic surfactants may be considered as a special case, it has been much more commonly reported that certain petrochemicals tend to form multilayers on various adsorbents, especially when their bulk concentration is relatively high (Bina et al. 2012) or when adsorption takes place from a gas phase (Bartholdy et al. 2013). The Brunauer-Emmett-Teller (BET) equation, which is often used for the analysis of surface areas of solid materials by adsorption of nitrogen or argon gas (e.g. Chen et al. 2012b; Isahak et al. 2013), has been shown to achieve a good fit to certain data from adsorption of petrochemicals onto cellulose-derived substrates from aqueous solution (Edgehill and Lu 1998; Rao and Viraraghavan 2002; Bina et al. 2012). In some other cases the BET isotherm was tried, but it was found not to fit certain data as well as more commonly used isotherm models, such as the Freundlich isotherm (Khan et al. 1997a). In the cited work of Bina et al. (2012) it is notable that evidence of multilayer adsorption was found for the adsorbate ethylbenzene, a relatively small molecule, for which hydrophobicity and low solubility (see 
earlier) provide a driving force that favors self-association of the adsorbate in the adsorbed state.

\section{Pore filling models and hysteresis}

It does not require too much extension beyond a concept of multilayer adsorption before one passes into a somewhat different approach to predicting adsorption capacities models in which the adsorption capacity is mainly determined by the void volume within a microporous or mesoporous adsorbent. Such a model has been proposed by many authors to account for the adsorption of various petrochemical compounds onto and into activated carbon products (Xia and Ball 1999; Ahmad et al. 2013; Hao et al. 2013; Ran et al. 2013). Chiu et al. (2003) found that a pore-filling model could account for toluene adsorption from the vapor phase onto peat, with the results not too far from the pore volume determined by nitrogen adsorption isotherms. Xia et al. (1999) observed the same limiting sorption capacity for a wide range of nonpolar organic chemicals, and they used this finding as evidence that void volume, rather than surface interactions, mainly provides the upper limit of sorption capacity in the studied systems.

It seems remarkable that few researchers dealing with adsorption of petrochemicals from aqueous solution have considered use of the Kelvin equation to account for adsorption phenomena (Hseih and Teng 2000). It is well known that the Kelvin equation predicts a decreased vapor pressure of liquid contained within a finely porous solid, depending on the contact angles (Adamson and Gast 1997; Beverley et al. 1999). As shown by the form of the Kelvin equation given below, the vapor pressure of adsorbate in a gas phase in equilibrium with a small pore can be strongly depressed, depending on the shape of the meniscus within the pore. The Kelvin equation can be written in the following form (Chen et al. 2006),

$$
R T \ln \left(p / p_{\mathrm{s}}\right)=V\left(p-p_{\mathrm{s}}+2 \gamma \cos \theta / r\right)
$$

where $R$ is the gas constant $\left(8314 \mathrm{~J} \mathrm{kmol}^{-1} \mathrm{~K}^{-1}\right), T$ is the absolute temperature, $p$ is the equilibrium vapor pressure, $p_{\mathrm{s}}$ is the same in the case of a flat interface, $V$ is the volume of a mole of the liquid, $\gamma$ is the interfacial tension, $\theta$ is the contact angle with respect to the liquid in the capillary, and $r$ is the radius of a capillary (modeled as a cylinder). Assuming perfect wetting of the internal liquid, the $\cos \theta$ term approaches unity. While it is widely used to account for the condensation of gases in finely porous solids, the Kelvin model has been considered much less often for adsorption of dissolved compounds from aqueous solution onto micro- and mesoporous solids (Gun'ko et al. 2003; Chen et al. 2006). There does not appear to be any strong theoretical reason to doubt that the same principles hold true when a liquid within a capillary is adjacent to an immiscible liquid phase. In either case, the pressure difference due to the capillary forces will result in a difference in chemical potential on the two sides of the interface. In principle, depending on the contact angles at the adsorbate-aqueous-adsorbent interface at the entrance to an unfilled pore structure, one can expect that there to be bias in favor of adsorption, compared to adsorption onto outer surfaces of the adsorbent. This appears to be a neglected field in terms of both theory and practical demonstrations.

One type of evidence that can support the pore-filling concept involves hysteresis. In other words, the relationship between adsorbed amount and bulk concentration is 
different, depending on whether the bulk concentration is being raised or lowered. Strong hysteresis could be expected based on a pore-filling model if the affinity between an adsorbate molecule and an adsorbent is strongly enhanced by the presence of condensed adsorbate molecules already occupying some of the pores. The Kelvin equation, as just introduced, predicts strong hysteresis in some cases, since a strongly curved meniscus can contribute to a strong suppression of desorption, beyond what would be expected for adsorption on a flat surface. Such a mechanism has been proposed by Farrell et al. (1999). Evidence of irreversibility of adsorption has been reported in many relevant cases (Snoeyink et al. 1969; Ferro-Garcia et al. 1996; Pignatello and Xing 1996; Farrell et al. 1999; Ning et al. 1999; Ha and Vinitnantharat 2000; Pan and Xiing 2008; Chen and Ding 2012; Cong et al. 2013; ElHaddad et al. 2013). However, irreversibility also can be attributed to other effects, such as polymerization and covalent bonding to the surface of the adsorbent (Terzyk 2003a,b), as will be discussed next.

\section{Covalent Reactions of the Adsorbate}

As just mentioned, one way to account for unexpectedly depressed extents of desorption, in cases where the bulk concentration of adsorbate is reduced, is to suppose that a reaction has taken place to render the compound insoluble. Several research teams have reached the conclusion that phenolic compounds may become covalently coupled to suitable carbonaceous surfaces (Magne and Walker 1986; Grant and King 1990; FerroGarcia et al. 1996; Vidic et al. 1997; Juhasz et al. 2002; Namasivayam and Kavitha 2003; Salame and Bandosz 2003; Terzyk 2003a; Moreno-Castilla 2004; Alvarez et al. 2005). Results reported by Mathialagan and Viraraghavan (2009) are also consistent with covalent bonding as a possible mechanism. Grant and King (1990) quantified such bound phenolicbased compounds by extracting the activated carbons with a variety of different solvents; the portion that could not be removed was considered to have been covalently reacted. Moreno-Castilla (2004) likewise found that a portion of adsorbed phenols could be removed from activated carbon surfaces by heating, whereas another portion could not. Terzyk (2003a) used thermogravimetric analysis and concluded that the covalently bound phenol-derived material was of minor amount. Vidic et al. (1997) and Uranowski et al. (1998) observed that the binding of phenolics to activated carbon was promoted by the presence of molecular oxygen. Figure 11 illustrates a mechanism that was proposed by Osei-Twum et al. (1996) to account for such coupling.

Though the reaction is shown in Fig. 11 as occurring between a pair of isolated monoaromatic phenol molecules, one could readily apply such a model to other situations, such as when a phenolic group is associated with the surface of an activated carbon product. Indeed, oxidative coupling of phenols appears to be enabled by oxygen-containing groups at the surface of suitably treated activated carbons (Alvarez et al. 2005). Salame and Bandosz (2003) proposed an esterification between the phenolic group and carboxyl groups at the carbon surface. Magne and Walker (1986) found that it was possible to avoid what they called "chemisorption" of phenol to activated carbon by minimizing both the contact time and temperature of exposure of the phenol to the absorbate. An analogous oxidative coupling reaction also can take place in the presence of chlorine (Voudrias et al. 1985); however, the cited work warned of the likely formation of chlorinated phenols when carbon products are exposed to residual chlorine in water. 

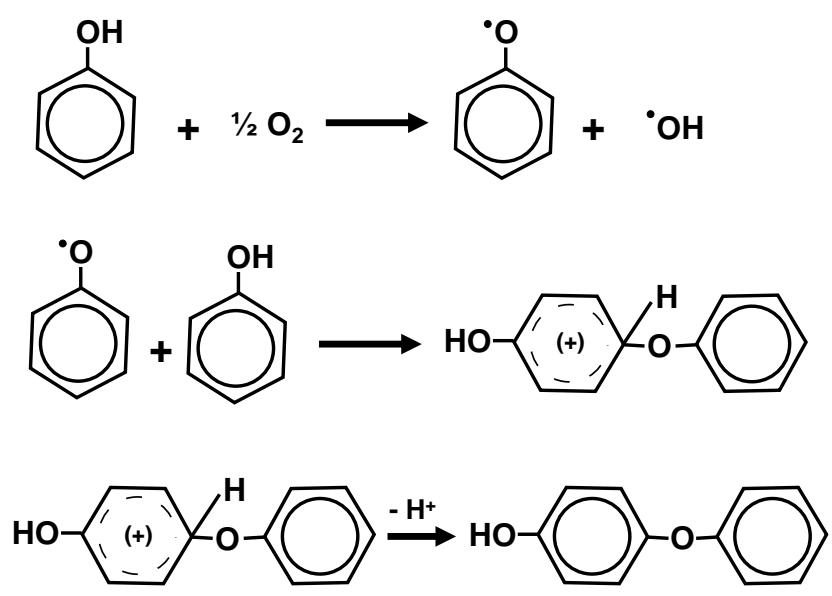

Fig. 11. Reaction scheme for oxidative coupling of phenols, forming dimers and larger species that presumably have much lower solubility in water. Scheme redrawn based on a concept by Osei-Twum et al. (1996).

Another possibility is that the phenolic compounds react among themselves, giving rise to oligomeric species having very low solubility (Vidic et al. 1994; Leng and Pinto 1997; Uranowski et al. 1998; Terzyk 2003a,b). Ravi et al. (1998) proposed that the adsorbed species undergo "chemical transformations", making them more difficult to desorb. Vidic et al. (1994) and Uranowski et al. (1998) concluded that polymerization of phenolic compounds took place in the solution phase and was not affected by the presence of activated carbon. Again, the cited studies gave evidence that molecular oxygen in solution promoted the reaction.

\section{Kinetic Aspects of Adsorption}

The kinetic aspects of adsorption of petrochemicals onto cellulose-derived adsorbents are generally the same as has been earlier discussed in reviews dealing with the biosorption of heavy metal ions and dyes (Hubbe et al. 2011, 2012). One important difference is that in the case of petrochemical compounds, the compilation in Table A reveals a much greater emphasis on activated carbon products. Thus, the microporous and mesoporous nature of activated carbon products merits particular attention here in terms of explaining rates of adsorption of petrochemical compounds.

\section{Pseudo-first-order model}

Several sets of investigators have reported good fits of adsorption data to a pseudofirst-order kinetic model (for instance Aber et al. 2009; Agarry et al. 2013). Many more examples can be found by inspection of Table A, where such behavior is denoted by " 1 st" in the column headed by "Rate law best fit". Of all the theoretical models that have been used to fit adsorption data, perhaps the pseudo-first-order model is the most logical. To begin, it should be noted that the word "pseudo" is used because the concentration of adsorbate in the bulk of solution does not show up in the rate expression; presumably its value is high enough that it does not change appreciably during the experiment. Second, the term "first-order" implies that the rate of adsorption is always proportional to the number of unfilled adsorption sites, a value that decreases during the course of an 
adsorption experiment. A typical expression for the pseudo-first-order model is given in Eq. 4 (Lagergren 1898; Arslan and Dursun 2008),

$$
\mathrm{d} q / \mathrm{d} t=k_{1}\left(q_{\mathrm{e}}-q\right)
$$

which can be integrated to arrive at the following expression:

$$
\ln \left(q_{\mathrm{e}}-q\right)=\ln q_{\mathrm{e}}-k_{1} t
$$

In these expressions $q$ indicates the amount of adsorbed compound per unit mass of adsorbate, $t$ is the duration of exposure, $q_{\mathrm{e}}$ is the equilibrium amount of adsorption, and $k_{1}$ is the pseudo-first-order rate constant.

In terms of what happens at a molecular level, the fact that a set of data fits well to a pseudo-first-order model implies that the unfilled sites at the surface are essentially equivalent to each other in terms of accessibility and that they remain so throughout the course of the experiment. There are two corollaries to this interpretation. The first is that such systems do not display a significant tendency for more favorable sites to be filled first. The second is that adsorption of one adsorbate molecule does not appear to affect the subsequent adsorption in an adjacent site. As one can see from Table A, a great many of the surveyed articles reported good fits to the pseudo-first order model. However, many systems did not, so various other models have been considered.

\section{Pseudo-second-order model}

Table A shows that the data from a great many of the surveyed systems could be well fitted to a pseudo-second-order expression for the rate of adsorption (for example $\mathrm{Fu}$ et al. 2012b). But as soon as one attempts to understand the implications for such fits, a serious problem becomes apparent. That is, the usual assumptions underlying the model do not appear to be consistent with the physical situation. In the pseudo-second order model, the rate expression indicates that the rate of adsorption is proportional to the square of the un-filled sites. This relationship can be expressed in the form shown in Eq. 6 (Ho and McKay 1999).

$$
\mathrm{d} q_{t} / \mathrm{d} t=k\left(q_{e}-q_{t}\right)^{2}
$$

In Eq. $6, q_{t}$ is the amount of the compound adsorbed at time $t, k$ is the rate constant, and $q_{e}$ is the amount adsorbed at equilibrium. After integration and rearrangement, the following form is obtained:

$$
\left(t / q_{t}\right)=1 /\left(k_{2} q_{\mathrm{e}}^{2}\right)+\left(1 / q_{e}\right) t
$$

The usual way to interpret a good fit of data to such a rate expression is to assume that the rate-limiting step involves a tri-fold collision, such that the transition state involves one adsorbate molecule and two independent adsorption sites. But in cases where the adsorption sites are bound a solid surface, such an explanation lacks internal consistency. Because the sites bound on the adsorbent are unable to move independently of each other, 
they cannot join in such a three-membered transition state. Thus, the usual way to account for pseudo-second-order rate behavior needs to be abandoned.

Fortunately, there is an alternative way the account for good fits of adsorption data to a pseudo-second-order rate expression. As first proposed in an earlier review article in this series (Hubbe et al. 2012), one relaxes the assumption that all adsorption sites have equal accessibility to adsorbate molecules. Instead, one assumes that the more easily occupied sites tend to fill up first, and the later sites become increasingly slower to be filled. Possible contributions to the slower filling of later-to-be-filled sites might be due to a wide range of circumstances, including the chemical nature of the site, the location of a site deeper within a narrow pore structure, or a degree of repulsion between already-adsorbed molecules and yet-to-be adsorbed molecules. The form of Eq. 7 is such that the deceleration in the rate of adsorption becomes increasingly severe as the surface approaches $100 \%$ saturation. The fact that the pseudo-second-order expression gives good fits to so many sets of data seems to be telling us that strong non-uniformity of accessibility or affinity of adsorption sites is the norm, rather than the exception, especially with respect to the last-to-be-filled sites.

To be consistent with the explanation just given, it is proposed that the pseudosecond-order rate expression be regarded as an empirical expression, very much in the same manner as the Freundlich adsorption isotherm has been regarded as being mainly a means to summarize experimental data (Freundlich 1907; Cal et al. 1994; Furuya et al. 1997). It is recommended that careful research be undertaken, with a focus on pure systems with well-defined pore structures, to shed more light on the underlying causes of pseudosecond-order adsorption rate behavior.

\section{Intraparticle diffusion}

Another model that has been very widely employed to fit and to interpret data for adsorption of petrochemicals onto cellulose-related adsorbents is the so-called intraparticle diffusion model (Webber and Morris 1963). Figure 12 provides a schematic view of the situation assumed in such cases. As shown, one envisions two possibilities for the ratelimiting step in adsorption, including (a) diffusion across a boundary layer at the outer surface of the particle of adsorbent material, and (b) diffusion within the particle.

Webber and Morris (1963) considered cases in which the rate-limiting step appeared to be controlled by an activation energy. Presumably the activation energy is needed to cause momentary release of an adsorbate molecule from a surface site so that it is free to diffuse to an adjacent unoccupied site (either via surface diffusion or through the aqueous phase within the pore). Thus the rate of adsorption follows an Arhenius relationship of the form,

$$
k=A e^{-E / R T}
$$

where $A$ is sometimes called the frequency factor, $E$ is the activation energy for adsorption, $R$ is the gas constant, and $T$ is absolute temperature.

Webber and Morris (1963) proposed that such a factor, in combination with a firstorder model (essentially that of the pseudo-first-order model discussed earlier), could account for adsorption rates that were mainly controlled by rates of diffusion of adsorbate molecules from the outsides of finely porous activated carbon particles into their interiors. 
The equation has been validated by carrying out experiments with different particle sizes of activated carbon (Webber and Morris 1963; Namasivayam and Sangreetha 2006; Zheng et al. 2010).

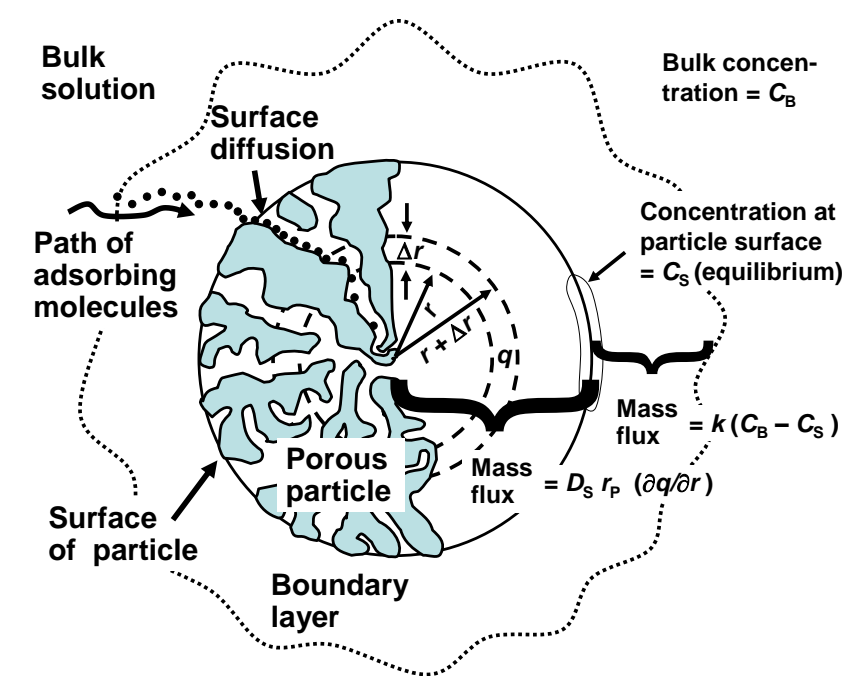

Fig. 12. Schematic diagram representing two potential rate-determining processes, including external diffusion and intra-particle diffusion (redrawn based on a concept from Hand et al. (1983) as discussed by Slaney and Bhamidimarri (1998).

The amount of adsorption can be expressed as a function of the square-root of time as (Aksu and Kabasakal 2005),

$$
q=f\left[D t / r_{\mathrm{p}}^{2}\right]^{0.5}=K t^{0.5}
$$

where $f$ is a fitting parameter related to the activation energy, $D$ is the effective diffusion constant of the adsorbate molecules within the finely porous particle, $t$ is time duration, $r_{\mathrm{p}}$ is the radius of the porous particle of adsorbent, and $K$ is the intraparticle diffusion rate constant.

The following studies found good to excellent fits of the intraparticle diffusion equation to their adsorption rate data (Mohan et al. 2005; Akhtar et al. 2009). The activation energies computed from the intraparticle diffusion model sometimes have been used as a basis for deciding if the term "physisorption" or "chemisorption" is more appropriate in a given case (Allen et al. 2005).

\section{Other kinetic models}

Several additional kinetic models are worthy of note, since research teams have found that they sometimes achieve better fits to data, compared with the models already mentioned. Selected examples of such studies and kinetic models are listed and described in Table 5. 
Table 5. Selected Examples Where Other Rate Equations Were Used to Account for Adsorption of Petrochemicals onto Cellulose-derived Adsorbents \begin{tabular}{|l|}
\hline Model and its Attributes \\
\hline $\begin{array}{l}\text { Surface diffusion. A model is presented for cases in which the rate of } \\
\text { diffusion of sorbate as it progresses in two dimensions across the }\end{array}$ \\
\hline
\end{tabular} surface of an adsorbent is a function of the degree of saturation. Presumably, as the surface sites become filled, diffusion becomes greatly restricted.

Saturation-type kinetics with film and intraparticle diffusion. This type of model was used to interpret rates of pesticide adsorption onto powdered activated carbon. A good fit to this type of model implies that at least part of the process does not depend on the concentration of adsorbate in the bulk solution; the concentration-independent factor might involve the diffusion of adsorbate as a film at the surface of pores in the adsorbent.

Pseudo-second-order rate with evidence of intraparticle diffusion control. Though Morris and Webber (1963) did not consider use of the pseudo-second-order rate model when proposing the "intraparticle diffusion" theory, other authors have shown that such an approach can make sense. Good fits to such a combination of models seem to imply that there is an activation energy involved (perhaps related to the energy required to cause an adsorbate molecules to jump from one site to an adjacent site somewhat deeper in the adsorbent), and that sites differ significantly with respect to their favorability for adsorption.

Boyd plot. Data are plotted in such a way as to determine whether the rate of adsorption is controlled by intraparticle diffusion or by mass transfer at the surface of the adsorbent.

Bangham's equation. A linear fit to the equation provides evidence that the slow step in adsorption involves diffusion into pores.

Elovich equation. The model assumes an exponential decrease in the rate of adsorption with increasing adsorbed amount. The model may imply that the remaining sites are less and less accessible. Alternatively, the presence of adsorbed molecules may impede diffusion to the more deeply located sites.

Plots of adsorption vs. square root of time. In principle, if such a plot shows more than one linear section, then one may conclude that adsorption is controlled by parallel processes occurring at different rates. The cited work by loannou and Simitzis (2009) was particularly ambitious in such an approach, making a case for four different regions of the curve. Such findings will require more critical evaluation, since not all transport mechanisms give rise to a dependency of adsorbed amount on the square root of time.

Shrinking core model. A careful analysis of adsorption onto spherelike porous particles needs to consider how the adsorbate may diffuse as a "front", which gradually decreases the remaining diameter of a shrinking core in which adsorption sites are still not filled.

Retarded diffusion. It has been found useful to define a retarded diffusion constant when considering transport of adsorbate into relatively large, dense materials such as wood chips.

Slow steps in adsorption. The cited authors focused on diffusion limitations posed by natural organic matter matrices and extremely fine Citation

Chatzopoulos et al. 1994; Chatzopoulos and Varma 1995; Karimi-Jashni and Narbaitz 1997 Aksu 2002; Aksu and Kabaskal 2005

El Bakouri et al. 2009

Boyd et al. 1947;

Aravindhan et al. 2009

Gupta and Ali 2008; Guptu et al. 2011 Wu and Tseng 2006 pores. 


\begin{tabular}{|l|l|}
\hline $\begin{array}{l}\text { Divergence between adsorption rate and capacity. The cited } \\
\text { authors reported that the highest rate of adsorption did not coincide } \\
\text { with the highest capacity. Such findings are generally consistent with } \\
\text { the idea that micropores within activated carbon are the most difficult } \\
\text { to access, and they also have the highest surface area for adsorption. }\end{array}$ & $\begin{array}{l}\text { Roostaei and Tezel } \\
\text { Half-life, half-capacity approach. This analysis, based on a }\end{array}$ \\
$\begin{array}{l}\text { Langmuir isotherm model and a pseudo-second-order rate of } \\
\text { adsorption, revealed a case in which a lower capacity adsorbent was } \\
\text { more effective for packed-bed applications, requiring fewer stages of } \\
\text { treatment. }\end{array}$ & \\
\hline $\begin{array}{l}\text { Adsorbate's diffusivity in the substrate's partition phase. Fast } \\
\text { and slow rates of adsorption can be accounted for by a model in which } \\
\text { adsorption first takes place onto a "partition phase", from which } \\
\text { release into other parts of the adsorbent is relatively slow. }\end{array}$ & \\
\hline
\end{tabular}

\section{Interpretation of Packed Bed Results}

Much of the emphasis, up to this point in the article, has been on studies focused on quasi-equilibrium conditions. Indeed, most of the studies represented in Table A can be described as batch-type adsorption experiments. But important research also has been carried out with continuous flow-through systems, i.e. packed beds (Gupta et al. 2000; Garcia-Mendeita et al. 2003; Gupta and Ali 2008; Rossner and Knappe 2008; Hank et al. 2010). Such studies provide an essential link to some of the most promising scale-up opportunities for biosorption technologies.

A key goal of studies involving packed beds has been to accurately predict breakthrough - often defined by the point in time at which the concentration of contaminant at the outlet of the column reaches half of its value at the inlet (Slaney and Bhamidimarri 1998; Chern and Chien 2002, 2003; Chuang et al. 2003a,b; Akzu and Gönen 2004; Rossner and Knappe 2008; Wu and Yu 2008; Sulaymon et al. 2012; Zeinali et al. 2012). Researchers also have been concerned with the steepness of the breakthrough curves (Brasquet et al. 1996; Brás et al. 1999), a factor that affects the degree to which the capacity of the adsorbent can be utilized before the concentration of pollutant in the outlet stream becomes unacceptably high. The concentration distribution in a column also can be used as the basis for estimation of rates of adsorption, as well as diffusion rates (Wolborska 1989).

In principle, since continuous flow experiments do not provide time for equilibration, one might expect such experiments to reveal lower adsorption capacities in comparison to batch-type types. However, the opposite has been reported in a couple of cases (Tyagi and Srivastava 1996; Gupta et al. 2000). Thus, there is reason to more closely consider some theoretical aspects.

In terms of modeling, there appears to be general agreement that the breakthrough curve can be estimated from an equation of the form,

$$
\varepsilon \frac{\partial C}{\partial t}+u_{o} \varepsilon \frac{\partial C}{\partial z}+\rho \frac{\partial q}{\partial t}=0
$$

where $\varepsilon$ is the void volume, $C$ is the local concentration of pollutant in solution, $t$ is the elapsed time since the start of elution, $u_{\mathrm{o}}$ is the interstitial flow velocity, $z$ is the distance from the inlet of the packed bed, $\rho$ is the density of solid (carbon) in the packed bed, and 
$q$ is the local concentration of pollutant in the stationary phase (Chern and Chien 2002). The cited article gives a good description of the assumptions and boundary conditions that are used when applying the equation. Through use of various simplifications, the elution time can be expressed in the following form,

$$
t=t_{1 / 2}+\frac{\rho q_{F}}{\varepsilon K_{L} a C_{F}} \int_{C_{F} / 2}^{C} \frac{1}{C-g\left(\frac{q_{F} C}{C_{F}}\right)} d C
$$

where $t_{1 / 2}$ is the time at which the dimensionless effluent concentration equals 0.5 , the subscript "F" stands for "feed", $a$ is the mass transfer area per unit volume of the bed, and $g$ is the mobile phase concentration at equilibrium.

In order to make predictions related to breakthrough curves it is necessary to input information about adsorbed amounts as a function of local concentration. This is usually done with use of the Langmuir model, or some other suitable model, to express the adsorption isotherm. In the case of the Langmuir model, the following equation can be used to relate elution time to other variables (Chern and Chien 2002),

$$
t=t_{1 / 2}+\frac{\rho N}{\varepsilon K_{L} a C_{F}}\left\{\ln 2 x+\frac{1}{1+K C_{F}} \ln \frac{1}{2(1-x)}\right\}
$$

where $N$ and $K$ are Langmuir parameters ( $\mathrm{mol} / \mathrm{kg}$ and $\mathrm{m}^{3} /$ mole, respectively) and $x$ is the normalized effluent concentration, i.e. the local concentration divided by the feed concentration (dimensionless).

Various aspects of the predictions of models have been confirmed in studies of adsorption of petrochemicals onto cellulose-derived adsorbents (Wolborska 1989; Chuang et al. 2003a; Gupta and Ali 2008; Rossner and Knappe 2008; Hank et al. 2010; Zeinali et al. 2012). For example, it has been found that the efficiency of uptake tends to fall when the flow rate is increased (Aksu and Gönen 2004; Wu and Yu 2008). Effects of the size of porous particles have been quantified (Garcia-Mendieta et al. 2003). Chern and Chien (2002, 2003) showed that the breakthrough performance could be envisioned based on constant wave patterns of solute concentrations progressing through a bed. Sulaymonn et al. (2012) predicted breakthrough curves using a model based on external and internal mass transfer, with provision for axial dispersion. Slaney and Bhamidimarri (1998) were able to account for breakthrough curves by assuming a surface diffusion model of the adsorbate within the particles of activated carbon. Brasquet et al. (1996) observed a strong selectivity, with ready adsorption of the small hydrophobic molecules phenol and atrazine, but very inefficient adsorption of high-mass humic substances.

One of the odd consequences of data fitting is that the value obtained for maximum adsorption, based on a fitting of data from packed bed experiments, is sometimes higher than what has been obtained for the same systems when batch adsorption tests were carried out (Tyagi and Srivastava 1996; Gupta 2000). Such findings are unexpected due to the fact that batch experiments allow much more time for adsorption to approach equilibrium. A possible explanation for the seemingly reversed results is that different ranges of input data are often used in such pairs of analyses. The packed bed experiments seldom incorporate data corresponding to nearly full saturation. As a consequence, the fitting of a value for 
maximum adsorption inherently involves an extrapolation somewhat beyond the range of the actual data, especially in the case of data from dynamic testing in a packed bed.

\section{Biodegradation Aspects}

Another factor that can affect not only the rate but even the amount of petrochemical compounds removed from water in the presence of cellulose-based materials is biodegradation. Biodegradation is also considered in parts 2 and 3 of this series of articles, which deal with the removal of dyes and liquid oils from water (Hubbe et al. 2012, 2013). As has been pointed out in some review articles, various petrochemical compounds can be effectively degraded by the enzymatic action of bacteria and fungi (Juhasz and Naidu 2000a; Bamforth and Singleton 2005; Julinová and Slavík 2012). However, as noted by Julinová and Slavík (2012), the process of biodegradation under ambient conditions often requires a long time.

Several teams of researchers have presented evidence that biodegradation can play a significant role as a process that goes on in parallel to biosorption (Dec and Bollag 1994; Ha and Vinitnantharat 2000; Lei et al. 2002; Raghukumar et al. 20006; Kliaugaite et al. 2008; Liu et al. 2009; Oh et al. 2011; Chen and Ding 2012; Hai et al. 2012; Ding et al. 2013; Senkaran et al. 2013; Ye et al. 2013). For instance, Dec and Bollag (1994) noted that peroxidases were able to detoxify water that was contaminated with phenolic compounds. Most notable are studies in which the decomposition products from biodegradation of petrochemical compounds were either detected or quantified (Tsezos and Wang 1991; Benoit et al. 1998; Sethunathan et al. 2004; Chan et al. 2006; Gao et al. 2011).

Liu et al. (2009) were able to distinguish between biodegraded alkanes and those that remained within biofloccules, a location that appeared to protect part of the alkanes from biodegradation. Such entrapment, meaning biosorption rather than just biodegradation, was observed after about 50 to 60 hours of bacterial culturing. Chen et al. (2010) found evidence that biosorption tended to inhibit biodegradation by white-rot fungi. Similar findings were reported by Pignatello and Xing (1996) for various organic compounds, and Wang and Grady (1995) found the same in the case of di-n-butylphthalate. Stringfellow and Alvarez-Cohen (1999) concluded that although adsorption of polynuclear aromatic hydrocarbons onto bacterial biomass tended to suppress their biodegradation in the short run, the pollutants may be ultimately degraded in the longer term, and in any case the biosorbed hydrocarbons become removed from the water phase.

Seo et al. (1997) found that the ability of activated carbon to take up peptone and various other pollutants was increased by a factor of four after inoculation of the system with microorganisms. Hank et al. (2010) found that the ability of activated carbon to remove phenol from solution was greatly enhanced by the presence of a biofilm, and the effect was attributed partly to biodegradation. Likewise, Hu et al. (2013) and Li et al. (2013) demonstrated the effectiveness of activated carbon that had been "bioaugmented" with bacterial films for the removal of methyltert-butyl ether (MTBE) from soil samples. The growth of degrading organisms as a biofilm on the carbon particles provided the capability of long-term removal of MTBE, making it unnecessary to replace or otherwise reactivate the adsorbent.

Various researchers have used microbes to decompose adsorbed petrochemicals, thereby restoring the adsorptive capacity to activated carbon (Vinitnantharat et al. 2001). Ivancev-Tumbas et al. (1998) used aerobic microbial treatment to achieve regeneration of 
activated carbon that had been used for the adsorption of phenol. Oh et al. (2013) used biodegradation to regenerate activated carbon that had become loaded with 4-chlorophenol. Toh et al. (2013) found that granular activated carbon could be regenerated after having been loaded with phenol and o-cresol, by exposure to microbial cultures. Sodha et al. (2013) achieved only about 58\% of regeneration of the adsorption capacity of activated carbon for phenol after bacterial culturing to degrade the phenol. Oh et al. (2011) found that biofilm-coated activated carbon particles were effective in degrading chlorophenols only when the concentration of the pollutant was at or below the level to which the microorganisms had become acclimatized. Romeh (2010) found that inoculation of water with certain bacteria resulted in a drastic decrease in the pesticide imidacloprid within $48 \mathrm{~h}$, whereas a much lesser change was observed in parallel experiments with the same biomass in suspension, but without innoculation. Samanta et al. (2002) noted that although naturally occurring bacteria can break down many polycyclic aromatic compounds, their performance may be improved by metabolic engineering.

In some other cases the authors concluded that most of the removal of the petrochemical compounds was attributable to biosorption rather than biodegradation (Augulyte et al. 2009; Namane et al. 2012). To add some perspective, it should be recalled from an earlier part of this article that many researchers found little or no advantage of utilizing live micro-organisms, rather than heat-killed microbial biomass of the same type as a means of removing the petrochemicals from solution (Yan and Allen 1994; Lei et al 2002; Chen et al. 2010; Ding et al. 2013), and in a few cases the dead biomass was found to be more effective (Wang and Grady 1994; Lang et al. 2009).

Another factor that can help put matters into perspective is to compare the times required to get rid of a target pollutant; for example, while most of the studies represented in Table A indicate that most of the biosorption took place within the first hour, a study by Chen and Ding (2012) found that three days was required to decrease the phenanthrene content of soil by 20 to $40 \%$, and 90 days was needed to reduce the amount by 60 to $95 \%$ in the presence of various bacterial or fungal cultures. Similar results were reported by Gao et al. (2011) for nonylphenol and biosorption and/or biodegradation by Chlorella species. Also Lei et al. (2002) found that pyrene was first adsorbed onto live microbial cells and then more gradually biodegraded, with the rates differing for different microorganisms and conditions. Sethunathan et al. (2004) found that algae were effective for relatively quick biosorption of an endocrine disrupting insecticide from water, allowing most of it to be biodegraded within 10 to 50 days, depending on the details.

\section{LIFE CYCLE ISSUES}

Up to this point in this article the relative success of biosorption has been mainly considered in terms of adsorption capacities and rates. But full success of a biosorption process also requires that an approach is cost-effective, that each step fits well with the next in an integrated program, and that potential adverse environmental impacts are avoided or minimized. Some aspects of environmental impacts will be considered here, with attention to the possible fate of cellulose-based absorbent material after it has been used to collect various petrochemical compounds from water. For instance, it has been pointed out that the production of the adsorbent material itself will ideally be carried out in 
an environmentally friendly way, with preference given to bio-based, photosynthetically renewable materials (Ali et al. 2012). Because some of these same issues already were covered in an earlier review article (Hubbe et al. 2013), the discussion that follows is somewhat abbreviated.

\section{Practical Handling of Particulate Matter}

As has been mentioned in an earlier review article (Hubbe et al. 2011), relatively large particle or fibers of adsorbent material are likely to be advantageous in term of practical handling. In batch operations relatively large particles are more easily collected, and in packed bed systems they may provide less resistance to flow. But again when considering adsorption of petrochemical compounds, little research could be found dealing with such practical issues. As an exception, Han et al. (2013) showed that activated carbon could be rendered ferromagnetic by incorporation of $\gamma-\mathrm{Fe}_{2} \mathrm{O}_{3}$ nanoparticles. Khoshmood and Azizian (2012) likewise prepared activated carbons having magnetic properties. Such materials could be easily removed from solution by use of a magnet. It is worth noting that such issues were hardly mentioned in the great majority of articles considered in this review. Once again, the paucity of research concerning various highly practical issues implies that there remain critical needs for academic and industrial research by engineers and scientists in the coming years.

\section{Regeneration}

The philosophy behind regeneration is that the biosorbent ought to be used multiple times, thus minimizing any environmental costs associated with its preparation. Once the biosorbent material has become loaded with the target pollutant or pollutants, there ought to be a benign way to remove the target compounds and to restore the adsorbent near to its initial state and capacity. As proposed by Pollard et al. (1992), it would be most desirable for such regeneration to be carried out in situ, thus allowing a packed bed of the adsorbent to be used multiple times. Several approaches to accomplish this are considered in the subsections that follow.

\section{Regeneration by rinsing with an organic solvent}

In principle it would be possible to restore many adsorbents by a kind of drycleaning, essentially rinsing them off with an organic solvent (Srivastava and Tyagi 1995b; Ferro-Garcia et al. 1996; Leng and Pinto 1997; Gupta et al. 2000; Juhasz and Naidu 2000b; Denizli et al. 2004, 2005; Akhtar et al. 2007b; Sathishkumar et al. 2008; Stasinakis et al. 2008; Lang et al. 2009; Tan et al. 2009a,b). However, there is reason to doubt that such approaches make sense in terms of environmental impact. While the adsorbent may become cleaned, the solvent becomes contaminated. A possible exception to this rule is that sometimes it is possible to use adsorption as a means to pre-concentrate organic liquids as a step towards obtaining them in their pure form (Aktar et al. 2007a). In general, however, it makes sense to seek alternatives to the use of organic solvents in the regeneration of adsorbents.

\section{Release back into an alkaline aqueous phase as a concentrate}

When dealing with phenolic compounds many researchers have observed that it is possible to transfer much of the adsorbed material back into aqueous solution by raising 
the pH to approximately 10 or 11 or higher (Leng and Pinto 1997; Tyagi et al. 1997; Akhtar et al. 2009; Anirudhan et al. 2009; Gupta et al. 2000; Kujawski et al. 2004; Özkaya 2006; Tang et al. 2007; Kumar 2009b; Kumar and Min 2011b; Abdallah 2013). Brandt et al. (1997) found that raising the $\mathrm{pH}$ to 7 was sufficient to regenerate bacterial biomass that had been loaded with pentachlorophenol; such results are consistent with the much stronger acidity of that compound in comparison to most other phenols. Chularueangaksorn et al. (2013) employed a mixture of $\mathrm{NaOH}$ and $\mathrm{NaCl}$ in a methanol-water (70:30) solution to remove perfluorooctane sulfonate from an anionic exchange resin. Presumably the regeneration by base should be performed with a minimum of aqueous phase, such that the resulting aqueous solution is many times more concentrated than the original polluted water. Leng and Pinto (1997) found that oxygen-free conditions were much more effective than oxygenated conditions when using a methanol- $\mathrm{NaOH}$ combination to remove phenol from activated carbons. Treatment with alkaline solution also has been found to be effective for regeneration of activated carbons that had been loaded with certain other contaminants, such as pesticides (Hamadi et al. 2004). In work that calls into question the need to always raise the $\mathrm{pH}$ of the desorbing solution, $\mathrm{Wu}$ and $\mathrm{Yu}(2007,2008)$ found that simple equilibration with deionized water was able to remove over $80 \%$ of adsorbed 2,4 dichlorophenol from fungal beds; however such easy desorption may raise concerns regarding insufficient affinity in those cases between the target adsorbate and a candidate adsorbent to achieve effective removal in the first place.

Figure 13 describes a possible scheme that might be employed to treat the concentrated rinsate from an alkaline regeneration operation. After $\mathrm{pH}$ adjustment, it is proposed that the mixture be subjected to biological treatment with activated sludge in conventional wastewater treatment systems or bioreactors (Farhadian et al. 2008; Kwon et al. 2011; Al-Khalid and El-Naas 2012; Niti et al. 2013).

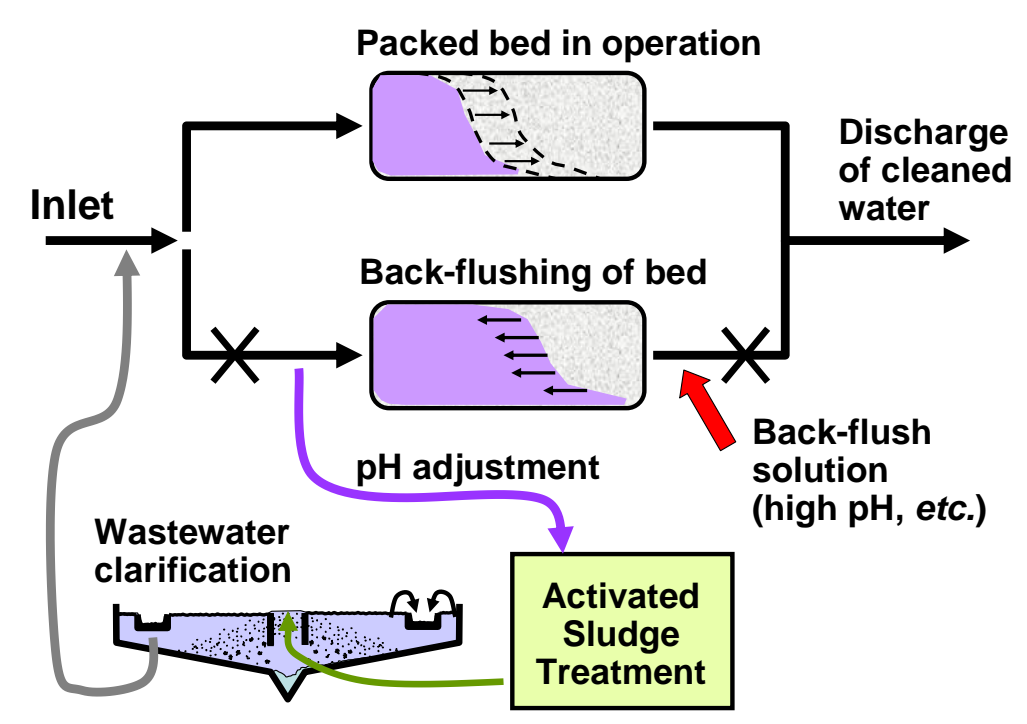

Fig. 13. Schematic diagram of a scheme for desorptive regeneration of a packed bed, followed by biodegradation of the rinsate, and then recapture of any remaining contaminant onto the packed bed, allowing release of purified water 
Note that according to the diagram the biologically clarified water is then sent once again through the packed bed system. Incorporation of such a repetition of biosorption is justified by the presumed low rates of biodegradation of many petrochemical products. On the other hand, it can be expected that an activated sludge system can become increasingly effective in biodegradation during repeated cycles due to the enrichment of microbes in the activated sludge that are capable of breaking down various recalcitrant compounds.

\section{Oxidative degradation}

Another promising approach to the regeneration of a contaminated adsorbent material can involve oxidation or bleaching, with the aim of breaking down the adsorbed compounds into non-harmful byproducts. Such an approach depends both on the nature of the adsorbed compounds and the type of oxidant. Compared to the biological processes just described, oxidative processes can be quite rapid, offering the possibility of in-situ regeneration of packed beds.

Advanced oxidation processes (AOP) are of particular interest relative to their possible use in the regeneration of packed beds contaminated with hard-to-oxidize compounds (Pera-Titus et al. 2004; Pignatello et al. 2006). For instance, such processes can employ a combination of UV light and an oxidant such as $\mathrm{H}_{2} \mathrm{O}_{2}$ to generate $\mathrm{OH} \bullet-$ radicals. Another approach is to use Fenton's reaction, wherein $\mathrm{Fe}(\mathrm{II})$ is used with $\mathrm{H}_{2} \mathrm{O}_{2}$ to generate such radicals. Much less is known regarding possible scale-up of such processes for in-situ treatment of packed beds. Doocey and Sharratt (2004) showed that a Fenton catalysis system could be used to regenerate zeolite that had been contaminated with chlorophenols. Chan et al. (2007) employed photocatalytic oxidation for the treatment of seaweed that had been used to adsorb di(2-ethylhexyl)phthalate. Titanium dioxide particles were employed as a catalyst along with hydrogen peroxide as the oxidant and ultraviolet light to initiate the reaction. Complete regeneration was achieved within $45 \mathrm{~min}$ under optimum conditions. Okawa et al. (2007) achieved similar results using wet peroxide oxidation to remove trichloroethylene from activated carbon. Apparently the activated carbon itself was able to play the role of catalyst, causing $\mathrm{H}_{2} \mathrm{O}_{2}$ to decompose, yielding the desired $\mathrm{OH} \bullet \bullet^{-}$radical. Some loss of adsorption capacity was observed, and this was attributed to partial oxidation of the adsorbent. Omri and Benzina (2014) generated very small anatase $\mathrm{TiO}_{2}$ particles onto the surface of activated carbon particles; such systems made it possible to first adsorb phenol, then subject it to photocatalytic oxidation.

Figure 14 provides a schematic diagram suggesting how an advanced oxidation treatment could be integrated into a packed bed system for the removal of oxidizable petrochemical compounds from water. As shown, once the packed bed has reached its capacity, the concept is to backflush the system is such a way that the derived oxidative radical species are in their active form and able to interact with the adsorbed contaminants. Because the packed bed material presumably will be opaque to ultraviolet light, there are various research questions that need to be answered. For instance, the limited lifetimes of radical species may make it difficult to optimize the oxidation of compounds held within the adsorbent material. 


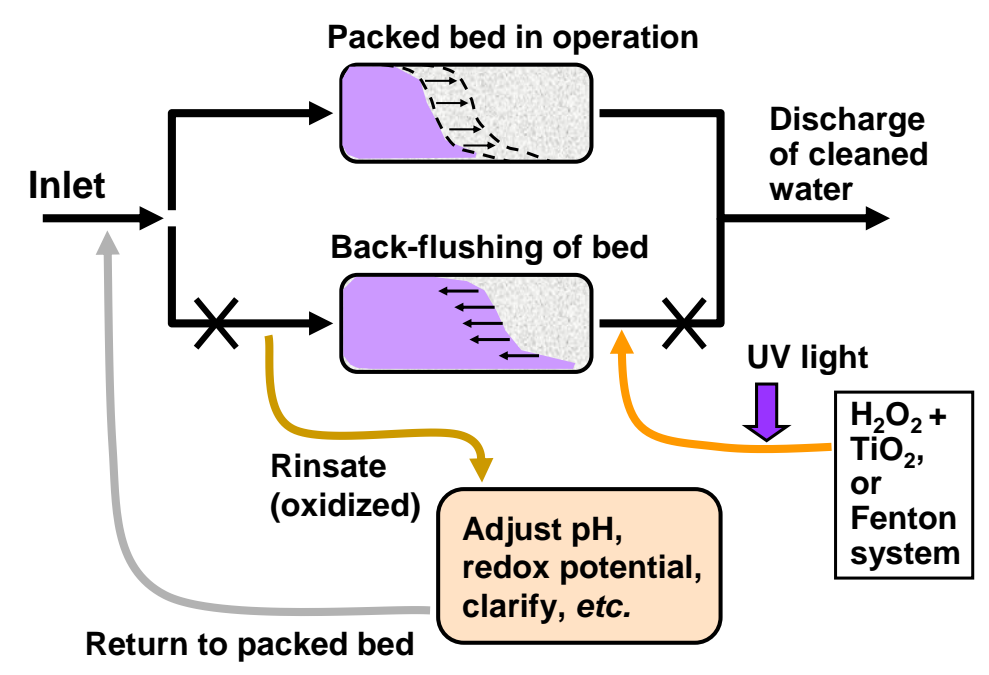

Fig. 14. Schematic diagram of a concept for in-situ oxidative regeneration of a packed bed that has been used for the adsorption of petrochemical compounds

\section{Thermal regeneration}

The idea behind thermal regeneration is to employ conditions similar to, but generally milder than those used in the initial preparation of activated carbons. Basically, one heats the material in the absence of oxygen such as to cause desorption of the collected organic molecules and restoration of the pristine conditions within the mesopores and micropores of the carbon (Moreno-Castilla et al. 1995a; San Miguel et al. 2001; Denizli et al. 2004; Sabio et al. 2004; Namasivayam and Sangreetha 2006; Maldonado-Hódar et al. 2007; Stasinakis et al. 2008; Román et al. 2013). Román et al. (2013) attributed the observed desorption to thermal removal of functional groups from the carbon surface, as well as cracking of the chemisorbed compounds. Álvarez et al. $(2004,2009)$ found that an additional $15 \%$ of mass loss from the carbon was incurred during heating at $1123{ }^{\circ} \mathrm{K}$ with carbon dioxide gas to restore activated carbon that had been used to adsorb phenol. It was found that similar results could be obtained with ozone gas treatment at room temperature (Álvarez et al. 2005, 2009). Sabio et al. (2004) found that gasification with carbon dioxide was much more effective than simple pyrolysis in the regeneration of active carbon loaded with $p$-nitrophenol. Ania et al. (2005) found that microwave heating made it possible to achieve more rapid regeneration of activated carbon with less harmful effect on the pore size distribution than conventional heating. San Miguel et al. (2001) found that steam gasification was very effective for regeneration of activated carbon, but that excessively severe conditions deteriorated the microporosity of the adsorbent.

\section{Biological regeneration or treatment}

Adsorbent material also can be regenerated by exposing it to conditions that allow biological decomposition (Ivancev-Tubas et al. 1998; Vinitnantharat et al. 2001; Oh et al. 2013; Sodha et al. 2013; Toh et al. 2013). For instance Ivancev-Tubas et al. (1998) employed aerobic conditions that allowed micro-organisms to break down adsorbed phenol on activated carbon. A study by $\mathrm{Oh}$ et al. (2013) revealed no effect of the amount of adsorbed chlorophenol on the bioregeneration of activated carbon. Sekaran et al. (2013) 
immobilized bacteria on activated carbon to decontaminate sulphonated phenolic compounds. On the other hand, Toh et al. (2013) found that it made no difference whether microbial biomass was immobilized or free-floating during the bioregeneration of activated carbon loaded with phenol and $o$-cresol.

One of the key concerns about the kind of approach just mentioned is that biodegradation may be too slow for practical use in many packed bed systems. A possible way to get around this dilemma is to allow biodegradation to take place continuously within the bed. Examples employing of such an approach were mentioned earlier (Hu et al. 2013; Li et al. 2013c). A challenging aspect of such an approach is the need to maintain conditions is a suitable range for biological growth, possibly including control of $\mathrm{pH}$, temperature, and micronutrients. While the cited studies claimed success for semicontinuous biosorption and biodegradation of some selected contaminants, more such research is needed to determine if the concept can be scaled up and used for diverse and variable streams of contaminated water.

In addition to considering use of biodegradation as a way to recondition adsorbent material, one needs to appreciate that biodegradation constitutes a key step in conventional wastewater treatment programs. For instance, Al-Khalid and El-Nass (2012) have reviewed studies dealing with the aerobic biodegradation of phenols. Such treatment can be understood as involving adsorption of the pollutants onto bacterial sludge, in addition to the possibility of enzymatic breakdown while the target compounds are in the soluble phase. Several studies have documented the adsorption of phenolic compounds and other petrochemicals onto bacterial sludge of the type generated during wastewater treatment (Bell and Tsezos 1988, 1989; Tsezos and Wang 1991a,b; Kennedy et al. 1992; Yan and Allen 1994; Aksu and Yener 1998, 2001; Stringfellow and Avlarez-Cohen 1999; Karim and Gupta 2002; Aksu and Gönen 2004; Gao and Wang 2007; Thawornchaisit and Pakulanon 2007; Arslan and Dursun 2008; Augulyte et al. 2008; Ochoa-Herrera and SierraAlverez 2008; Yu and Hu 2011; Julinová and Slavík 2012; Li et al. 2013b; Sulaymon et al. 2013). Pan et al. (2010) also documented the adsorption of phenanthrene to watersoluble polymeric substances released by bacterial sludge. These studies can serve as a reminder not to draw a sharp dividing line between biosorption and biodegradation processes. In fact, the two processes appear to be working in tandem during conventional wastewater treatment with the application of activated sludge.

\section{Life-Cycle Comments for the Series of Review Articles}

Table 6 provides a summary of options for the handling of spent cellulose-based adsorbent materials corresponding to the contaminant classes considered in the four review articles in this series (Hubbe et al. 2011, 2012, 2013, and the present article). In this table the word "Yes" is used to indicate that the effectiveness of the proposed approach is at least partly supported by published articles. The question mark is used in cases where there is a serious need for more research. And the word "No" is used when the existing literature has revealed scant support for the given option. As can be seen, there are many question marks in the table. That's good news for people who want to embark on a career to try to solve some of those problems. The table also exposes the seriousness of the challenge regarding commercial-scale implementation of concepts that already have shown promise in the laboratory. 
Table 6. Tentative Rating of Possible Regeneration Schemes for Use with the Four Classes of Pollutants Considered in this Series of Articles

\begin{tabular}{|c|c|c|c|c|}
\hline & Metals & Dyes & Oil & $\begin{array}{l}\text { Petro- } \\
\text { chem. }\end{array}$ \\
\hline $\begin{array}{l}\text { REGENERATE THE ADSORBENT } \\
\text { Concentrate the rinsate. } \\
\text { Biodegrade rinsate \& recirculate. } \\
\text { Chemically degrade in situ. }\end{array}$ & $\begin{array}{l}\text { Yes } \\
\text { No } \\
\text { No }\end{array}$ & $\begin{array}{l}\text { No } \\
\text { Yes } \\
\text { Yes }\end{array}$ & $\begin{array}{l}\text { No } \\
-?- \\
\text { No }\end{array}$ & $\begin{array}{l}\text { No } \\
-?- \\
-?-\end{array}$ \\
\hline $\begin{array}{l}\text { INCINERATE FILLED ADSORBENT } \\
\text { Recover energy from biomass. } \\
\text { Recover concentrated adsorbate. }\end{array}$ & $\begin{array}{l}\text { Yes } \\
\text {-?- }\end{array}$ & $\begin{array}{l}\text { Yes } \\
\text { No }\end{array}$ & $\begin{array}{l}\text { Yes } \\
\text { No }\end{array}$ & $\begin{array}{l}-?- \\
\text { No }\end{array}$ \\
\hline LANDFILL (leaching concerns) & $-?-$ & Yes & No & No \\
\hline $\begin{array}{l}\text { BIODEGRADATION OF ADSOBENT } \\
\text { Anaerobic (then recirculate) } \\
\text { Activated sludge water treatment } \\
\text { Composting (self-contained) }\end{array}$ & $\begin{array}{l}\text { No } \\
\text { No } \\
\text { No }\end{array}$ & $\begin{array}{l}\text { Yes } \\
\text { Yes } \\
-?-\end{array}$ & $\begin{array}{l}-?- \\
\text { No } \\
-?-\end{array}$ & $\begin{array}{l}-?- \\
-?- \\
-?-\end{array}$ \\
\hline
\end{tabular}

\section{CONCLUDING REMARKS}

Based on the many scientific works that have been considered in this review, it is clear that there is a great deal of interest in using adsorbents based on cellulosic materials as a means to remove various petrochemical pollutants from water. However, full-scale implementation of this type of technology does not appear to have kept pace. According to Gadd (2009) as well as Fomina and Gadd (2014), there has been little or no industrial exploitation of plant-based adsorbent materials other than activated carbon products. To put a positive spin on this statement, however, there has been substantial progress in understanding the wide range of cellulose-based sources that can be used in the preparation of activated carbons, and progress has been made in understanding how to achieve favorable pore structures - achieving a good balance between high surface area and ready accessibility of internal sites for adsorption.

Activated carbon products generally can be described as being highly efficient adsorbents that can be fully combusted after their use, as one promising option. In addition, activated carbons loaded with various pollutants can be regenerated by such means as mild pyrolysis, microbial treatment, and by back-washing. Although back-washing with high$\mathrm{pH}$ aqueous solution appears to be a good approach for removing non-covalently bound phenolic compounds from cellulose-based adsorbents, such an approach presupposes that a wastewater treatment facility is available and that it has adequate means of dealing with the highly polluted rinsate that results from such operations. One promising approach would be to subject such rinsate to biodegradation under controlled conditions, possibly using biosorption once again in a follow-up step to polish water before it passes from a wastewater treatment system to a natural waterway.

Though it is clear from the surveyed literature that a lot of progress has been made concerning the regeneration of spent adsorbent, it would appear that there should be a priority to develop even better systems for in-situ regeneration, with emphasis on 
approaches that break down the contaminant rather than just transferring it to another phase. The published literature, as has been discussed in this article, already has shown substantial progress in this area, e.g. the in-situ oxidative treatment of the adsorbent (Chan et al. 2007; Okawa et al. 2007), or biodegradation of various compounds while they are mainly being held in place by activated carbon or other cellulose-derived adsorbents (Ivancev-Tubas et al. 1998; Vinitnantharat et al. 2001; Oh et al. 2013; Sodha et al. 2013; Toh et al. 2013). Research in this area needs to address a reported tendency for biosorption to suppress rates of degradation of the adsorbed species (Stringfellow and Alvarez-Cohen 1999; Liu et al. 2009). It would seem that a suitable balance of containment of the contaminant on the adsorbent material, while also allowing sufficient diffusion to enable the desired degradative processes to occur, could be achieved by varying such parameters as $\mathrm{pH}$, temperature, and strategic uses of surfactants, among other variables.

If one's goal is to promote the usage of cellulose-based adsorbents, it would make sense to aim for applications that are likely to play to the strength of this type of technology. As noted by Moreno-Castilla (2004), the use of adsorbents is especially appropriate when there is a need to remove low concentrations of highly objectionable compounds from aqueous solution. Biosorption can be recommended as a polishing step after other wastewater treatment operations, such as pre-filtration, coagulative settling (primary clarification), and activated sludge (secondary wastewater treatment) have removed the major portion of contaminants. Relative to membrane-based separations, biosorption offers far fewer concerns about flow restrictions and fouling. Other options such as evaporation and fully effective reverse osmosis as means to purify water involve much higher cost per volume of water to be purified.

Finally, it would seem that the time is ripe for further exploitation of torrefied wood in certain applications calling for biosorption. One of the promising attributes of torrefied wood, compared to the source material, is its more hydrophobic character in comparison to the original plant material, especially following more severe levels of treatment (Ibrahim et al. 2013). As noted by Penmetsa and Steele (2012), there is potential to impart stronger hydrophobic character to torrefied wood by treating it with certain low-cost hydrophobic materials. Such treatment would likely increase the effectiveness of the material for removing various synthetic organic compounds from water. Compared to activated carbons, torrefied wood products offer potential advantages such as much higher yield (relative to the raw material), a well-developed, interconnecting macro-pore structure associated with fiber lumens, and a rich diversity of surface chemical groups, all attributable to the much lower level of thermal degradation in comparison to conventional activated carbons. A wide diversity of surface sites would tend to favor use of an adsorbent material for a broad range of potential applications. Thus it is hoped that when a similar review article is written ten years from now, some key developments in the field will include large-scale, economical preparation of torrefied biomass products that have been engineered for more effective use as adsorbents. 


\section{REFERENCES CITED}

Abdallah, M. A. M. (2013). "The potential of different bio adsorbents for removing phenol from its aqueous solution," Environ. Monitoring Assess. 185(8), 6495-6503. DOI: 10.1007/s10661-012-3041-y

Abe, I., Hayashi, K., Tatsumoto, H., Kitagawa, M., and Hirashima, T. (1985). "The relation between activated carbon adsorption and water-quality indexes," Water Res. 19(9), 1191-1193. DOI: 10.1016/0043-1354(85)90356-2

Aber, S., Khataee, A., and Sheydaei, M. (2009). "Optimization of activated carbon fiber preparation from Kenaf using $\mathrm{K}_{2} \mathrm{HPO}_{4}$ as chemical activator for adsorption of phenolic compounds," Bioresour. Technol. 100(24), 6586-6591. DOI: 10.1016/j.biortech.2009.07.074

Abuzaid, N. S., and Nakhla, G. F. (1994). "Dissolved oxygen effects on equilibrium and kinetics of phenolics adsorption by activated carbon," Environ. Sci. Technol. 28(2), 216-221. DOI: 10.1021/es00051a006

Adachi, A., Ikeda, C., Takagi, S., Fukao, N., Yoshie, E., and Okano, T. (2001a). "Efficiency of rice bran for removal of organochlorine compounds and benzene from industrial wastewater," J. Agric. Food Chem. 49, 1309-1314. DOI: $10.1021 / \mathrm{jf} 001147 \mathrm{c}$

Adachi, A., Komiyama, T., Tanaka, T., Nakatani, M., Muguruma, R., and Okano, T. (2001b). "Removal efficiency of defatted seed for organochlorine compounds," $J$. Health Sci. 47(1), 54-59. DOI: 10.1248/jhs.47.54

Adamson, A. W., and Gast, A. P. (1997). Physical Chemistry of Surfaces, Wiley, New York.

Adhikari, S., Chattopadhyay, P., and Ray, L. (2010). "Biosorption of Malathion by dry cells of an isolated Bacillus sp. S-14," Chem. Speciation Bioavail. 22(3), 207-213. DOI: $10.3184 / 095422910 X 12843150483621$

Adolphs, J. (2007). "Excess surface work - A modelless way of getting surface energies and specific surface areas directly from sorption isotherms," Applied Surf. Sci. 253(13), 5645-5649. DOI: 10.1016/j.apsusc.2006.12.089

Agarry, S. E., Ogunleye, O. O., and Aworanti, O. A. (2013). "Biosorption equilibrium, kinetic and thermodynamic modelling of naphthalene removal from aqueous solution onto modified spent tea leaves," Environ. Technol. 34(7), 825-839. DOI: 10.1080/09593330.2012.720616

Agarwal, B., Thakur, P. K., and Balomajumder, C. (2013). "Use of iron-impregnated granular activated carbon for co-adsorptive removal of phenol and cyanide: Insight into equilibrium and kinetics," Chemical Engineering Communications 200(9), 12781292. DOI: $10.1080 / 00986445.2012 .744749$

Aharoni, C., and Tomkins, F. E. (1970). "Kinetics of adsorption and desorption and the Elovich equation," in: Advances in Catalysis and Related Subjects, Eley, D. D., Pines, H., and Weisz, P. B. (eds.), Academic Press, New York, pp. 1-49.

Ahmad, M., Lee, S. S., Dou, X. M., Mohan, D., Sung, J.-K., Yang, J. E., and Ok, Y. S. (2012). "Effects of pyrolysis temperature on soybean stover- and peanut shell-derived biochar properties and TCE adsorption in water," Bioresource Technology 118, 536544. DOI: 10.1016/j.biortech.2012.05.042 
Ahmad, M., Lee, S. S., Rajapaksha, A. U., Vithanage, M., Zhang, M., Cho, J. S., Lee, S.E., and Ok, Y. S. (2013). "Trichloroethylene adsorption by pine needle biochars produced at various pyrolysis temperatures," Bioresource Technology 143, 615-622. DOI: 10.1016/j.biortech.2013.06.033

Ahmaruzzaman, M., and Sharma, D. K. (2005). "Adsorption of phenols from wastewater," J. Colloid Interface Sci. 287(1), 14-24. DOI: 10.1016/j.jcis.2005.01.075

Ahmed, M. J., and Theydan, S. K. (2012). "Equilibrium isotherms, kinetics and thermodynamics studies of phenolic compounds adsorption on palm-tree fruit stones," Ecotoxicology and Environmental Safety 84, 39-45. DOI: 10.1016/j.ecoenv.2012.06.019

Ahmedna, M., Marshall, W. E., Husseiny, A. A., Goktepe, I., and Rao, R. M. (2004). "The use of nutshell carbons in drinking water filters for removal of chlorination byproducts," J. Chem. Technol. Biotechnol. 79, 1092-1097. DOI: 10.1002/jctb.1087

Ahn, S., Werner, D., Karapanagioti, H. K., McGlothlin, D. R., Zare, R. N., and Luthy, R. G. (2005). "Phenanthrene and pyrene sorption and intraparticle diffusion in polyoxymethyene, coke and activated carbon," Environ. Sci. Technol. 39(17), 65166526. DOI: 10.1021/es050113o

Akhtar, M., Bhanger, M. E., Iqbal, S., and Hasany, S. M. (2005). "Efficiency of rice bran for the removal of selected organics from water: Kinetic and thermodynamic investigations," J. Agric. Food Chem. 53, 8655-8662. DOI: 10.1021/jf058060h

Akhtar, M., Bhanger, M. I., Iqbal, S., and Hasany, S. M. (2006). "Sorption potential of rice husk for the removal of 2,4-dichlorophenol from aqueous solutions: Kinetic and thermodynamic investigations," J. Hazard. Mater. 128, 44-52. DOI: 10.1016/j.jhazmat.2005.07.025

Akhtar, M., Hasany, S. M., Bhanger, M. I., and Iqbal, S. (2007a). "Sorption potential of Moringa olifeira pods for the removal of organic pollutants from aqueous solutions," J. Hazard. Mater. 141, 546-556. DOI: 10.1016/j.jhazmat.2006.07.016

Akhtar, M., Hasany, S. M., Bhanger, M. I., and Iqbal, S. (2007b). "Low cost sorbents for the removal of methyl parathion pesticide from aqueous solutions," Chemosphere 66(10), 1829-1838. DOI: 10.1016/j.chemosphere.2006.09.006

Akhtar, M., Iqbal, S., Bhanger, M. I., Zia-Ul-Haq, M., and Moazzam, M. (2009). "Sorption of organophosphorous pesticides onto chickpea husk from aqueous solutions," Colloids Surf. B - Biointerfaces 69(1), 63-70. DOI:

10.1016/j.colsurfb.2008.10.019

Aksu, Z. (2002). "Determination of the equilibrium, kinetic and thermodynamic parameters of the batch biosorption of nickel(II) ions onto Chlorella vulgaris," Process Biochem. 38, 89-99. DOI: 10.1016/S0032-9592(02)00051-1

Aksu, Z. (2005). "Application of biosorption for the removal of organic pollutants: A review," Process Biochem. 40, 997-1026. DOI: 10.1016/j.procbio.2004.04.008

Aksu, Z., and Gönen, F. (2004). "Biosorption of phenol by immobilized activated sludge in a continuous packed pad: Prediction of breakthrough curves," Process Biochem. 39(5), 599-613. DOI: 10.1016/S0032-9592(03)00132-8

Aksu, Z., and Kabasakal, E. (2003). "Batch adsorption of 2,3-dichloropehnoxy-acetic acid (2,4-D) from aqueous solution by granular activated carbon," Separation and Purification Technology 35, 223-240. DOI:10.1016/S1383-5866(03)00144-8

Aksu, Z., and Kabasakal, E. (2005). "Adsorption characteristics of 2,4- 
dichlorophenoxyacetic acid (2,4-D) from aqueous solution on powdered activated carbon," J. Environ. Sci. Health. Pt. B-Pesticides Food Contam. Ag. Wastes 40(4), 545-570. DOI: 10.1081/PFC-200061533

Aksu, Z., and Yener, J. (1998). "Investigation of the biosorption of phenol and monochlorinated phenols on the dried activated sludge," Proc. Biochem. 33(6), 649655. DOI: 10.1016/S0032-9592(98)00029-6

Aksu, Z, and Yener, J. (2001). "A comparative adsorption/biosorption study of monochlorinated phenols onto various sorbents," Waste Manage. 21, 695-702. DOI: 10.1016/S0956-053X(01)00006-X

Alam, M. Z., Muyibi, S. A., and Toramae, J. (2007). "Statistical optimization of adsorption processes for removal of 2,4-dichlorophenol by activated carbon derived from oil palm empty fruit bunches," J. Environ. Sci. - China 19(6), 674-677. DOI: 10.1016/S1001-0742(07)60113-2

Allen, S. J., Koumanova, B., Kircheva, Z., and Nenkova, S. (2005). "Adsorption of 2nitrophenol by technical hydrolysis lignin: Kinetics, mass transfer, and equilibrium studies," Indust. Eng. Chem. Res. 44(7), 2281-2287. DOI: 10.1021/ie049455d

Ali, I., Asim, M., and Khan, T. A. (2012). "Low cost adsorbents for the removal of organic pollutants from wastewater," Journal of Environmental Management 113, 170-183. DOI: 10.1016/j.jenvman.2012.08.028

Al-Khalid, T., and El-Naas, M. H. (2012). "Aerobic biodegradation of phenols: A comprehensive review," Crit. Revs. Environ. Sci. Technol. 42(16), 1631-1690. DOI: 10.1080/10643389.2011.569872

Álvarez, P. M., Beltrán, F. J., Gómez-Serrano, V., Jaramillo, J., and Rodríguez, E. M. (2004). "Comparison between thermal and ozone regenerations of spent activated carbon exhausted with phenol," Water Res. 38, 2155-2165. DOI:

10.1016/j.watres.2004.01.030

Alvarez, P. M., Beltran, F. J., Masa, F. J., and Pocostales, J. P. (2009). “A comparison between catalytic ozonation and activated carbon adsorption/ozone-regeneration processes for wastewater treatment," Appl. Catal. B - Environ. 92(3-4), 393-400. DOI: $10.1016 /$ j.apcatb.2009.08.019

Alvarez, P. M., García-Araya, J. F., Beltrán, F. J., Masa, F. J., and Medina, F. (2005). "Ozonation of activated carbons: Effect on the adsorption of selected phenolic compounds from aqueous solutions," J. Colloid Interface Sci. 283(2), 503-512. DOI: 10.1016/j.jcis.2004.09.014

Amstaetter, K., Eek, E., and Cornelissen, G. (2012). "Sorption of PAHs and PCBs to activated carbon: Coal versus biomass-based quality," Chemosphere 87(5), 573-578. DOI: 10.1016/j.chemosphere.2012.01.007

Anderson, N., Jones, J. G., Page-Dumroese, D., McCollum, D., Baker, S., Loeffler, D., and Chung, W. (2013). "A comparison of producer gas, biochar, and activated carbon from two distributed scale thermochemical conversion systems used to process forest biomass," Energies 6(1), 164-183. DOI: 10.3390/en6010164

Ania, C. O., Parra, J. B., Menéndez, J. A., and Pis, J. J. (2005). "Effect of microwave and conventional regeneration on the microporous and mesoporous network and on the adsorptive capacity of activated carbons," Micropor. Mesopor. Mater. 85, 7-15. DOI: 10.1016/j.micromeso.2005.06.013

Anirudhan, T. S., Sreekumari, S. S., and Bringle, C. D. (2009). "Removal of phenols 
from water and petroleum industry refinery effluents by activated carbon obtained from coconut coir pith," Adsorp. J. Inernat. Adsorp. Soc. 15(5-6), 439-451. DOI: 10.1007/s10450-009-9193-6

Antizar-Ladislao, B., and Galil, N. I. (2004). "Biosorption of phenol and chlorophenols by acclimated residential biomass under bioremediation conditions in a sandy aquifer," Water Res. 38, 267.276. doi:10.1016/j.watres.2003.09.032

Aravindhan, R., Rao, J. R., and Nair, B. U. (2009). "Application of a chemically modified green macro alga as a biosorbent for phenol removal," J. Environ. Manag. 90(5), 1877-1883. DOI: 10.1016/j.jenvman.2008.12.005

Aravindhan, R., Rao, J. R., and Nair, B. U. (2011). "Adsorption of phenol onto activated carbon from seaweed: Determination of the optimal experimental parameters using factorial design," Journal of The Taiwan Institute of Chemical Engineers 42(6), 952956. DOI: $10.1016 /$ j.jtice.2011.04.003

Arslan, C. S., and Dursun, A. Y. (2008). "Biosorption of phenol on dried activated sludge: Effect of temperature," Separ. Sci. Technol. 43(11-12), 3251-3268. DOI: 10.1080/01496390802063671

Ashour, I., Al-Rub, F. A., Sheikha, D., and Volesky, B. (2008). "Biosorption of naphthalene from refinery simulated waste-water on blank alginate beads and immobilized dead algal cells," Separ. Sci. Technol. 43(8), 2208-2224. DOI: 10.1080/01496390801887351

Augulyte, L., Kliaugaite, D., Racys, V., Jankunaite, D., Zaliauskiene, A., Andersson, P. L., and Bergqvist, P.-A. (2008). "Chemical and ecotoxicological assessment of selected biologically activated sorbents for treating wastewater polluted with petroleum products with special emphasis on polycyclic aromatic hydrocarbons," Water Air Soil Pollution 195, 243-256. DOI: 10.1007/s11270-008-9743-7

Augulyte, L., Kliaugaite, D., Racys, V., Jankunaite, D., Zaliauskiene, A., Bergqvist, P. A., and Andersson, P. L. (2009). "Multivariate analysis of a biologically activated carbon (BAC) system and its efficiency for removing PAHs and aliphatic hydrocarbons from wastewater polluted with petroleum products," J. Hazard. Mater. 170(1), 103-110. DOI: 10.1016/j.jhazmat.2009.04.129

Ayotamuno, M. J., Kogbara, R. B., Ogaji, S. O. T., and Probert, S. D. (2006). "Petroleum contaminated ground-water: Remediation using activated carbon," Applied Energy 83, 1258-1264. DOI: 10.1016/j.apenergy.2006.01.004

Ayranci, E., and Duman, O. (2006). "Adsorption of aromatic organic acids onto high area activated carbon cloth in relation to wastewater purification," J. Hazard. Mater. B 136, 542-552. DOI: 10.1016/j.jhazmat.2005.12.029

Aytekin, C. (1991). "Application of the Polanyi adsorption potential theory to adsorption of phenolic compounds from water solution onto activated carbon," Spectros. Lett. 24(5), 653-664. DOI: 10.1080/00387019108018146

Azad, F. S., Abedi, J., and Iranmanesh, S. (2013). "Removal of naphthenic acids using adsorption process and the effect of the addition of salt," Journal of Environmental Science and Health Part A-Toxic/Hazardous Substances \& Environmental Engineering 48(13), 1649-1654. DOI: 10.1080/10934529.2013.815457

Bai, Y., Huang, Z.-H., Wang, M.-X., and Kang, F. Y. (2013). "Adsorption of benzene and ethanol on activated carbon nanofibers prepared by electrospinning," Adsorption - Journal of the International Adsorption Society 19(5), 1035-1043. DOI: 
10.1007/s 10450-013-9524-5

Bamforth, S. M., and Singleton, I. (2005). "Bioremediation of polycyclic aromatic hydrocarbons: Current knowledge and future directions," J. Chem. Technol.

Biotechnol. 80, 723-736. DOI: 10.1002/jctb.1276

Bansode, R. R., Losso, J. N., Marshall, W. E., Rao, R. M., and Portier, R. J. (2003).

"Adsorption of volatile organic compounds by pecan shell and almost shell-based granular activated carbons," Bioresour. Technol. 90, 175-184. DOI: 10.1016/S09608524(03)00117-2

Barbour, J. P., Smith, J. A., and Chiou, C. T. (2005). "Sorption of aromatic organic pollutants to grasses from water," Environ Sci. Technol. 39(21), 8369-8373. DOI: 10.1021/es0504946

Bartholdy, S., Bjorner, M. G., Solbraa, E., Shapiro, A., and Kontogeorgis, G. M. (2013). "Capabilities and limitations of predictive engineering theories for multicomponent adsorption," Industrial \& Engineering Chemistry Research 52(33), 11552-11563. DOI: $10.1021 /$ ie400593b

Bayramoglu, G., Gursel, I., Tunali, Y., and Arica, M. Y. (2009). "Biosorption of phenol and 2-chlorophenol by Funalia trogii pellets," Bioresour. Technol. 100(10), 26852691. DOI: 10.1016/j.biortech.2008.12.042

Belashchenko, D. K., Rodnikova, M. N., Balabaev, N. K., and Solonina, I. A. (2014). "Investigating hydrogen bonds in liquid ethylene glycol structure by means of molecular dynamics," Russian J. Phys. Chem. A. 88(1), 94-102. DOI: $10.1134 / \mathrm{S} 0036024414010063$

Bell, J. P., and Tsezos, M. (1987). "Removal of hazardous organic pollutants by biomass adsorption," J. Water Pollut. Control Fed. 59(4), 191-198.

Bell, J. P., and Tsezos, M. (1988). "The selectivity of biosorption of hazardous organics by microbial biomass,” Water Res. 22(10), 1245-1251. DOI: 10.1016/00431354(88)90111-X

Bello-Huitle, V., Atenco-Fernández, P., and Reyes-Mazzoco, R. (2010). “Adsorption studies of methylene blue and phenol onto pecan and castile nutshells prepared by chemical activation," Revista Mexicana de Ingeniería Quimica 9(3), 313-322.

Benoit, P., Barriuso, E., and Calvet, R. (1998). "Biosorption characterization of herbicides, 2,4-D and atrazine, and two chlorophenols on fungal mycelium," Chemosphere 37(7), 1271-1282. DOI: 10.1016/S0045-6535(98)00125-8

Berezkin, V. I., Viktorovskiı̌, I. V., Golubev, L. V., Petrova, V. N., and Khoroshko, L. O. (2002). "A comparative study of the sorption capacity of activated charcoal, soot, and fullerenes for organochlorine compounds," Tech. Phys. Lett. 28(11), 885-888. DOI: $10.1134 / 1.1526872$

Beverley, K. J., Cling, J. H., Fletcher, P. D. I, and Thubron, S. (1999). "Evaporation rates of water containing within porous silica particles," Phys. Chem. Chem. Phys. 1(5), 909-911. DOI: 10.1039/a809241i

Bhatnagar, A., Vilar, V. J. P., Botelho, C. M. S., and Boaventura, R. A. R. (2010). "Coconut-based biosorbents for water treatment - A review of the recent literature," Advan. Colloid Interface Sci. 160, 1-15. DOI: 10.1016/j.cis.2010.06.011

Bhowmik, M., and Bajpai, S. K. (2012). "Sorptive removal of gatifloxacin from synthetic wastewater using chitin: An equilibrium study," Environ. Eng. Manag. J. 11(8), 1395-1406. 
Bilgili, M. S., Varank, G., Sekman, E., Top, S., Özçimen, D., and Yazici, R. (2012). "Modeling 4-chlorophenol removal from aqueous solutions by granular activated carbon," Environ. Model. Assess. 17(3), 289-300. DOI: 10.1007/s10666-011-9293-z

Bina, B., Pourzamani, H., Rashidi, A., and Amin, M. M. (2012). "Ethylbenzene removal by carbon nanotubes from aqueous solution," J. Environ. Public Health 2012, article no. 817187.

Blackburn, R. S., Harvey, A., Kettle, L. L., Manian, A. P., Payne, J. D., and Russell, S. J. (2007). "Sorption of chlorhexidine on cellulose: Mechanism of binding and molecular recognition," Journal of Physical Chemistry B 111, 8775-8784. DOI: 10.1021/jp070856r

Blanco-Martínez, D. A., Giraldo, L., and Moreno-Piraján, J. C. (2009). "Effect of the pH in the adsorption and in the immersion enthalpy of mono-hydroxylated phenols from aqueous solutions on activated carbons," J. Hazard. Mater. 169, 291-296. DOI: 10.1016/j.jhazmat.2009.03.099

Bloom, J. W. G., and Wheeler, S. E. (2011). "Taking the aromaticity out of aromatic hydrocarbons by insoluble dietary fiber," Angew. Chem. 123(34), 7993-7995. DOI: 10.1002/ange.201102982

Boki, K., Kadota, S., Takahashi, M., and Kitakouji, M. (2007). "Uptake of polycyclic aromatic hydrocarbons by insoluble dietary fiber," J. Health Sci. 53(1), 99-106. DOI: 10.1248/jhs.53.99

Boucher, J., Steiner, L., and Marison, I. W. (2007). "Bio-sorption of atrazine in the presscake from oilseeds,” Water Res. 41, 3209-3216. DOI: 10.1016/j.watres.2007.05.038

Boussahel, R., Irinislimane, H., Harik, D., and Moussaoui, K. M. (2009). “Adsorption, kinetics, and equilibrium studies on removal of 4,4-DDT from aqueous solutions using low-cost adsorbents," Chem. Eng. Commun. 196(12), 1547-1558. DOI: 10.1080/00986440903155733

Boving, T. G., and Zhang, W. (2004). "Removal of aqueous-phase polynuclear aromatic hydrocarbons using aspen wood fibers," Chemosphere 54(7), 831-839. DOI: 10.1016/j.chemosphere.2003.07.007

Bowen, W. R., and Jenner, F. (1995). "The calculation of dispersion forces for engineering applications," Advan. Colloid Interface Sci. 56, 201-243. DOI: 10.1016/0001-8686(94)00233-3

Boyd, G. E., Adamson, A. W., and Myers, L. S. (1947). "The exchange adsorption of ions from aqueous solution by organic zeolites. II. Kinetics," Journal of the American Chemical Society 69, 2836-2848. DOI: 10.1021/ja01203a066

Brandt, S., and Zeng, A. P., and Deckwer, W. D. (1997). "Adsorption and desorption of pentachlorophenol on cells of Mycobacterium chloropehnolicum PCP-1," Biotechnol. Bioeng. 55(3), 480-489. DOI: 10.1002/(SICI)1097-0290(19970805)55:3<480::AIDBIT3>3.0.CO;2-8

Brás, I., Lemos, L. T., Alves, A., and Pereira, M. F. R. (2004). "Application of pine bark as a sorbent for organic pollutants in effluents," Manag. Environ. Qual. 15(5), 491501. DOI: 10.1108/14777830410553933

Brás, I., Lemos, L., Alves, A., and Pereira, M. F. R. (2005). "Sorption of pentachlorophenol on pine bark," Chemosphere 60, 1095-1102. DOI: 10.1016/j.chemosphere.2004.12.064 
Brás, I., Santos, L., and Alves, A. (1999). "Organochlorine pesticides removal by Pinus bark sorption,” Environ. Sci. Technol. 33, 631-634. DOI: 10.1021/es980402v

Brasquet, C., and Le Cloirec, P. (1999). "Effects of activated carbon cloth surface on organic adsorption in aqueous solutions. Use of statistical methods to describe mechanisms," Langmuir 15(18), 5906-5912. DOI: 10.1021/la9811160

Brasquet, C., Roussy, J., Subrenat, E., and Le Cloirec, P. (1996). "Adsorption and selectivity of activated carbon fibers application to organics," Environ. Technol. 17(11), 1245-1252. DOI: 10.1080/09593331708616494

Browne, T. E., and Cohen, Y. (1990). "Aqueous-phase adsorption of trichloroethylene and chloroform onto polymeric resins and activated carbon," Ind Eng. Chem. Res. 29(7), 1338-1345. DOI: 10.1021/ie00103a038

Brunauer, S., Emmet, P. H., and Teller, E. (1938). "Adsorption of gases in multimolecular layers," Journal of the American Chemical Society 60, 309-319. DOI: 10.1021/ja01269a023

Cabrera, A., Cox, L., Spokas, K. A., Celis, R., Hermosín, M. C., Cornejo, J., and Koskinen, W. C. (2011). "Comparative sorption and leaching study of the herbicides fluometuron and 4-chloro-2-methylphenoxyacetic acid (MCPA) in a soil amended with biochars and other sorbents," Journal of Agricultural and Food Chemistry 59(23), 12550-12560. DOI: 10.1021/jf202713q

Cal, M. P., Larson, S. M., and Rood, M. J. (1994). "Experimental and modeled results describing the adsorption of acetone and benzene onto activated carbon fibers," Environ. Prog. 13(1), 26-30. DOI: 10.1002/ep.670130114

Calace, N., Nardi, E., Petronio, B. M., and Pietroletti, M. (2002). “Adsorption of phenols by papermill sludges," Environ. Pollut. 118, 315-319. DOI: 10.1016/S02697491(01)00303-7

Calleja, G., Serna, J., and Rodríguez, J. (1993). "Kinetics of adsorption of phenolic compounds from wastewater onto activated carbon," Carbon 31(5), 691-697. DOI: 10.1016/0008-6223(93)90005-U

Cao, X. D., Ma, L. N., Gao, B., and Harris, W. (2009). "Dairy-manure derived biochar effectively sorbs lead and atrazine," Environ. Sci. Technol. 43(9), 3285-3291. DOI: 10.1021/es803092k

Capasso, R., and De Martino, A. (2010). "Polymerin and lignimerin, as humic acid-like sorbents from vegetable waste, for the potential remediation of waters contaminated with heavy metals, herbicides, or polycyclic aromatic hydrocarbons," J. Agr. Food Chem. 58(19), 10283-10299. DOI: 10.1021/jf101574r

Caturla, F., Martín-Martínez, J. M., Molina-Sabio, M., Rodriguez-Reinoso, F., and Torregrosa, R. (1988). "Adsorption of substituted phenols on activated carbon," J. Colloid Interface Sci. 124, 528-534. DOI: 10.1016/0021-9797(88)90189-0

Chan, H. W., Chan, C. M., Ang, P. O., and Wong, P. K. (2007). "Integrated biosorption and photocatalytic oxidation treatment of di(2-ethylhexyl)phthalate," J. Appl. Phycol. 19(6), 745-753. DOI: 10.1007/s10811-007-9218-Z

Chan, S. M. N., Luan, T. G., Wong, M. H., and Tam, N. F Y. (2006). "Removal and biodegradation of polycyclic aromatic hydrocarbons by Selenastrum capricornutum," Environ. Toxic. Chem. 25(7), 1772-1779. DOI: 10.1897/05-354R.1

Chang, K. L., Hsieh, J. F., Ou, B. M., Chang, M. H., Hseih, W. Y., Lin, J. H., Huang, P. J., Wong, K. F., and Chen, S. T. (2012). "Adsorption studies on the removal of an 
endocrine-disrupting compound (Bisphenol A) using activated carbon from rice straw agricultural waste," Separation Science and Technology 47(10), 1514-1521. DOI: 10.1080/01496395.2011.647212

Chatzopoulos, D., and Varma, A. (1995). "Aqueous-phase adsorption and desorption of toluene in activated carbon fixed beds: Experiments and model," Chem. Eng. Sci. 50, 127-141. DOI: 10.1016/0009-2509(94)00195-W

Chatzopoulos, D., Varma, A., Irvine, R. L. (1994). "Adsorption and desorption studies in the aqueous-phase for the toluene/activated carbon system," Environ. Prog. 13(1), 2125. DOI: 10.1002/ep.670130113

Chen, B., and Chen, Z. (2009). "Sorption of naphthalene and 1-naphthol by biochars or orange peels with different pyrolytic temperatures," Chemosphere 76(1), 127-133. DOI: 10.1016/j.chemosphere.2009.02.004

Chen, B., and Schnoor, J. L. (2009). "Role of suberin, suberan, and hemicellulose in phenanthrene sorption by root tissue fractions of switchgrass (Panicum virgatum)," Environ. Sci. Technol. 43, 4130-4136. DOI: 10.1021/es803510u

Chen, B., Zhou, D., and Zhu, L. (2008). "Transitional adsorption and partition of nonpolar and polar aromatic contaminants by biochar of pine needles with different pyrolytic temperatures," Environ. Sci. Technol. 42(14), 5137-5143. DOI: $10.1021 / \mathrm{es} 8002684$

Chen, B. L., and Ding, J. (2012). "Biosorption and biodegradation of phenanthrene and pyrene in sterilized and unsterilized soil slurry systems stimulated by Phanerochaete chrysosporium," J. Hazard. Mater. 229, 159-169. DOI:

10.1016/j.jhazmat.2012.05.090

Chen, B. L., Johnson, E. J., Chefetz, B., Zhu, L. Z., and Xing, B. S. (2005). "Sorption of polar and nonpolar aromatic organic contaminants by plant cuticular materials: Role of polarity and accessibility," Environ. Sci. Technol. 39, 6138-6146. DOI: 10.1021/es050622q

Chen, B.-L., and Li, Y.-G. (2007). "Sorption of 1-naphthol by plant cuticular fractions," J. Environ. Sci. - China 19(10), 1214-1220. DOI: 10.1016/S1001-0742(07)60198-3

Chen, B. L., Wang, Y. S., and Hu, D. F. (2010). "Biosorption and biodegradation of polycyclic aromatic hydrocarbons in aqueous solutions by a consortium of white-rot fungi," J. Hazard. Mater. 179, 845-851. DOI: 10.1016/j.jhazmat.2010.03.082

Chen, B. L., Yuan, M. X., and Liu, H. (2011). "Removal of polycyclic aromatic hydrocarbons from aqueous solution using plant residue materials as a biosorbent," $J$. Hazard. Mater. 188, 436-442. DOI: 10.1016/j.jhazmat.2011.01.114

Chen, Y., Wetzel, T., Aranovich, G. L., and Donohue, M. D. (2006). "Generalization of Kelvin's equation for compressible liquids in nanoconfinement," J. Colloid Interface Sci. 300(1), 45-51. DOI: 10.1016/j.jcis.2006.03.025

Chen, Y.-D., Huang, M.-J., Huang, B., and Chen, X.-R. (2012a). "Mesoporous activated carbon from inherently potassium-rich pokeweed by in situ self-activation and its use for phenol removal," Journal of Analytical and Applied Pyrolysis 98, 159-165. DOI: 10.1016/j.jaap.2012.09.011

Chen, Z. M., Chen, B. L., and Chiou, C. T. (2012b). "Fast and slow rates of naphthalene sorption to biochars produced at different temperatures," Environmental Science \& Technology 46(20), 11104-11111. DOI: 10.1021/es302345e 
Cheng, X., Kan, A. T., and Tomson, M. B. (2005). "Uptake and sequestration of naphthalene and 1,2-dichlorobenzene by $\mathrm{C}_{60}$," J. Nanoparticle Res. 7, 555-567. DOI: 10.1007/s11051-005-5674-Z

Cherifi, H., Hanini, S., and Bentahar, F. (2009). "Adsorption of phenol from wastewater using vegetal cords as a new adsorbent," Desalination 244, 177-187. DOI: 10.1016/j.desal.2008.05.022

Chern, J.-M., and Chien, Y.-W. (2002). "Adsorption of nitrophenol onto activated carbon: Isotherms and breakthrough curves," Water Res. 36, 647-655. DOI: 10.1016/S0043-1354(01)00258-5

Chern, J. M., Chien, Y. W. (2003). "Competitive adsorption of benzoic acid and $p$ nitrophenol onto activated carbon: Isotherm and breakthrough curves," Water Res. 37(10), 2347-2356. DOI: 10.1016/S0043-1354(03)00038-1

Chiu, C.-H., Lin, T.-F., and Young, C.-C. (2003). "Short-term sorption of toluene vapor onto natural organic materials," Water Air Soil Pollution 144, 223-241. DOI: 10.1023/A:1022977503362

Choi, S.-D., Hong, H.-B., and Chang, Y.-S. (2003). "Adsorption of halogenated aromatic pollutants by a protein released from Bacillus pumilus," Water Res. 37(16), 40044010. DOI: 10.1016/S0043-1354(03)00308-7

Choi, S. T., and Huber, D. J. (2009). "Differential sorption of 1-methylcyclopropene to fruit and vegetable tissues, storage and cell wall polysaccharides, oils, and lignins," Postharvest Biology Technol. 52, 62-70. DOI: 10.1016/j.postharvbio.2008.11.002

Chowdhury, Z. Z., Abd Hamid, S. B., Das, R., Hasan, M. R., Zain, S. M., Khalid, K., and Uddin, M. N. (2013). "Preparation of carbonaceous adsorbents from lignocellulosic biomass and their use in removal of contaminants from aqueous solution," BioResources 8(4), 6523-6555.

Chuang, C.-L., Chiang, P.-C., and Chang, E. E. (2003a). "Kinetics of benzene adsorption onto activated carbon," Environ. Sci. Pollut. Res. 10(1), 6-8. DOI: 10.1065/espr2001.10.098

Chuang, C. L., Chiang, P. C., and Chang, E. E. (2003b). "Column study of benzene adsorption onto activated carbon," Carbon 41(12), 2427-2430. DOI: 10.1016/S00086223(03)00153-2

Chularueangaksorn, P., Tanaka, S., Fujii, S., and Kunacheva, C. (2013). "Regeneration and reusability of anion exchange resin used in perfluorooctane sulfonate removal by batch experiments," Journal of Applied Polymer Science 130(2), 884-890. DOI: 10.1002/app.39169

Chung, M. K., Tsui, M. T. K., Cheung, K. C., Tam, N. F. Y., and Wong, M. H. (2007). "Removal of aqueous phenanthrene by brown seaweed Sargassum hemiphyllum: Sorption-kinetic and equilibrium studies," Separ. Purif. Technol. 54(3), 355-362. DOI: 10.1016/j.seppur.2006.10.008

Cong, Q., Yuan, X., and Qu, J. (2013). “A review on the removal of antibiotics by carbon nanotubes,” Water Sci. Technol. 68(8), 1679-1687. DOI: 10.2166/wst.2013.420

Cookson, J. T. (1978). "Adsorption mechanisms: The chemistry of organic adsorption on activated carbon,” In: Cheremisinoff, P. N., and Ellerbusch, F. (eds.), Carbon Adsorption Handbook, Ann Arbor Science, Ann Arbor, MI, pp. 241-279.

Costa, A. S., Romao, L. P. C., Araújo, B. R., Lucas, S. C. O., Maciel, S. T. A., Wisniewski, M. A., and Alexandre, M. R. (2012). "Environmental strategies to 
remove volatile aromatic fractions (BTEX) from petroleum industry wastewater using biomass," Bioresour. Technol. 105, 31-39. DOI: http://dx.doi.org/10.1016/j.biortech.2011.11.096

Coughlin, R. W., and Ezra, F. S. (1968). "Role of surface acidity in the adsorption of organic pollutants on the surface of carbon," Environ. Sci. Technol. 2(4), 291-297. DOI: $10.1021 /$ es60016a002

Coughlin, R. W., Ezra, F. S., and Tan, R. N. (1968). "Influence of chemisorbed oxygen in adsorption onto carbon from aqueous solution," J. Colloid Interface Sci. 28(3-4), 386396. DOI: 10.1016/0021-9797(68)90069-6

Crisafully, R., Milhome, M. A. L., Cavalcante, R. M., Silveira, E. R., Keukeleire, D. D., and Nascimento, R. F. (2008). "Removal of some polycyclic aromatic hydrocarbons from petrochemical wastewater using low-cost adsorbents of natural origin," Bioresour. Technol. 99, 4515-4519. DOI: 10.1016/j.biortech.2007.08.041

Crosby, D. G. (1981). "Environmental chemistry of pentachlorophenol," Pure Appl. Chem. 53, 1051-1080. DOI: 10.1351/pac198153051051

Cuerda-Correa, E. M., Díaz-Díez, M. A., Macías-García, A., and Gañán-Gómez, J. (2006). "Preparation of activated carbons previously treated with sulfuric acid - A study of their adsorption capacity in solution," Appl. Surf. Sci. 252(17), 6042-6045. DOI: 10.1016/j.apsusc.2005.11.013

Cunha, G. D., Romão, L. P. C., Santos, M. C., Araújo, B. R., Navickiene, S., and de Pádua, V. L. (2010). "Adsorption of trihalomethanes by humin: Batch and fixed bed column studies,” Bioresour. Technol. 101(10), 3345-3354. DOI: 10.1016/j.biortech.2009.11.096

Dąbrowski, A., Podkościelny, P., Hubicki M., and Barczak, M. (2005). "Adsorption of phenolic compounds by activated carbon - A critical review," Chemosphere 58, 1049-1070. DOI: 10.1016/j.chemosphere.2004.09.067

Daifullah, A. A. M., and Girgis, B. S. (1998). "Removal of some substituted phenols by activated carbon obtained from agricultural waste," Water Res. 32(4), 1169-1177. DOI: $10.1016 / \mathrm{S} 0043-1354(97) 00310-2$

Daifullah, A. A. M., and Girgis, B. S. (2003). "Impact of surface characterisitics of activated carbon on adsorption of BTEX," Colloids Surf. A - Physicochem. Eng. Aspects 214, 181-193. DOI: 10.1016/S0927-7757(02)00392-8

Dalmacija, B., Tamaš, Z., Miškovic, D., Karlovic, E., and Petrovic, O. (1992). "The biosorption of selected pesticides from water by biologically activated carbon," Water Sci. Technol. 26(9-11), 1991-1994.

Dargaville, T. R., Guerzoni, F. N., Looney, M. G., and Solomon, D. H. (1996). "The adsorption of multinuclear phenolic compounds on activated carbon," J. Colloid Interface Sci. 182(1), 17-25. DOI: 10.1006/jcis.1996.0432

Das, L., Kolar, P., Classen, J. J., and Osborne, J. A. (2013). "Adsorbents from pine wood via $\mathrm{K}_{2} \mathrm{CO}_{3}$-assisted low temperature carbonization for adsorption of p-cresol," Industrial Crops and Products 45, 215-222. DOI: 10.1016/j.indcrop.2012.12.010

Daughney, C. J., and Fein, J. B. (1998). "Sorption of 2,4,6-trichlorophenol by Bacillus subtillis," Environ. Sci. Technol. 32, 749-752. DOI: 10.1021/es970295p

de Araujo, B. S., Dec, J., Bollag, J. M., and Pletsch, M. (2006). "Uptake and transformation of phenol and chlorophenols by hairy root cultures of Daucus carota, Ipomoea batas, and Solanum aviculare," Chemosphere 63, 642-651. DOI: 
doi:10.1016/j.chemosphere.2005.08.005

de Boer, J. H. (1953). The Dynamical Character of Adsorption, Oxford University Press, Oxford.

Dec, J., and Bollag, J.-M. (1994). "Use of plant material for decontamination of water polluted with phenols," Biotech. Bion. 44, 1132-1139. DOI: 10.1002/bit.260440915

Delgado, L. F., Charles, P., Glucina, K., and Morlay, C. (2012). "The removal of endocrine disrupting compounds, pharmaceutically activated compounds and cyanobacterial toxins during drinking water preparation using activated carbon - A review," Sci. Total Environ. 435-436, 509-525. DOI:

10.1016/j.scitotenv.2012.07.046

Demirak, A., Dalman, Ö., Tilkan, E., Yildiz, D., Yavuz, E., and Gökçe, C. (2011). "Biosorption of 2,4 dichlorophenol (2,4-DCP) onto Posidonia oceanica (L.) seagrass in a batch system: Equilibrium and kinetic modeling," Microchemical Journal 99(1), 97-102. DOI: 10.1016/j.microc.2011.04.002

Demirev, A. (2008). "Ozonation of phenols in water solutions intermediates and mechanism of destruction. A review," Oxidation Commun. 31(4), 812-818.

Denizli, A., Cihangir, N., Rad, A. Y., Taner, M., and Alsancak, G. (2004). "Removal of chlorophenols from synthetic solutions using Phanerochaete chrysosporium," Proc. Biochem. 39(12), 2025-2030. DOI: 10.1016/j.procbio.2003.10.003

Denizli, A., Cihangir, N., Tüzmen, N., and Alsancak, G. (2005). "Removal of chlorophenols from aquatic systems using the dried and dead fungus Pleurotus sajor caju," Bioresour. Technol. 96(1), 59-62. DOI: 10.1016/j.biortech.2003.11.029

Denyes, M. J., Langlois, V. S., Rutter, A., and Zeeb, B. A. (2012). "The use of biochar to reduce soil PCB bioavailability to Cucurbita pepo and Eisenia fetida," Science of the Total Environment 437, 76-82. DOI: 10.1016/j.scitotenv.2012.07.081

Dias, J. M., Alvim-Ferraz, M. C. M., Almeida, M. F., Rivera-Utrilla, J., and SanchezPolo, M. (2007). "Waste materials for activated carbon preparation and its use in aqueous-phase treatment: A review," J. Environ. Manag. 85(4), 833-846. DOI: 10.1016/j.jenvman.2007.07.031

Diaz-Flores, P. E., Leyva-Ramos, R., Guerrero-Coronado, R. M., and Mendoza-Barron, J. (2006). "Adsorption of pentachlorophenol from aqueous solution onto activated carbon fiber," Ind. Eng. Chem. Res. 45(1), 330-336. DOI: 10.1021/ie050507o

Ding, J., Chen, B. L., and Zhu, L. Z. (2013). "Biosorption and biodegradation of polycyclic aromatic hydrocarbons by Phanerochaete chrysosporium in aqueous solution," Chin. Sci. Bull. 58(6), 613-621. DOI: 10.1007/s11434-012-5411-9

Dobbs, R. A., and Cohen, J. M. (1980). "Carbon adsorption isotherm of toxic organics," EPA-600/8-80-023, V.S. Environmental Protection Agency.

Domingues, V., Alves, A., Cabral, M., and Delerue-Matos, C. (2005). "Sorption behavior of bifenthrin on cork," J. Chromatogr. A 1069, 127-132. DOI: 10.1016/j.chroma.2004.10.011

Domingues, V. E., Priolo, G., Alves, A. C., Cabral, M. E., and Delerue-Matos, C. (2007). "Adsorption behavior of alpha-cypermethrin on cork and activated carbon," J. Environ. Sci. Health. Pt. B - Pesticides Food Contam. Ag. Wastes 42(6), 649-654. DOI: $10.1080 / 03601230701465635$

Domínguez-Vargas, J. R., Navarro-Rodríguez, J. A., de Heredia, J. B., and CuerdaCorrea, E. M. (2009). "Removal of chlorophenols in aqueous solution by carbon 
black low-cost adsorbents. Equilibrium study and influence of operation conditions," J. Hazard. Mater. 169, 302-308. DOI: 10.1016/j.jhazmat.2009.03.075

Doocey, D. J., and Sharratt, P. N. (2004). "Zeolite-mediated advanced oxidation of model chlorinated phenolic aqueous waste. Part 1: Aqueous phase Fenton catalysis," Process Safety Environ. Prot. 82(B5), 352-358. DOI: 10.1205/psep.82.5.352.44198

Dotto, G. L., Gonçalves, J. O., Cadaval, T. R. S., and Pinto, L. A. A. (2013). "Biosorption of phenol onto bionanoparticles from Spirulina sp. LEB 18," J. Colloid Interface Sci. 407, 450-456. DOI: 10.1016/j.jcis.2013.06.044

Droste, R. L. (1997). Theory and Practice of Water and Wastewater Treatment, Wiley, New York.

Dubinin, M. M. (1975). "Physical adsorption of gases and vapors in micropores," Prog. Surf. Membrane Sci. 9, 1070.

Dubinin, M. M. (1989). "Fundamentals of the theory of adsorption in micropores of carbon adsorbents: Characteristics of their adsorption properties and microporous structures," Carbon 27(3), 457-467. DOI: 10.1016/0008-6223(89)90078-X

Dumanli, A., and Windle, A. H. (2012). "Carbon fibres from cellulosic precursors: A review," J. Mater. Sci. 47(10), 4236-4250. DOI: 10.1007/s10853-011-6081-8

Dursun, G., Çiçek, H., and Dursun, A. Y. (2005). "Adsorption of phenol from aqueous solution by using carbonized beet pulp," J. Hazard. Mater. 125, 175-182. DOI: 10.1016/j.jhazmat.2005.05.023

Dvorak, B. I., Lawler, D. F., Speitel, G. E., Jones, D. L., and Badway, D. A. (1993). "Selecting among physical/chemical processes for removing synthetic organics from water," Water Environ. Res. 65(7), 827-839. DOI: 10.2175/WER.65.7.4

Edgehill, R. U., and Lu, G. Q. (1998). "Adsorption characteristics of carbonized bark for phenol and pentachlorophenol," J. Chem. Technol. Biotechnol. 71(1), 27-34. DOI: 10.1002/(SICI)1097-4660(199801)71:1<27::AID-JCTB796>3.0.CO;2-T

El Bakouri, H., Usero, J., Morillo, J., Rojas, R., and Ouassini, A. (2009). "Drin pesticides removal from aqueous solutions using acid-treated date stones," Bioresour. Technol. 100, 2676-2584. DOI: 10.1016/j.biortech.2008.12.051

ElHaddad, E., Ensinger, W., and Schuth, C. (2013). "Sorption reversibility of organic contaminants in activated carbon, charcoal and Zeolite Y-200," Grundwasser 18(3), 197-202. DOI: 10.1007/s00767-013-0229-1

El-Sheikh, A. H., Alzawahreh, A. M., and Sweileh, J. A. (2011). "Preparation of an efficient sorbent by washing then pyrolysis of olive wood for simultaneous solid phase extraction of chloro-phenols and nitro-phenols from water," Talanta 85(2), 1034-1042. DOI: 10.1016/j.talanta.2011.05.016

El-Sheikh, A. H., Newman, A. P., Said, A. J., Alzawahreh, A. M., and Abu-Helal, M. (2013). "Improving the adsorption efficiency of phenolic compounds into olive wood biosorbents by pre-washing with organic solvents: Equilibrium, kinetic and thermodynamic aspects," J. Environ. Manag. 118, 1-10. DOI: 10.1016/j.jenvman.2013.01.009

Estevinho, B. N., Ratola, N., Alves, A., and Santos, L. (2006). "Pentachlorophenol removal from aqueous matrices by sorption with almond shell residues," J. Hazard. Mater. 137(2), 1175-1181. DOI: 10.1016/j.jhazmat.2006.04.001 
Fabbri, D., Rombolà, A. G., Torri, C., and Spokas, K. A. (2013). "Determination of polycyclic aromatic hydrocarbons in biochar and biochar amended soil," Journal of Analytical and Applied Pyrolysis 103, 60-67. DOI: 10.1016/j.jaap.2012.10.003

Fanelli, D. (2012). "Negative results are disappearing from most disciplines and countries," Scientometrics 90(3), 891-904. DOI: 10.1007/s11192-011-0494-7

Farhadian, M., Duchez, D., Vachelard, C., and Larroche, C. (2008). "Monoaromatics removal from polluted water through bioreactors - A review," Water Res. 42(6-7), 1325-1341. DOI: 10.1016/j.watres.2007.10.021

Farkas, V., Felinger, A., Hegedüsova, A., Dékány, I., and Pernyeszi, T. (2013). "Comparative study of the kinetics and equilibrium of phenol biosorption on immobilized white-rot fungus Phanerochaete chrysosporium from aqueous solution," Colloids Surf. B - Biointerfaces 103, 381-390. DOI: 10.1016/j.colsurfb.2012.09.029

Farrell, J., Hauck, B., and Jones, M. (1999). "Thermodynamic investigation of trichloroethylene adsorption in water-saturated microporous adsorbents," Environ. Toxic. Chem. 18(8), 1637-1642. DOI: 10.1002/etc.5620180805

Ferro-Garcia, M. A., Rivera-Utrilla, J., Bautista-Toledo, I., and Moreno-Castilla, C. (1996). "Chemical and thermal regeneration of an activated carbon saturated with chlorophenols," J. Chem. Technol. Biotechnol. 67, 183-189. DOI: 10.1002/(SICI)1097-4660(199610)67:2<183::AID-JCTB550>3.0.CO;2-K

Fierro, V., Torné-Fernández, V., Montané, D., and Celzard, A. (2008). “Adsorption of phenol onto activated carbons having different textural and surface properties," Micropor. Mesopor. Mater. 111(1-3), 276-284. DOI:

10.1016/j.micromeso.2007.08.002

Fomina, M., and Gadd, G. M. (2014). "Biosorption: Current perspectives on concept, definition and application," Bioresour. Technol. 160, 3-14. DOI: 10.1016/j.biortech.2013.12.102

Fowler, R. H., and Guggenheim, E. A. (1939). Statistical Thermodynamics, Cambridge University Press, London, pp. 431-450.

Franklin, L. B. (1991). Wastewater Engineering: Treatment, Disposal and Reuse, McGraw-Hill, New York.

Franz, M., Arafat, H. A., and Pinto, N. G. (2000). "Effect of chemical surface heterogeneity on the adsorption mechanism of dissolved aromatics on activated carbon," Carbon 38(13), 1807-1819. DOI: 10.1016/S0008-6223(00)00012-9

Freundlich, H. M. F. (1907). "Uber die adsorption in losungen," Zeitschrift fur Physikalische Chemie (Leipzig). A 57, 385-470.

Fritz, W., and Schluender, E. U. (1974). "Simultaneous adsorption equilibria of organic solutes in dilute aqueous solutions on activated carbon," Chem. Eng. Sci. 29, 12791282. DOI: 10.1016/0009-2509(74)80128-4

Fu, D., Zhang, Y. H., Lv, F. Z., Chu, P. K., and Shang, J. W. (2012a). "Removal of organic materials from TNT red water by bamboo charcoal adsorption," Chem. Eng. J. 193, 39-49.

Fu, D., Zhang, Y. H., Wang, H. L., and Lv, F. Z. (2012b). "Rice husk active carbon as a potential low-cost adsorbent for TNT wastewater," Prog. Environ. Sci. Eng., Adv. Mater. Res. series, Li, H., Xy, Q. J., and Zhang, D. (eds.), Vol. 356-360, 1289-1292. 
Furuya, E. G., Chang, H. T., Miyura, Y., and Noll, K. E. (1997). “A fundamental analysis of the isotherm of the adsorption of phenolic compounds on activated carbon," Sep. Purif. Technol. 11, 69-78. DOI: 10.1016/S1383-5866(96)01001-5

Gadd, G. M. (2009). "Biosorption: Critical review of scientific rationale, environmental importance and significance for pollution treatment," J. Chem. Technol. Biotechnol. 84(1), 12-28. DOI: 10.1002/jctb.1999

Galiatsatou, P., Metaxas, M., Arapoglou, D., and Kasselouri-Rigopoulou, V. (2002). "Treatment of olive mill waste water with activated carbons from agricultural byproducts," Waste Management 22(7), 803-812. DOI: 10.1016/S0956-053X(02)000557

Gamelas, J. A. F. (2013). "The surface properties of cellulose and lignocellulosic materials assessed by inverse gas chromatography: A review," Cellulose 20(6), 26752693. DOI: $10.1007 / \mathrm{s} 10570-013-0066-5$

Gao, Q. T., Wong, Y. S., and Tam, N. F. Y. (2011). "Removal and biodegradation of nonylphenol by different Chlorella species," Marine Pollut. Bull. 63, 445-451. DOI: 10.1016/j.marpolbul.2011.03.030

Gao, R. Y., and Wang, J. L. (2007). "Effects of $\mathrm{pH}$ and temperature on isotherm parameters of chlorophenols biosorption to anaerobic granular sludge," J. Hazard. Mater. 145(3), 398-403. DOI: 10.1016/j.jhazmat.2006.11.036

García-Araya, J. F., Beltrán, F. J., Álvarez, P., and Masa, F. J. (2003). “Activated carbon adsorption of some phenolic compounds present in agroindustrial wastewater," Adsorption 9(2), 107-115. DOI: 10.1023/A:1024228708675

Garcia-Mendieta, A., Slache-Ríos, M., and Olguín, M. T. (2003). “Comparison of phenol and 4-chlorophenol adsorption in activated carbon with different physical properties," Sep. Sci. Technol. 38, 2549-2564. DOI: 10.1081/SS-120022287

Ghosh, S., Das, S. K., Guha, A. K., and Sanyal, A. K. (2009). “Adsorption behavior of lindane on Rhizopus oryzae biomass: Physico-chemical studies," J. Hazard. Mater. 172(1), 485-490. DOI: 10.1016/j.jhazmat.2009.06.156

Giudicianni, P., Cardone, G., and Ragucci, R. (2013). "Cellulose, hemicellulose and lignin slow steam pyrolysis: Thermal decomposition of biomass components mixtures," J. Anal. Appl. Pyrol. 100, 213-222. DOI: 10.1016/j.jaap.2012.12.026

Gotovac, S., Hattori, Y., Noguchi, E., Miyamoto, J., Kanamura, M., Utsumi, S., Kanoh, H., and Kaneko, K. (2006). "Phenanthrene adsorption from solution on single wall carbon nanotubes," J. Phys. Chem. B 110(33), 16219-16224. DOI:

$10.1021 /$ jp0611830

Gotovac, S., Song, L., Kanoh, H., and Kaneko, K. (2007a). “Assembly structure control of single wall carbon nanotubes with liquid phase naphthanlene adsorption," Colloids Surf. A - Physicochem Eng. Aspects 300(1-2), 117-121. DOI:

10.1016/j.colsurfa.2006.10.035

Gotovac, S., Yang, C. M., Hattori, Y., Takahashi, K., Kanoh, H., and Kaneko, K. (2007b). "Adsorption of polyaromatic hydrocarbons on single wall carbon nanotubes of different functionalities and diameters," J. Colloid Interface Sci. 314(1), 18-24. DOI: $10.1016 /$ j.jcis.2007.04.080

Grant, T. M., and King, C. J. (1990). "Mechanism of irreversible adsorption of phenolic compounds by activated carbons," Ind. Eng. Chem. Res. 29(2), 264-271. DOI: 10.1021/ie00098a017 
Greenbank, M., and Manes, M. (1981). “Application of the Polanyi adsorption potential theory to adsorption from solution on activated carbon. 11. Adsorption of organic liquid mixtures from water solution," J. Phys Chem. 85, 3050-3059. DOI: 10.1021/j150621a009

Grimme, S. (2008). "Do special noncovalent pi-pi stacking interactions really exist?," Angew. Chemie Int. Ed. 47(18), 3430-3434. DOI: 10.1002/anie.200705157

Gun'ko, V. M., Voronin, E. F., Mironyuk, I. F., Leboda, R., Skubiszewska-Zieba, J., Pakhlov, E. M., Guzenko, N. V., and Chuiko, A. A. (2003). "The effect of heat, adsorption and mechanochemical treatments on stuck structure and adsorption properties of fumed silicas," Colloids Surf. A. - Physicochem. Eng. Aspects 218, $125-$ 135. DOI: $10.1016 / \mathrm{S} 0927-7757(02) 00598-8$

Gupta, V. K., and Ali, I. (2001). "Removal of DDD and DDE from wastewater using bagasse fly ash, a sugar industry waste," Water Res. 35, 33-40. DOI: 10.1016/S00431354(00)00232-3

Gupta, V. K., and Ali, I. (2008). "Removal of endosulfan and methoxychlor from water on carbon slurry," Environ. Sci. Technology 42(3), 766-770. DOI: 10.1021/es7025032

Gupta, V. K., Gupta, B., Rastogi, A., Agarwal, S., and Nayak, A. (2011). "Pesticides removal from wastewater by activated carbon prepared from waste rubber tire," Water Res. 45(13), 4047-4055. DOI: 10.1016/j.watres.2011.05.016

Gupta, V. K., and Saleh, T. A. (2013). "Sorption of pollutants by porous carbon, carbon nanotubes and fullerene - An overview," Environmental Science and Pollution Research 20(5), 2828-2843. DOI: 10.1007/s11356-013-1524-1

Gupta, V. K., Sharma, S., Yadav, I. S., and Mohan, D. (1998). "Utilization of bagasse fly ash generated in the sugar industry for the removal and recovery of phenol and $p$ nitrophenol from wastewater," J. Chem. Technol. Biotechnol. 71, 180-186. DOI: 10.1002/(SICI)1097-4660(199802)71:2<180::AID-JCTB798>3.0.CO;2-I

Gupta, V. K., Srivastava, S. K., and Tyagi, R. (2000). "Design parameters for the treatment of phenolic waste by carbon columns (obtained from fertilizer waste material)," Water Res. 34(5), 1543-1550. DOI: 10.1016/S0043-1354(99)00322-X

Ha, S. R., and Vinitnantharat, S. (2000). "Competitive removal of phenol and 2,4dichlorophenol in biological activated carbon system," Environ. Technol. 21(4), 387396. DOI: $10.1080 / 09593332108618107$

Haghseresht, F., Finnerty, J. J., Nouri, S., and Lu, G. Q. (2002a). “Adsorption of aromatic compounds onto activated carbons: Effects of the orientation of the adsorbates," Langmuir 18(16), 6193-6200. DOI: 10.1021/la025541b

Haghseresht, F., Nouri, S., Finnerty, J. J., and Lu, G. Q. (2002b). "Effects of surface chemistry on aromatic compound adsorption from dilute aqueous solutions by activated carbon," J. Phys. Chem. B 106, 10935-10943. DOI: 10.1021/jp025522a

Haghseresht, F., Nouri, S., and Lu, G. Q. (2002c). "Effects of the solute ionization on the adsorption of aromatic compounds from dilute aqueous solutions by activated carbon," Langmuir 18(5), 1574-1579. 10.1021/la0109031

Haghseresht, F., Nouri, S., and Lu, G. Q. M. (2003). "Effects of carbon surface chemistry and solution $\mathrm{pH}$ on the adsorption of binary aromatic solutes," Carbon 41(5), 881-892. DOI: 10.1016/S0008-6223(02)00437-2

Hai, F. I., Modin, O., Yamamoto, K., Fukushi, K., Nakajima, F., and Nghiem, L. D. 
(2012). "Pesticide removal by a mixed culture of bacteria and white-rot fungi," $J$. Taiwan Inst. Chem. Eng. 43(3), 459-462. DOI: 10.1016/j.jtice.2011.11.002

Halhouli, K. A., Darwish, N. A., and Al-Dhoon, N. M. (1995). "Effects of pH and inorganic salts on the adsorption of phenol from aqueous systems on activated decoloring charcoal," Sep. Sci. Technol. 30(17), 3313-3324. DOI:

10.1080/01496399508013147

Halhouli, K. A., Darwish, N. A., and Al-Jahmany, Y. Y. (1997). "Effects of temperature and inorganic salts on the adsorption of phenol from multicomponent systems onto a decolorizing carbon," Separation Sci. Technol. 32(18), 3027-3036. DOI: 10.1080/01496399708000793

Hamadi, N. K., Swaminathan, S., and Chen, X. D. (2004). "Adsorption of paraquat dichloride from aqueous solution by activated carbon derived from used tires," $J$. Hazard Mater. 112, 133-141. DOI: 10.1016/j.jhazmat.2004.04.011

Hamdaoui, O., and Naffrechoux, E. (2007a). "Modeling of adsorption isotherms of phenol and chlorophenols onto granular activated carbon. Part I. Two-parameter models and equations allowing determination of thermodynamic parameters," $J$. Hazard. Mater. 147, 381-394. DOI: 10.1016/j.jhazmat.2007.01.021

Hamdaoui, O., and Naffrechoux, E. (2007b). "Modeling of adsorption isotherms of phenol and chlorophenols onto granular activated carbon - Part II. Models with more than two parameters," J. Hazard. Mater. 147(1-2), 401-411. DOI: 10.1016/j.jhazmat.2007.01.023

Hameed, B. H., Chin, L. H., and Rengaraj, S. (2008a). "Adsorption of 4-chlorophenol onto activated carbon prepared from rattan sawdust," Desalination 225, 185-198. DOI: 10.1016/j.desal.2007.04.095

Hameed, B. H., and Rahman, A. A. (2008b). "Removal of phenol from aqueous solutions by adsorption onto activated carbon prepared from biomass material," J. Hazard Mater. 160(2-3), 576-581. DOI: 10.1016/j.jhazmat.2008.03.028

Hameed, B. H., Tan, I. A. W., and Ahmad, A. L. (2009). "Preparation of oil palm empty fruit bunch-based activated carbon for removal of 2,4,6-trichlorophenol: Optimization using response surface methodology," J. Hazard Mater. 164(2-3), 1316-1324. DOI: 10.1016/j.jhazmat.2008.09.042

Han, S., Zhao, F., Sun, J., Wang, B., Wei, R. Y., and Yan, S. Q. (2013). "Removal of pnitrophenol from aqueous solution by magnetically modified activated carbon," Journal of Magnetism and Magnetic Materials 341, 133-137. DOI: 10.1016/j.jmmm.2013.04.018

Hand, D. W., Crittenden, J.-C., and Thacker, W. E. (1983). "User-oriented batch reactor solutions to the homogeneous surface diffusion model," J. Env. Eng. Dev., ASCE 109, 82-101. DOI: 10.1061/(ASCE)0733-9372(1983)109:1(82)

Hank, D., Namane, A., and Hellal, A. (2010). "Biosorption of phenol by Pseudomonas aeruginosa biofilm fixed on granular activated carbon," Environ. Eng. Manag. J. 9(9), 1211-1216.

Hansen, C. M. (2007). Hansen Solubility Parameters. A User's Handbook, $2^{\text {nd }}$ Ed., CRC Press, Taylor and Francis, Boca Raton. DOI: 10.1201/9781420006834

Hansen, M. C., Børresen, M. H., Schlabach, M., and Cornelissen, G. (2010). "Sorption of perfluorinated compounds from contaminated water to activated carbon," J. Soils Sediments 10, 179-185. DOI: 10.1007/s11368-009-0172-z 
Hao, F. H., Zhao, X. C., Ouyang, W., Lin, C. Y., Chen, S. Y., Shan, Y. S., and Lai, X. H. (2013). "Molecular structure of corncob-derived biochars and the mechanism of atrazine sorption," Agronomy Journal 105(3), 773-782. DOI:

10.2134/agronj2012.0311

Haydar, S., Ferro-García, M. A., Rivera-Utrilla, J., and Joly, J. P. (2003). "Adsorption of p-nitrophenol on an activated carbon with different oxidations," Carbon 41, 387-395. DOI: 10.1016/S0008-6223(02)00344-5

Hildebrand, J. H. (1936). Solubility of Non-electrolytes, Reinhold, New York.

Hill, T. L. (1946). "Localized and mobile adsorption and adsorption," J. Chem. Phys. 14, 441-453. DOI: 10.1063/1.1724166

Ho, Y. S., and McKay, G. (1999). "Pseudo-second order model for sorption processes," Process Biochem. 34, 451-465. DOI: 10.1016/S0032-9592(98)00112-5

House, J. E. (2013). Inorganic Chemistry, $2^{\text {nd }}$ Ed., Elsevier - Academic Press, Amsterdam; see Ch. 9, p. 288.

Hsieh, C. T., and Teng, H. S. (2000). "Liquid-phase adsorption of phenol onto activated carbons prepared with different activation levels," J. Colloid Interface Sci. 230(1), 171-175. DOI: 10.1006/jcis.2000.7052

Hsu, S.-T., Chen, L.-C., Lee, C.-C., Pan, T.-C., You, B.-X., and Yan, Q.-F. (2009). "Preparation of methacrylic acid-modified rice husk improved by an experimental design and application for paraquat adsorption," J. Hazard. Mater. 171, 465-470. DOI: 10.1016/j.jhazmat.2009.06.144

Hsu, S., and Pan, T.-C. (2007). "Adsorption of paraquat using methacrylic acid-modified rice husk," Bioresour. Technol. 98, 3616-3621. DOI: 10.1016/j.biortech.2006.11.060

Hu, J., Li, B. J., Huang, L.-Y., Zuo, J., Zhang, W., Ying, W.-C., and Matsumoto, M. R. (2013). "Biological-activated carbon process for removing MTBE from groundwater," Environmental Progress \& Sustainable Energy 32(3), 512-523. DOI: 10.1002/ep.11651

Hu, J., Shao, D., Chen, C., Sheng, G., Ren, X., and Wang, X. (2011). "Removal of 1naphthylamine from aqueous solution by multiwall carbon nanotubes/iron oxides/cyclodextrin composite," J. Hazard. Mater. 185, 463-471. DOI: 10.1016/j.jhazmat.2010.09.055

Huang, L., Boving, T. B., and Xing, B. S. (2006). "Sorption of PAHs by aspen wood fibers as affected by chemical alterations," Environ. Sci. Technol. 40, 3279-3284. DOI: 10.1021/es0524651

Huang, Y., Zhang, S. Y., Lv, M. J., and Xie, S. G. (2010). "Biosorption characteristics of ectomycorrhizal fungal mycelium for anthracene," Biomed. Environ. Sci. 23(5), 378383. DOI: 10.1016/S0895-3988(10)60079-7

Hubbe, M. A., Hasan, S. H., and Ducoste, J. J. (2011). "Cellulosic substrates for removal of pollutants from aqueous systems: A review. 1. Metals," BioResources 6(2), 21612287.

Hubbe, M. A., Beck, K. R., O'Neal, W. G., and Sharma, Y. C. (2012). “Cellulosic substrates for removal of pollutants from aqueous systems: A review. 2. Dyes,” BioResources 7(2), 2592-2687.

Hubbe, M. A., Rojas, O. J., Fingas, M., and Gupta, B. S. (2013). “Cellulosic substrates for removal of pollutants from aqueous systems: A Review. 3. Spilled oil and emulsified organic liquids," BioResources 8(2), 3038-3097. 
Ibrahim, R. H. H., Darvell, L. I., Jones, J. M., and Williams, A. (2013). "Physicochemical characterisation of torrefied biomass," J. Anal. Appl. Pyrol. 103, 21-30. DOI: 10.1016/j.jaap.2012.10.004

Igbinosa, E. O., Odjadjare, E. E., Chigor, V. N., Igbinosa, I. H., Emoghene, A. O., Ekhaise, F. O., Igiehon, N. O., and Idemudia, O. G. (2013). "Toxicological profile of chlorophenols and their derivatives in the environment: The public health perspective," Sci. World J., article number 460215. DOI 10.1155/2013/460215.

Iniesta, E., Sánchez, F., García, A. N., and Marcilla, A. (2001). "Yields and $\mathrm{CO}_{2}$ reactivity of chars from almond shells obtianed by a two heating step carbonisation process. Effect of different chemical pre-treatments and ash content," J. Analytical Appl. Pyrol. 58-59, 983-994. DOI: 10.1016/S0165-2370(00)00212-6

Ioannou, Z., and Simitzis, J. (2009). "Adsorption kinetics of phenol and 3-nitrophenol from aqueous solutions on conventional and novel carbons," J. Hazard. Mater. 171(1-3), 954964. DOI: 10.1016/j.jhazmat.2009.06.098

Iqbal, Y., Khan, M., and Ihsanullah, N. (2005). "Effect of selected parameters on the adsorption of phenol on activated charcoal," Int. J. Environ. Stud. 62, 47-57. DOI: 10.1080/0020723042000253875

Isahak, W. N. R. W., Hisham, M. W. M., and Yarmo, M. A. (2013). "Highly porous carbon materials from biomass by chemical and carbonization method: A comparison study," $J$. Chem., article number 620346, DOI: 10.1155/2013/620346.

Ivancev-Tumbas, I., Dalmacija, B., Tamas, Z., and Karlovic, E. (1998). "Reuse of biologically regenerated activated carbon for phenol removal," Water Res. 32(4), 1085-1094. DOI: 10.1016/S0043-1354(97)00337-0

Jacobsen, B. N., Arvin, E., and Reinders, M. (1996). "Factors affecting sorption of pentachlorophenol to suspended microbial biomass," Water Res. 30(1), 13-20. DOI: 10.1016/0043-1354(95)00108-W

Jain, A. K., Gupta, V. K., Jain, S., and Suhas (2004). "Removal of chlorophenols using industrial wastes," Environ. Sci. Technol. 38(4), 1195-1200. DOI: 10.1021/es034412u

James, G., Sabatini, D. A., Chiou, C. T., Rutherford, D., Scott, A. C., and Karapanagioti, H. K. (2005). "Evaluating phenanthrene sorption on various wood chars," Water Res. 39, 549-558. DOI: 10.1016/j.watres.2004.10.015

Jamil, N., Ahsan, N., Munawar, M. A., Anwar, J., and Shafique, U. (2011). "Removal of toxic dichlorophenol from water by sorption with chemically activated carbon of almond shells - A green approach," J. Chem. Soc. Pakistan 33(5), 640-645.

Jaroniec, M., and Choma, J. (1997). "Characterization of geometrical and energetic heterogeneities of active carbons by using sorption measurements," in: Equilibria and Dynamics of Gas Adsorption on Heterogeneous Solid Surfaces, Rudzinski, W., Steele, W. A., and Zgrablich, G., Book Series: Studies in Surface Science and Catalysis, Vol. 104, CH. 14, pp. 715-744.

Jayme, G., and Büttel, H. (1968). "Über die Bestimmung und Bedeutung des Wasserrückhaltevermögens (des WRV-Wertes) verschiedener gebleichter und ungebleichter Zellstoffe. II. Beziehung zwischen dem WRV-Wert und anderen Zellstoffeigenschaften," Wochenblatt für Papierfabrikation 96(6), 180-187.

Jeffrey, G. A. (1997). An Introduction to Hydrogen Bonding, Oxford Univ. Press, New York. 
Ji, L. L., Chen, W., Bi, J., Zheng, S. R., Xu, Z. Y., Zhu, D. Q., and Alvarez, P. J. (2010). "Adsorption of tetracycline on single-walled and multi-walled carbon nanotubes as affected by aqueous solution chemistry," Environ. Toxicol. Chem. 29(12), 2713-2719. DOI: $10.1002 /$ etc. 350

Jonker, M. T. O., and Koelmans, A. A. (2002). "Sorption of polycyclic aromatic hydrocarbons and polychlorinated biphenyls to soot and soot-like materials in the aqueous environment: Mechanistic considerations," Environ. Sci. Technol. 36(17), 3725-3734. DOI: 10.1021/es020019x

Joo, J. C., Shackelford, C. D., and Reardon, K. F. (2008). "Sorption of nonpolar neutral organic compounds to humic acid-coated sands: Contributions of organic and mineral components," Chemosphere 70(7), 1290-1297. DOI: 10.1016/j.chemosphere.2007.07.052

Ju, Y.-H., Chen, T.-C., and Liu, J. C. (1997). "A study on the biosorption of lindane," Colloids Surf. B. - Biointerfaces 9(3-4), 187-196. DOI: 10.1016/S0927-7765(97)00019-2

Juang, R.-S. , Tseng, R.-L., and Wu, F.-C. (2001). "Role of microporosity of activated carbons on their adsorption abilities for phenols and dyes," Adsorption 7, 65-72. DOI: 10.1023/A:1011225001324

Juang, R.-S., Tseng, R.-L., Wu, F.-C., and Lee, S.-H. (1996a). “Liquid-phase adsorption of phenol and its derivatives on activated carbon fibers," Separ. Sci. Technol. 31(14), 19151931. DOI: 10.1080/01496399608001020

Juang, R.-S., Wu, F.-C., and Tseng, R.-L. (1996b). “Adsorption isotherms of phenolic compounds from aqueous solutions onto activated carbon fibers," J. Chem. Eng. Data 41, 487-492. DOI: 10.1021/je950238g

Juang, R.-S., Wu, F.-C., and Tseng, R.-L. (2000). "Mechanism of adsorption of dyes and phenols from water using activated carbons prepared from plum kernels," J. Colloid Interface Sci. 227, 437-444. DOI: 10.1006/jcis.2000.6912

Juhasz, A., L., and Naidu, R. (2000a). "Bioremediation of high molecular polycyclic aromatic hydrocarbons: A review of the microbial degradation, of benzo[a]pyrene," Intl.

Biodeterior. Biodegrad. 45, 57-88. DOI: 10.1016/S0964-8305(00)00052-4

Juhasz, A. L., and Naidu, R. (2000b). "Extraction and recovery of organochlorine pesticides from fungal mycelia," J. Microbiolog. Methods 39(2), 149-158. DOI: 10.1016/S01677012(99)00111-6

Juhasz, A. L., Smith, E., Smith, J., and Naidu, R. (2002). "Biosorption of organochlorine pesticides using fungal biomass," J. Indust. Microbiol. Biotechnol. 29(4), 163-169. DOI: 10.1038/sj.jim.7000280

Julinová, M., and Slavík, R. (2012). "Removal of phthalates from aqueous solution by different adsorbents: A short review," Journal of Environmental Management 94(1), 13 24. DOI: 10.1016/j.jenvman.2011.09.006

Jung, C., Park, J., Lim, K. H., Park, S., Heo, J., Her, N.-G., Oh, J., and Yoon, Y. (2013). "Adsorption of selected endocrine disrupting compounds and pharmaceuticals on activated biochars," J. Hazard Mater. 263(2), 702-710. DOI: 10.1016/j.jhazmat.2013.10.033

Jung, M.-W., Ahn, K.-H., Lee, Y., Kim, K.-P., Rhee, J.-S., Park, J. T., and Paeng, K.-J. (2001). "Adsorption characteristics of phenol and chlorophenols on granular activated carbons (GAC)," Microchem. J. 70, 123-131. DOI: 10.1016/S0026-265X(01)00109-6 
Kao, P.-C., Tzeng, J.-H., and Huang, T.-L. (2000). "Removal of chlorophenols from aqueous solution by fly ash," J. Hazard. Mater. 76(2-3), 237-249. DOI: 10.1016/S03043894(00)00201-6

Karakoyun, N., Kubilay, S., Aktas, N., Turhan, O., Kasimoglu, M., Yilmaz, S., and Sahiner, N. (2011). "Hydrogel-biochar composites for effective organic contaminant removal from aqueous media," Desalination 280(1-3), 319-325. DOI: 10.1016/j.desal.2011.07.014

Karanfil, T., and Dastgheib, S. A. (2004). "Trichloroethylene adsorption by fibrous and granular activated carbons: Aqueous phase, gas phase, and water vapor adsorption studies," Environ. Sci. Technol. 38, 5834-5841. DOI: 10.1021/es0497936

Karanfil, T., Dastgheib, S. A., and Mauldin, D. (2006). "Exploring molecular sieve capabilities of activated carbon fibers to reduce the impact of NOM preloading on trichloroethylene adsorption," Environ. Sci. Technol. 40(4), 1321-1327. DOI: 10.1021/es051285o

Karim, K., and Gupta, S. K. (2002). "Biosorption of nitrophenols on anaerobic granular sludge," Environ. Technol. 23(12), 1379-1384. DOI: 10.1080/09593332508618443

Karimi-Jashni, A., and Narbaitz, R. M. (1997). "Impact of pH on the adsorption and desorption kinetics of 2-nitrophenol on activated carbons," Water Res. 31(12), 30393044. DOI: 10.1016/S0043-1354(97)00176-0

Keith, L. H., and Telliard, W. A. (1979). "Priority pollutants. 1. A perspective view," Environ. Sci. Technol. 13(4), 416-423. DOI: 10.1021/es60152a601

Kennedy, K. J., Lu, J. H., and Mohn, W. W. (1992). "Biosorption of chlorophenols to anaerobic granular sludge,” Water Res. 26(8), 1085-1092. DOI: 10.1016/00431354(92)90144-S

Kennedy, L. J., Vijaya, J. J., Kayalvishi, K., and Sekaran, G. (2007). “Adsorption of phenol from aqueous solutions using mesoporous carbon prepared by two-stage process," Chem. Eng. J. 132, 279-287. DOI: 10.1016/j.cej.2007.01.009

Khalaf, S., Al-Rimawi, F., Khamis, M., Nir, S., Bufo, S. A., Scrano, L., Mecca, G., and Karaman, R. (2013). "Efficiency of membrane technology, activated charcoal, and a micelle-clay complex for removal of the acidic pharmaceutical mefenamic acid," Journal of Environmental Science and Health Part A-Toxic/Hazardous Substances \& Environmental Engineering 48(13), 1655-1662. DOI: 10.1080/10934529.2013.815475

Khan, A. R., Al-Bahri, T. A., and Al-Haddad, A. (1997a). "Adsorption of phenol-based organic pollutants on activated carbon from multi-component dilute aqueous solutions," Water Res. 31(8), 2102-2112. DOI: 10.1016/S0043-1354(97)00043-2

Khan, A. R., Ataullah, R., and Al-Haddad, A. (1997b). "Equilibrium adsorption studies of some aromatic pollutants from dilute aqueous solutions on activated carbon at different temperatures," J. Colloid Interface Sci. 194, 154-165. DOI: 10.1006/jcis.1997.5041

Khan, E., Khaodhir, S., and Rotwiron, P. (2007). "Polycyclic aromatic hydrocarbon removal from water by natural fiber sorption," Water Environ. Res. 79(8), 901-911. DOI: 10.2175/106143007X176040

Khan, M. A., Kim, S.-W., Rao, R. A. K., Abou-Shanab, R. A. I., Bhatnagar, A., Song, H., and Jeon, B.-H. (2010). "Adsorption studies of dichloromethane on some commercially available GACs: Effect of kinetics, thermodynamics and competitive ions," J. Hazard. Mater. 178, 963-972. DOI: 10.1016/j.jhazmat.2010.02.032

Khan, S., Wang, N., Reid, B. J., Freddo, A., and Cai, C. (2013). "Reduced bioaccumulation of PAHs by Lactuca sativa L. grown in contaminated soil amended with sewage sludge and 
sewage sludge derived biochar," Environmental Pollution 175, 64-68. DOI: 10.1016/j.envpol.2012.12.014

Khoshnood, M., and Azizian, S. (2012). "Adsorption of 2,4-dichlorophenoxyacetic acid pesticide by graphitic carbon nanostructures prepared from biomasses," Journal of Industrial and Engineering Chemistry 18(5), 1796-1800. DOI: 10.1016/j.jiec.2012.04.007

Kilduff, J. E., Karanfil, T., and Weber, W. J., Jr. (1998). "TCE adsorption by GAC preloaded with humic substances," J. Amer Water Works Assoc. 90, 76-89.

Kilic, M., Apaydin-Varol, E., and Pütün, A. E. (2011). “Adsorptive removal of phenol from aqueous solutions on activated carbon prepared from tobacco residues: Equilibrium, kinetics and thermodynamics," Journal of Hazardous Materials 189(1-2), 397-403. DOI: 10.1016/j.jhazmat.2011.02.051

Kim, T. Y., Cho, S. Y., and Kim, S. J. (2011). "Adsorption equilibrium and kinetics of copper ions and phenol onto modified adsorbents," Adsorp. - J. Intl. Adsorp. Soc. 17(1), 135-143. DOI: $10.1007 / \mathrm{s} 10450-010-9306-2$

Kiselev, A. V. (1958). "Vapor adsorption in the formation of adsorbate molecule complexes on the surface," Kolloid. Zhur. 20, 338-348.

Klasson, K. T., Ledbetter, C. A., Wartelle, L. H., and Lingle, S. E. (2010). "Feasibility of dibromochloropropane (DBCP) and trichloroethylene (TCE) adsorption onto activated carbons made from nut shells of different almond varieties," Indus. Crops Prod. 31(2), 261-265. DOI: 10.1016/j.indcrop.2009.11.002

Klasson, K. T., Wartelle, L. H., Lima, I. M., Marshall, W. E., and Akin, D. E. (2009). "Activated carbons from flax shive and cotton gin waste as environmental adsorbents for the chlorinated hydrocarbon trichloroethylene," Biores. Technol. 100(21), 50455050. DOI: 10.1016/j.biortech.2009.02.068

Kliaugaite, D., Jankunaite, D., and Racys, V. (2008). "Factors influencing treatment of petroleum polluted wastewater using biologically activated carbon," $7^{\text {th }}$ International Conference Environmental Engineering, Cygas, D., and Froehner, K. D. (eds.), 569575.

Kolker, A. M., Korolev, V. P., and Batov, D. V. (2005). "Relationship between the internal pressure and cohesive energy density of liquids," J. Structural Chem. 46(5), 927-930. DOI: 10.1007/s10947-006-0221-Z

Kong, H. L., He, J., Gao, Y. Z., Han, J., and Zhu, X. Z. (2011a). "Removal of polycyclic aromatic hydrocarbons from aqueous solution on soybean stalk-based carbon," $J$. Environ. Qual. 40(6), 1737-1744. DOI: 10.2134/jeq2010.0343

Kong, H., He, J., Gao, Y., Wu, H., and Zhu, X. (2011b). “Cosorption of phenanthrene and mercury(II) from aqueous solution by soybean stalk-based biochar," J. Agric. Food Chem. 59(22), 12116-12123. DOI: 10.1021/jf202924a

Kong, H. L., He, J., Wu, H. F., Wu, H., and Gao, Y. Z. (2012). "Phenanthrene removal from aqueous solution on sesame stalk-based carbon," Clean - Soil Air Water 40(7), 752-759. DOI: 10.1002/clen.201100322

Košíková, B., Sláviková, E., and Lábaj, J. (2009). “Affinity of lignin preparations towards genotoxic compounds," BioResources 4(1), 72-79.

Koumanova, B., Peeva, P., and Allen, S. J. (2003). "Variation of intra-particle diffusion parameter during adsorption of $p$-chlorophenol onto activated carbon made from apricot stones," J. Chem. Technol. Biotechnol. 78(5), 582-587. DOI: 10.1002/jctb.839 
Krastanov, A., Alexieva, Z., and Yemendzhiev, H. (2013). "Microbial degradation of phenol and phenolic derivatives," Eng. Life Sci. 13(1), 76-87. DOI: 10.1002/elsc.201100227

Kujawski, W., Warzawski, A., Ratajczak, W., Porębski, W., Capała, W., and Ostrowska, I. (2004). "Application of pervaporation and adsorption to the phenol removal from wastewater," Sep. Purif. Technol. 40, 123-132. DOI: 10.1016/j.seppur.2004.01.013

Kumagai, S., Shimizu, Y., Toida, Y., and Enda, Y. (2009). "Removal of dibenzothiophenes in kerosene by adsorption on rice husk activated carbon," Fuel 88, 1975-1982. DOI: 10.1016/j.fuel.2009.03.016

Kumar, A., Kumar, S., Kumar, S., and Gupta, D. V. (2007). “Adsorption of phenol and 4nitrophenol on granular activated carbon in basal salt medium: Equilibrium and kinetics," J. Hazard. Mater. 147, 155-166. DOI: 10.1016/j.jhazmat.2006.12.062

Kumar, A. K., Mohan, S. V., and Sarma, P. N. (2009a). "Sorptive removal of endocrinedisruptive compound (estriol, E3) from aqueous phase by batch and column studies: Kinetic and mechanistic evaluation," J. Hazard. Mater. 164, 820-828. DOI: 10.1016/j.jhazmat.2008.08.075

Kumar, A., Prasad, B., and Mishra, I. M. (2008). “Optimization of process parameters for acrylonitrile removal by a low-cost adsorbent using Box-Behnken design," $J$. Hazard. Mater. 150, 174-182. 10.1016/j.jhazmat.2007.09.043

Kumar, B. G. P., Shivakamy, K., Miranda, L. R., and Velan, M. (2006). "Preparation of steam activated carbon from rubberwood sawdust (Hevea brasiliensis) and its adsorption kinetics," J. Hazard. Mater. 136(3), 922-929. DOI: 10.1016/j.jhazmat.2006.01.037

Kumar, N. S., Boddu, V. M., and Krishnaiah, A. (2009b). "Biosorption of phenolic compounds by Trametes versicolor polyporus fungus," Adsorp. Sci. Technol. 27(1), 31-46. DOI: 10.1260/026361709788921597

Kumar, N. S., Che Man, H., and Woo, H.-S. (2014). "Biosorption of phenolic compounds from aqueous solutions using pine (Pinus densiflora Sieb) bark powder," BioResources 9(3), 5155-5174.

Kumar, N. S., and Min, K. (2011a). "Removal of phenolic compounds from aqueous solutions by biosorption onto Acacia leucocephala bark powder: Equilibrium and kinetic studies," J. Chilean Chem. Soc. 56(1), 539-545. DOI: 10.4067/S071797072011000100004

Kumar, N. S., and Min, K. (2011b). "Phenolic compounds biosorption onto Schizophyllum commune fungus: FTIR analysis, kinetics and adsorption isotherms modeling," Chem. Eng. J. 168(2), 562-571. DOI: 10.1016/j.cej.2011.01.023

Kumar, N. S., Woo, H. S., and Min, K. (2012). "Equilibrium and kinetic studies on biosorption of 2,4,6-trichlorophenol from aqueous solutions by Acacia leucocephala bark," Colloids Surf. B-Biointerfaces 94, 125-132. DOI: 10.1016/j.colsurfb.2012.01.048

Kusmierek, K., Dabek, L., Kaminski, W., and Swiatkowski, A. (2013). "Evaluation of the usefulness of peat for removal of chlorophenols from water solutions," Ochrona Srodowiska 35(2), 51-55.

Kwon, S., Sullivan, E. J., Katz, L. E., Bowman, R. S., and Kinney, K. A. (2011). "Laboratory and field evaluation of a pretreatment system for removing organics 
from produced water," Water Environment Research 83(9), 843-854. DOI: $10.2175 / 106143011 \mathrm{X} 12928814445212$

Lagergren, S. (1898). "About the theory of so-called adsorption of soluble substances," K. Sven. Vetenskapsakad. Handl. 24, 1-39.

Lang, W., Dejma, C., Sirisansaneeyakul, S., and Sakairi, N. (2009). "Biosorption of nonylphenol on dead biomass of Rhizopus arrhizus encapsulated in chitosan beads," Biores. Technol. 100(23), 5616-5623. DOI: 10.1016/j.biortech.2009.06.021

Langmuir, I. (1918). "The adsorption of gases on plane surface of glass, mica and platinum," J. Am. Chem. Soc. 40, 1361-1403. DOI: 10.1021/ja02242a004

László, K., Podkościelny, P., and Dąbrowski, A. (2003). "Heterogeneity of polymerbased active carbons in adsorption of aqueous solutions of phenol and 2,3,4trichlorophenol," Langmuir 19(13), 5287-5294. DOI: 10.1021/la026761s

László, K., Podkościelny, P., Dąbrowski, A. (2006). "Heterogeneity of activated carbons with different surface chemistry in adsorption of phenol from aqueous solutions," Appl. Surf. Sci. 252(16), 5752-5762. DOI: 10.1016/j.apsusc.2005.07.027

László, K., and Szücs, A. (2001). "Surface characterization of polyethyleneterephthalate PET based activated carbon and the effect of $\mathrm{pH}$ on its adsorption capacity from aqueous phenol and 2,3,4-trichlorophenol solutions," Carbon 39, 1945-1953. DOI: 10.1016/S0008-6223(00)00245-1

Lei, A. P., Wong, Y. S., and Tam, N. F. Y. (2002). "Removal of pyrene by different microalgal species," Water Sci. Technol. 46(11-12), 195-201.

Leng, C. C. (1996). "Mechanism of adsorption and desorption of oxygen and nitrogen containing aromatics on activated carbon," $\mathrm{PhD}$ dissertation, University of Cincinnati.

Leng, C.-C., and Pinto, N. G. (1997). "Effects of surface properties of activated carbons on adsorption behavior of selected aromatics," Carbon 35(9), 1375-1385. DOI: 10.1016/S0008-6223(97)00091-2

Leyva-Ramos, R., Bernal-Jacome, L. A., Mendoza-Barron, J., and Hernandez-Orta, M. M. G. (2009a). "Kinetic modeling of pentachlorophenol adsorption onto granular activated carbon," J. Taiwan Inst. Chem. Eng. 40(6), 622-629. DOI: 10.1016/j.jtice.2009.05.006

Leyva-Ramos, R., Diaz-Flores, P. E., Leyva-Ramos, J., and Femat-Flores, R. A. (2007). "Kinetic modeling of pentachlorophenol adsorption from aqueous solution on activated carbon fibers," Carbon 45(11), 2280-2289. DOI: 10.1016/j.carbon.2007.06.010

Leyva-Ramos, R., Rivera-Utrilla, J., Medellín-Castillo, N. A., and Sánchez-Polo, M. (2009b). "Kinetic modelling of naphthalenesulphonic acid adsorption from aqueous solution onto untreated and ozonated activated carbons," Adsorp. Sci. Technol. 27(4), 395-411. DOI: 10.1260/026361709790252650

Leyva-Ramos, R., Zuniga, J. H. S., Barron, J. M., and Coronado, R. M. G. (1999). "Adsorption of phenol from aqueous solution on to activated carbon. Effect of solvent, temperature and particle size," Adsorp. Sci. Technol. 17(7), 533-543.

Li, B.-J., Hu, J., Huang, L.-Y., Lv, Y., Zuo, J., Zhang, W., Ying, W.-C., and Matsumoto, M. R. (2013c). "Removal of MTBE in biological activated carbon adsorbers," Environ. Prog. Sustain. Energy 32(2), 239-248. DOI: 10.1002/ep.11614

Li, H., Zhou, B., Lin, Y., Gu, L., Wang, W., Fernando, K. A. S., Kumar, S., Allard, L. F., and Sun, Y.-P. (2004). "Selective interactions of porphyrins with semi-conducting 
single-walled carbon nanotubes," J. Amer. Chem. Soc. 126, 1014-1015. DOI: 10.1021/ja037142o

Li, J. F., Li, Y. M., Wu, M. J., Zhang, Z. Y., and Lü, J. H. (2013a). "Effectiveness of lowtemperature biochar in controlling the release and leaching of herbicides in soil," Plant and Soil 370(1-2), 333-344. DOI: 10.1007/s11104-013-1639-7

Li, K., Ji, F., Liu, Y. L., Tong, Z. L., Zhan, X. M., and Hu, Z. H. (2013b). “Adsorption removal of tetracycline from aqueous solution by anaerobic granular sludge: Equilibrium and kinetic studies," Water Sci. Technol. 67(7), 1490-1496. DOI: 10.2166/wst.2013.016

Li, K. Q., Zheng, Z., Feng, J. W., Zhang, J. B., Luo, X. Z., Zhao, G. H., and Huang, X. F. (2009). "Adsorption of $p$-nitroaniline from aqueous solutions onto activated carbon fiber prepared from cotton stalk," J. Hazard. Mater. 166(2-3), 1180-1185. DOI: 10.1016/j.jhazmat.2008.12.035

Li, L., Quinlivan, P. A., and Knappe, D. R. U. (2002). "Effects of activated carbon surface chemistry and pore structure on the adsorption of organic contaminants from aqueous solution," Carbon 40, 2085-2100. DOI: 10.1016/S0008-6223(02)00069-6

Li, Y., and Chen, B. (2009). "Phenanthrene sorption by fruit cuticles and potato periderm with different compositional characteristics," J. Agric. Food Chem. 57(2), 637-644. DOI: $10.1021 / \mathrm{jf} 802719 \mathrm{~h}$

Li, Y., Chen, B., and Zhu, L. (2010a). "Enhanced sorption of polycyclic aromatic hydrocarbons from aqueous solution by modified pine bark," Bioresour. Technol. 101, 7307-7313. DOI: 10.1016/j.biortech.2010.04.088

Li, Y., Lin, M., and Davenport, J. W. (2011). “Ab initio studies of cellulose I: Crystal structure, intermolecular forces, and interactions with water," J. Phys. Chem. 155, 11533-15539.

Li, Y. G., Chen, B. L., and Zhu, L. Z. (2010b). "Single-solute and bi-solute sorption of phenanthrene and pyrene onto pine needle cuticular fractions," Environ. Pollut. 158(7), 2478-2484. DOI: 10.1016/j.envpol.2010.03.021

Li, Y. G., Deng, Y. Q., and Chen, B. L. (2012). "Sorption of chlorophenols onto fruit cuticles and potato periderm," J. Environ. Sci. - China 24(4), 675-681. DOI: 10.1016/S1001-0742(11)60891-7

Liang, Y., Hilal, N., Langston, P., and Starov, V. (2007). "Interaction forces between colloidal particles in liquid: Theory and experiment," Advan. Colloid Interface Sci. 134-135, 151-166. DOI: 10.1016/j.cis.2007.04.003

Lin, D. H., Pan, B., Zhu, L. Z., and Xing, B. S. (2007). "Characterization and phenanthrene sorption of tea leaf powders," J. Agric. Food Chem. 55(14), 5718-5724. DOI: $10.1021 /$ jf0707031

Lin, S.-H., and Juang, R.-S. (2009). "Adsorption of phenol and its derivatives from water using synthetic resins and low-cost natural adsorbents: A review," J. Environ. Manag. 90(3), 1336-1349. DOI: 10.1016/j.jenvman.2008.09.003

Lin, Y., Munroe, P., Joseph, S., Henderson, R., Ziolkowski, A. (2012). "Water extractable organic carbon in untreated and chemical treated biochars," Chemosphere 87(2), 151-157. 10.1016/j.chemosphere.2011.12.007

Liu, C. W., Chang, W. N., and Liu, H. S. (2009). "Bioremediation of n-alkanes and the formation of biofloccules by Rhodococcus erythropolis NTU-1 under various saline 
conditions and sea water," Biochem. Eng. J. 45(1), 69-75. DOI:

10.1016/j.bej.2009.02.009

Liu, X., and Pinto, N. G. (1997). "Ideal adsorbed phase model for adsorption of phenolic compounds on activated carbon," Carbon 35(9), 1387-1397. DOI: 10.1016/S00086223(97)00092-4

Liu, X. B., Xie, X. X., Yan, H., Sun, X. J., and Sun, Y. (2013). "A review of the adsorption of organic pollutants on mesoporous carbons and carbon/silica hybrids," New Carbon Materials 28(4), 241-253.

Lou, L. P., Wu, B. B., Wang, L. N., Luo, L., Xu, X. H., Hou, J. A., Xun, B., Hu, B. L., and Chen, Y. X. (2011). "Sorption and ecotoxicity of pentachlorophenol polluted sediment amended with rice-straw derived biochar," Bioresour. Technol. 102(5), 4036-4041. DOI: 10.1016/j.biortech.2010.12.010

Lu, C., Chung, Y.-L., and Chang, K.-F. (2005). "Adsorption of trihalomethanes from water with carbon nanotubes," Water Res. 39, 1183-1189. DOI:

10.1016/j.watres.2004.12.033

Lu, C. S., Chung, Y.-L., and Chang, K.-F. (2006). “Adsorption thermodynamic and kinetic studies of trihalomethanes on multiwalled carbon nanotubes," J. Hazard. Mater. 138(2), 304-310. DOI: 10.1016/j.jhazmat.2006.05.076

Mackay, A. A., and Gschwend, P. M. (2000). "Sorption of monoaromatic hydrocarbons to wood," Environ. Sci. Technol. 34, 839-845. DOI: 10.1021/es9900858

Maginn, E. J., Bell, A. T., and Theodorou, D. N. (1995). "Sorption thermodynamics, siting, and conformation of long n-alkanes in silicalite as predicted by configurational-bias monte-carlo integration," J. Phys. Chem. 99(7), 2057-2079. DOI: 10.1021/j100007a042

Magne, P., and Walker Jr., P. L. (1986). "Phenol adsorption on activated carbons: Application to the regeneration of activated carbons polluted with phenol," Carbon 24(2), 101-107. MOI: 10.1016/0008-6223(86)90102-8

Mahajan, O. P., Moreno-Castilla, C., and Walker, P. L. (1980). "Surface-treated activated carbon for removal of phenol from water," Sep. Sci. Technol. 15(10), 1733-1752. DOI: $10.1080 / 01496398008055619$

Mahvi, A. H., Maleki, A., and Eslami, A. (2004). "Potential of rice husk and rice husk ash for phenol removal in aqueous systems," Am. J. Appl. Sci. 1(4), 321-326. DOI: 10.3844/ajassp.2004.321.326

Maldonado-Hódar, F. J., Moreno-Castilla, C., Carrasco-Marín, F., and Pérez-Cadenas, A. F. (2007). "Reversible toluene adsorption on monolithic carbon aerogels," J. Hazard. Mater. 148(3), 548-552. DOI: 10.1016/j.jhazmat.2007.03.007

Manes, M., and Hofer, (1969). "Application of the Polanyi adsorption potential theory to adsorption from solution on activated carbon," J. Phys. Chem. 73(3), 584-590. DOI: $10.1021 / \mathrm{j} 100723 \mathrm{a} 018$

Maréchal, Y. (2007). The Hydrogen Bond and the Water Molecule: The Physics and Chemistry of Water, Aqueous and Bio Media, Elsevier, Amsterdam.

Margot, J., Kienle, C., Magnet, A., Weil, M., Rossi, L., de Alencastro, L. F., Abegglen, C., Thonney, D., Chèvre, N., Schärer, M., and Barry, D. A. (2013). "Treatment of micropollutants in municipal wastewater: Ozone or powdered activated carbon?" Science of the Total Environment 461, 480-498. DOI: 10.1016/j.scitotenv.2013.05.034 
Marin, J., Kennedy, K. J., and Eskicioglu, C. (2010). "Characterization of an anaerobic baffled reactor treating dilute aircraft de-icing fluid and long term effects of operation on granular biomass," Biores. Technol. 101(7), 2217-2223. DOI: 10.1016/j.biortech.2009.11.055

Martín-Gullón, I., and Font, R. (2001). "Dynamic pesticide removal with activated carbon fibers," Water Res. 35(2), 516-520. DOI: 10.1016/S0043-1354(00)00262-1

Mathialagan, T., and Viraraghavan, T. (2008). "Biosorption of chlorophenols: A review," Intl. J. Environ. Pollut. 34, 164-194. DOI: 10.1504/IJEP.2008.020790

Mathialagan, T., and Viraraghavan, T. (2009). "Biosorption of pentachlorophenol from aqueous solution by a fungal biomass," Bioresour. Technol. 100(2), 549-558. DOI: 10.1016/j.biortech.2008.06.054

Mattson, J. A., and Mark H. B. (1971). Activated Carbon Surface Chemistry and Adsorption from Aqueous Solution, Marcel Dekker, New York.

Mattson, J. A., Mark, H. B., Malbin, M. D., Weber, W. J., and Crittenden, J. C. (1969). "Surface chemistry of active carbon: Specific adsorption of phenols," J. Colloid Interface Sci. 31, 116-130. DOI: 10.1016/0021-9797(69)90089-7

Maurin, E., Clement, A., Gerardin, P., and Loubinoux, B. (1999). "A feasibility study on the use of chemically modified sawdusts bearing fatty alkyl chains for removal of oleic acid and olive-oil from water," Holz Roh Werkstoff 57(4), 265-266. DOI: 10.1007/s001070050055

Mbui, D. N., Shiundu, P. M., Ndonye, R. M., and Kamau, G. N. (2002). "Adsorption and detection of some phenolic compounds by rice husk ash of Kenyan origin," $J$. Environ. Monit. 4, 978-984. DOI: 10.1039/b207257m

Medronho, B., Romano, A., Miguel, M. G., Stigsson, L., and Lindman, B. (2012). "Rationalizing cellulose (in)solubility: Reviewing basic physicochemical aspects and role of hydrophobic interactions," Cellulose 19(3), 581-587. DOI: 10.1007/s10570-011-9644-6

Memon, G. Z., Bhanger, M. I., and Akhtar, M. (2007). "The removal efficiency of chestnut shells for selected pesticides from aqueous solutions," J. Colloid Interface Sci. 315(1), 33-40. DOI: 10.1016/j.jcis.2007.06.037

Memon, G. Z., Bhanger, M. I., Akhtar, M., Talpur, F. N., and Memon, J. R. (2008). "Adsorption of methyl parathion pesticide from water using watermelon peels as low cost adsorbent," Chem. Eng. J. 138, 616-621. DOI: 10.1016/j.cej.2007.09.027

Memon, G. Z., Bhanger, M. I., Memon, J. R., and Akhtar, M. (2009). "Adsorption of methyl parathion from aqueous solutions using mango kernels: Equilibrium, kinetic and thermodynamic studies," Bioremediation J. 13(2), 102-106; 13(3), 154-157.

Mercier, A., Wille, G., Michel, C., Harris-Hellal, J., Amalric, L., Morlay, C., and Battaglia-Brunet, F. (2013). "Biofilm formation vs. PCB adsorption on granular activated carbon in PCB-contaminated aquatic sediment," Journal of Soils and Sediments 13(4), 793-800. DOI: 10.1007/s11368-012-0647-1

Mestre, A. S., Pires, J., Nogueira, J. M. F., and Carvalho, A. P. (2007). "Activated carbons for the adsorption of ibuprofen," Carbon 45(10), 1979-1988. DOI: 10.1016/j.carbon.2007.06.005

Meyer, E. E., Rosenberg, K. J., and Israelachvili, J. (2006). "Recent progress in understanding hydrophobic interactions," Proc. Natl. Acad. Sci. USA 103(43), 1573915746. DOI: 10.1073/pnas.0606422103 
Michalak, I., Chojnacka, K., and Witek-Krowiak, A. (2013). "State of the art for the biosorption process - A review," Appl. Biochem. Biotechnol. 170(6), 1389-1416. DOI: 10.1007/s12010-013-0269-0

Mikhalovska, L. I., Gun'ko, V. M., Rugal, A. A., Oranska, O. I., Gornikov, Y. I., Morvan, C., Follain, N., Domas, C., Pakhlov, E. M., and Mikhalovsky, S. V. (2012). "Cottonised flax fibres vs. cotton fibres: Structural, textural and adsorption characteristics," RSC Advan. 2(5), 2032-2042. DOI: 10.1039/c2ra00725h

Miyake, Y., Sakoda, A., Yamanashi, H., Kaneda, H., and Suzuki, M. (2003). “Activated carbon adsorption of trichloroethylene (TCE) vapor stripped from TCEcontaminated water," Water Res. 37(8), 1852-1858. DOI: 10.1016/S00431354(02)00564-X

Mohan, D., Sarswat, A., Ok, Y. S., and Pittman, C. U. (2014). “Organic and inorganic contaminants removal from water with biochar, a renewable, low cost and sustainable adsorbent - A critical review," Bioresour. Technol. 160, 191-202. DOI: 10.1016/j.biortech.2014.01.120

Mohan, D., Singh, K. P., Sinha, S., and Gosh, D. (2004). "Removal of pyridine from aqueous solution using low cost activated carbons derived from agricultural waste materials," Carbon 42(12-13), 2409-2421. DOI: 10.1016/j.carbon.2004.04.026

Mohan, D., Singh, K. P., Sinha, S., and Gosh, D. (2005). "Removal of pyridine derivatives from aqueous solution by activated carbons developed from agricultural waste materials," Carbon 43(8), 1680-1693. DOI: 10.1016/j.carbon.2005.02.017

Mohanty, K., Das, D., and Biswas, M. N. (2005). "Adsorption of phenol from aqueous solutions using activated carbons prepared form Tectona grandis sawdust by $\mathrm{ZnCl}_{2}$ activation," Chem. Eng. J. 115, 121-131. DOI: 10.1016/j.cej.2005.09.016

Mollah, A. H., and Robinson, C. W. (1996a). "Pentachlorophenol adsorption and desorption characteristics of granular activated carbon. 1. Isotherms," Water Res. 30(12), 2901-2906. DOI: 10.1016/S0043-1354(96)00131-5

Mollah, A. H., and Robinson, C. W. (1996b). "Pentachlorophenol adsorption and desorption characteristics of granular activated carbon. 2. Kinetics," Water Res. 30(12), 2907-2913. DOI: 10.1016/S0043-1354(96)00132-7

Moreno-Castilla, C. (2004). "Adsorption of organic molecules from aqueous solutions on carbon materials," Carbon 42, 83-94. DOI: 10.1016/j.carbon.2003.09.022

Moreno-Castilla, C., Rivera-Utrilla, J., Joly, J. P., López-Ramón, M. V., Ferro-García, M. A., and Carrasco-Marín, F. (1995a). "Thermal regeneration of an activated carbon exhausted with different substituted phenols," Carbon 33(10), 1417-1423. DOI: 10.1016/0008-6223(95)00090-Z

Moreno-Castilla, C., Rivera-Utrilla, J., López-Ramón, M. V., and Carrasco-Marín, F. (1995b). "Adsorption of some substituted phenols on activated carbons from a bituminous coal," Carbon 33(6), 845-851. DOI: 10.1016/0008-6223(94)00182-Y

Moreno-Pirajan, J. C., Giraldo, L., and Gonzalez, J. F. (2011). “Adsorption of phenol in aqueous solutions using activated carbon monoliths of Coco shell: Adsorption isotherms and kinetics," Afinidad 68(554), 290-295.

Morris, J. C., and Weber, W. J. (1962). "The use of adsorption for the removal of biologically-resistant pollutants from wastewaters," J. Water Pollut. Control Fed. 34(3), 235-236. 
Mourão, P. A. M., Laginhas, C., Custódio, F., Nabais, J. M. V., Carrott, P. J. M., and Ribeiro Carrott, M. M. L. (2011). "Influence of oxidation process on the adsorption capacity of activated carbon from lignocellulosic precursors," Fuel Process Technol. 92(2), 241-246. DOI: 10.1016/j.fuproc.2010.04.013

Mubarik, S., Saeed, A., Mehmood, Z., and Iqbal, M. (2012). "Phenol adsorption by charred sawdust of sheesham (Indian rosewood; Dalbergia sissoo) from single, binary and ternary contaminated solutions," J. Taiwan Inst. Chem. Eng. 43(6), 926933. DOI: 10.1016/j.jtice.2012.07.003

Müller, G., Radke, C. J., and Prausnitz, J. M. (1980). "Adsorption of weak organic electrolytes from aqueous solution on activated carbon. Effect of $\mathrm{pH}$," J. Phys. Chem. 84, 369-376. DOI: 10.1021/j100441a006

Müller, G., Radke, C. J., and Prausnitz, J. M. (1985a). “Adsorption of weak organic electrolytes from dilute aqueous solution onto activated carbon. Part 1. Single-solute systems," J. Colloid Interf. Sci. 103(2), 466-483. DOI: 10.1016/0021-9797(85)901237

Müller, G., Radke, C. J., and Prausnitz, J. M. (1985b). “Adsorption of weak organic electrolytes from dilute aqueous-solution onto activated carbon. 2. Multisolute systems," J. Colloid Interface Sci. 103(2), 484-492. DOI: 10.1016/00219797(85)90124-9

Munaf, E., Zein, R., and Kurniadi, I. (1997). "The use of rice husk for removal of phenol from wastewater as studied using 4-aminoantipyrine spectrophotometric method," Environ. Technol. 18(3), 355-358. DOI: 10.1080/09593331808616548

Musteret, C.-P., Cailean, D., Barjoveanu, G., and Teodosiu, C. (2010). "An assessment of operational parameters for the removal of chlorophenols from wastewater," Environ. Eng. Manag. J. 9(10), 1451-1457.

Nabais, J. M. V., Gomes, J. A., Suhas, Carrott, P. J. M., Laginhas, C., and Roman, S. (2009). "Phenol removal onto novel activated carbons made from lignocellulosic precursors: Influence of surface properties," J. Hazard Mater. 167(1-3), 904-910. DOI: 10.1016/j.jhazmat.2009.01.075

Nakhla, G. F., Abuzaid, N., Farooq, S., and Ala'ama, S. (1992). "Oxygen-induced enhancement of the adsorptive capacity of activated charcoal," Environ. Technol. 13, 181-188. DOI: 10.1080/09593339209385142

Namane, A., Ali, O., Cabana, H., and Hellal, A. (2012). "Evaluation of biological treatments for the adsorption of phenol from polluted waters," Adsorption Science \& Technology 30(6), 521-532. DOI: 10.1260/0263-6174.30.6.521

Namasivayam, C., and Kavitha, D. (2003). "Adsorptive removal of 2-chlorophenol by low-cost coir pith carbon,” J. Hazard. Mater. B98, 257-274. DOI: 10.1016/S03043894(03)00006-2

Namasivayam, C., and Sangreetha, D. (2006). "Recycling of agricultural solid waste, coir pith: Removal of anions, heavy metals, organics and dyes from water by adsorption onto $\mathrm{ZnCl}_{2}$ activated coir pith carbon," J. Hazard. Mater. B135(1-3), 449-452. DOI: 10.1016/j.jhazmat.2005.11.066

Nanseu-Njiki, C. P., Dedzo, G. K., and Ngameni, E. (2010). "Study of the removal of paraquat from aqueous solution by biosorption onto Ayous (Triplochiton schleroxylon) sawdust," J. Hazard. Mater. 179(1-3), 63-71. DOI: 10.1016/j.jhazmat.2010.02.058 
Nath, K., Thummar, M., Vaghela, M., and Jani, P. (2008). "Sorption of phenol from aqueous solution using activated carbon prepared from Manilkara zapota seed," Indian J. Chem. Technol. 15(6), 533-540.

Navarro, A. E., Cuizano, N. A., Lazo, J. C., Sun-Kou, M. R., and Llanos, B. P. (2009). "Comparative study of the removal of phenolic compounds by biological and nonbiological adsorbents," J. Hazard. Mater. 164, 1439-1446. DOI: 10.1016/j.jhazmat.2008.09.077

Navarro, A. E., Portales, R. F., Sun-Kou, M. R., and Llanos, B. P. (2008). "Effect of pH on phenol biosorption by marine seaweeds," J. Hazard. Mater. 156, 405-411. DOI: 10.1016/j.jhazmat.2007.12.039

Ncibi, M. C., Mahjoub, B., and Seffen, M. (2006). "Biosorption of phenol onto Posidonia oceanica (L.) seagrass in batch system: Equilibrium and kinetic modeling," Canad. J. Chem. Eng. 84(4), 495-500. DOI: 10.1002/cjce.5450840411

Nelson, P. O., and Yang, M. (1995). "Equilibrium adsorption of chlorophenols on granular activated carbon," Water Environ. Res. 67(6), 892-898. DOI: 10.2175/106143095X133103

Nevskaia, D. M., and Guerrero-Ruiz, A. (2001). "Comparative study of the adsorption from aqueous solutions and the desorption of phenol and nonylphenol substrates on activated carbons," J. Colloid Interface Sci. 234, 316-321. DOI: 10.1006/jcis. 2000.7300

Nevskaia, D. M., Sepulveda-Escribano, A., and Guerrero-Ruiz, A. (2001). "Surface properties of activated carbons in relation to their ability to adsorb nonylphenol aqueous contaminant," Phys. Chem. Chem. Physics 3(3), 463-468. DOI: 10.1039/b008883h

Newcombe, G., and Drikas, M. (1997). "Adsorption of NOM onto activated carbon: Electrostatic and non-electrostatic effects," Carbon 35(9), 1239-1250. DOI: 10.1016/S0008-6223(97)00078-X

Newcombe, G., Morrison, J., and Hepplewhite, C. (2002a). "Simultaneous adsorption of MIB and NOM onto activated carbon. I. Characterisation of the system and NOM adsorption," Carbon 40(12), 2135-2146. DOI: 10.1016/S0008-6223(02)00097-0

Newcombe, G., Morrison, J., Hepplewhite, C., and Knappe, D. R. U. (2002b). "Simultaneous adsorption of MIB and NOM onto activated carbon: II. Competitive effects," Carbon 40(12), 2147-2156. DOI: 10.1016/S0008-6223(02)00098-2

Ng, C., Losso, J. N., Marshall, W. E., and Rao, R. M. (2000). "Physical and chemical properties of selected agricultural by products based activated carbons and their ability to adsorb geosim," Bioresour. Technol. 84, 177-185. DOI: 10.1016/S09608524(02)00014-7

Ni, J. Z., Pignatello, J. J., and Xing, B. S. (2011). “Adsorption of aromatic carboxylate ions to black carbon (biochar) is accompanied by proton exchange with water," Environ. Sci. Technol. 45(21), 9240-9248; 46(11), 5633.

Ning, Z., Fernandes, L., and Kennedy, K. J. (1999). "Chlorophenol sorption to anaerobic granules under dynamic conditions," Water Res. 33(1), 180-188. DOI: 10.1016/S0043-1354(98)00185-7

Niti, C., Sunita, S., Kamlesh, K., and Rakesh, K. (2013). "Bioremediation: An emerging technology for remediation of pesticides," Res. J. Chem. Environ. 17(4), 88-105. 
Nouri, S., and Haghseresht, F. (2004). "Adsorption of p-nitrophenol in untreated and treated activated carbon," Adsorp. - J. Intl. Adsorp. Soc. 10(1), 79-86. DOI: 10.1023/B:ADSO.0000024037.31407.15

Nouri, S., and Haghseresht, F. (2005). "Estimation of adsorption capacity for dissociating and non dissociating aromatic compounds on activated carbon with different models," Adsorption - J. Intern. Adsorp. Soc. 11(1), 77-86. DOI: 10.1007/s10450-005-1095-7

Nouri, S., Haghseresht, F., and Lu, M. (2002a). "Adsorption of aromatic compounds by activated carbon: Effects of functional groups and molecular size," Adsorpt. Sci. Technol. 20, 1-15. DOI: 10.1260/026361702760120890

Nouri, S., Haghseresht, F., and Lu, G. Q. M. (2002b). "Comparison of adsorption capacity of $p$-cresol and $p$-nitrophenol by activated carbon in single and double solute," Adsorption 8(3), 215-223. DOI: 10.1023/A:1021260501001

Ochoa-Herrera, V., and Sierra-Alverez, R. (2008). "Removal of perfluorinated surfactants by sorption onto granular activated carbon, zeolite, and sludge," Chemosphere 72, 1588-1593. DOI: 10.1016/j.chemosphere.2008.04.029

Ofomaja, A. E. (2011). "Kinetics and pseudo-isotherm studies of 4-nitrophenol adsorption onto mansonia wood sawdust," Indust. Crops Prod. 33(2), 418-428. DOI:

10.1016/j.indcrop.2010.10.036

Ofomaja, A. E., and Unuabonah, E. I. (2011). “Adsorption kinetics of 4-nitrophenol onto a cellulosic material, mansonia wood sawdust and multistage batch adsorption process optimization," Carbohyd. Polym. 83(3), 1192-1200. DOI: 10.1016/j.carbpol.2010.09.023

Ofomaja, A. E., and Unuabonah, E. I. (2013). "Kinetics and time-dependent Langmuir modeling of 4-nitrophenol adsorption onto Mansonia sawdust," Journal of the Taiwan Institute of Chemical Engineers 44(4), 566-576. DOI: 10.1016/j.jtice.2012.12.021

Oh, W.-D., Lim, P.-E., Seng, C.-E., Mohamed, N., Adnan, R., Leong, K.-Y., and Voon, S.Y. (2013). "Effect of initial biomass concentration on bioregeneration of 4chlorophenol-loaded granular activated carbon: Kinetic and efficiency studies," Journal of Chemical Technology and Biotechnology 88(6), 1157-1163. DOI: 10.1002/jctb.3960

Oh, W.-D., Lim, P.-E., Seng, C.-E., and Sujari, A. N. A. (2011). "Bioregeneration of granular activated carbon in simultaneous adsorption and biodegradation of chlorophenols," Bioresource Technology 102(20), 9497-9502. DOI:

10.1016/j.biortech.2011.07.107

Okawa, K., Suzuki, K., Takeshita, T., and Nakano, K. (2007). "Regeneration of granular activated carbon with adsorbed trichloroethylene using wet peroxide oxidation," Water Res. 41, 1045-1051. DOI: 10.1016/j.watres.2006.10.032

Olivella, M. À., Jové, P., Bianchi, A., Bazzicalupi, C., and Cano, L. (2013). “An integrated approach to understanding the sorption mechanism of phenanthrene by cork," Chemosphere 90(6), 1939-1944. DOI: 10.1016/j.chemosphere.2012.10.035

Omri, A., and Benzina, M. (2014). "Almond shell activated carbon: Adsorbent and catalytic support in the phenol degradation," Environ. Monitor. Assess. 186(6), 38753890. DOI: $10.1007 / \mathrm{s} 10661-014-3664-2$

Osei-Twum, E. Y., Abuzaid, N. S., and Nahkla, G. (1996). "Carbon-catalyzed oxidative coupling of phenolic compounds," Bull Environ. Contam. Toxicol. 56, 513-519. DOI: $10.1007 / \mathrm{s} 001289900074$ 
Özbelge, T. A., Özbelge, Ö. H., and Başkaya, S. Z. (2002). "Removal of phenolic compounds from rubber-textile wastewaters by physicochemical methods," Chem. Eng. Process 41(8), 719-730. DOI: 10.1016/S0255-2701(01)00189-1

Ozdemir, S., Bekler, F. M., Okumus, V., Dundar, A., and Kilinc, E. (2012). "Biosorption of 2,4-D, 2,4-DP, and 2,4-DB from aqueous solution by using thermophilic Anoxybacillus flavithermus and analysis by high-performance thin layer chromatography: Equilibrium and kinetic studies," Environ. Prog. Sustain. Energy 31(4), 544-552. DOI: 10.1002/ep.10576

Özkaya, B. (2006). "Adsorption and desorption of phenol on activated carbon and a comparison of isotherm models," J. Hazard Mater. B 129, 128-163. DOI: 10.1016/j.jhazmat.2005.08.025

Pajooheshfar, S. P., and Saeedi, M. (2009). "Adsorptive removal of phenol from contaminated water and wastewater by activated carbon, almond, and walnut shells charcoal," Water Environ. Res. 81(6), 641-648. DOI: 10.2175/106143008X390780

Pan, B., and Xing, B. (2008). "Adsorption mechanisms of organic chemicals on carbon nanotubes," Environ. Sci. Technol. 42(24), 9005-9013. DOI: 10.1021/es801777n

Pan, X. L., Liu, J., and Zhang, D. Y. (2010). "Binding of phenanthrene to extracellular polymeric substances (EPS) from aerobic activated sludge: A fluorescence study," Colloids Surf. B - Biointerfaces 80(1), 103-106. DOI: 10.1016/j.colsurfb.2010.05.002

Park, J., Meng, J., Lim, K. H., Rojas, O. J., and Park, S. (2013). "Transformation of lignocellulosic biomass during torrefaction," J. Anal. Appl. Pyrol. 100(3), 199-206. DOI: $10.1016 /$ j.jaap.2012.12.024

Park, S., Venditti, R. A., Jameel, H., and Pawlak, J. J. (2007). "Studies of the heat of vaporization of water associated with cellulose fibers characterized by thermal analysis," Cellulose 14(3), 195-402. DOI: 10.1007/s10570-007-9108-1

Pavoni, B., Drusian, D., Giacometti, A., and Zanette, M. (2006). "Assessment of organic chlorinated compound removal from aqueous matrices by adsorption on activated carbon," Water Res. 40, 3571-3579. DOI: 10.1016/j.watres.2006.05.027

Peng, X., Li, Y., Luan, Z., Di, Z., Wang, H., Tian, B., and Jia, Z. (2003). "Adsorption of 1,2-dichlorobenzene from water to carbon nanotubes," Chem. Phys. Lett. 376, 154-158. DOI: $10.1016 / \mathrm{S} 0009-2614(03) 00960-6$

Penmetsa, V. K., and Steele, P. H. (2012). "Preliminary findings for the production of water repellent torrefied wood pellets with pyrolysis oil," Environ. Prog. Sustain. Energy 31(2), 235-239. DOI: 10.1002/ep.11624

Pera-Titus, M., Garcia-Molina, V., Banos, M. A., Gimenez, J., and Esplugas, S. (2004). "Degradation of chlorophenols by means of advanced oxidation processes: A general review," Appl. Catal. B - Environ. 47(4), 219-256. DOI: 10.1016/j.apcatb.2003.09.010

Pernyeszi, T., Honfi, K., Boros, B., Talos, K., Kilar, F., and Majdik, C. (2009).

"Biosorption of phenol from aqueous solutions by fungal biomass of Phanerochaete chrysosporium," Studia Univ. Babes-Bolyai Chemia 54(3), 173-183.

Perrich, J. R. (1981). Activated Carbon Adsorption for Wastewater Treatment, CRC Press, Boca Raton, FL.

Pigatto, G., Lodi, A., Finocchio, E., Palma, M. S. A., and Converti, A. (2013). "Chitin as biosorbent for phenol removal from aqueous solution: Equilibrium, kinetic and thermodynamic studies," Chemical Engineering and Processing 70, 131-139. DOI: 10.1016/j.cep.2013.04.009 
Pignatello, J. J., Oliveros, E., and MacKay, A. (2006). “Advanced oxidation processes for organic contaminant destruction based on the Fenton reaction and related chemistry," Crit. Revs. Environ. Sci. Technol. 36(1), 1-84. DOI: 0.1080/10643380500326564

Pignatello, J. J., and Xing, B. (1996). "Mechanisms of slow sorption of organic chemicals to natural particles," Environ. Sci. Technol. 30(1), 1-11. DOI: 10.1021/es940683g

Pintor, A. M. A., Ferreira, C. I. A., Pereira, J. C., Correia, P., Silva, S. P., Vilar, V. J. P., Botelho, C. M. S., and Boaventura, R. A. R. (2012). "Use of cork powder and granules for the adsorption of pollutants: A review," Water Res. 46(10), 3152-3166. DOI: 10.1016/j.watres.2012.03.048

Plazinski, W., and Plazinska, A. (2011). "Molecular dynamics study of the interactions between phenolic compounds and alginate/alginic acid chains," New J. Chem. 35(8), 1607-1614. DOI: 10.1039/c1nj20273a

Podkościelny, P., Dąbrowski, A., and Marijuk, O. V. (2003). "Heterogeneity of active carbons in adsorption of phenol aqueous solutions," Appl. Surf. Sci. 205, 297-303. DOI: 10.1016/S0169-4332(02)01154-6

Pollard, S. J. T., Fowler, G. D., Sollars, C. J., and Perry, R. (1992). "Low cost adsorbents for waste and wastewater treatment: A review," Sci. Total Environ. 116, 31-52. DOI: 10.1016/0048-9697(92)90363-W

Pratarn, W., Pornsiri, T., Thanit, S., Tawatchai, C., and Wiwut, T. (2011). “Adsorption and ozonation kinetic model for phenolic wastewater treatment," Chin. J. Chem. Eng. 19(1), 76-82. DOI: 10.1016/S1004-9541(09)60180-4

Qu, G.-Z., Li, J., Liang, D.-L., Huang, D.-L., Qu, D., and Huang, Y.-M. (2013). "Surface modification of a granular activated carbon by dielectric barrier discharge plasma and its effects on pentachlorophenol adsorption," Journal of Electrostatics 71(4), 689-694. DOI: 10.1016/j.elstat.2013.03.013

Qu, X. L., Xiao, L., and Zhu, D. Q. (2008). "Site-specific adsorption of 1,3dinitrobenzene to bacterial surfaces: A mechanism of n-pi electron-donor-acceptor interactions," J. Environ. Qual. 37(3), 824-829. DOI: 10.2134/jeq2007.0236

Quilliam, R. S., Rangecroft, S., Emmett, B. A., Deluca, T. H., and Jones, D. L. (2013). "Is biochar a source or sink for polycyclic aromatic hydrocarbon (PAH) compounds in agricultural soils?" Global Change Biology Bioenergy 5(2), 96-103. DOI: $10.1111 / \mathrm{gcbb} .12007$

Quinlivan, P. A., Li, L., and Knappe, D. R. U. (2005). "Effects of activated carbon characteristics on the simultaneous adsorption of aqueous organic micropollutants and natural organic matter," Water Res. 39, 1663-1673. DOI: 10.1016/j.watres.2005.01.029

Radhika, M., and Palanivelu, K. (2006). "Adsorptive removal of chlorophenol from aqueous solution by low cost adsorbent - Kinetics and isotherm analysis," J. Hazard Mater B138, 116-124. DOI: 10.1016/j.jhazmat.2006.05.045

Radovic, L. R., Silva, I. F., Ume, J. I., Menéndez, J. A., León y León, C., and Scaroni, A. W. (1997). "An experimental and theoretical study of the adsorption of aromatics possessing electron-withdrawing and electron-donating functional groups by chemically modified activated carbons," Carbon 35(9), 1339-1348. DOI: 10.1016/S0008-6223(97)00072-9

Raghukumar, C., Shailaja, M. S., Parameswaran, M. S., and Singh, S. K. (2006). "Removal of polycyclic aromatic hydrocarbons from aqueous media by the marine fungus 
NIOCC \#312: Involvement of lignin-degrading enzymes and exopolysaccharides," Ind. J. Mar. Sci. 35, 373-379.

Ran, Y., Yang, Y., Xing, B. S., Pignatello, J. J., Kwon, S., Su, W., and Zhou, L. (2013).

"Evidence of micropore filling for sorption of nonpolar organic contaminants by condensed organic matter," J. Environ. Qual. 42(3), 806-814. DOI:

$10.2134 /$ jeq2012.0286

Rao, J. R., and Viraraghavan, T. (2002). "Biosorption of phenol from an aqueous solution by Aspergillus niger biomass," Bioresour. Technol. 85(2), 165-171. DOI: 10.1016/S0960-8524(02)00079-2

Ratola, N., Botelho, C., and Alves, A. (2003). "The use of pine bark as a natural adsorbent for persistent organic pollutants - Study of lindane and heptachlor adsorption," J. Chem. Technol. Biotechnol. 78, 347-351. DOI: 10.1002/jctb.784

Ravi, V. P., Jasra, R. V., and Bhat, T. S. G. (1998). "Adsorption of phenol, cresol isomers and benzyl alcohol from aqueous solution on activated carbon," J. Chem. Technol. Biotechnol. 71, 173-179. DOI: 10.1002/(SICI)1097-4660(199802)71:2<173::AIDJCTB818>3.0.CO;2-N

Redlich, O. J., and Peterson, D. L. (1959). “A useful adsorption isotherm,” J. Phys. Chem. 63, 1024-1024. DOI: 10.1021/j150576a611

Reed, A. R., and Williams, P. T. (2004). "Thermal processing of biomass natural fibre wastes by pyrolysis,” Int. J. Energy Res. 28(2), 131-145. DOI: 10.1002/er.956

Rengaraj, S., Moon, S. H., Sivabalan, R., Arabindoo, B., and Murugesan, V. (2002a). "Agricultural solids waste for the removal of organics: Adsorption of phenol from water and wastewater by palm seed coat activated carbon," Waste Manage. 22(5), 543-548. DOI: 10.1016/S0956-053X(01)00016-2

Rengaraj, S., Moon, S. H., Sivabalan, R., Arabindoo, B., and Murugesan, V. (2002b). "Removal of phenol from aqueous solution and resin manufacturing industry wastewater using an agricultural waste: Rubber seed coat," J. Hazard Mater. 89(2-3), 185-196. DOI: 10.1016/S0304-3894(01)00308-9

Rivera-Utrilla, J., Utrera-Hidalgo, E., Ferro-García, M. A., and Moreno-Castilla, C. (1991). "Comparison of activated carbons prepared from agricultural raw materials and Spanish lignites when removing chlorophenols from aqueous solutions," Carbon 29(4/5), 613-619. DOI: 10.1016/0008-6223(91)90128-6

Rodrigues, L. A., da Silva, M. L. C. P., Alvarez-Mendes, M. O., Coutinho, A. R., and Thim, G. P. (2011). "Phenol removal from aqueous solution by activated carbon produced from avocado kernel seeds," Chem. Eng. J. 174(1), 49-57. DOI: 10.1016/j.cej.2011.08.027

Rodrigues, L. A., Ribeiro, L. A. D., Thim, G. P., Ferreira, R. R., Alvarez-Mendez, M. O., and Coutinho, A. D. (2013). "Activated carbon derived from macadamia nut shells: An effective adsorbent for phenol removal," Journal of Porous Materials 20(4), 619627. DOI: 10.1007/s10934-012-9635-5

Rodriguez-Cruz, S., Andrades, M. S., Sanchez-Camazano, M., and Sanchez-Martin, M. J. (2007). "Relationship between the adsorption capacity of pesticides by wood residues and the properties of woods and pesticides," Environ. Sci. Technol. 41, 3613-3619. DOI: 10.1021/es062616f

Román, S., Ledesma, B., González, J. F., Al-Kassir, A., Engo, G., and Álvarez-Murillo, A. (2013). "Two stage thermal regeneration of exhausted activated carbons. Steam 
gasification of effluents," Journal of Analytical and Applied Pyrolysis 103(Special Issue), 201-206. DOI: 10.1016/j.jaap.2012.08.017

Romeh, A. A. (2010). "Phytoremediation of water and soil contaminated with imidacloprid pesticide by Plantago major, L.," Intl. J. Phytoremed. 12(2), 188-199. DOI: $10.1080 / 15226510903213936$

Roostaei, N., and Tezel, F. H. (2004). "Removal of phenol from aqueous solutions by adsorption,” J. Environ. Manag. 70, 157-164. DOI: 10.1016/j.jenvman.2003.11.004

Rosenholm, J. B. (2010). "Critical comparison of molecular mixing and interaction models for liquids, solutions and mixtures," Advan. Colloid Interface Sci. 156(1-2), 14-34. DOI: 10.1016/j.cis.2010.02.005

Rossner, A., and Knappe, D. R. U. (2008). "MTBE adsorption on alternative adsorbents and packed bed adsorber performance," Water Res. 42(8-9), 2287-2299. DOI: 10.1016/j.watres.2007.12.009

Rossner, A., Snyder, S. A., and Knappe, D. R. U. (2009). "Removal of emerging contaminants of concern by alternative adsorbents," Water Res. 43(15), 3787-3796. DOI: 10.1016/j.watres.2009.06.009

Rouquerol, J., Avnir, E., Fairbridge, C. W., Everett, D. H., Haynes, J. M., Pernicone, N., Ramsay, J. D. F., Sing, K. S. W., and Unger, K. K. (1994). "Recommendations for the characterization of porous solids (Technical Report)," Pure \& Appl. Chem. 66(8), 1739-1758. DOI:10.1351/pac199466081739

Rubin, E., Rodriguez, P., Herrero, R., and de Vincente, M. E. S. (2006). "Biosorption of phenolic compounds by the brown alga Sargassum muticum," J. Chem. Technol. Biotechnol. 81(7), 1093-1099. DOI: 10.1002/jctb.1430

Rutherford, D. W., Wershaw, R. L., Rostad, C. E., and Kelly, C. N. (2012). "Effect of formation conditions on biochars: Compositional and structural properties of cellulose, lignin, and pine biochars," Biomass \& Bioenergy 46, 693-701. DOI: 10.1016/j.biombioe.2012.06.026

Sabio, E., González, E., González, J. F., González-García, C. M., Ramiro, A., and Gañan, J. (2004). "Thermal regeneration of activated carbon saturated with $p$-nitrophenol," Carbon 42, 2285-2293. DOI: 10.1016/j.carbon.2004.05.007

Sakoda, A., Kawazoe, K., and Suzuki, M. (1987). "Adsorption of tri- and tetrachloroethylene from aqueous solutions on activated carbon fibers," Water Res. 21(6), 717-722. DOI: 10.1016/0043-1354(87)90084-4

Salame, I. I., and Bandosz, T. J. (2003). "Role of surface chemistry in adsorption of phenol on activated carbons," J. Colloid Interf. Sci. 264, 307-312. DOI: 10.1016/S0021-9797(03)00420-X

Salloum, M. J., Chefetz, B., and Hatcher, P. G. (2002). "Phenanthrene sorption by aliphatic-rich natural organic matter," Environ. Sci. Technol. 36, 1953-1558. DOI: 10.1021/es015796w

Samanta, S. K., Singh, O. V., and Jain, R. K. (2002). "Polycyclic aromatic hydrocarbons: Environmental pollution and bioremediation," Trend. Biotechnol. 20(6), 243-248. DOI: $10.1016 / \mathrm{S} 0167-7799(02) 01943-1$

San Miguel, G., Lambert, S. D., and Graham, N. J. D. (2001). "The regeneration of field-spent granular activated carbon," Water Res. 35(11), 2740-2748. DOI: $10.1016 / \mathrm{S} 0043-1354(00) 00549-2$ 
Sathishkumar, M., Binupriya, A. R., Kavitha, D., Selvakumar, R., Jayabalan, R., Choi, J. G., and Yun, S. E. (2009). "Adsorption potential of maize cob carbon for 2,4dichlorophenol removal from aqueous solutions: Equilibrium, kinetics and thermodynamics modeling," Chem. Eng. J. 147(2-3), 265-271. DOI: 10.1016/j.cej.2008.07.020

Sathishkumar, M., Choi, J. G., Ku, C. S., Vijayaraghavan, K., Binupriya, A. R., and Yun, S. E. (2008). "Carbaryl sorption by porogen-treated banana pith carbon," Adsorp. Sci. Technol. 26(9), 679-686. DOI: 10.1260/026361708788251367

Sekaran, G., Karthikeyan, S., Gupta, V. K., Boopathy, R., and Maharaja, P. (2013). "Immobilization of Bacillus sp in mesoporous activated carbon for degradation of sulphonated phenolic compound in wastewater," Mater. Sci. Eng. C-Materials Bio. Appl. 33(2), 735-745. DOI: 10.1016/j.msec.2012.10.026

Şenel, S., Kara, A., Alsancak, G., and Denizli, A. (2006). "Removal of phenol and chlorophenols from water with reusable dye-affinity hollow fibers," J. Hazard. Mater. 138(2), 317-324. DOI: 10.1016/j.jhazmat.2006.05.121

Seo, G. T., Ohgaki, S., and Suzuki, Y. (1997). "Sorption characteristics of biological powdered activated carbon in BPAC-MF (biological powdered activated carbonmicrofiltration) system for refractory organic removal," Water Sci. Technol. 35(7), 163-170. DOI: 10.1016/S0273-1223(97)00127-3

Seredych, M., and Bandosz, T. J. (2010). “Adsorption of dibenzothiophenes on nanoporous carbons: identification of specific adsorption sites governing capacity and selectivity," Energy Fuels 24, 3352-3360. DOI: 10.1021/ef9015087

Seredych, M., and Bandosz, T. J. (2011). "Removal of dibenzothiophenes from model diesel fuel on sulfur rich activated carbons." Applied Catalysis B - Environmental 106(1-2), 133-141.

Sethunathan, N., Megharaj, M., Chen, Z. L., Williams, B. D., Lewis, G., and Naidu, R. (2004). "Algal degradation of a known endocrine disrupting insecticide, alphaendosulfan, and its metabolite, endosulfan sulfate, in liquid medium and soil," $J$. Agric. Food Chem. 52(10), 3030-3035. DOI: 10.1021/jf035173x

Severtson, S. J., and Banerjee, S. (1996). "Sorption of chlorophenols to wood pulp," Environ. Sci. Technol. 30, 1961-1969. DOI: 10.1021/es950649h

Shaikh, H., Memon, N., Khan, H., Bhander, M. I., and Nizamani, S. M. (2012). "Preparation and characterization of molecularly imprinted polymer for di(2ethylhexyl) phthalate: Application to sample clean-up prior to gas chromatographic determination," J. Chromatography A 1247, 125-133. DOI: 10.1016/j.chroma.2012.05.056

Shen, Q. (2009). "Surface properties of cellulose and cellulose derivatives: A review," in: Model Cellulosic Surfaces, Roman, M. (ed.), ACS Symposium Ser. 1019, 259-289. DOI: 10.1021/bk-2009-1019.ch012

Shen, Q., Mikkola, P., and Rosenholm, J. B. (1998). "Quantitative characterization of the subsurface acid-base properties of wood by XPS and Fowkes theory," Colloids Surf. A: Physicochem. Eng. Aspects 145, 235-241. DOI: 10.1016/S0927-7757(98)00655-4

Shen, W. Z., Guo, Q. J., Zhang, Y. S., Liu, Y., Zheng, J. T., Cheng, J., and Fan, J. (2006). "The effect of activated carbon fiber structure and loaded copper, cobalt, silver on the 
adsorption of dichloroethylene," Colloids Surf. A. - Physicochem. Eng. Aspects 273(13), 147-153. DOI: 10.1016/j.colsurfa.2005.08.010

Shimizu, Y., Yamazaki, S., and Terashima, Y. (1992). "Sorption of anionic pentachlorophenol (PCP) in aqueous environments: The effect of $\mathrm{pH}$," Water Sci. Technol. 25(11), 41-48.

Singh, B. K., and Rawat, N. S. (1994a). "Comparative sorption kinetic-studies of phenolic-compounds on fly-ash and impregnated fly-ash," J. Chem. Technol. Biotech. 61(1), 57-65. DOI: $10.1002 /$ jetb.280610109

Singh, B. K., and Rawat, N. S. (1994b). "Comparative sorption equilibrium studies of toxic phenols on fly ash and impregnated fly ash," J. Chem. Technol. Biotechnol. 61, 307-315. DOI: $10.1002 /$ jctb.280610405

Singh, K. P., Malik, A., Sinha, S., and Ojha, P. (2008). "Liquid-phase adsorption of phenols using activated carbons derived from agricultural waste material," J. Hazard. Mater. 150, 626-641. DOI: 10.1016/j.jhazmat.2007.05.017

Sinnokrot, M. O., Valeev, E. F., and Sherrill, C. D. (2002). "Estimates of the ab initio limit for pi-pi interactions: The benzene dimer," J. Amer. Chem. Soc. 124(36), 10887-10893. DOI: $10.1021 / \mathrm{ja} 025896 \mathrm{~h}$

Slaney, A. J., and Bhamidimarri, R. (1998). "Adsorption of pentachlorophenol (PCP) by activated carbon in fixed beds: Application of homogeneous surface diffusion model," Water Sci. Technol. 38(7), 227-235. DOI: 10.1016/S0273-1223(98)00630-1

Snoeyink, V. L., Weber, W. J., and Mark, H. B. (1969). "Sorption of phenol and nitrophenol by active carbon," Environ. Sci. Technol. 31(10), 918-926. DOI: 10.1021/es60033a008

Sodha, K., Panchani, S. C., and Nath, K. (2013). "Feasibility study of microbial regeneration of spent activated carbon sorbed with phenol using mixed bacterial culture," Indian Journal of Chemical Technology 20(1), 33-39.

Sokker, H. H., Badawy, S. M., Zayed, E. M., Eldien, F. A. N., and Farag, A. M. (2009). "Radiation-induced grafting of glycidyl methacrylate onto cotton fabric waste and its modification for anchoring hazardous wastes from their solutions," J. Hazardous Mater. 168(1), 137-144. DOI: 10.1016/j.jhazmat.2009.02.039

Soni, H., and Padmaja, P. (2014). "Palm shell based activated carbon for removal of bisphenol A: An equilibrium, kinetic and thermodynamic study," J. Porous Mater. 21(3), 275-284. DOI: 10.1007/s10934-013-9772-5

Sothornvit, R., and Sampoompuang, C. (2012). "Rice straw paper incorporated with activated carbon as an ethylene scavenger in a paper-making process," International Journal of Food Science and Technology 47(3), 511-517. DOI: 10.1111/j.1365-2621.2011.02871.x

Speranza, F., Pilkington, G. A., Dane, T. G., Cresswell, P. T., Li, P. X., Jacobs, R. M. J., Arnold, T., Bouchenoire, L., Thomas, R. K., and Briscoe, W. H. (2013), "Quiescent bilayers at the mica-water interface," Soft Matter 9(29), 7028-7041. DOI: $10.1039 / \mathrm{c} 3 \mathrm{sm} 50336 \mathrm{~d}$

Srivastava, S. K., and Tyagi, R. (1995a). "Competitive adsorption of substituted phenols by activated carbon developed from the fertilizer waste slurry," Water Res. 29(2), 483-488. DOI: 10.1016/0043-1354(94)00182-7

Srivastava, S. K., and Tyagi, R. (1995b). "Organic desorption and chemical regeneration of spent carbon developed from fertilizer waste slurry," J. Environ. 
Eng. - ASCE 121(2), 186-193. DOI: 10.1061/(ASCE)0733-

9372(1995)121:2(186)

Srivastava, S. K., Tyagi, R., Pal, N., and Mohan, D. (1997). "Process development for removal of substituted phenols by carbonaceous adsorbent obtained from fertilizer waste," J. Environ. Eng. 123, 842-851. DOI: 10.1061/(ASCE)07339372(1997)123:9(842)

Srivastava, V. C., Swamy, M. M., Mall, I. D., Prasad, B., and Mishra, I. M. (2006). "Adsorptive removal of phenol by bagasse fly ash and activated carbon: Equilibrium, kinetics and thermodynamics," Colloids Surf. A: Physicochem. Aspects 272, 89-104. DOI: 10.1016/j.colsurfa.2005.07.016

Stasinakis, A. S., Elia, I., Petalas, A. V., and Halvadakis, C. P. (2008). "Removal of total phenols from olive-mill wastewater using an agricultural by-product olive pomace," J. Hazard. Mater. 160, 408-413, Doi: 10.1016/j.jhazmat.2008.03.012.

Stavropoulos, G. G., Samaras, P., and Sakellaropoulos, G. P. (2008). "Effect of activated carbons modification on porosity, surface structure and phenol adsorption," J. Hazard Mater. 151, 414-421. DOI: 10.1016/j.jhazmat.2007.06.005

Steen, W. C., and Karickhoff, S. W. (1981). "Biosorption of hydrophobic organic pollutants by mixed microbial-populations," Chemosphere 10(1), 27-32. DOI: 10.1016/0045-6535(81)90156-9

Stoeckli, F., López-Ramón, M. V., and Moreno-Castilla, C. (2001). “Adsorption of phenolic compounds from aqueous solutions by activated carbons, described by the Dubinin-Astakhov equation," Langmuir 17, 3301-3306. DOI: 10.1021/la0014407

Stone, J. E., and Scallan, A. M. (1996). "Influence of drying on the pore structures of the cell wall," in: Consolidation of the Paper Web, Transactions of the symposium held at Cambridge, Sept. 1965, Bolam, F. (ed.), Tech. Sec. British Paper and Board Makers' Assoc., London, pp. 145-174.

Streat, M., Patrick, J. W., and Camporro Perrez, M. J. (1995). "Sorption of phenol and parachlorophenol from water using conventional and novel activated carbons," Water Res. 29(2), 467-472. DOI: 10.1016/0043-1354(94)00187-C

Stringfellow, W. T., and Alvarez-Cohen, L. (1999). "Evaluating the relationship between the sorption of PAHs to bacterial biomass and biodegradation," Water Res. 33(11), 2535-2544. DOI: 10.1016/S0043-1354(98)00497-7

Subha, R., and Namasivayam, C. (2009). "Kinetics and isotherm studies for the adsorption of phenol using low cost micro porous $\mathrm{ZnCl}_{2}$ activated coir pith carbon," Canad. J. Civil Eng. 36(1), 148-159. DOI: 10.1139/S08-039

Subha, R., and Namasivayam, C. (2010). " $\mathrm{ZnCl}_{2}$-modified activated carbon from biomass coir pith for the removal of 2-chlorophenol by adsorption process," Bioremed. J. 14(1), 1-9. DOI: 10.1080/10889860903455360

Suhas, Carrott, P. J. M., and Carrott, M. M. L. R. (2007). "Lignin - from natural adsorbent to activated carbon: A review," Bioresour. Technol. 98(12), 2301-2312. DOI: 10.1016/j.biortech.2006.08.008

Sulaymon, A. H., Abbood, D. W., Ali, A. H. (2012). "Removal of phenol and lead from synthetic wastewater by adsorption onto granular activated carbon in fixed bed adsorbers: Prediction of breakthrough curves," Desalination Water Treat. 40, 244253. DOI: $10.1080 / 19443994.2012 .671253$

Sulaymon, A. H., Abbood, D. W., and Ali, A. H. (2013). “A comparative 
adsorption/biosorption for the removal of phenol and lead onto granular activated carbon and dried anaerobic sludge," Desalination Water Treat. 51(10-12), 20552067. DOI: 10.1080/19443994.2013.734497

Sun, K., Gao, B., Ro, K. S., Novak, J. M., Wang, Z. Y., Herbert, S., and Xing, B. S. (2012a). "Assessment of herbicide sorption by biochars and organic matter associated with soil and sediment," Environmental Pollution 163, 167-173. DOI: 10.1016/j.envpol.2011.12.015

Sun, K., Jin, J., Keiluweit, M., Kleber, M., Wang, Z. Y., Pan, Z. Z., and Xing, B. S. (2012b). "Polar and aliphatic domains regulate sorption of phthalic acid esters (PAEs) to biochars," Bioresour. Technol. 118, 120-127. DOI: 10.1016/j.biortech.2012.05.008

Sun, K., Keiluweit, M., Kleber, M., Pan, Z., and Xing, B. (2011a). "Sorption of fluorinated herbicides to plant biomass-derived biochars as a function of molecular structure," Bioresour. Technol. 102(21), 9897-9903. DOI: 10.1016/j.biortech.2011.08.036

Sun, K., Ro, K., Guo, M., Novak, J., Mashayekhi, H., and Xing, B. (2011b). "'Sorption of bisphenol A, 17alpha-ethinyl estradiol and phenanthrene on thermally and hydrothermally produced biochars," Bioresour. Technol. 102(10), 5757-5763. DOI: 10.1016/j.biortech.2011.03.038

Tan, I. A. W., Ahmad, A. L., and Hameed, B. H. (2008). "Preparation of activated carbon from coconut husk: Optimization study on removal of 2,4,6-trichlorophenol using response surface methodology," J. Hazard Mater. 153(1-2), 709-717. DOI: 10.1016/j.jhazmat.2007.09.014

Tan, I. A. W., Ahmad, A. L., and Hameed, B. H. (2009a). "Fixed-bed adsorption performance of oil palm shell-based activated carbon for removal of 2,4,6trichlorophenol," Bioresour. Technol. 100(3), 1494-1496. DOI: 10.1016/j.biortech.2008.08.017

Tan, I. A. W., Ahmad, A. L., and Hameed, B. H. (2009b). “Adsorption isotherms, kinetics, thermodynamics and desorption studies of 2,4,6-trichlorophenol on oil palm empty fruit bunch-based activated carbon," J. Hazard. Mater. 164(2-3), 473-482. DOI: 10.1016/j.jhazmat.2008.08.025

Tancredi, N., Medero, N., Möller, F., Piriz, J., Plada, X., and Cordero, T. (2004). "Phenol adsorption onto powdered and granular activated carbon prepared from Eucalyptus wood," J. Colloid Interface Sci. 279, 357-363. DOI: 10.1016/j.jcis.2004.06.067

Tang, D., Zheng, Z., Lin, K., Luan, J., and Zhang, J. (2007). “Adsorption of pnitrophenol from aqueous solutions onto activated carbon fiber," J. Hazard Mater. 143, 49-56. DOI: 10.1016/j.jhazmat.2006.08.066

Temkin, M. I. (1941). "Adsorption equilibrium and the kinetics of processes on nonhomogeneous surfaces and in the interaction between adsorbed molecules," $\mathrm{Zh}$. Fiz. Chim. 15, 296-332.

Teng, H., and Hseih, C.-T. (1999). "Liquid-phase adsorption of phenol by activated carbons prepared from biotuminous coals with different oxygen contents," J. Chem. Technol. Biotechnol. 74, 123-130. DOI: 10.1002/(SICI)10974660(199902)74:2<123::AID-JCTB991>3.0.CO;2-5

Terzyk, A. P. (2003a). “Adsorption of biologically active compounds from aqueous solutions on to commercial unmodified activated carbons. Part V. The mechanism of 
the physical and chemical adsorption of phenol," Adsorp. Sci. Technol. 21(6), 539585. DOI: $10.1260 / 026361703771953596$

Terzyk, A. P. (2003b). "Further insights into the role of carbon surface functionalities in the mechanism of phenol adsorption," J. Colloid Interf. Sci. 268, 301-329. DOI: 10.1016/S0021-9797(03)00690-8

Terzyk, A. P., Gauden, P. A., Furmaniak, S., Wesołowski, R. P., and Harris, P. J. F. (2010). "Molecular dynamics simulation insight into the mechanism of phenol adsorption at low coverages from aqueous solutions on microporous carbons," Phys. Chem. Chem. Phys. 12(4), 812-817. DOI: 10.1039/b919794j

Tessmer, C. H., Vidic, R. D., and Uranowski, L. J. (1997). "Impact of oxygen-containing surface functional groups on activated carbon adsorption of phenols," Environ. Sci. Technol. 31(7), 1872-1878. DOI: 10.1021/es960474r

Thawornchaisit, U., and Pakulanon, K. (2007). "Application of dried sewage sludge as phenol biosorbent," Bioresour. Technol. 98, 140-144. DOI:

10.1016/j.biortech.2005.11.004

Thuy, P. T., Anh, N. V., and van der Bruggen, B. (2012). "Evaluation of two low-costhigh-performance adsorbent materials in the waste-to-product approach for the removal of pesticides from drinking water," Clean-Soil Air Water 40(3), 246-253. DOI: 10.1002/clen.201100209

Thuy, P. T., Moons, K., van Dijk, J. C., Anh, N. V., and Van der Bruggen, B. (2008). "To what extent are pesticides removed from surface water during coagulationflocculation?" Water Environ. J. 22(3), 217-223. DOI: 10.1111/j.17476593.2008.00128.x

Timur, S., Kantarli, I. C., Onenc, S., and Yanik, J. (2010). "Characterization and application of activated carbon produced from oak cups pulp," J. Anal. Appl. Pyrol. 89(1), 129-136. DOI: 10.1016/j.jaap.2010.07.002

Toh, R. H., Lim, P. E., Seng, C. E., and Adnan, R. (2013). "Immobilized acclimated biomass-powdered activated carbon for the bioregeneration of granular activated carbon loaded with phenol and o-cresol," Bioresource Technology 143, 265-274. DOI: 10.1016/j.biortech.2013.05.126

Toles, C. A., Marshall, W. E., and Johns, M. M. (1997). “Granular activated carbons from nutshells for the uptake of metals and organic compounds," Carbon 35(9), 1407-1414. DOI: 10.1016/S0008-6223(97)00073-0

Toles, C. A., Marshall, W. E., and Johns, M. M. (1998). "Phosphoric acid activation of nutshells for metals and organic remediation: Process optimization," J. Chem. Technol. Biotechnol. 72, 255-263. DOI: 10.1002/(SICI)10974660(199807)72:3<255::AID-JCTB890>3.0.CO;2-P

Tsai, W.-T. (2013). "A review on environmental distributions and risk management of phenols pertaining to the endocrine disrupting chemicals in Taiwan," Toxicological And Environmental Chemistry 95(5), 723-736. DOI: 10.1080/02772248.2013.818150

Tseng, R. L., Wu, F. C., and Juang, R. S. (2003). "Liquid-phase adsorption of dyes and phenols using pinewood-based activated carbons," Carbon 41(3), 487-495. DOI: 10.1016/S0008-6223(02)00367-6

Tseng, R.-L., Wu, K.-T., Wu, F.-C., and Juang, R.-S. (2010). "Kinetic studies on the adsorption of phenol, 4-chlorophenol, and 2,4-dichlorophenol from water using 
activated carbons," J. Environ. Manag. 91(11), 2208-2214. DOI:

10.1016/j.jenvman.2010.05.018

Tseng, R.-L., Wu, P.-H., Wu, F.-C., and Juang, R.-S. (2011). "Half-life and half-capacity concentration approach for the adsorption of 2,4-dichlorophenol and methyl blue from water on activated carbons," J. Taiwan Inst. Chem. Eng. 42(2), 312-319. DOI: 10.1016/j.jtice.2010.07.002

Tsezos, M., and Bell, J. P. (1988). "Significance of biosorption for the hazardous organics removal efficiency of a biological reactor," Water Res. 22(3), 391-394. DOI: 10.1016/S0043-1354(88)90320-X

Tsezos, M., and Bell, J. P. (1989). "Comparison of the biosorption and desorption of hazardous organic pollutants by live and dead biomass," Water Res. 23(5), 561-568. DOI: 10.1016/0043-1354(89)90022-5

Tsezos, M., and Bell, J. P. (1991). "A mechanistic study on the fate of malathion following interaction with microbial biomass," Water Res. 25(9), 1039-1046. DOI: /10.1016/0043-1354(91)90197-X

Tsezos, M., and Wang, X. (1991a). "Biosorption and biodegradation interactions - A study on lindane," Biotech. Forum Eur. 8(3), 120-125.

Tsezos, M., and Wang, X. (1991b). "Study on the kinetics of hazardous pollutants adsorption and desorption by biomass: Mechanistic considerations," J. Chem. Technol. Biotechnol. 50(4), 507-521. DOI: 10.1002/jctb.280500408

Tyagi, R., and Srivastava, S. K. (1996). "Chemical regeneration of spent carbon developed from the fertilizer waste slurry by column method," Fresenius Environ. Bull 5(5-6), 314-318.

Urano, K., Yamamoto, E., Tonegawa, M., and Fujie, K. (1991). “Adsorption of chlorinated organic compounds on activated carbon from water," Water Res. 25(12), 1459-1464. DOI: 10.1016/0043-1354(91)90175-P

Uranowski, L. J., Tessmer, C. H., and Vidic, R. D. (1998). “The effect of surface metal oxides on activated carbon adsorption of phenolics," Water Res. 32(6), 1841-1851. DOI: 10.1016/S0043-1354(97)00479-X

van der Stelt, M. J. C., Gerhauser, H., Kiel, J. H. A., and Ptasinski, K. J. (2011). "Biomass upgrading by torrefaction for the production of biofuels: A review," Biomass Bioenergy 35(9), 3748-3762.

Vázquez, I., Rodríguez-Iglesias, J., Marañón, E., Castrillón, L, and Álvarez, M. (2007). "Removal of residual phenols from coke wastewater by adsorption," J. Hazard. Mater. 147, 395-400. DOI: 10.1016/j.jhazmat.2007.01.019

Vidic, R. D., Suidan, M. T., Sorial, G. A., and Brenner, R. C. (1994). "Effect of molecular oxygen on adsorptive capacity and extraction efficiency of granulated activated carbon for three ortho-substituted phenols," J. Hazard Mater. 38, 373-388. DOI: 10.1016/0304-3894(93)E0129-P

Vidic, R. D., Tessmer, C. H., and Uranowski, L. J. (1997). "Impact of surface properties of activated carbons on oxidative coupling of phenolic compounds," Carbon 35(9), 1349-1359. DOI: 10.1016/S0008-6223(97)00071-7

Villacanas, F., Pereira, M. F. R., Órfäo, J. J. M., and Figueiredo, J. L. (2006). "Adsorption of simple aromatic compounds on activated carbons," J. Colloid Interface Sci. 293(1), 128-136. DOI: 10.1016/j.jcis.2005.06.032 
Vinitnantharat, S., Baral, A., Ishibashi, Y., and Ha, S. R. (2001). "Quantitative bioregeneration of granular activated carbon loaded with phenol and 2,4dichlorophenol," Environ. Technol. 22(3), 339-344. DOI: 10.1080/09593332208618288

Vinod, V. P., and Anirudhan, T. S. (2002). "Effect of experimental variables on phenol adsorption on activated carbon prepared from coconut husk by single-step steam pyrolysis: Mass transfer process and equilibrium studies," J. Sci. Ind. Res. 61, 128138.

Viraraghavan, T., and Alfaro, F. D. (1998). "Adsorption of phenol from wastewater by peat, fly ash and bentonite," J. Hazard Mater. 57, 59-70. DOI: 10.1016/S03043894(97)00062-9

Vismara, E., Melone, L., Gastaldi, G., Cosentino, C., and Torri, G. (2009). "Surface functionalization of cotton cellulose with glycidyl methacrylate and its application for the adsorption of aromatic pollutants from wastewaters," J. Hazard. Mater. 170(2-3), 798-808. DOI: 10.1016/j.jhazmat.2009.05.042

Visser, J. (1972). "On Hamaker constants: A comparison between Hamaker constants and Lifshitz - van der Waals constants," Advan. Colloid Interface Sci. 3, 331-361. DOI: 10.1016/0001-8686(72)85001-2

Vrana, B., Balaz, S., Dercova, K., and Tandlich, R. (1998). "Biosorption of hydrophobic organic pollutants," Chemicke Listy 92(3), 186-196.

Voudrias, E. A., Larson, R. A., and Snoeyin, V. L. (1985). "Effects of activated carbon on the reactions of free chlorine with phenols," Environ. Sci. Technol. 19(5), 441-449. DOI: 10.1021/es00135a010

Wang, J.-P., Chen, Y.-Z., Feng, H.-M., Zhang, S.-J., and Yu, H.-Q. (2007a). "Removal of 2,4-dichlorophenol from aqueous solution by static-air-activated carbon fibers," $J$. Colloid Interface Sci. 313(1), 80-85. DOI: 10.1016/j.jcis.2007.04.012

Wang, J.-P., Feng, H.-M., and Yu, H.-Q. (2007b). "Analysis of adsorption characteristics of 2,4-dichlorophenol from aqueous solutions by activated carbon fiber," J. Hazard Mater. 144, 200-207. DOI: 10.1016/j.jhazmat.2006.10.003

Wang, X. L., and Grady, C. P. L. (1994). "Comparison of biosorption isotherms for di-nbutyl phthalate by live and dead bacteria," Water Res. 28(5), 1247-1251. DOI: 10.1016/0043-1354(94)90214-3

Wang, X. L., and Grady, C. P. L. (1995). "Effects of biosorption and dissolution on the biodegradation of di-n-butyl phthalate," Water Environ. Res. 67(5), 863-871. DOI: $10.2175 / 106143095 X 131808$

Weber, W. J., and Morris, J. C. (1963). "Kinetics of adsorption on carbon from solution," J. Sanity Eng. Div. Am. Soc. Civil Eng. 89, 31-59.

Wei, Z. S., and Seo, Y. (2010). "Trichloroethylene (TCE) adsorption using sustainable organic mulch," J. Hazard. Mater. 181(1-3), 147-153. DOI: 10.1016/j.jhazmat.2010.04.109

Weise, U. (1998). "Hornification - Mechanisms and terminology," Paperi Puu 80(2), 110115.

Westall, J. C., Leuenberger, C., and Schwarzenbach, R. P. (1985). "Influence of pH and ionic strength on the aqueous-nonaqueous distribution of chlorinated phenols," Environ. Sci. Technol. 19(2), 193-198. DOI: 10.1021/es00132a014

Widom, B., Bhimalapuram, P., and Koga, K. (2003). "The hydrophobic effect," Phys. 
Chem. Chem. Phys. 5(15), 3085-3093. DOI: 10.1039/b304038k

Wightman, P. G., and Fein, J. B. (1999). "Experimental study of 2,4,6-trichlorophenol and pentachlorophenol solubilities in aqueous solutions: Derivation of a speciation-based chlorophenol solubility model," Appl. Geochem. 14, 319-331. DOI: 10.1016/S08832927(98)00054-7

Wolborska, A. (1989). “Adsorption on activated carbon of $p$-nitrophenol from aqueous solution,” Water Res. 23(1), 85-91. DOI: 10.1016/0043-1354(89)90066-3

Wu, F.-C., and Tseng, R.-L. (2006). "Preparation of highly porous carbon from fir wood by $\mathrm{KOH}$ etching and $\mathrm{CO}_{2}$ gasification for adsorption of dyes and phenols from water," $J$. Colloid Interf. Sci. 294(1), 21-30. DOI: 10.1016/j.jcis.2005.06.084

Wu, F.-C., Tseng, R.-L., and Juang, R.-S. (1999). "Preparation of activated carbons from bamboo and their adsorption abilities for dyes and phenol," J. Enviorn. Sci. Health. Pt. A - Toxic Hazard Subst. Environ. Eng. 34(9), 1753-1775. DOI: 10.1080/10934529909376927

Wu, F. C., Tseng, R. L., and Juang, R. S. (2005). "Preparation of highly microporous carbons from fir wood by KOH activation for adsorption of dyes and phenols from water," Separ. Purif. Technol. 47(1-2), 10-19. DOI: 10.1016/j.seppur.2005.03.013

Wu, F.-C., Wu, P.-H., Tseng, R.-L., and Juang, R.-S. (2011). "Preparation of novel activated carbons from $\mathrm{H}_{2} \mathrm{SO}_{4}$-pretreated corncob hulls with $\mathrm{KOH}$ activation for quick adsorption of dye and 4-chlorophenol," J. Environ. Manag. 92(3), 708-713. DOI: 10.1016/j.jenvman.2010.10.003

$\mathrm{Wu}$, J., and Yu, H.-Q. (2006a). "Biosorption of phenol and chlorophenols from aqueous solutions by fungal mycelia," Proc. Biochem. 41(1), 44-49. DOI: 10.1016/j.procbio.2005.03.065

$\mathrm{Wu}, \mathrm{J}$. , and $\mathrm{Yu}, \mathrm{H} . \mathrm{-Q}$. (2006b). "Biosorption of 2,4-dichlorophenol from aqueous solution by Phanerochaete chrysosporium biomass: Isotherms, kinetics and thermodynamics," J. Hazard. Mater. B137(1), 498-508. DOI: 10.1016/j.jhazmat.2006.02.026

Wu, J., and Yu, H.-Q. (2007). "Biosorption of 2,4-dichlorophenol by immobilized whiterot fungus Phanerochaete chrysosporium from aqueous solutions," Bioresour. Technol. 98(2), 253-259. DOI: 10.1016/j.biortech.2006.01.018

$\mathrm{Wu}$, J., and Yu, H. Q. (2008). "Biosorption of 2,4-dichlorophenol from aqueous solutions by immobilized Phanerochaete chrysospor $2 T$ ium biomass in a fixed-bed column," Chem. Eng. J. 138, 128-135. DOI: 10.1016/j.cej.2007.05.051

Wu, P., Yang, G.-P., and Zhao, X.-K. (2003). "Sorption behavior of 2,4-dichlorophenol on marine sediment," J. Colloid Interface Sci. 265, 251-256. DOI: 10.1016/S00219797(03)00515-0

Wu, W., Jiang, W., Xia, W., Yang, K., and Xing, B. (2012a). "Influence of pH and surface oxygen-containing groups on multiwalled carbon nanotubes on the transformation and adsorption of 1-naphthol," J. Colloid Interface Sci. 374(1), 226231. DOI: 10.1016/j.jcis.2012.01.045

Wu, Y., Jin, X. J., Zhang, M. Y., and Xu, D. (2012b). "Phenol adsorption on nitrogenenriched activated carbon from wood fiberboard waste," Wood and Fiber Science 44(2), 220-226.

Xia, G., and Ball, W. P. (1999). "Adsorption-partitioning uptake of nine low-polarity organic chemicals on a natural sorbent," Environ. Sci. Technol. 33, 262-269. DOI: $10.1021 / \mathrm{es} 980581 \mathrm{~g}$ 
Xu, J., Lv, X., Li, J., Li, Y., Shen, L., Zhou, H., and Xu, X. (2012). “Simultaneous adsorption and dechlorination of 2-4-dichlorophenol by Pd/Fe nanoparticles with multi-walled carbon nanotube support," J. Hazard. Mater. 225-226, 36-45. DOI: 10.1016/j.jhazmat.2012.04.061

Yaghmaeian, K., Moussavi, G., and Alahabadi, A. (2014). "Removal of amoxicillin from contaminated water using $\mathrm{NH}_{4} \mathrm{Cl}$-activated carbon: Continuous flow fixed-bed adsorption and catalytic ozonation regeneration," Chem. Eng. J. 236, 538-544. DOI: 10.1016/j.cej.2013.08.118

Yan, G., and Allen, D. G. (1994). "Biosorption of high-molecular-weight organochlorines in pulp-mill effluent," Water Res. 28(9), 1933-1941. DOI: 10.1016/0043-1354(94)90168-6

Yang, K., Zhu, L., and Xing, B. (2006a). "Adsorption of polycyclic aromatic hydrocarbons by carbon nanomaterials," Environ. Sci. Technol. 40, 1855-1861. DOI: $10.1021 /$ es052208w

Yang, K., Wang, X. L., Zhu, L. Z., Xing, B. S. (2006b). “Competitive sorption of pyrene, phenanthrene, and naphthalene on multiwalled carbon nanotubes," Environ. Sci. Technol. 40(18), 5804-5810. DOI: 10.1021/es061081n

Ye, J. S., Yin, H., Peng, H., Bai, J. Q., Xie, D. P., and Wang, L. L. (2013). "Biosorption and biodegradation of triphenyltin by Brevibacillus brevis," Bioresour. Technol. 129, 236-241. DOI: 10.1016/j.biortech.2012.11.076

Yeganeh, M. N., Kaghazchi, T., and Soleimani, M. (2006). "Effect of raw materials on properties of activated carbons," Chem. Eng. Technol. 29(10), 1247-1251. DOI: 10.1002/ceat.200500298

Young, E., and Banks, C. J. (1998). "The removal of lindane from aqueous solution using a fungal biosorbent: The influence of $\mathrm{pH}$, temperature, biomass concentration, and culture age," Environ. Technol. 19(6), 619-625. DOI: $10.1080 / 09593331908616718$

Yu, J.-J., and Chou, S.-Y. (2000). "Contaminated site remedial investigation and feasibility of removal of chlorinated volatile organic compounds from groundwater by activated carbon fiber adsorption," Chemosphere 41, 371-378. DOI: 10.1016/S0045-6535(99)00437-3

$\mathrm{Yu}, \mathrm{J}$. , and Hu, J. Y. (2011). “Adsorption of perfluorinated compounds onto activated carbon and activated sludge," J. Environ. Eng. - ASCE 137(10), 945-951. DOI: 10.1061/(ASCE)EE.1943-7870.0000402

Yu, J.-W., and Neretnieks, I. (1990). "Single-component and multicomponent adsorption equilibrium on activated carbon of methylcyclohexane, toluene, and isobutyl methyl ketone," Ind. Eng. Chem. Res. 29, 220-231. DOI: 10.1021/ie00098a012

Yu, Q., Zhang, R., Deng, S., Huang, J., and Yu, G. (2009). "Sorption of perfluorooctane sulfonate and perfluorooctanoate on activated carbons and resin: Kinetic and isothermal study," Water Res. 43, 1150-1158. DOI: 10.1016/j.watres.2008.12.001

Yu, Z. R., Peldszus, S., and Huck, P. M. (2008). "Adsorption characteristics of selected pharmaceuticals and an endocrine disrupting compound - Napoxen, carbamazepine and nonylphenol - on activated carbon," Water Res. 42(12), 2873-2882. DOI: 10.1016/j.watres.2008.02.020 
Zakharov, A. G., Voronova, M. I., Surov, O. V., and Batov, D. V. (2010). "Phenol sorption on cellulose from binary aqueous-organic mixtures," J. Molecular Liquids 151(1), 74-80. DOI: 10.1016/j.molliq.2009.10.017

Zeinali, F., Ghoreyshi, A. A., Najafpour, G. (2012). "Removal of toluene and dichloromethane from aqueous phase by granular activated carbon (GAC)," Chem. Eng. Commun. 199(2), 203-220. DOI: 10.1080/00986445.2011.584354

Zhang, D. N., Ran, C. Y., Yang, Y., and Ran, Y. (2013). "Biosorption of phenanthrene by pure algae and field-collected planktons and their fractions," Chemosphere 93(1), 6168. DOI: 10.1016/j.chemosphere.2013.04.068

Zhang, G., Zhang, Q., Sun, K., Liu, X., Zheng, W., and Zhao, Y. (2011a). "Sorption of simazine to corn straw biochars prepared at different pyrolytic temperatures," Environ. Pollut. 159(10), 2594-2601. DOI: 10.1016/j.envpol.2011.06.012

Zhang, L., Xu, T., Liu, X., Zhang, Y., and Jin, H. (2011b). “Adsorption behavior of multi-walled carbon nanotubes for the removal of olaquindox from aqueous solutions," J. Hazard. Mater. 197, 389-396. DOI: 10.1016/j.jhazmat.2011.09.100

Zhang, Y., Wei, D. B., Huang, R. D., Yang, M., Zhang, S. J., Dou, X. M., Wang, D. S., and Vimonses, V. (2011c). "Binding mechanisms and QSAR modeling of aromatic pollutant biosorption on Penicillium oxalicum biomass," Chem. Eng. J. 166(2), 624630. DOI: 10.1016/j.cej.2010.11.034

Zheng, H., Wang, Z. Y., Zhao, J., Herbert, S., and Xing, B. S. (2013). "Sorption of antibiotic sulfamethoxazole varies with biochars produced at different temperatures," Environmental Pollution 181, 60-67. DOI: 10.1016/j.envpol.2013.05.056

Zheng, W., Guo, M., Chow, T., Bennett, D. N., and Rajagopalan, N. (2010). "Sorption properties of greenwaste biochar for two triazine pesticides," J. Hazard Mater. 181, 121-126. DOI: 10.1016/j.jhazmat.2010.04.103

Zhong, M., Wang, Y., Yu, J., Tian, Y. J., and Xu, G. W. (2012). "Porous carbon from vinegar lees for phenol adsorption," Particuology 10(1), 35-41. DOI: 10.1016/j.partic.2011.05.006

Zolgharnein, J., Shahmoradi, A., and Ghasemi, J. (2011). "Pesticides removal using conventional and low-cost adsorbents: A review," Clean - Soil Air Water 39(12), 1105-1119. DOI: $10.1002 /$ clen.201000306

\section{ERRATUM}

A correction was made to Table 3 on October 14, 2018. The entry for the item headed "Elovich" was changed. The words "increase exponentially" were changed to "decrease exponentially", and the statement was modified to refer to the kinetics of adsorption rather than an equilibrium state. 


\section{APPENDIX}

Table A. Tabulation of Research Publications for Removal of Dissolved Petrochemicals from Dilute Aqueous Solution by Use of Raw or Modified Lignocellulosic Materials (See notes below table for key to abbreviations)

\begin{tabular}{|c|c|c|c|c|c|c|c|c|c|}
\hline Pollutant & Sorbent & 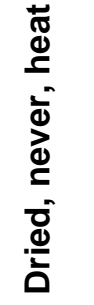 & 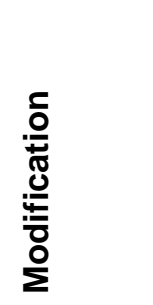 & 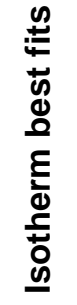 & $\begin{array}{l}\text { Adsorp. } \\
\text { capac. } \\
(\mathrm{mg} / \mathrm{g})\end{array}$ & 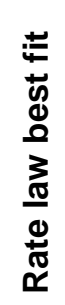 & 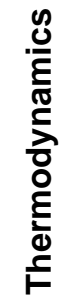 & Key Findings & Author (year) \\
\hline Phenol & $\begin{array}{l}\text { Brown algae, } \\
\text { Macrophyta, } \\
\text { Tea residue }\end{array}$ & $\begin{array}{l}\text { Air } \\
\text { dry }\end{array}$ & $\begin{array}{l}\mathrm{HCl} \\
0.1 \mathrm{~N}\end{array}$ & $\begin{array}{l}\mathrm{F} \\
(\mathrm{L})\end{array}$ & $\begin{array}{l}0.04 \\
0.87 \\
0.02\end{array}$ & - & - & Favorable $\mathrm{pH}=10$; heterogeneous sites & Abdallah 2013 \\
\hline $\begin{array}{l}101 \text { organic } \\
\text { compounds }\end{array}$ & $\begin{array}{l}\text { Activated } \\
\text { carbon }\end{array}$ & - & - & - & - & - & - & $\begin{array}{l}\text { Adsorption favored by } \mathrm{C}, \mathrm{Br}, \mathrm{Cl} \text { in } \\
\text { molecule. Decreased by } \mathrm{O} \text { and } \mathrm{H} \text {. }\end{array}$ & Abe et al. 1985 \\
\hline $\begin{array}{l}\text { Phenol, } \\
\text { p-Nitrophenol }\end{array}$ & $\begin{array}{l}\text { Kenaf cloth } \\
\text { act. C }\end{array}$ & $A C$ & $\begin{array}{l}\mathrm{K}_{2} \mathrm{HPO}_{4} \\
\text { activ. }\end{array}$ & $\begin{array}{l}\mathrm{L}, \\
\mathrm{T}\end{array}$ & $137-141$ & $1^{\text {st }}$ & - & Activation conditions & $\begin{array}{l}\text { Aber et al. } \\
2009\end{array}$ \\
\hline $\begin{array}{l}\text { Phenol and } \\
\text { o-Cresol }\end{array}$ & $\begin{array}{l}\text { Activated } \\
\text { carbon (coal) }\end{array}$ & $\mathrm{AC}$ & - & $\mathrm{L}$ & $\begin{array}{l}100-300 \\
200-400\end{array}$ & ID & - & Intraparticle diffusion is rate-limiting step. & $\begin{array}{l}\text { Abuzaid \& } \\
\text { Nakhala } 1994\end{array}$ \\
\hline $\begin{array}{l}\text { Dichoromethane, } \\
\mathrm{CHCl}_{3}, \mathrm{CCl}_{4}, \mathrm{TCE}, \\
\text { Tetrachloroethylene, } \\
\text { Benzene }\end{array}$ & Rice bran & - & $\begin{array}{l}\text { As } \\
\text { received }\end{array}$ & $\mathrm{F}$ & $100-600$ & - & - & $\begin{array}{l}\text { Spherosomes (intracellular particles) } \\
\text { involved in the adsorption; rice bran was } \\
\text { as effective as activated carbon \& superior } \\
\text { to various other sorbents. }\end{array}$ & $\begin{array}{l}\text { Adachi et al. } \\
\text { 2001a }\end{array}$ \\
\hline $\begin{array}{l}\mathrm{CHCl}_{3}, \mathrm{CH}_{2} \mathrm{Cl}_{2}, \\
\text { Trichloroethylene }\end{array}$ & Defatted seed & - & $\begin{array}{l}\text { As } \\
\text { received }\end{array}$ & - & - & - & - & $\begin{array}{l}\text { Effective sorption; results were similar to } \\
\text { those obtained with activated carbon. }\end{array}$ & $\begin{array}{l}\text { Adachi et al. } \\
\text { 2001b }\end{array}$ \\
\hline Malathion & Bacillus cells & $80 C$ & Ground & $\mathrm{L}$ & 80 & - & - & $\begin{array}{l}\text { Best pH 6.5; no further effect of time } \\
\text { beyond "zero days" of equilibration }\end{array}$ & $\begin{array}{l}\text { Adhikari et al. } \\
2010\end{array}$ \\
\hline Trichloroethylene & $\begin{array}{l}\text { Soy stover, } \\
\text { peanut shell } \\
\text { biochar }\end{array}$ & $\mathrm{BC}$ & $\begin{array}{l}300-700 \\
\text { pyrol. }\end{array}$ & $\mathrm{L}$ & $12-32$ & - & - & $\begin{array}{l}\text { Higher temperature yielded higher area \& } \\
\text { higher sorption capacity. }\end{array}$ & $\begin{array}{l}\text { Ahmad et al. } \\
2012\end{array}$ \\
\hline Trichloroethylene & Pine needles & $\mathrm{BC}$ & $\begin{array}{l}300-700 \\
\text { pyrol. }\end{array}$ & $\begin{array}{l}\mathrm{DR} \\
\mathrm{L}\end{array}$ & $5-79$ & & & $\begin{array}{l}\text { Higher temperature yielded higher area \& } \\
\text { higher sorption capacity; pore filling. }\end{array}$ & $\begin{array}{l}\text { Ahmad et al. } \\
2013\end{array}$ \\
\hline
\end{tabular}




\begin{tabular}{|c|c|c|c|c|c|c|c|c|c|}
\hline Pollutant & Sorbent & 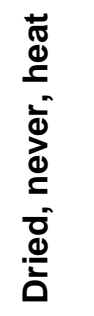 & 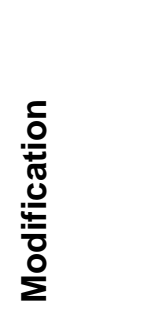 & 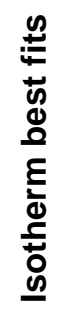 & $\begin{array}{l}\text { Adsorp. } \\
\text { capac. } \\
(\mathrm{mg} / \mathrm{g})\end{array}$ & 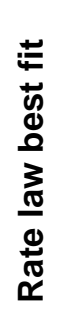 & 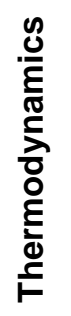 & Key Findings & Author (year) \\
\hline $\begin{array}{l}\text { Phenol, } \\
\text { p-Nitrophenol, } \\
\text { p-Chlorophenol }\end{array}$ & $\begin{array}{l}\text { Activated rice } \\
\text { husk carbon, } \\
\text { etc. }\end{array}$ & $\mathrm{AC}$ & $\begin{array}{l}\mathrm{H}_{3} \mathrm{PO}_{4} \\
550 \mathrm{C}\end{array}$ & $\begin{array}{l}\mathrm{L}, \\
\mathrm{F}, \\
\mathrm{RP}\end{array}$ & $\begin{array}{l}8-300 \\
10-525 \\
10-500\end{array}$ & $1^{\text {st }}$ & Ex & $\begin{array}{l}\text { Diffusion control with surface diffusion; } \\
\text { external followed by internal diffusion; } \\
\text { drops off at } \mathrm{pH}>9 \text {. }\end{array}$ & $\begin{array}{l}\text { Ahmaruzzaman } \\
\& \text { Sharma } 2005\end{array}$ \\
\hline $\begin{array}{l}\text { Phenol, } \\
\text { p-Nitrophenol }\end{array}$ & $\begin{array}{l}\text { Palm fruit } \\
\text { stones }\end{array}$ & $\begin{array}{l}100 \\
\mathrm{C}\end{array}$ & Crushed & $\begin{array}{l}\mathrm{L}, \\
\mathrm{F} T\end{array}$ & $\begin{array}{l}115-132 \\
136-161\end{array}$ & $2^{\text {nd }}$ & En & Best $\mathrm{pH}=4$ to 5 & $\begin{array}{l}\text { Ahmed \& } \\
\text { Theydan } 2012\end{array}$ \\
\hline Trihalomethanes & $\begin{array}{l}\text { Carbon from } \\
\text { nut shells }\end{array}$ & $\mathrm{AC}$ & $\begin{array}{l}\mathrm{H}_{3} \mathrm{PO}_{4} \\
\text { steam } \\
\text { activate }\end{array}$ & - & - & - & - & $\begin{array}{l}\text { "Enviro-filters" outperformed commercially } \\
\text { available filters. Steam-activated carbons } \\
\text { worked the best. }\end{array}$ & $\begin{array}{l}\text { Ahmedna et al. } \\
2004\end{array}$ \\
\hline $\begin{array}{l}\text { Phenanthrene, } \\
\text { Pyrene }\end{array}$ & $\begin{array}{l}\text { Activated } \\
\text { carbon }\end{array}$ & $\mathrm{AC}$ & $\begin{array}{l}\text { Crush, } \\
\text { sieve }\end{array}$ & - & $\begin{array}{l}100-200 \\
20-100\end{array}$ & ID & - & $\begin{array}{l}\text { Intraparticle and "branched pore" kinetic } \\
\text { models employed. }\end{array}$ & Ahn et al. 2005 \\
\hline $\begin{array}{l}\text { Benzene, } \\
\text { Toluene, } \\
\text { Ethylbenzene, } \\
\text { Cumene }\end{array}$ & Rice bran & Sun & - & $\mathrm{L}$ & $\begin{array}{l}520 \\
690 \\
1000 \\
1100\end{array}$ & $1^{\text {st }}$ & Ex & Successful sorbent & $\begin{array}{l}\text { Akhtar et al. } \\
2005\end{array}$ \\
\hline 2,4-Dichlorophenol & Rice husk & - & - & $\mathrm{L}$ & 156 & - & Ex & $\begin{array}{l}\text { Moderate } \mathrm{pH} \text { dependency with lowest } \\
\text { value best; relatively low surface area }\end{array}$ & $\begin{array}{l}\text { Akhtar et al. } \\
2006\end{array}$ \\
\hline $\begin{array}{l}\text { Benzene, } \\
\text { Toluene, } \\
\text { Ethylbenzene, } \\
\text { Cumene }\end{array}$ & $\begin{array}{l}\text { Horseradish } \\
\text { pods }\end{array}$ & Sun & - & $\mathrm{L}$ & $\begin{array}{l}620 \\
830 \\
1000 \\
1300\end{array}$ & $1^{\text {st }}$ & Ex & $\begin{array}{l}\text { Moderate } \mathrm{pH} \text { dependency with lowest } \\
\text { value best }\end{array}$ & $\begin{array}{l}\text { Akhtar et al. } \\
2007 a\end{array}$ \\
\hline $\begin{array}{l}\text { Methyl parathion } \\
\text { pesticide }\end{array}$ & $\begin{array}{l}\text { Rice bran, } \\
\text { bagasse ash, } \\
\text { sgr.cane pod, } \\
\text { rice husk }\end{array}$ & $\begin{array}{l}110 \\
\mathrm{C} \\
8 \mathrm{~h}\end{array}$ & Ground & $\mathrm{L}$ & $\begin{array}{l}114, \\
114, \\
105, \\
102\end{array}$ & $1^{\text {st }}$ & Ex & Regenerate by sonication with methanol. & $\begin{array}{l}\text { Akhtar et al. } \\
\text { 2007b }\end{array}$ \\
\hline $\begin{array}{l}\text { Triazophos pesticid, } \\
\text { Methyl parathion }\end{array}$ & Chickpea husk & $\begin{array}{l}110 \\
24 \mathrm{~h}\end{array}$ & Crushed & $\mathrm{L}$ & $\begin{array}{l}2.4 \\
7.3\end{array}$ & $1^{\text {st }}$ & Ex & Successful sorbent & $\begin{array}{l}\text { Akhtar et al. } \\
2009\end{array}$ \\
\hline Phenol & $\begin{array}{l}\text { Activated } \\
\text { sludge, immob }\end{array}$ & - & - & $\begin{array}{l}\mathrm{L}, \\
\mathrm{F}\end{array}$ & - & - & - & $\mathrm{pH}=1$, slow flow best & $\begin{array}{l}\text { Aksu \& Gönen } \\
2004\end{array}$ \\
\hline
\end{tabular}




\begin{tabular}{|c|c|c|c|c|c|c|c|c|c|}
\hline Pollutant & Sorbent & 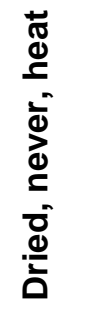 & 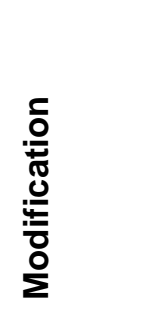 & 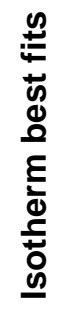 & $\begin{array}{l}\text { Adsorp. } \\
\text { capac. } \\
(\mathrm{mg} / \mathrm{g})\end{array}$ & 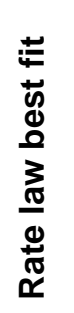 & 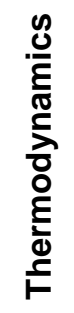 & Key Findings & Author (year) \\
\hline $\begin{array}{l}\text { 2,4-Dichlorophenoxy } \\
\text { acetic acid }(2,4-D)\end{array}$ & $\begin{array}{l}\text { Activated } \\
\text { carbon (gran) }\end{array}$ & $\mathrm{AC}$ & H-type & $\mathrm{L}$ & 518 & $\begin{array}{l}1^{\text {st }} \\
\text { ID }\end{array}$ & - & Best at $\mathrm{pH}=2$, intraparticle diffusion rate & $\begin{array}{l}\text { Aksu \& Kabas- } \\
\text { akal } 2003\end{array}$ \\
\hline $\begin{array}{l}\text { 2,4-Dichlorophenoxy } \\
\text { acetic acid }(2,4-D)\end{array}$ & $\begin{array}{l}\text { Activated } \\
\text { carbon (powd) }\end{array}$ & $A C$ & - & F, & 333 & ID & Ex & $\begin{array}{l}\text { Best at } \mathrm{pH}=2 \text {, film and intraparticle } \\
\text { diffusion, activation energy }-1.69 \mathrm{~kJ} \mathrm{~mole}^{-1}\end{array}$ & $\begin{array}{l}\text { Aksu \& Kabas- } \\
\text { akal } 2005\end{array}$ \\
\hline $\begin{array}{l}\text { Phenol, } \\
\text { o-Chlorophenol, } \\
\text { p-Chlorophenol }\end{array}$ & $\begin{array}{l}\text { Dried } \\
\text { activated } \\
\text { sludge }\end{array}$ & $60 \mathrm{C}$ & - & $\begin{array}{l}\mathrm{L}, \\
\mathrm{F}\end{array}$ & $\begin{array}{l}86 \\
102 \\
116\end{array}$ & - & - & Best at $\mathrm{pH}=1$, worst at $\mathrm{pH}=4$ & $\begin{array}{l}\text { Aksu \& Yener } \\
1998\end{array}$ \\
\hline $\begin{array}{l}\text { o-Chlorophenol, } \\
\text { p-Chlorophenol }\end{array}$ & $\begin{array}{l}\text { Activ. sludge, } \\
\text { Fly ash, } \\
\text { Gran. act. C } \\
\text { Activ. sludge, } \\
\text { Fly ash, } \\
\text { Gran. act. C }\end{array}$ & $\begin{array}{l}60 \mathrm{C} \\
- \\
\mathrm{AC} \\
60 \mathrm{C} \\
- \\
\mathrm{AC}\end{array}$ & - & $\mathrm{RP}$ & $\begin{array}{l}281 \\
99 \\
380 \\
287 \\
119 \\
422\end{array}$ & - & - & Best at $\mathrm{pH}=1$ & $\begin{array}{l}\text { Aksu \& Yener } \\
2001\end{array}$ \\
\hline 2,4-Dichlorophenol & $\begin{array}{l}\text { Activ. C from } \\
\text { oil palm EFB }\end{array}$ & $A C$ & $\begin{array}{l}\text { Activat. } \\
\text { in air }\end{array}$ & $\mathrm{L}$ & 27 & - & - & Best at $\mathrm{pH}=4$ & $\begin{array}{l}\text { Alam et al. } \\
2007\end{array}$ \\
\hline 2-Nitrophenol & $\begin{array}{l}\text { Hydrolysis } \\
\text { lignin }\end{array}$ & - & - & L & 2 & $2^{\text {nd }}$ & - & $\begin{array}{l}\text { Chemisorption is rate-limiting; listed } \\
\text { sorption capacity } 12 \mathrm{dm}^{3} / \mathrm{g} \text { seems wrong. }\end{array}$ & $\begin{array}{l}\text { Allen et al. } \\
2005\end{array}$ \\
\hline Phenol & $\begin{array}{l}\text { Active carbon, } \\
\text { granulated }\end{array}$ & $A C$ & $\begin{array}{l}\text { Thermal } \\
\text { regen. }\end{array}$ & $\mathrm{L}$ & $126-209$ & - & - & $\begin{array}{l}\text { Ozone thermal regeneration must be done } \\
\text { with great care or capacity is lost. }\end{array}$ & $\begin{array}{l}\text { Álvarez et al. } \\
2004\end{array}$ \\
\hline Gallic acid & $\begin{array}{l}\text { Active carbon, } \\
\text { granulated }\end{array}$ & $A C$ & $\begin{array}{l}\text { Ozone } \\
\text { regen. }\end{array}$ & L & $192-287$ & - & - & $\begin{array}{l}\text { Ozone dosage is critical it was better to } \\
\text { oxide adsorbed gallic avid vs. directly. }\end{array}$ & $\begin{array}{l}\text { Álvarez et al. } \\
2009\end{array}$ \\
\hline $\begin{array}{l}\text { Phenol, } \\
p \text {-Nitrophenol, } \\
p \text {-Chlorophenol }\end{array}$ & $\begin{array}{l}\text { Active carbon, } \\
\text { granulated }\end{array}$ & $A C$ & - & $\mathrm{L}$ & $\begin{array}{l}140-190 \\
190-390 \\
170-350\end{array}$ & - & - & $\begin{array}{l}\text { Microporosity and pi-pi interactions were } \\
\text { involved; surface oxygen groups catalyze } \\
\text { oxidative coupling of phenolics. }\end{array}$ & $\begin{array}{l}\text { Álvarez et al. } \\
2005\end{array}$ \\
\hline
\end{tabular}




\begin{tabular}{|c|c|c|c|c|c|c|c|c|c|}
\hline Pollutant & Sorbent & 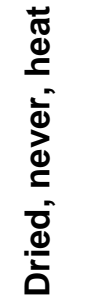 & 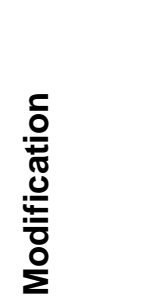 & 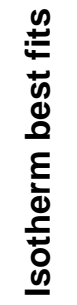 & $\begin{array}{l}\text { Adsorp. } \\
\text { capac. } \\
(\mathrm{mg} / \mathrm{g})\end{array}$ & 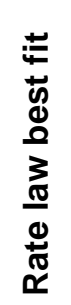 & 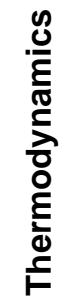 & Key Findings & Author (year) \\
\hline $\begin{array}{l}\text { Pyrene, } \\
\text { PCB-101 }\end{array}$ & $\begin{array}{l}\text { Active C from: } \\
\text { coconut shell, } \\
\text { anthracite. } \\
\text { coconut shell, } \\
\text { anthracite. }\end{array}$ & $\begin{array}{l}A C \\
A C \\
A C \\
A C\end{array}$ & $\begin{array}{l}- \\
- \\
-\end{array}$ & $\mathrm{F}$ & $\begin{array}{l}9 \\
11 \\
12 \\
13\end{array}$ & - & - & $\begin{array}{l}\text { The narrower pores of the bio-based } \\
\text { carbon were more easily clogged. }\end{array}$ & $\begin{array}{l}\text { Amstaetter et } \\
\text { al. } 2012\end{array}$ \\
\hline $\begin{array}{l}\text { Phenol, } \\
\text { p-chlorophenol, } \\
\text { p-nitrophenol }\end{array}$ & $\begin{array}{l}\text { Activ.carbon } \\
\text { from coir pith }\end{array}$ & $\mathrm{AC}$ & $\mathrm{H}_{3} \mathrm{PO}_{4}$ & $\mathrm{~F}$ & $\begin{array}{l}43 \\
63 \\
72 \\
\end{array}$ & UT & - & Best $\mathrm{pH}=6$; regeneration with $0.1 \mathrm{~N} \mathrm{NaOH}$ & $\begin{array}{l}\text { Anirudhan et al. } \\
2009\end{array}$ \\
\hline $\begin{array}{l}\text { Phenol, } \\
\text { Chlorophenol, } \\
\text { Trichlorophenol, } \\
\text { Pentachlorophenol }\end{array}$ & $\begin{array}{l}\text { Sandy aquifer } \\
\text { media (non- } \\
\text { viable bacteria } \\
\text { cells) }\end{array}$ & - & - & $\mathrm{F}$ & \begin{tabular}{|l|}
$2-3$ \\
$1-2$ \\
$5-15$ \\
$0.2-0.4$
\end{tabular} & - & - & $\begin{array}{l}\text { Lower pH favorable; adsorption was at } \\
\text { most weakly correlated to hydrophobicity. }\end{array}$ & $\begin{array}{l}\text { Antizar-L. \& } \\
\text { Galil } 2004\end{array}$ \\
\hline Phenol & $\begin{array}{l}\text { Green macro } \\
\text { algae }\end{array}$ & Air & $\begin{array}{l}\text { Crushed } \\
\mathrm{H}_{2} \mathrm{SO}_{4}\end{array}$ & $\mathrm{~L}$ & 20 & $2^{\text {nd }}$ & - & Best $\mathrm{pH}=6$ & $\begin{array}{l}\text { Aravindhan et } \\
\text { al. } 2009\end{array}$ \\
\hline Phenol & $\begin{array}{l}\text { Active carbon } \\
\text { from seaweed }\end{array}$ & $\mathrm{AC}$ & $\mathrm{ZnCl}_{2}$ & - & - & - & - & Best $\mathrm{pH}=3$ & $\begin{array}{l}\text { Aravindhan et } \\
\text { al. } 2011\end{array}$ \\
\hline Phenol & $\begin{array}{l}\text { Dried activat. } \\
\text { sludge }\end{array}$ & $\begin{array}{l}60 \mathrm{C} \\
24 \mathrm{~h}\end{array}$ & - & $\begin{array}{l}\mathrm{F} \\
\mathrm{L}\end{array}$ & 43 & $2^{\text {nd }}$ & En & Best $\mathrm{pH}=8$, weak function & $\begin{array}{l}\text { Arslan \& } \\
\text { Dursun } 2008\end{array}$ \\
\hline Naphthalene & $\begin{array}{l}\text { Aganate bead, } \\
\text { immob. cells }\end{array}$ & - & $\mathrm{Ca}^{2+}$ & $\begin{array}{l}\mathrm{L}, \\
\mathrm{F}, \\
\mathrm{DR}\end{array}$ & $\begin{array}{l}18 \\
12\end{array}$ & $2^{\text {nd }}$ & - & $\begin{array}{l}\text { Best } \mathrm{pH}>3 \text {; Adsorbent was adversely } \\
\text { affected by heavy metals. }\end{array}$ & $\begin{array}{l}\text { Ashour et al. } \\
2008\end{array}$ \\
\hline $\begin{array}{l}\text { Polycyclic aromatic } \\
\text { hydrocarbons }\end{array}$ & Active carbons & $A C$ & - & - & - & - & - & $\begin{array}{l}\text { Reduction in hydrocarbons was achieved; } \\
\text { combined sorption \& biodegradation. }\end{array}$ & $\begin{array}{l}\text { Augulyte et al. } \\
2008\end{array}$ \\
\hline $\begin{array}{l}\text { Polycyclic aromatic } \\
\text { hydrocarbons, etc. }\end{array}$ & $\begin{array}{l}\text { Biologically } \\
\text { active carbons }\end{array}$ & - & - & - & - & - & - & $\begin{array}{l}\text { Semipermeable membrane was used for } \\
\text { the separation; enzymatic action is key. }\end{array}$ & $\begin{array}{l}\text { Augulyte et al. } \\
2009\end{array}$ \\
\hline $\begin{array}{l}\text { Petroleum } \\
\text { components }\end{array}$ & $\begin{array}{l}\text { Two active } \\
\text { carbons }\end{array}$ & $A C$ & - & $\mathrm{F}$ & $400-2000$ & - & - & $\begin{array}{l}\text { Two contacting basins in series are } \\
\text { common. }\end{array}$ & $\begin{array}{l}\text { Ayotamuno et } \\
\text { al. } 2006\end{array}$ \\
\hline
\end{tabular}




\begin{tabular}{|c|c|c|c|c|c|c|c|c|c|}
\hline Pollutant & Sorbent & 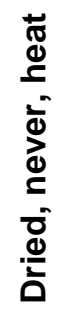 & 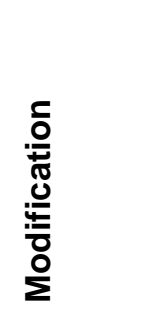 & 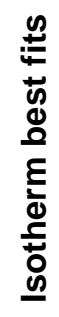 & $\begin{array}{l}\text { Adsorp. } \\
\text { capac. } \\
(\mathrm{mg} / \mathrm{g})\end{array}$ & 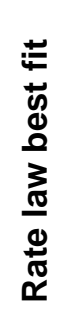 & 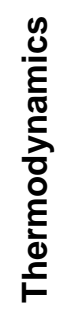 & Key Findings & Author (year) \\
\hline $\begin{array}{l}\text { Phenol, } \\
\text { Hydroquinone, } \\
\text { m-Cresol, } \\
\text { p-Cresol, } \\
\text { p-Nitrophenol }\end{array}$ & Active carbon & $\mathrm{AC}$ & - & $\mathrm{L}$ & $\begin{array}{l}173 \\
205 \\
244 \\
208 \\
292\end{array}$ & $1^{\text {st }}$ & - & Best pH at "as-is" condition & $\begin{array}{l}\text { Ayranci and } \\
\text { Duman } 2006\end{array}$ \\
\hline $\begin{array}{l}\text { Phenol, } \\
\text { Hydroquinone, } \\
\text { m-Cresol, } \\
p \text {-Cresol, } \\
p \text {-Nitrophenol }\end{array}$ & Active carbon & $\mathrm{AC}$ & - & - & - & - & - & $\begin{array}{l}\text { Best pH at "as-is" condition; Polanyi } \\
\text { adsorption potential theory applied; } \\
\text { adsorption was adversely affected by } \\
\text { salinity. }\end{array}$ & Aytekin 1991 \\
\hline Naphthalenic acids & $\begin{array}{l}\text { Active carbon } \\
\text { \& various }\end{array}$ & $\mathrm{AC}$ & - & - & 15 & - & - & $\begin{array}{l}\text { Salt sharply reduced sorption; odd } \\
\text { dependency on sorbent amount. }\end{array}$ & $\begin{array}{l}\text { Azad et al. } \\
2013\end{array}$ \\
\hline Benzene (\& ethanol) & $\begin{array}{l}\text { Active carbon } \\
\text { nanofibers }\end{array}$ & $A C$ & $\begin{array}{l}\text { Steam } \\
\text { activat. }\end{array}$ & - & - & - & - & $\begin{array}{l}\text { Electro-spinning of PAN; high adsorption } \\
\text { was attributed to small diameter fibers and } \\
\text { pi-pi interactions. }\end{array}$ & Bai et al. 2013 \\
\hline $\begin{array}{l}\text { Br-dichloromethan, } \\
\text { Benzene, } \\
\text { Carbon tetrachloride } \\
\text { Trichloromethane, } \\
\text { Chloroform, } \\
\text { Dichloromethane }\end{array}$ & $\begin{array}{l}\text { Pecan shell; } \\
\text { Pecan GAC }\end{array}$ & $\mathrm{AC}$ & $\begin{array}{l}\text { Steam, } \\
\mathrm{CO}_{2} \\
\mathrm{H}_{3} \mathrm{PO}_{4}\end{array}$ & - & - & - & - & $\begin{array}{l}\text { The steam-activated and phosphoric acid } \\
\text { activated pecan shell carbons achieved } \\
\text { sorption results similar to those of } \\
\text { commercial activated carbons, according } \\
\text { the principle component analysis. }\end{array}$ & $\begin{array}{l}\text { Bansode et al. } \\
2003\end{array}$ \\
\hline $\begin{array}{l}\text { Benzene, } \\
\text { Dichlorobenzene, } \\
\text { Phenanthrene }\end{array}$ & $\begin{array}{l}\text { Grasses: rye, } \\
\text { fescue, } \\
\text { spinach, roots }\end{array}$ & Yes & $\begin{array}{l}\text { Freeze- } \\
\text { dried }\end{array}$ & - & - & - & - & $\begin{array}{l}\text { Highest sorption was observed for the } \\
\text { least soluble organic species; lipids in the } \\
\text { grasses appeared to play a key role. }\end{array}$ & $\begin{array}{l}\text { Barbour et al. } \\
2005\end{array}$ \\
\hline $\begin{array}{l}\text { Phenol, } \\
\text { 2-Chlorophenol } \\
\text { Phenol, } \\
\text { 2-Chlorophenol }\end{array}$ & $\begin{array}{l}\text { Fungus pellet; } \\
\text { Dried fungus } \\
\text { pellet }\end{array}$ & $\begin{array}{l}- \\
- \\
90 C \\
90 C\end{array}$ & $\begin{array}{l}- \\
- \\
\text { Heated } \\
\text { Heated }\end{array}$ & $\mathrm{L}$ & $\begin{array}{l}133 \\
289 \\
42 \\
204\end{array}$ & $2^{\text {nd }}$ & - & $\begin{array}{l}\text { Best } \mathrm{pH}=8 \text {; drying reduced sorption } \\
\text { capacity. }\end{array}$ & $\begin{array}{l}\text { Bayramoglu } \\
2009\end{array}$ \\
\hline
\end{tabular}




\begin{tabular}{|c|c|c|c|c|c|c|c|c|c|}
\hline Pollutant & Sorbent & 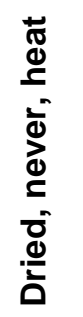 & 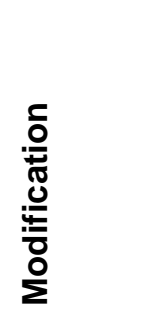 & 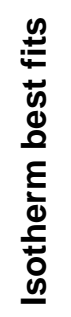 & $\begin{array}{l}\text { Adsorp. } \\
\text { capac. } \\
(\mathbf{m g} / \mathrm{g})\end{array}$ & 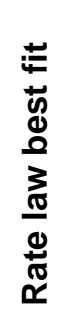 & 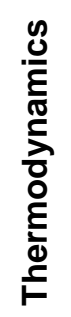 & Key Findings & Author (year) \\
\hline $\begin{array}{l}\text { Lindane, } \\
\text { Diazinon, } \\
\text { Malathion, } \\
\text { Pentachlorophenol, } \\
\text { 2-Chlorobiphenyl } \\
\text { Lindane, } \\
\text { Diazinon, } \\
\text { Malathion, } \\
\text { Pentachlorophenol, } \\
\text { 2-Chlorobiphenyl }\end{array}$ & $\begin{array}{l}\text { Rhizopus } \\
\text { arrhizus; } \\
\\
\text { Mixed } \\
\text { activated } \\
\text { sludge }\end{array}$ & $\begin{array}{l}\text { Vac } \\
\text { dr. } \\
\\
115 \\
\text { C }\end{array}$ & $\begin{array}{l}\text { Auto- } \\
\text { claved; } \\
\text { vacuum } \\
\text { dried } \\
\text { Oven } \\
\text { dried }\end{array}$ & $\mathrm{F}$ & $\begin{array}{l}3 \\
0.5 \\
13 \\
15 \\
109 \\
1.6 \\
0.5 \\
19 \\
3 \\
7 \\
\end{array}$ & -- & & $\begin{array}{l}\text { It is not clear whether the authors used } \\
\text { high enough concentrations to exceed the } \\
\text { adsorption capacities. }\end{array}$ & $\begin{array}{l}\text { Bell \& Tsezos } \\
1987\end{array}$ \\
\hline $\begin{array}{l}\text { Lindane, } \\
\text { Pentachlorophenol, } \\
\text { Diazinon, } \\
\text { Malathion } \\
\text { Lindane, } \\
\text { Pentachlorophenol, } \\
\text { Diazinon, } \\
\text { Malathion }\end{array}$ & $\begin{array}{l}\text { Rhizopus } \\
\text { arrhizus; } \\
\text { Mixed } \\
\text { activated } \\
\text { sludge }\end{array}$ & $\begin{array}{l}\text { Vac } \\
\text { dr. } \\
115 \\
\text { C }\end{array}$ & $\begin{array}{l}\text { Auto- } \\
\text { claved; } \\
\text { vacuum } \\
\text { dried } \\
\text { Oven } \\
\text { dried }\end{array}$ & - & - & - & - & $\begin{array}{l}\text { Results were consistent with "simple } \\
\text { adsorption", rather than competition; } \\
\text { bioconcentration factors were compared. }\end{array}$ & $\begin{array}{l}\text { Bell \& Tsezos } \\
1988\end{array}$ \\
\hline $\begin{array}{l}\text { Various solvents } \\
\text { used in synthesis of } \\
\text { pharmaceuticals }\end{array}$ & $\begin{array}{l}\text { Activated } \\
\text { charcoal gran. }\end{array}$ & $A C$ & - & - & - & - & - & $\begin{array}{l}\text { Pharmaceutical plant wastewater; fullerene } \\
\text { soot was } 10 X \text { more effective than activated } \\
\text { carbon, maybe due to pi-pi interactions. }\end{array}$ & $\begin{array}{l}\text { Berezkin et al. } \\
2002\end{array}$ \\
\hline $\begin{array}{l}\text { Gatifloxacin anti- } \\
\text { biotic drug }\end{array}$ & Chitin & $60 C$ & $\begin{array}{l}.1 \mathrm{~N} \mathrm{HCl}, \\
\mathrm{NaOH}\end{array}$ & $\mathrm{L}$ & $97-182$ & - & En & Best $\mathrm{pH}=6$ & $\begin{array}{l}\text { Bhowmik \& } \\
\text { Bajpai } 2012\end{array}$ \\
\hline 4-Chlorophenol & $\begin{array}{l}\text { Commercial } \\
\text { activated } \\
\text { carbon }\end{array}$ & $A C$ & - & $\begin{array}{l}\mathrm{L}, \\
\mathrm{T} \\
\mathrm{RP}\end{array}$ & 104-112 & $1 \mathrm{st}$ & Ex & - & $\begin{array}{l}\text { Bilgili et al. } \\
2012\end{array}$ \\
\hline
\end{tabular}




\begin{tabular}{|c|c|c|c|c|c|c|c|c|c|}
\hline Pollutant & Sorbent & 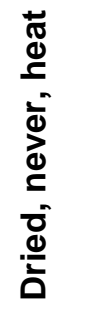 & 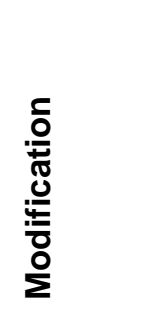 & 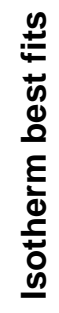 & $\begin{array}{l}\text { Adsorp. } \\
\text { capac. } \\
(\mathbf{m g} / \mathrm{g})\end{array}$ & 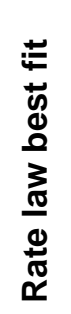 & 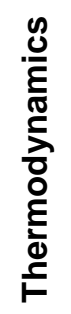 & Key Findings & Author (year) \\
\hline Ethylbenzene & $\begin{array}{l}\text { Carbon } \\
\text { nanotubes }\end{array}$ & - & - & - & $>100$ & - & - & $\begin{array}{l}\text { Evaluated at } \mathrm{pH}=7 \text {; the concentration of } \\
\text { sorbate may have been too low. }\end{array}$ & Bina et al. 2012 \\
\hline $\begin{array}{l}\text { Chlorohexidine; } \\
\text { Poly-hexamthylene- } \\
\text { biguanide }\end{array}$ & $\begin{array}{l}\text { Bleached } \\
\text { cotton }\end{array}$ & - & - & $\mathrm{L}$ & $3-7$ & - & - & $\begin{array}{l}\text { Electrostatic \& hydrogen bonding; } \\
\text { agglomerate of sorbate at higher } \\
\text { concentrations }\end{array}$ & $\begin{array}{l}\text { Blackburn et al. } \\
2007\end{array}$ \\
\hline $\begin{array}{l}\text { Catechol, } \\
\text { Hydroquinone, } \\
\text { Resourcinol }\end{array}$ & $\begin{array}{l}\text { Activated } \\
\text { carbons }\end{array}$ & $\mathrm{AC}$ & $\mathrm{H}_{2}$ flow & $\mathrm{L}$ & $\begin{array}{l}178-238 \\
169-233 \\
163-233 \\
\end{array}$ & - & - & $\begin{array}{l}\text { Lower } \mathrm{pH} \text { was favorable for adsorption; } \\
\text { oxidation \& reduction treatments had } \\
\text { inconsistent effects. }\end{array}$ & $\begin{array}{l}\text { Blanco-M. et al. } \\
2009\end{array}$ \\
\hline $\begin{array}{l}\text { Benz[a]anthracene, } \\
\text { Chrysene, } \\
\text { Benzo[b]fluoranthen, } \\
\text { Benzo[k]fluoranthen, } \\
\text { Benzo[a]pyrene }\end{array}$ & $\begin{array}{l}\text { Insoluble } \\
\text { dietary fiber } \\
\text { (barley leaves) }\end{array}$ & $\begin{array}{l}100 \\
C \\
24 h\end{array}$ & Amylase & - & $14-37$ & - & - & $\begin{array}{l}\text { The concentration of sorbate may have } \\
\text { been too low. }\end{array}$ & Boki et al. 2007 \\
\hline $\begin{array}{l}\text { Carbaryl, } \\
\text { Atrazine, } \\
\text { Parathion pesticides }\end{array}$ & $\begin{array}{l}\text { Oilseed press } \\
\text { cake }\end{array}$ & - & $\begin{array}{l}\text { Optional } \\
\text { extrac., } \\
\text { grinding }\end{array}$ & - & $1-2$ & - & - & $\begin{array}{l}\text { Adsorption was associated with residual } \\
\text { oils in the press-cake.; ground seeds were } \\
\text { much less effective sorbents. }\end{array}$ & $\begin{array}{l}\text { Boucher et al. } \\
2007\end{array}$ \\
\hline 4,4-DDT & $\begin{array}{l}\text { Wood sawdust } \\
\text { Cork waste } \\
\text { Active carbon }\end{array}$ & $\begin{array}{l}110 \\
\mathrm{C} 24 \\
\mathrm{~h}\end{array}$ & Ground & $\mathrm{L}$ & $\begin{array}{l}69 \\
19 \\
164 \\
\end{array}$ & $\begin{array}{l}2^{\text {nd }} \\
\text { ID }\end{array}$ & - & $\begin{array}{l}\text { Diffusion (boundary \& intraparticle) rate } \\
\text { control; adsorption was negatively affected } \\
\text { by organic matter in the water. }\end{array}$ & $\begin{array}{l}\text { Boussahel et } \\
\text { al. } 2009\end{array}$ \\
\hline $\begin{array}{l}\text { Naphthalene, } \\
\text { Fluorene, } \\
\text { Anthracene, } \\
\text { Pyrene }\end{array}$ & $\begin{array}{l}\text { Aspen wood } \\
\text { fibers }\end{array}$ & - & As rec'd & - & - & - & - & $\begin{array}{l}\text { Uptake proportional to octanol-water } \\
\text { partition coefficients; judged to be effective } \\
\text { for decontaminating storm runoff. }\end{array}$ & $\begin{array}{l}\text { Boving \& } \\
\text { Zhang } 2004\end{array}$ \\
\hline Pentachlorophenol & $\begin{array}{l}\text { Mycobacter- } \\
\text { ium chlorophe. }\end{array}$ & No & Viable & $\mathrm{F}$ & $>12$ & - & - & $\begin{array}{l}\text { Acidic } \mathrm{pH} \text { favors sorption; desorption at } \\
\text { neutral } \mathrm{pH} \text {; added amount probably below } \\
\text { capacity of sorbent. }\end{array}$ & $\begin{array}{l}\text { Brandt et al. } \\
1997\end{array}$ \\
\hline Pentachlorophenol & Pine bark & $\begin{array}{l}105 \\
\mathrm{C}\end{array}$ & Ground & $\mathrm{L}$ & 9 & - & - & $\begin{array}{l}\text { The bark had low porosity, low surface } \\
\text { area, but high aromatic character. }\end{array}$ & Brás et al. 2004 \\
\hline
\end{tabular}




\begin{tabular}{|c|c|c|c|c|c|c|c|c|c|}
\hline Pollutant & Sorbent & 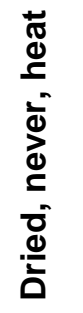 & 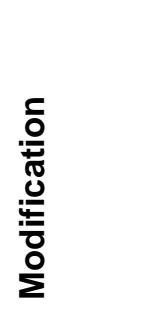 & 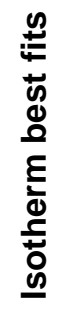 & $\begin{array}{l}\text { Adsorp. } \\
\text { capac. } \\
(\mathrm{mg} / \mathrm{g})\end{array}$ & 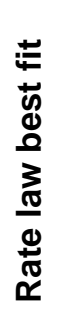 & 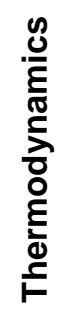 & Key Findings & Author (year) \\
\hline Pentachlorophenol & Pine bark & $\begin{array}{l}105 \\
\mathrm{C}\end{array}$ & Ground & $\mathrm{L}$ & 3 & - & - & $\begin{array}{l}\text { Best at low pH, no significant temperature } \\
\text { effect was observed. }\end{array}$ & Brás et al. 2005 \\
\hline $\begin{array}{l}\text { Heptachlor, Aldrin, } \\
\text { Endrin, Dieldrin, } \\
\text { DDD, DDT, DDE }\end{array}$ & Pine bark & $\begin{array}{l}105 \\
\mathrm{C}\end{array}$ & Ground & - & - & - & - & $\begin{array}{l}\text { A low concentration range was considered, } \\
\text { so it was not possible to estimate } \\
\text { adsorption capacities. }\end{array}$ & Brás et al. 1999 \\
\hline $\begin{array}{l}15 \text { organic } \\
\text { compounds }\end{array}$ & $\begin{array}{l}\text { Activated } \\
\text { carbon cloth }\end{array}$ & $\mathrm{AC}$ & $\begin{array}{l}\text { Three } \\
\text { types }\end{array}$ & - & - & - & - & $\begin{array}{l}\text { Surface area and microporosity were found } \\
\text { to be critical. Mesoporous carbon was } \\
\text { more effective for larger molecules. }\end{array}$ & $\begin{array}{l}\text { Brasquet \& Le } \\
\text { Cloirec } 1999\end{array}$ \\
\hline Phenol & $\begin{array}{l}\text { Gran. act. C, } \\
\text { Fibrous act. C }\end{array}$ & $A C$ & - & $\mathrm{L}$ & $\begin{array}{l}150 \\
183 \\
\end{array}$ & - & - & $\begin{array}{l}\text { Selectivity based on the size of the } \\
\text { micropollutant molecule. }\end{array}$ & $\begin{array}{l}\text { Brasquet et al. } \\
1996\end{array}$ \\
\hline $\begin{array}{l}\text { Trichloroethylene, } \\
\text { Chloroform }\end{array}$ & Active carbon & $A C$ & - & & $10-60$ & - & - & $\begin{array}{l}\text { Adsorption was correlated to Hildebrand } \\
\text { parameters. }\end{array}$ & $\begin{array}{l}\text { Browne \& } \\
\text { Cohen } 1990\end{array}$ \\
\hline $\begin{array}{l}\text { Fluometuron, } \\
\text { Chloromethylpenoxy } \\
\text { acetic acid (MCPA) }\end{array}$ & $\begin{array}{l}\text { Biochars (six } \\
\text { different } \\
\text { types) }\end{array}$ & $\mathrm{BC}$ & - & - & $\begin{array}{l}0.05-2.0 \\
0.05-0.3\end{array}$ & - & - & $\begin{array}{l}\text { High-area chars decreased leaching, } \\
\text { except that soluble components gave } \\
\text { greater leaching in some cases. }\end{array}$ & $\begin{array}{l}\text { Cabrera et al. } \\
2011\end{array}$ \\
\hline Benzene & $\begin{array}{l}\text { Active carbon } \\
\text { fiber cloth }\end{array}$ & $\mathrm{AC}$ & - & $\mathrm{F}$ & $300-375$ & - & - & $\begin{array}{l}\text { Mean pore size, BET surface area, and } \\
\text { pore volume were key variables. }\end{array}$ & Cal et al. 1994 \\
\hline $\begin{array}{l}\text { Phenol } \\
\text { 2-Chlorophenol, } \\
\text { 3-Chlorophenol, } \\
\text { 4-Chlorophenol, } \\
\text { 2-Nitrophenol, } \\
\text { 2,4-Dichlorophenol, } \\
\text { 3,4-Dichlorophenol, } \\
\text { 3,5-Dichlorophenol, } \\
\text { 2,4,5-trichlorophenol }\end{array}$ & $\begin{array}{l}\text { Paper mill } \\
\text { sludge }\end{array}$ & Dry & $\mathrm{pH} 8.4$ & LF & $\begin{array}{l}0.4 \\
0.1 \\
0.35 \\
0.2 \\
0.1 \\
2 \\
2.5 \\
3 \\
2.5 \\
\end{array}$ & - & - & $\begin{array}{l}\text { Particle diffusion was not the only } \\
\text { controlling mechanism. }\end{array}$ & $\begin{array}{l}\text { Calace et al. } \\
2002\end{array}$ \\
\hline $\begin{array}{l}\text { Phenol } \\
\text { p-Nitrophenol }\end{array}$ & Active carbon & $A C$ & - & - & - & - & - & Pore diffusion & $\begin{array}{l}\text { Calleja et al. } \\
1993\end{array}$ \\
\hline
\end{tabular}




\begin{tabular}{|c|c|c|c|c|c|c|c|c|c|}
\hline Pollutant & Sorbent & 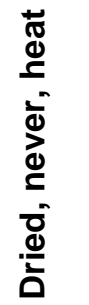 & 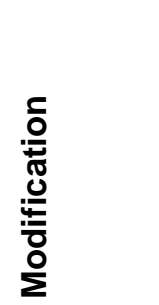 & 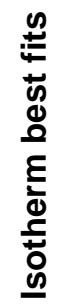 & $\begin{array}{l}\text { Adsorp. } \\
\text { capac. } \\
(\mathrm{mg} / \mathrm{g})\end{array}$ & 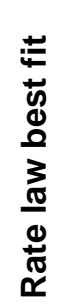 & 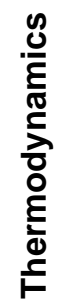 & Key Findings & Author (year) \\
\hline Atrazine & $\begin{array}{l}\text { Biochar from } \\
\text { manure } \\
\text { Active carbon }\end{array}$ & $\begin{array}{l}25 \\
200 \\
350 \\
-\end{array}$ & - & - & $\begin{array}{l}10 \\
18 \\
12 \\
117\end{array}$ & - & - & $\begin{array}{l}\text { Competition was observed between lead } \\
\text { and atrazine for adsorption on activated } \\
\text { carbon. }\end{array}$ & Cao et al. 2009 \\
\hline $\begin{array}{l}2,4-D, \\
\text { Paraquat }\end{array}$ & Polymerin & - & $\begin{array}{l}\text { From } \\
\text { olive mill } \\
\text { waste } \\
\text { water }\end{array}$ & $\mathrm{L}$ & $\begin{array}{l}14.7-40.5 \\
137-233\end{array}$ & - & - & Humic-like sorbents & $\begin{array}{l}\text { Capasso \& De } \\
\text { Martino } 2010\end{array}$ \\
\hline $\begin{array}{l}\text { Phenol, } \\
\text { 4-Nitrophenol, } \\
\text { 2,4-Dinitrophenol, } \\
\text { 4-Chlorophenol, } \\
\text { 2,4-Dichlorophenol }\end{array}$ & Active carbon & $A C$ & $\begin{array}{l}\text { From } \\
\text { olive } \\
\text { stones }\end{array}$ & $\mathrm{L}$ & $\begin{array}{l}246 \\
306 \\
307 \\
316 \\
333 \\
\end{array}$ & - & - & $\begin{array}{l}\text { Pore size and surface acidity were } \\
\text { important. }\end{array}$ & $\begin{array}{l}\text { Caturla et al. } \\
1988\end{array}$ \\
\hline $\begin{array}{l}\text { Di(ethylhexyl)phthal } \\
\text { ate (DEHP) }\end{array}$ & $\begin{array}{l}\text { Sargassum s } \\
\text { seaweed }\end{array}$ & $\begin{array}{l}60 \mathrm{C} \\
24 \mathrm{~h}\end{array}$ & $\begin{array}{l}\text { Option: } \\
\text { bleach }\end{array}$ & - & - & - & - & $\begin{array}{l}\text { Photocatalytic oxidation of the adsorbed } \\
\text { toxin was very effective. }\end{array}$ & $\begin{array}{l}\text { Chan et al. } \\
2007\end{array}$ \\
\hline $\begin{array}{l}\text { Phenanthrene, } \\
\text { Fluoranthrene, } \\
\text { Pyrene }\end{array}$ & $\begin{array}{l}\text { Selenastrum c } \\
\text { green alga }\end{array}$ & - & - & - & - & - & - & Degradation pathway evidence & $\begin{array}{l}\text { Chan et al. } \\
2006\end{array}$ \\
\hline Toluene & $\begin{array}{l}\text { Gran. active } \\
\text { carbon bed }\end{array}$ & - & - & FS & $163-267$ & - & - & $\begin{array}{l}\text { Homogeneous surface diffusion limited; } \\
\text { breakthrough curves modeled; desorption }\end{array}$ & $\begin{array}{l}\text { Chatzopoulos } \\
\text { \& Varma } 1995\end{array}$ \\
\hline Toluene & $\begin{array}{l}\text { Gran. active } \\
\text { carbon bed }\end{array}$ & - & - & FS & 250 & - & - & $\begin{array}{l}\text { Homogeneous surface diffusion limited; } \\
\text { breakthrough curves modeled; desorption }\end{array}$ & $\begin{array}{l}\text { Chatzopoulos } \\
\text { et al. } 1994\end{array}$ \\
\hline $\begin{array}{l}\text { Naphthalene, } \\
\text { 1-Naphthol }\end{array}$ & $\begin{array}{l}\text { Nine biochars } \\
\text { from orange } \\
\text { peel }\end{array}$ & $\mathrm{BC}$ & $\begin{array}{l}150-700 \\
\text { C limited } \\
\text { oxygen }\end{array}$ & $\begin{array}{l}\text { Lin } \\
F\end{array}$ & $\begin{array}{l}2-30+ \\
20-100_{+}\end{array}$ & - & - & $\begin{array}{l}\text { Increasing temperature caused transition } \\
\text { from linear to Freundlich adsorption; a } \\
\text { polar effect seems to have been important. }\end{array}$ & $\begin{array}{l}\text { Chen \& Chen } \\
2009\end{array}$ \\
\hline Phenanthrene & $\begin{array}{l}\text { Root tissue } \\
\text { fractions }\end{array}$ & $75 \mathrm{C}$ & $\begin{array}{l}\text { Optional } \\
\text { saponif. }\end{array}$ & - & $>2$ & - & - & $\begin{array}{l}\text { The suberin component was found to have } \\
\text { high sorption capacity. }\end{array}$ & $\begin{array}{l}\text { Chen \& } \\
\text { Schnoor } 2009\end{array}$ \\
\hline
\end{tabular}




\begin{tabular}{|c|c|c|c|c|c|c|c|c|c|}
\hline Pollutant & Sorbent & 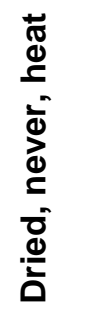 & 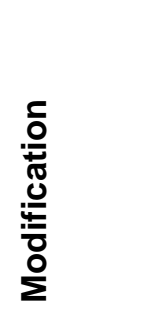 & 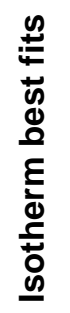 & $\begin{array}{l}\text { Adsorp. } \\
\text { capac. } \\
(\mathrm{mg} / \mathrm{g})\end{array}$ & 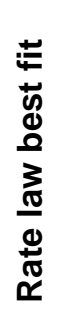 & 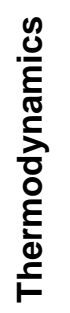 & Key Findings & Author (year) \\
\hline $\begin{array}{l}\text { Naphthalene, } \\
\text { Nitrobenzene, } \\
\text { m-dinitrobenzene }\end{array}$ & $\begin{array}{l}\text { Biochar from } \\
\text { pine needles }\end{array}$ & $\begin{array}{l}100- \\
700 \\
C\end{array}$ & $1 \mathrm{M} \mathrm{HCl}$ & - & $100-450$ & - & - & Higher heating yielded higher sorption. & $\begin{array}{l}\text { Chen et al. } \\
2008\end{array}$ \\
\hline $\begin{array}{l}\text { Phenanthrene, } \\
\text { Pyrene }\end{array}$ & $\begin{array}{l}\text { Phanero- } \\
\text { chaete } c .\end{array}$ & - & $\begin{array}{l}\text { Viable } \\
\text { mycelia }\end{array}$ & $\mathrm{F}$ & - & - & - & $\begin{array}{l}\text { Combined biosorption \& biodegradation } \\
\text { shown. }\end{array}$ & $\begin{array}{l}\text { Chen \& Ding } \\
2012\end{array}$ \\
\hline $\begin{array}{l}\text { Naphthanlene, } \\
\text { Phenanthrene, } \\
\text { Phenol, } \\
\text { 1-Napthol }\end{array}$ & $\begin{array}{l}\text { Plant cuticles } \\
\text { (green pepper } \\
\text { fractions) }\end{array}$ & FD & $\begin{array}{l}\text { Boil, } \\
\text { freeze- } \\
\text { dry, } \\
\text { grind; } \\
\text { Dewax }\end{array}$ & $F$ & $\begin{array}{l}1-20 \\
1-10 \\
100-400 \\
10-200\end{array}$ & - & - & $\begin{array}{l}\text { Polarity of the solute and accessibility to } \\
\text { surface sites were key factors; Low affinity } \\
\text { behavior apparent. }\end{array}$ & $\begin{array}{l}\text { Chen et al. } \\
2005\end{array}$ \\
\hline 1-Napthol & $\begin{array}{l}\text { Tomato cuticle } \\
\text { sheet fractions }\end{array}$ & Dry & $\begin{array}{l}\text { Oxalic, } \\
\text { dewax }\end{array}$ & $\mathrm{F}$ & $40-160$ & - & - & $\begin{array}{l}\text { Cutin makes a key contribution to sorption; } \\
\text { hydrophobic and } \mathrm{H} \text {-bonding interactions. }\end{array}$ & Chen \& Li 2007 \\
\hline $\begin{array}{l}\text { Naphthanlene, } \\
\text { Acenaphthene, } \\
\text { Fluorene, } \\
\text { Phenanthrene, } \\
\text { Pyrene }\end{array}$ & White rot fungi & $\begin{array}{l}-, \\
60 \mathrm{C} \\
24 \mathrm{~h}\end{array}$ & $\begin{array}{l}\text { Live, } \\
\text { killed }\end{array}$ & $\mathrm{F}$ & - & - & - & $\begin{array}{l}\text { Biosorption might restrict biodegradation; } \\
\text { low affinity behavior. }\end{array}$ & $\begin{array}{l}\text { Chen et al. } \\
2010\end{array}$ \\
\hline $\begin{array}{l}\text { Naphthalene, } \\
\text { Acenaphthene, } \\
\text { Fluorene } \\
\text { Phenanathrene } \\
\text { Pyrene }\end{array}$ & $\begin{array}{l}\text { Wood chips, } \\
\text { ryegrass } \\
\text { roots, orange } \\
\text { peels, bamboo } \\
\text { leaves, pine } \\
\text { needles }\end{array}$ & $\begin{array}{l}\text { Air } \\
25 \mathrm{C}\end{array}$ & Ground & $\mathrm{F}$ & $0-1.5$ & - & - & $\begin{array}{l}\text { Low affinity; removal of polar components } \\
\text { by acid hydrolysis increased uptake. }\end{array}$ & $\begin{array}{l}\text { Chen et al. } \\
2011\end{array}$ \\
\hline Phenol & $\begin{array}{l}\text { Mesoporous } \\
\text { active carbon } \\
\text { fr. pokeweed }\end{array}$ & $\mathrm{AC}$ & $\begin{array}{l}450 \\
\text { then } \\
900 \mathrm{C}\end{array}$ & L & 172 & - & - & $\begin{array}{l}\text { Potassium in the pokeweed helps activate } \\
\text { the carbon. }\end{array}$ & $\begin{array}{l}\text { Chen et al. } \\
2012 \mathrm{a}\end{array}$ \\
\hline
\end{tabular}




\begin{tabular}{|c|c|c|c|c|c|c|c|c|c|}
\hline Pollutant & Sorbent & 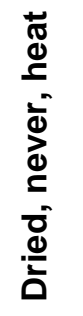 & 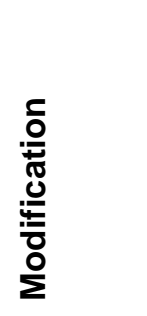 & 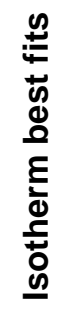 & $\begin{array}{l}\text { Adsorp. } \\
\text { capac. } \\
(\mathrm{mg} / \mathrm{g})\end{array}$ & 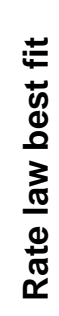 & 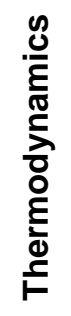 & Key Findings & Author (year) \\
\hline Naphthalene & Biochar series & $\mathrm{BC}$ & $150-700$ & $\mathrm{~F}$ & $0.02-177$ & - & - & $\begin{array}{l}\text { Diffusivity was the key factor; low affinity } \\
\text { behavior evident; intermediate temp the } \\
\text { micropores were hard to access; capacity } \\
\text { increased with carbonation temperature. }\end{array}$ & $\begin{array}{l}\text { Chen et al. } \\
2012 b\end{array}$ \\
\hline $\begin{array}{l}\text { Naphthalene, } \\
\text { 1,2-Dichlorobenzene }\end{array}$ & $\begin{array}{l}\text { C-60 (Bucky- } \\
\text { balls) }\end{array}$ & - & - & - & $5-50$ & - & En & $\begin{array}{l}\text { Low affinity behavior; best results when } \\
\text { C60 was well dispersed in water. }\end{array}$ & $\begin{array}{l}\text { Cheng et al. } \\
2005\end{array}$ \\
\hline Phenol & $\begin{array}{l}\text { Loofa vegetal } \\
\text { cords }\end{array}$ & 105 & $\begin{array}{l}\mathrm{NaOH} \\
\text { bleach }\end{array}$ & $\mathrm{L}$ & 5 & - & En & $\begin{array}{l}\text { Bleaching with peroxide increased uptake } \\
\text { greatly. }\end{array}$ & $\begin{array}{l}\text { Cherifi et al. } \\
2009\end{array}$ \\
\hline p-Nitrophenol & Active carbon & $\mathrm{AC}$ & - & $\begin{array}{l}\mathrm{F} \\
\mathrm{RP}\end{array}$ & 4 & - & Ex & Breakthrough curves & $\begin{array}{l}\text { Chern \& Chien } \\
2002\end{array}$ \\
\hline Toluene vapor & $\begin{array}{l}\text { Peats (2), } \\
\text { Compost }\end{array}$ & $\begin{array}{l}65 \mathrm{C} \\
48 \mathrm{~h}\end{array}$ & - & - & $\begin{array}{l}0.5-14 \\
1-4\end{array}$ & - & - & Pore filling mechanism & Chiu et al. 2003 \\
\hline $\begin{array}{l}\text { 1,2,3,4-Tetrachlor. } \\
\text { Dibenzofuran, } \\
\text { PCDD/Fs, } \\
\text { PCBs } \\
\text { Chlorobenzenes, } \\
\text { Chloronaphthalenes }\end{array}$ & $\begin{array}{l}\text { Bacillus pumil. } \\
\text { exudates }\end{array}$ & - & $\begin{array}{l}\text { Boiled } \\
\text { to } \\
\text { release } \\
\text { chems. }\end{array}$ & - & - & - & - & $\begin{array}{l}\text { Uptake amounts are expressed based on } \\
\text { volume of sorbent, not mass; hard to } \\
\text { compare; proteins sorbed much more than } \\
\text { the carbohydrates or the insulin. }\end{array}$ & Choi et al. 2003 \\
\hline 1-Methlcyclpropene & $\begin{array}{l}\text { Fruit \& veg. } \\
\text { tissues }\end{array}$ & $\begin{array}{l}\text { No, } \\
\text { Yes }\end{array}$ & $50 C$ & - & - & - & - & $\begin{array}{l}\text { External tissues had greater sorption; } \\
\text { drying reduced sorption; pectins \& lignin } \\
\text { were sinks for sorption; rates compared. }\end{array}$ & $\begin{array}{l}\text { Choi \& Huber. } \\
2009\end{array}$ \\
\hline Benzene & $\begin{array}{l}\text { Active carbon } \\
\text { bed }\end{array}$ & $A C$ & - & - & 650 & - & Ex & Simulation based on kinetic model. & $\begin{array}{l}\text { Chuang et al. } \\
2003 a\end{array}$ \\
\hline Benzene vapor & $\begin{array}{l}\text { Active carbon } \\
\text { bed }\end{array}$ & $A C$ & - & $\mathrm{L}$ & $200-450$ & - & Ex & Simulation based on kinetic model. & $\begin{array}{l}\text { Chuang et al. } \\
2003 a\end{array}$ \\
\hline $\begin{array}{l}\text { Perfluorooctane } \\
\text { sulfonate }\end{array}$ & $\begin{array}{l}\text { Granulated } \\
\text { active carbon }\end{array}$ & $A C$ & - & $\mathrm{F}$ & 455 & - & - & $\begin{array}{l}\text { Regeneration highly successful with } \\
\text { methanol solutions of } \mathrm{NaOH}, \mathrm{NaCl} \text {. }\end{array}$ & $\begin{array}{l}\text { Chularueang- } \\
\text { aksorn } 2013\end{array}$ \\
\hline
\end{tabular}




\begin{tabular}{|c|c|c|c|c|c|c|c|c|c|}
\hline Pollutant & Sorbent & 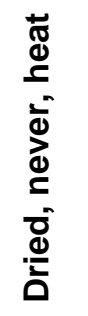 & 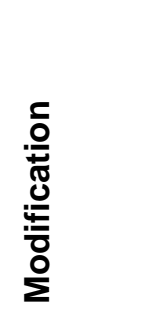 & 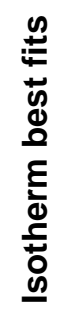 & $\begin{array}{l}\text { Adsorp. } \\
\text { capac. } \\
\text { (mg/g) }\end{array}$ & 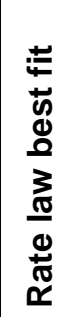 & 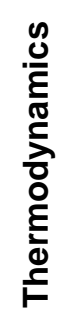 & Key Findings & Author (year) \\
\hline Phenanthrene & $\begin{array}{l}\text { Sargassum } \\
\text { hemiphyllum }\end{array}$ & $\begin{array}{l}50 \mathrm{C} \\
16 \mathrm{~h}\end{array}$ & - & - & $0.4-0.5$ & $2^{\text {nd }}$ & En & Shaking sped up sorption. & $\begin{array}{l}\text { Chung et al. } \\
2007\end{array}$ \\
\hline $\begin{array}{l}\text { Benzene } \\
\text { Toluene } \\
\text { Ethylbenzene } \\
\text { m,p-Xylenes } \\
\text { o-Xylene }\end{array}$ & $\begin{array}{l}\text { Angico } \\
\text { sawdust \& } \\
\text { peat }\end{array}$ & $\begin{array}{l}\text { Air } \\
25 \mathrm{C}\end{array}$ & None & $\mathrm{L}$ & $\begin{array}{l}0.002 \text { to } \\
0.011 \\
\text { reported } \\
\text { for whole } \\
\text { set }\end{array}$ & - & - & Peat performed better than the sawdust. & $\begin{array}{l}\text { Costa et al. } \\
2012\end{array}$ \\
\hline $\begin{array}{l}\text { Phenol, } \\
\text { Nitrobenzene }\end{array}$ & Carbon & $\mathrm{BC}$ & $\begin{array}{l}\text { Acidity } \\
\text { content }\end{array}$ & - & $\begin{array}{l}10-100 \\
50-200\end{array}$ & - & - & $\begin{array}{l}\text { Oxygen content of carbon suppressed } \\
\text { adsorption. }\end{array}$ & $\begin{array}{l}\text { Coughlin \& } \\
\text { Ezra } 1968\end{array}$ \\
\hline $\begin{array}{l}\text { Phenol, } \\
\text { Nitrobenzene, } \\
\text { Na benzenesolufon. }\end{array}$ & Carbon & $\mathrm{BC}$ & - & - & $\begin{array}{l}10-100 \\
50-200 \\
-\end{array}$ & - & - & $\begin{array}{l}\text { Dilute phenol adsorption was reduced by } \\
\text { oxygenated sites. }\end{array}$ & $\begin{array}{l}\text { Coughlin et al. } \\
1968\end{array}$ \\
\hline $\begin{array}{l}\text { Naphthalene, } \\
\text { Acenaphthene, } \\
\text { Anthrene } \\
\text { Pyrene } \\
\end{array}$ & $\begin{array}{l}\text { Bagasse, } \\
\text { Green cocon., } \\
\text { Chitosan, } \\
\text { Chitin } \\
\end{array}$ & Dry & - & $\mathrm{F}$ & $0.1-0.8$ & - & - & $\begin{array}{l}\text { Lignin seemed to be mainly responsible for } \\
\text { adsorption. }\end{array}$ & $\begin{array}{l}\text { Crisafully et al. } \\
2008\end{array}$ \\
\hline p-Nitrophenol & $\begin{array}{l}\text { Active carbon } \\
\text { fr. cedar wood }\end{array}$ & $\mathrm{AC}$ & $\begin{array}{l}\mathrm{H}_{2} \mathrm{SO}_{4} \& \\
\mathrm{CO}_{2}\end{array}$ & L & $300-630$ & - & - & $\begin{array}{l}\text { Surface sulfur appeared to inhibit uptake of } \\
\text { p-nitrophenol; previous dehydration } \\
\text { favored activation \& adsorption. }\end{array}$ & $\begin{array}{l}\text { CuerdaCorrea } \\
\text { et al. } 2006\end{array}$ \\
\hline $\begin{array}{l}\text { Chloroform, } \\
\text { DiClBrmethane, } \\
\text { Bromoform }\end{array}$ & $\begin{array}{l}\text { Humin from } \\
\text { peat bog }\end{array}$ & $\begin{array}{l}\text { Air } \\
25 \mathrm{C}\end{array}$ & Ground & - & $18-21$ & $2^{\text {nd }}$ & - & Humin was found to be effective. & $\begin{array}{l}\text { Cunha et al. } \\
2010\end{array}$ \\
\hline $\begin{array}{l}\text { Phenol, } \\
\text { Cresols, } \\
\text { Nitrophenols, } \\
\text { Chlorophenols }\end{array}$ & Active carbon & $\mathrm{AC}$ & $\mathrm{H}_{3} \mathrm{PO}_{4}$ & L & $232-339$ & - & - & $\begin{array}{l}\text { Uptake was inversely proportional to } \\
\text { solubility and pK } \mathrm{K}_{\mathrm{a}} \text {; uptake also correlated to } \\
\text { molecular size; they did not measure pH or } \\
\text { temperature. }\end{array}$ & $\begin{array}{l}\text { Daifullah \& } \\
\text { Girgis } 1998\end{array}$ \\
\hline
\end{tabular}




\begin{tabular}{|c|c|c|c|c|c|c|c|c|c|}
\hline Pollutant & Sorbent & 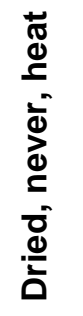 & $\frac{c}{\stackrel{0}{7}}$ & 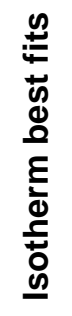 & $\begin{array}{l}\text { Adsorp. } \\
\text { capac. } \\
(\mathbf{m g} / \mathrm{g})\end{array}$ & 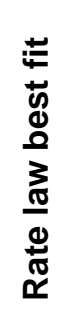 & 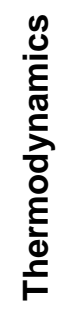 & Key Findings & Author (year) \\
\hline $\begin{array}{l}\text { BTEX: Benzene, } \\
\text { Toluene, } \\
\text { Ethylbenzene, } \\
\text { Xylene }\end{array}$ & $\begin{array}{l}\text { Active carbon } \\
\text { fr. date pits, } \\
\text { cotton stalk, } \\
\text { peach stones, } \\
\text { almond shell, } \\
\text { olive stone }\end{array}$ & $\mathrm{AC}$ & $\begin{array}{l}\mathrm{H}_{3} \mathrm{PO}_{4} \\
\text { post-tr., } \\
773 \mathrm{~K}\end{array}$ & - & $\begin{array}{l}1-9 \\
4-9 \\
5-9 \\
5-10\end{array}$ & - & - & $\begin{array}{l}\mathrm{B}<\mathrm{T}<\mathrm{E}<\mathrm{X} \text { uptake consistent with } \\
\text { decreasing solubility and increasing } \\
\text { molecular weight; air oxidation gave higher } \\
\text { uptake per unit area. }\end{array}$ & $\begin{array}{l}\text { Daifullah \& } \\
\text { Girgis } 2003\end{array}$ \\
\hline $\begin{array}{l}\text { Quinalphos, } \\
\text { Lindane pesticides }\end{array}$ & $\begin{array}{l}\text { Bio-activated } \\
\text { carbon }\end{array}$ & - & $\begin{array}{l}\text { Danube } \\
\text { River } \\
\text { flora }\end{array}$ & - & - & - & - & $\begin{array}{l}\text { Adsorption \& microbiological degradation } \\
\text { happen simultaneously; the system worked } \\
\text { better for the quinalphos; flow-through. }\end{array}$ & $\begin{array}{l}\text { Dalmacija et al. } \\
1992\end{array}$ \\
\hline $\begin{array}{l}\text { Phenol and its } \\
\text { successively } \\
\text { coupled multimers }\end{array}$ & Active carbon & $A C$ & - & $\mathrm{L}$ & $20-90$ & - & - & $\begin{array}{l}\text { Adsorption capacity increased with the size } \\
\text { of the molecule. }\end{array}$ & $\begin{array}{l}\text { Dargaville et al } \\
1996\end{array}$ \\
\hline p-Cresol & $\begin{array}{l}\text { Biochar from } \\
\text { pine }\end{array}$ & $\mathrm{BC}$ & $\begin{array}{l}\mathrm{K}_{2} \mathrm{CO}_{3} \\
300-400\end{array}$ & $\mathrm{~L}$ & $5-7$ & - & Ex & Adsorption inhibited by acidic groups. & Das et al. 2013 \\
\hline $\begin{array}{l}\text { 2,4,6- } \\
\text { Trichlorophenol }\end{array}$ & $\begin{array}{l}\text { Bacellus } \\
\text { subtillis }\end{array}$ & No & $\begin{array}{l}\text { Live } \\
\text { culture }\end{array}$ & - & - & - & - & Best $\mathrm{pH}<5$; stability constant fits & $\begin{array}{l}\text { Daughney } \\
\text { Fein } 1998\end{array}$ \\
\hline $\begin{array}{l}\text { Phenol, } \\
\text { 2-Chlorophenol, } \\
\text { 2,6-Dichlorophenol }\end{array}$ & $\begin{array}{l}\text { Daucus carota } \\
\text { Ipomoea bat. } \\
\text { Solanum avi. }\end{array}$ & No & Cultured & - & - & - & - & Roots were effective in removing phenols. & $\begin{array}{l}\text { De Araugjo et } \\
\text { al. } 2006\end{array}$ \\
\hline $\begin{array}{l}\text { 2,4-Dichlorophenol } \\
\text { \& other } \\
\text { contaminants }\end{array}$ & $\begin{array}{l}\text { Horseradish, } \\
\text { Potato, } \\
\text { White radish }\end{array}$ & No & $\begin{array}{l}- \\
- \\
\mathrm{H}_{2} \mathrm{O}_{2}\end{array}$ & - & - & - & - & $\begin{array}{l}\text { Showed effective biodegradation with } \\
\text { peroxidases; in the absence of } \mathrm{H}_{2} \mathrm{O}_{2} \text { the } \\
\text { removal was much less effective. }\end{array}$ & $\begin{array}{l}\text { Dec \& Bolag } \\
1994\end{array}$ \\
\hline 2,4-Dichlorophenol & $\begin{array}{l}\text { Posidonia } \\
\text { oceanica L. }\end{array}$ & $\begin{array}{l}60 \mathrm{C} \\
48 \mathrm{~h}\end{array}$ & - & $\begin{array}{l}\mathrm{L}, \\
\mathrm{F}\end{array}$ & $5-13$ & $2^{\text {nd }}$ & - & Seagrass; best pH 3 to 7; & $\begin{array}{l}\text { Demirak et al. } \\
2011\end{array}$ \\
\hline $\begin{array}{l}\text { Phenol, } \\
\text { o-Chlorophenol, } \\
\text { p-Chlorophenol, } \\
\text { 2,4,6-Trichlorophen. }\end{array}$ & $\begin{array}{l}\text { Phanerochaet } \\
\text { chrysosporium }\end{array}$ & $\begin{array}{l}30 \mathrm{C} \\
24 \mathrm{~h}\end{array}$ & Ground & $(\mathrm{L})$ & $\begin{array}{l}113 \\
193 \\
225 \\
424\end{array}$ & - & - & $\begin{array}{l}\text { Methanol was used for regeneration of the } \\
\text { fungus. }\end{array}$ & $\begin{array}{l}\text { Denizli et al. } \\
2004\end{array}$ \\
\hline
\end{tabular}




\begin{tabular}{|c|c|c|c|c|c|c|c|c|c|}
\hline Pollutant & Sorbent & 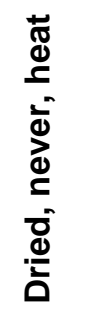 & 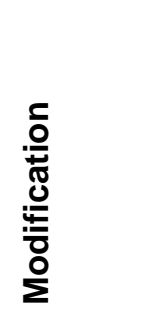 & 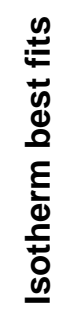 & $\begin{array}{l}\text { Adsorp. } \\
\text { capac. } \\
(\mathbf{m g} / \mathrm{g})\end{array}$ & 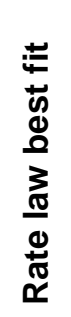 & 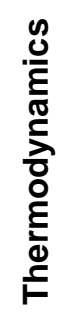 & Key Findings & Author (year) \\
\hline $\begin{array}{l}\text { Phenol, } \\
\text { o-Chlorophenol, } \\
\text { p-Chlorophenol, } \\
\text { 2,4,6-Trichlorophen. }\end{array}$ & $\begin{array}{l}\text { Pleurotus } \\
\text { sajor caju }\end{array}$ & $\begin{array}{l}30 \mathrm{C} \\
24 \mathrm{~h}\end{array}$ & Ground & $(\mathrm{L})$ & $\begin{array}{l}89 \\
159 \\
189 \\
373 \\
\end{array}$ & - & - & $\begin{array}{l}\text { Higher } \mathrm{pH} \text { gave higher uptake on the } \\
\text { fungus. }\end{array}$ & $\begin{array}{l}\text { Denizli et al. } \\
2005\end{array}$ \\
\hline PCB in soil & Biochar & $\mathrm{BC}$ & - & - & - & - & - & Biochar reduced PDB uptake by plants. & $\begin{array}{l}\text { Denyes et al. } \\
2012\end{array}$ \\
\hline Pentachlorophenol & Active carbon & $A C$ & - & - & $260-500$ & - & Ex & $\begin{array}{l}\text { Adsorption decreased with increasing } \mathrm{pH} \text {; } \\
\text { pi-pi interactions on basic sites cited. }\end{array}$ & $\begin{array}{l}\text { Diaz-Flores et } \\
\text { al. } 2006\end{array}$ \\
\hline $\begin{array}{l}\text { Phenanthrene, } \\
\text { Pyrene }\end{array}$ & $\begin{array}{l}\text { Phanerochaet } \\
\text { chrysosporium }\end{array}$ & - & $\begin{array}{l}\text { Live, } \\
\text { Heat- } \\
\text { killed }\end{array}$ & - & - & - & - & $\begin{array}{l}\text { Both biosorption \& biodegradation were } \\
\text { shown to be important; live material } \\
\text { showed an advantage for removal. }\end{array}$ & Ding et al. 2013 \\
\hline Befenthrin & $\begin{array}{l}\text { Cork } \\
\text { (granulated) }\end{array}$ & $\begin{array}{l}105 \\
\mathrm{C}\end{array}$ & - & $\mathrm{L}$ & $0.26-0.55$ & - & - & $\begin{array}{l}\text { The low uptake is consistent with the } \\
\text { impervious nature of cork. }\end{array}$ & $\begin{array}{l}\text { Domingues et } \\
\text { al. } 2005\end{array}$ \\
\hline Ci-cypermethrin & $\begin{array}{l}\text { Cork, } \\
\text { Active carbon }\end{array}$ & $\begin{array}{l}105 \\
\mathrm{C}\end{array}$ & - & $\mathrm{L}$ & $\begin{array}{l}0.3 \\
0.2\end{array}$ & - & - & $\begin{array}{l}\text { States that cork is successful; however the } \\
\text { reported numbers were very low. }\end{array}$ & $\begin{array}{l}\text { Domingues et } \\
\text { al. } 2007\end{array}$ \\
\hline $\begin{array}{l}\text { 4-Chlorophenol, } \\
\text { 3,5-Dichlorophenol, } \\
\text { 2,4,6-trichlorophen., } \\
\text { 2,3,4,6-tetrachlorop, } \\
\text { Pentachlorophenol }\end{array}$ & Carbon black & $\mathrm{BC}$ & - & $\mathrm{L}$ & $\begin{array}{l}296 \\
277 \\
237 \\
230 \\
239\end{array}$ & - & Ex & Best $\mathrm{pH}<11$ & $\begin{array}{l}\text { Domínguez-V. } \\
\text { et al. } 2009\end{array}$ \\
\hline Phenol & $\begin{array}{l}\text { Spirulina } \\
\text { bionanopart. }\end{array}$ & $60 \mathrm{C}$ & Ground & $\mathrm{L}$ & 159 & - & Ex & Best $\mathrm{pH}=6$; very strong temperature effect & $\begin{array}{l}\text { Dotto et al. } \\
2013\end{array}$ \\
\hline Phenol & $\begin{array}{l}\text { Carbonized } \\
\text { beet pulp }\end{array}$ & $\mathrm{BC}$ & $600 \mathrm{C}$ & $\begin{array}{l}\mathrm{F}, \\
\mathrm{L}\end{array}$ & $70-90$ & $2^{\text {nd }}$ & En & Best $\mathrm{pH}=6$ & $\begin{array}{l}\text { Dursun et al. } \\
2005\end{array}$ \\
\hline $\begin{array}{l}\text { Phenol, } \\
\text { Pentachlorophenol }\end{array}$ & $\begin{array}{l}\text { Carbonized } \\
\text { pine bark }\end{array}$ & $\mathrm{BC}$ & $672 \mathrm{C}$ & $\begin{array}{l}\mathrm{L}, \\
\mathrm{F}\end{array}$ & $\begin{array}{l}18-40 \\
1\end{array}$ & - & - & Slow carbonization & $\begin{array}{l}\text { Edgehill \& Lu } \\
1998\end{array}$ \\
\hline
\end{tabular}




\begin{tabular}{|c|c|c|c|c|c|c|c|c|c|}
\hline Pollutant & Sorbent & 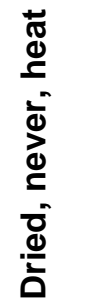 & $\begin{array}{l}\text { 음 } \\
\frac{\mathbb{Z}}{0} \\
\frac{0}{2} \\
\frac{0}{2}\end{array}$ & 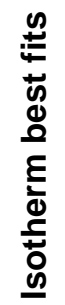 & $\begin{array}{l}\text { Adsorp. } \\
\text { capac. } \\
(\mathrm{mg} / \mathrm{g})\end{array}$ & 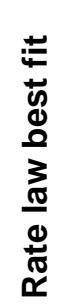 & 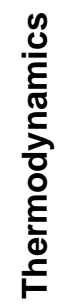 & Key Findings & Author (year) \\
\hline $\begin{array}{l}\text { Aldrin, } \\
\text { Dieldrin, } \\
\text { Endrin pesticides }\end{array}$ & Date stones & $\begin{array}{l}300 \\
\mathrm{C}\end{array}$ & - & $\mathrm{F}$ & $\begin{array}{l}16 \\
14 \\
12 \\
\end{array}$ & $2^{\text {nd }}$ & Ex & $\begin{array}{l}\text { Thermal treatment increased the sorption } \\
\text { capacity. }\end{array}$ & $\begin{array}{l}\text { El Bakouri et al. } \\
2009\end{array}$ \\
\hline $\begin{array}{l}\text { Chlorophenols, } \\
\text { Nitrophenols }\end{array}$ & $\begin{array}{l}\text { Torrefied olive } \\
\text { wood }\end{array}$ & $\begin{array}{l}100- \\
300\end{array}$ & Wash & - & $\begin{array}{l}(40-90 \% \\
\text { recov. })\end{array}$ & - & - & $\begin{array}{l}\text { Heating and washing may have made } \\
\text { pores more accessible. Weak pH effect. }\end{array}$ & $\begin{array}{l}\text { El-Sheikh et al. } \\
2011\end{array}$ \\
\hline $\begin{array}{l}\text { Phenol, } \\
\text { 2-Chlorophenol, } \\
\text { 3-Chlorophenol, } \\
\text { 4-Chlorophenol, } \\
\text { 2-Nitrophenol, } \\
\text { 4-Nitrophenol, } \\
\text { 2,4-Dinitrophenol }\end{array}$ & Olive wood & - & Ground & $\begin{array}{l}\mathrm{L}, \\
\mathrm{F}\end{array}$ & $\begin{array}{l}8 \\
12, \\
12, \\
12 \\
6 \\
10 \\
6 \\
\end{array}$ & $2^{\text {nd }}$ & - & $\begin{array}{l}\text { Adsorption improved by solvent washing; } \\
\text { pore diffusion. }\end{array}$ & $\begin{array}{l}\text { El-Sheikh et al. } \\
2013\end{array}$ \\
\hline Pentachlorophenol & Almond shell & $\begin{array}{l}\text { 30C } \\
\text { opt. }\end{array}$ & Ground & $\begin{array}{l}\mathrm{F} \\
\operatorname{lin}\end{array}$ & 0.3 & - & - & $\begin{array}{l}\text { Very low affinity, especially at low } \\
\text { concentration; "good natural adsorbent" }\end{array}$ & $\begin{array}{l}\text { Estevinho et al. } \\
2006\end{array}$ \\
\hline Benzopyrene, PAHs & Biochars & VC & Various & - & $\begin{array}{l}0.00001- \\
0.0007\end{array}$ & - & - & $\begin{array}{l}\text { Soxhlet extraction with acetone/ } \\
\text { cyclohexane mixture effective to remove } \\
\text { trace amounts already present in biochars. }\end{array}$ & $\begin{array}{l}\text { Fabbri et al. } \\
2013\end{array}$ \\
\hline Phenol & $\begin{array}{l}\text { Phanerochaet } \\
\text { chrysosporium }\end{array}$ & Not & $\begin{array}{l}\text { Immob., } \\
\text { free }\end{array}$ & $\mathrm{L}$ & $3-14$ & $2^{\text {nd }}$ & - & Best $\mathrm{pH}=5.5$ & $\begin{array}{l}\text { Farkas et al. } \\
2013\end{array}$ \\
\hline $\begin{array}{l}\text { o-Chlorophenol, } \\
\text { m-Chlorophenol }\end{array}$ & $\begin{array}{l}\text { Active carbons } \\
\text { fr. olive stones }\end{array}$ & $\mathrm{AC}$ & $1113 \mathrm{~K}$ & - & $\begin{array}{l}320 \\
313 \\
\end{array}$ & - & - & $\begin{array}{l}\text { Various solvents were used to regenerate } \\
\text { carbons; heating causes chemisorption. }\end{array}$ & $\begin{array}{l}\text { Ferro-Garcia et } \\
\text { al. } 1996\end{array}$ \\
\hline Phenol & Active carbons & $\mathrm{AC}$ & $\begin{array}{l}\mathrm{NaOH} \\
\mathrm{KOH}\end{array}$ & $\mathrm{L}$ & $213-238$ & $2^{\text {nd }}$ & & $\begin{array}{l}\text { Carbon from kraft lignin performed the } \\
\text { best. }\end{array}$ & $\begin{array}{l}\text { Fierro et al. } \\
2008\end{array}$ \\
\hline $\begin{array}{l}\text { Nitrobenzene, } \\
\text { Benzoic acid, }\end{array}$ & Active carbon & $A C$ & $\begin{array}{l}\mathrm{pH}=11.5 \\
\mathrm{pH}=3\end{array}$ & $\mathrm{~L}$ & $\begin{array}{l}290-360 \\
11-22 \\
200-220\end{array}$ & - & - & $\begin{array}{l}\text { Oxygen groups lowered sorption from } \\
\text { cyclohexane solution; high pH suppressed } \\
\text { benzoic acid sorption on all carbons. }\end{array}$ & Franz 2000 \\
\hline $\begin{array}{l}\text { Phenol. } \\
\text { p-Nitrophenol }\end{array}$ & Active carbon & $\mathrm{AC}$ & - & - & $\begin{array}{l}280 \\
560\end{array}$ & - & - & $\begin{array}{l}\text { Competition between the two phenols was } \\
\text { observed and accounted for. }\end{array}$ & $\begin{array}{l}\text { Fritz \& Schlu- } \\
\text { ender } 1974\end{array}$ \\
\hline
\end{tabular}




\begin{tabular}{|c|c|c|c|c|c|c|c|c|c|}
\hline Pollutant & Sorbent & 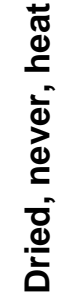 & $\frac{c}{\stackrel{c}{\frac{0}{\hbar}}}$ & 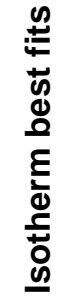 & $\begin{array}{l}\text { Adsorp. } \\
\text { capac. } \\
(\mathrm{mg} / \mathrm{g})\end{array}$ & 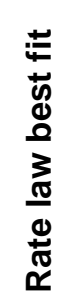 & 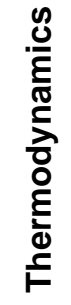 & Key Findings & Author (year) \\
\hline TNT red water & $\begin{array}{l}\text { Charcoal from } \\
\text { bamboo }\end{array}$ & $\mathrm{AC}$ & - & $\mathrm{L}$ & $23-29$ & $\begin{array}{l}2^{\text {nd }} \\
\text { ID }\end{array}$ & En & $\begin{array}{l}\text { Intraparticle diffusion affects rate. Sorption } \\
\text { affected by charge, } \mathrm{H} \text { bonding, acid-base. }\end{array}$ & Fu et al. $2012 a$ \\
\hline TNT red water & $\begin{array}{l}\text { Active carbon } \\
\text { from rice husk }\end{array}$ & $\mathrm{AC}$ & $\begin{array}{l}\mathrm{SiO}_{2} \\
\text { remov. }\end{array}$ & - & $3-8$ & $2^{\text {nd }}$ & - & Effective low-cost adsorbent & Fu et al. 2012b \\
\hline $\begin{array}{l}\text { Phenol, } \\
\text { p-Chlorophenol, } \\
\text { o-Chlorophenol, } \\
\text { 2,4-Dichlorophenol, } \\
\text { 2,4,6-Trichlorophen, } \\
\text { p-Nitrophenol, } \\
\text { 2,4-Dinitrophenol, } \\
\text { 2,4,6-Trinitrophenol }\end{array}$ & $\begin{array}{l}\text { Active carbon } \\
\text { (granular) }\end{array}$ & $A C$ & - & $\mathrm{F}$ & $\begin{array}{l}100-500 \\
130-600 \\
130-600 \\
160-800 \\
200-1000 \\
140-560 \\
100-150 \\
100-230 \\
\end{array}$ & - & - & $\begin{array}{l}\text { Interpretation based on percentage of } \\
\text { surface coverage of the carbon; the result } \\
\text { was interpreted using molecular orbital } \\
\text { theory and molecular size. }\end{array}$ & $\begin{array}{l}\text { Furuya et al. } \\
1997\end{array}$ \\
\hline $\begin{array}{l}\text { Phenols in olive mill } \\
\text { wastewater }\end{array}$ & $\begin{array}{l}\text { Active carbon } \\
\text { fr. olive stones }\end{array}$ & $A C$ & $\begin{array}{l}\text { Steam } \\
850,800\end{array}$ & $\mathrm{~L}$ & $6-90$ & $1^{\mathrm{st}}$ & - & $\begin{array}{l}\text { Mesoporosity is key; those carbons with } \\
\text { best-developed mesopores exhibited the } \\
\text { highest uptake. }\end{array}$ & $\begin{array}{l}\text { Galiatsatou et } \\
\text { al. } 2002\end{array}$ \\
\hline Nonylphenol & $\begin{array}{l}\text { Chorella sp. } \\
\text { (4 species) }\end{array}$ & No & $\begin{array}{l}\text { Living; } \\
121 \mathrm{C}\end{array}$ & - & 0.4-18 & - & - & $\begin{array}{l}\text { Biodegradation rate was affected by light } \\
\text { and temperature; but removal from water } \\
\text { was the same with live or dead cells. }\end{array}$ & Gao et al. 2011 \\
\hline $\begin{array}{l}\text { 4-Chlorophenol, } \\
\text { 2,4-Dichlorophenol }\end{array}$ & $\begin{array}{l}\text { Anaerobic } \\
\text { gran. sludge }\end{array}$ & No & $\begin{array}{l}\text { Fresh } \\
\text { (refrig.) }\end{array}$ & $\begin{array}{l}\mathrm{L} \text { L, } \\
\mathrm{F}\end{array}$ & $\begin{array}{l}1.5 \\
5\end{array}$ & - & En & Low pH best. & Gao et al. 2007 \\
\hline $\begin{array}{l}\text { Gallic acid, } \\
\text { p-Hydroxybenzoic, } \\
\text { Syringic acid }\end{array}$ & Active carbon & $A C$ & - & - & $\begin{array}{l}250 \\
220 \\
200\end{array}$ & - & En & Competition effects at high concentration. & $\begin{array}{l}\text { García-Araya } \\
\text { et al. } 2003\end{array}$ \\
\hline Lindane pesticide & $\begin{array}{l}\text { Rhizopus } \\
\text { oryzae }\end{array}$ & No & $\begin{array}{l}\text { Dead, } \\
\text { autocl. }\end{array}$ & $\begin{array}{l}\mathrm{F} \\
\mathrm{L}\end{array}$ & 0.1 & $2^{\text {nd }}$ & - & $\begin{array}{l}\text { Sorption was independent of } \mathrm{pH} \& \\
\text { temperature; high affinity but low capacity. }\end{array}$ & $\begin{array}{l}\text { Ghosh et al. } \\
2009\end{array}$ \\
\hline Phenanthrene & $\begin{array}{l}\text { Carbon single } \\
\text { wall nanotube }\end{array}$ & - & - & - & $70-300$ & - & - & $\begin{array}{l}\text { From ethanol solution; purification of the } \\
\text { carbon improved phenanthrene uptake. }\end{array}$ & $\begin{array}{l}\text { Gotovac et al. } \\
2006\end{array}$ \\
\hline
\end{tabular}




\begin{tabular}{|c|c|c|c|c|c|c|c|c|c|}
\hline Pollutant & Sorbent & 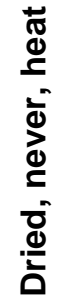 & 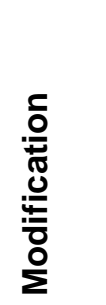 & 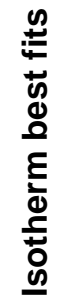 & $\begin{array}{l}\text { Adsorp. } \\
\text { capac. } \\
(\mathbf{m g} / \mathrm{g})\end{array}$ & 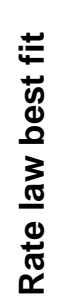 & 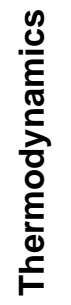 & Key Findings & Author (year) \\
\hline Naphthanlene & $\begin{array}{l}\text { Carbon single } \\
\text { wall nanotube }\end{array}$ & - & - & - & - & - & - & $\begin{array}{l}\text { From trichloroethylene solution; the } \\
\text { sorbate was on the outer surfaces. }\end{array}$ & $\begin{array}{l}\text { Gotovac et al. } \\
2007 a\end{array}$ \\
\hline $\begin{array}{l}\text { Phenanthrene, } \\
\text { Tetracene }\end{array}$ & $\begin{array}{l}\text { Carbon single } \\
\text { wall nanotube }\end{array}$ & - & - & - & $\begin{array}{l}50-350 \\
100-600\end{array}$ & - & - & $\begin{array}{l}\text { From toluene solution; acid functional- } \\
\text { ization increased sorption markedly. }\end{array}$ & $\begin{array}{l}\text { Gotovac et al. } \\
2007 \mathrm{~b}\end{array}$ \\
\hline Phenol & Active carbons & $A C$ & - & - & $30-38$ & - & - & $\begin{array}{l}\text { Regeneration by acetone leaching; } \\
\text { differences in surface groups did not } \\
\text { account for irreversible sorption; lower pH } \\
\text { favors irreversible adsorption. }\end{array}$ & $\begin{array}{l}\text { Grant et al. } \\
1990\end{array}$ \\
\hline $\begin{array}{l}\text { DDD, } \\
\text { DDE }\end{array}$ & $\begin{array}{l}\text { Fly ash from } \\
\text { bagasse }\end{array}$ & $\mathrm{FA}$ & $\mathrm{H}_{2} \mathrm{O}_{2}$ & $\begin{array}{l}\mathrm{L}, \\
\mathrm{F}\end{array}$ & $\begin{array}{l}0.008 \\
0.007\end{array}$ & - & Ex & Best $\mathrm{pH}=6$; high removal percentages & $\begin{array}{l}\text { Gupta \& Ali } \\
2001\end{array}$ \\
\hline $\begin{array}{l}\text { Endosulfan, } \\
\text { Methoxychlor }\end{array}$ & Active carbon & $\mathrm{AC}$ & $\begin{array}{l}450 \mathrm{C} \\
\mathrm{HCl}\end{array}$ & $\begin{array}{l}\mathrm{L} \\
\mathrm{F}\end{array}$ & $\begin{array}{l}34 \\
36 \\
\end{array}$ & $2^{\text {nd }}$ & Ex & Best $\mathrm{pH}$ low, $<8$ & $\begin{array}{l}\text { Gupta \& Ali } \\
2008\end{array}$ \\
\hline $\begin{array}{l}\text { Methoxychlor, } \\
\text { Methyl parathion, } \\
\text { Atrazine }\end{array}$ & $\begin{array}{l}\text { Active carbon } \\
\text { from rubber }\end{array}$ & $\mathrm{AC}$ & $\begin{array}{l}\mathrm{KOH} \\
900 \mathrm{C}\end{array}$ & $\mathrm{L}$ & $\begin{array}{l}112 \\
89 \\
105\end{array}$ & $1^{\text {st }}$ & Ex & Pore sorption control & $\begin{array}{l}\text { Gupta et al. } \\
2011\end{array}$ \\
\hline $\begin{array}{l}\text { Phenol, } \\
\text { p-Nitrophenol }\end{array}$ & $\begin{array}{l}\text { Fly ash from } \\
\text { bagasse }\end{array}$ & $\mathrm{FA}$ & $\mathrm{H}_{2} \mathrm{O}_{2}$ & $\begin{array}{l}\mathrm{L}, \\
\mathrm{F}\end{array}$ & $\begin{array}{l}0.5-0.7 \\
0.7-1.2\end{array}$ & - & Ex & Best $\mathrm{pH}<8$ & $\begin{array}{l}\text { Gupta et al. } \\
1998\end{array}$ \\
\hline $\begin{array}{l}\text { 2,4,6-Trinitrophenol, } \\
\text { 4-Nitrophenol, } \\
\text { 4-Chlorophenol, } \\
\text { 1,3-Dihydroxybenzn }\end{array}$ & $\begin{array}{l}\text { Carbon from } \\
\text { fertilizer waste }\end{array}$ & $\mathrm{BC}$ & $\begin{array}{l}450 \mathrm{C} \\
\mathrm{HCl}\end{array}$ & - & $\begin{array}{l}98-130 \\
77-104 \\
62-99 \\
50-92 \\
\end{array}$ & - & - & $\begin{array}{l}\text { Column tests gave higher capacities than } \\
\text { the corresponding batch tests. }\end{array}$ & $\begin{array}{l}\text { Gupta et al. } \\
2000\end{array}$ \\
\hline $\begin{array}{l}\text { Benzoic acid, } \\
\text { p-Nitrophenol, } \\
\text { p-Cresol, } \\
\text { Salicilic acid, } \\
\text { Nitrobenzene }\end{array}$ & $\begin{array}{l}\text { Activated } \\
\text { carbons } \\
\text { (commercial) }\end{array}$ & $A C$ & - & - & $\begin{array}{l}180-187 \\
207-238 \\
166-175 \\
199-200 \\
229-244\end{array}$ & - & - & $\begin{array}{l}\text { Adsorption depended on molecular size; } \\
\text { sideways ( } \mathrm{T} \text {-shaped) orientation in the pi- } \\
\text { stacking of aromatic adsorbates. }\end{array}$ & $\begin{array}{l}\text { Haghseresht et } \\
\text { al. } 2002 \mathrm{a}\end{array}$ \\
\hline
\end{tabular}




\begin{tabular}{|c|c|c|c|c|c|c|c|c|c|}
\hline Pollutant & Sorbent & 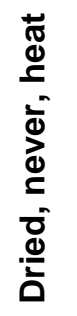 & 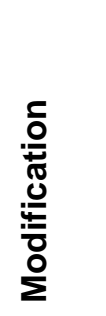 & 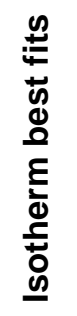 & $\begin{array}{l}\text { Adsorp. } \\
\text { capac. } \\
(\mathrm{mg} / \mathrm{g})\end{array}$ & 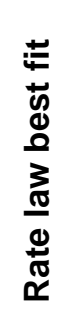 & 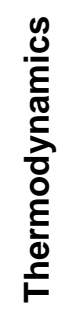 & Key Findings & Author (year) \\
\hline $\begin{array}{l}\text { Benzoic acid, } \\
\text { p-Nitrophenol, } \\
\text { p-Cresol, } \\
\text { Salicilic acid, } \\
\text { Nitrobenzene }\end{array}$ & $\begin{array}{l}\text { Activated } \\
\text { carbons } \\
\text { (commercial) }\end{array}$ & $\mathrm{AC}$ & - & - & $\begin{array}{l}180-234 \\
207-239 \\
166-221 \\
199-293 \\
229-266\end{array}$ & & & $\begin{array}{l}\text { Adsorption of dissociable aromatic } \\
\text { compounds provides evidence of London } \\
\text { dispersion contribution to adsorption. }\end{array}$ & $\begin{array}{l}\text { Haghseresht et } \\
\text { al. } 2002 \mathrm{~b}\end{array}$ \\
\hline $\begin{array}{l}\text { Benzoic acid, } \\
\text { p-Nitrophenol, } \\
\text { p-Cresol, } \\
\text { Salicilic acid, } \\
\text { Nitrobenzene }\end{array}$ & $\begin{array}{l}\text { Activated } \\
\text { carbons } \\
\text { (commercial) }\end{array}$ & $A C$ & - & - & $\begin{array}{l}186 \\
236 \\
176 \\
193 \\
246\end{array}$ & - & - & $\begin{array}{l}\text { Adsorption falls above critical } \mathrm{pH} \text { value: } \\
\text { Benzoic \& salicylic acids: } \mathrm{pH} \sim 6 \text {; } \\
\text { p-Nitrophenol \& cresol: } \mathrm{pH} \sim 10 \text {. }\end{array}$ & $\begin{array}{l}\text { Haghseresht et } \\
\text { al. } 2002 \mathrm{c}\end{array}$ \\
\hline $\begin{array}{l}\text { p-Nitrophenol, } \\
\text { p-Cresol, } \\
\text { Nitrobenzene }\end{array}$ & $\begin{array}{l}\text { Activated } \\
\text { carbons } \\
\text { (commercial) }\end{array}$ & $\mathrm{AC}$ & - & - & $\begin{array}{l}153-208 \\
119-151 \\
154-209\end{array}$ & - & - & $\begin{array}{l}\text { Binary isotherms predicted; oxidation } \\
\text { reduces capacity moderately (15-20\%). }\end{array}$ & $\begin{array}{l}\text { Haghseresht et } \\
\text { al. } 2003\end{array}$ \\
\hline Phenol & $\begin{array}{l}\text { Activated } \\
\text { charcoal }\end{array}$ & $A C$ & - & $\begin{array}{l}\mathrm{F}, \\
\mathrm{L}, \\
\mathrm{RP}\end{array}$ & 48 & - & Ex & $\begin{array}{l}\text { Large drop in adsorption about } \mathrm{pH} 10 ; \\
\text { scant effect of salt }\end{array}$ & $\begin{array}{l}\text { Halhouli et al. } \\
1995\end{array}$ \\
\hline Paraquot dichloride & $\begin{array}{l}\text { Activated } \\
\text { carbon }\end{array}$ & $A C$ & $\begin{array}{l}\mathrm{CO}_{2} \\
900 \mathrm{C}\end{array}$ & $\mathrm{L}$ & $28-34$ & $2^{\text {nd }}$ & Ex & $\begin{array}{l}\text { Particle size did not make a clear } \\
\text { difference; regenerate at high } \mathrm{pH} \text {. }\end{array}$ & $\begin{array}{l}\text { Hamadi et al. } \\
2004\end{array}$ \\
\hline $\begin{array}{l}\text { Phenol, } \\
\text { 2-Chlorophenol, } \\
\text { 4-Chlorophenol, } \\
\text { 2,4-Dichlorophenol, } \\
\text { 2,4,6-Trichlorophen. }\end{array}$ & $\begin{array}{l}\text { Granular } \\
\text { activated } \\
\text { carbon }\end{array}$ & $A C$ & - & $\begin{array}{l}\mathrm{FG} \\
\mathrm{HB} \\
\mathrm{T} \\
\mathrm{F}\end{array}$ & $\begin{array}{l}238-250 \\
284-303 \\
356-301 \\
303-370 \\
438-482\end{array}$ & - & - & $\begin{array}{l}\text { No association among the adsorbed } \\
\text { molecules detected; capacity increased } \\
\text { with molecular weight, hydrophobicity, } \\
\text { decreased solubility; various forms of } \\
\text { Langmuir model gave similar results. }\end{array}$ & $\begin{array}{l}\text { Hamdaoui \& N. } \\
2007 a\end{array}$ \\
\hline 4-Chlorophenol & $\begin{array}{l}\text { Activ. carbon } \\
\text { from rattan } \\
\text { sawdust }\end{array}$ & $A C$ & - & $\mathrm{L}$ & 189 & $2^{\text {nd }}$ & - & $\begin{array}{l}\text { Intra-particle diffusion; gradual dropoff in } \\
\text { capacity above } \mathrm{pH}=7\end{array}$ & $\begin{array}{l}\text { Hameed et al. } \\
2008 a\end{array}$ \\
\hline
\end{tabular}




\begin{tabular}{|c|c|c|c|c|c|c|c|c|c|}
\hline Pollutant & Sorbent & 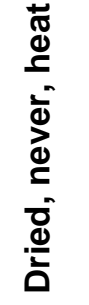 & 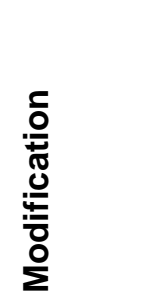 & 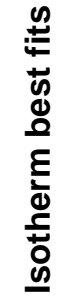 & $\begin{array}{l}\text { Adsorp. } \\
\text { capac. } \\
(\mathrm{mg} / \mathrm{g})\end{array}$ & 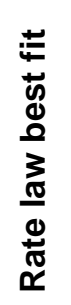 & 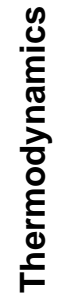 & Key Findings & Author (year) \\
\hline Phenol & $\begin{array}{l}\text { Activ. carbon } \\
\text { from rattan } \\
\text { sawdust }\end{array}$ & $\mathrm{AC}$ & $\begin{array}{l}\mathrm{KOH}, \\
850 \mathrm{C}\end{array}$ & $\mathrm{L}$ & 149 & $2^{\text {nd }}$ & - & Dropoff in capacity above $\mathrm{pH}=8$ & $\begin{array}{l}\text { Hameed et al. } \\
2008 \mathrm{~b}\end{array}$ \\
\hline 2,4,6-trichlorophenol & $\begin{array}{l}\text { Activated } \\
\text { carbon }\end{array}$ & $A C$ & $\begin{array}{l}\mathrm{KOH} \\
814 \mathrm{C}\end{array}$ & $\mathrm{L}$ & 169 & - & - & Activation conditions were optimized. & $\begin{array}{l}\text { Hameed et al. } \\
2009\end{array}$ \\
\hline p-Nitrophenol & $\begin{array}{l}\text { Magnetic } \\
\text { activated } \\
\text { carbon }\end{array}$ & $\mathrm{AC}$ & - & $\mathrm{L}$ & $\begin{array}{l}128-133 \\
61-72\end{array}$ & - & - & $\begin{array}{l}\text { Coprecipitation was effective for } \\
\text { magnetizing the carbon. }\end{array}$ & Han et al. 2013 \\
\hline Phenol & $\begin{array}{l}\text { Pseudomon. } \\
\text { on active C }\end{array}$ & - & - & - & - & - & - & $\begin{array}{l}\text { Adsorption happens first, then } \\
\text { biodegradation; packed bed. }\end{array}$ & $\begin{array}{l}\text { Hank et al. } \\
2010\end{array}$ \\
\hline $\begin{array}{l}\text { Perfluoroacetic acid } \\
\text { \& related } \\
\text { compounds }\end{array}$ & $\begin{array}{l}\text { Gran \& powd. } \\
\text { activated } \\
\text { carbon }\end{array}$ & $A C$ & - & $\mathrm{L}$ & $0.05-50$ & - & - & $\begin{array}{l}\text { Some of the surfactants exhibited tiny } \\
\text { values of adsorption capacity; low bulk } \\
\text { concentrations were employed. }\end{array}$ & $\begin{array}{l}\text { Hansen et al. } \\
2010\end{array}$ \\
\hline Atrazine & $\begin{array}{l}\text { Biochars from } \\
\text { corncob }\end{array}$ & $\mathrm{BC}$ & $\begin{array}{l}350- \\
650 \mathrm{C}\end{array}$ & $\mathrm{F}$ & $0.5-3$ & - & - & $\begin{array}{l}\text { The capacity Increased with higher } \\
\text { temperature of charring; low affinity. }\end{array}$ & Hao et al. 2013 \\
\hline p-Nitrophenol & $\begin{array}{l}\text { Activated } \\
\text { carbons }\end{array}$ & $\mathrm{AC}$ & $\begin{array}{l}\mathrm{HNO}_{3} \\
\mathrm{NaOH}\end{array}$ & - & $300-500$ & - & - & $\begin{array}{l}\text { Oxidation decreased the surface area but } \\
\text { had little effect on adsorption. }\end{array}$ & $\begin{array}{l}\text { Haydar et al. } \\
2003\end{array}$ \\
\hline Phenol & $\begin{array}{l}\text { Activated } \\
\text { carbons }\end{array}$ & $A C$ & $\begin{array}{l}\mathrm{CO}_{2} \\
900 \mathrm{C} \\
\end{array}$ & - & $60-200$ & - & - & $\begin{array}{l}\text { Different adsorption energies on different } \\
\text { sizes of pores; pore-filling mechanism. }\end{array}$ & $\begin{array}{l}\text { Hsieh \& Teng } \\
2000\end{array}$ \\
\hline Paraquot & Rice husk & $50 C$ & $\begin{array}{l}\text { Methacr } \\
\text { ylic acid }\end{array}$ & $\mathrm{L}$ & 292 & - & - & $\begin{array}{l}\text { The carboxylate form }(\mathrm{NaOH}) \text { was } \\
\text { effective for paraquot removal. }\end{array}$ & Hsu et al. 2009 \\
\hline Paraquot & Rice husk & $50 \mathrm{C}$ & $\begin{array}{l}\text { Methacr } \\
\text { ylic acid }\end{array}$ & $\mathrm{L}$ & 318 & - & - & - & $\begin{array}{l}\text { Hsu \& Pan } \\
2007\end{array}$ \\
\hline $\begin{array}{l}\text { Methyltertbutyl ether } \\
\text { MTBE }\end{array}$ & $\begin{array}{l}\text { Biolog. active. } \\
\text { carbon }\end{array}$ & - & - & - & $1-20$ & - & - & $\begin{array}{l}\text { Bioaugmentation was used to regenerate } \\
\text { the carbon adsorbent in-situ, adsorption } \\
\text { was mainly on the bacterial surfaces. }\end{array}$ & Hu et al. 2013 \\
\hline
\end{tabular}




\begin{tabular}{|c|c|c|c|c|c|c|c|c|c|}
\hline Pollutant & Sorbent & 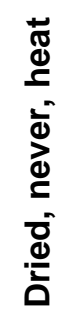 & 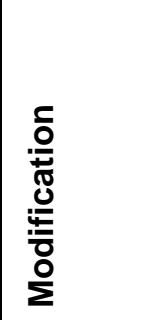 & 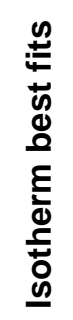 & $\begin{array}{l}\text { Adsorp. } \\
\text { capac. } \\
\text { (mg/g) }\end{array}$ & 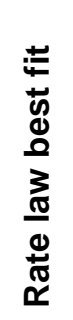 & 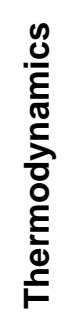 & Key Findings & Author (year) \\
\hline 1-Naphthylamine & $\begin{array}{l}\text { Multiwall } \\
\text { carbon } \\
\text { nanotubes }\end{array}$ & - & - & $\mathrm{L}$ & $154-294$ & $2^{\text {nd }}$ & En & $\begin{array}{l}\text { Best } \mathrm{pH} \text { range } 7-9 \text {; pi-pi interactions; } \\
\text { magnetic particles were effective for } \\
\text { remediation with separation. }\end{array}$ & Hu et al. 2011 \\
\hline $\begin{array}{l}\text { Phenanthrene; } \\
\text { Pyrene }\end{array}$ & $\begin{array}{l}\text { Aspen wood } \\
\text { fibers }\end{array}$ & - & $\begin{array}{l}\text { Bleach, } \\
\text { Hydrol. }\end{array}$ & $\mathrm{F}$ & $\begin{array}{l}0.01-5.0 \\
0.01-10\end{array}$ & - & - & $\begin{array}{l}\text { Bleaching decreased uptake; hydrolysis of } \\
\text { carbohydrates increased uptake. }\end{array}$ & $\begin{array}{l}\text { Huang et al. } \\
2006\end{array}$ \\
\hline Anthracene & $\begin{array}{l}\text { Gomphidius } \\
\text { viscidus }\end{array}$ & No & $\begin{array}{l}\text { Auto- } \\
\text { claved }\end{array}$ & $\bar{L}$ & $\begin{array}{l}1500- \\
1900\end{array}$ & $2^{\text {nd }}$ & - & $\begin{array}{l}\text { Fungal biomass most effective at } \mathrm{pH}>6 \text {; } \\
\text { fungus could become acclimated. }\end{array}$ & $\begin{array}{l}\text { Huang et al. } \\
2010\end{array}$ \\
\hline $\begin{array}{l}\text { Phenol, } \\
\text { 3-Nitrophenol }\end{array}$ & $\begin{array}{l}\text { Activated } \\
\text { carbons }\end{array}$ & $A C$ & $\begin{array}{l}\text { Up to } \\
1000 \mathrm{C}\end{array}$ & - & $\begin{array}{l}10-20 \\
10-20\end{array}$ & $\begin{array}{l}2^{\text {nd }} \\
\text { ID }\end{array}$ & - & Intraparticle diffusion & $\begin{array}{l}\text { loannou \& } \\
\text { Simitzis } 2009\end{array}$ \\
\hline Phenol & $\begin{array}{l}\text { Bio-active } \\
\text { carbon }\end{array}$ & - & $\begin{array}{l}\text { Com- } \\
\text { mercial }\end{array}$ & - & - & - & - & $\begin{array}{l}\text { Substituted phenols inhibited the biofilm; } \\
\text { packed bed system; > } 90 \% \text { biodegradation } \\
\text { in } 20-30 \text { days }\end{array}$ & $\begin{array}{l}\text { Ivancev-T. et } \\
\text { al. } 1998\end{array}$ \\
\hline Pentachlorophenol & $\begin{array}{l}\text { Microbial } \\
\text { biomass }\end{array}$ & No & - & - & - & - & - & $\begin{array}{l}\text { Higher uptake onto activated sludge at } \\
\text { lower } \mathrm{pH}\end{array}$ & $\begin{array}{l}\text { Jacobsen et al. } \\
1996\end{array}$ \\
\hline $\begin{array}{l}\text { Phenol, } \\
\text { 2-Chlorophenol, } \\
\text { 4-Chlorophenol, } \\
\text { 2,,4-Dichlorophenol }\end{array}$ & $\begin{array}{l}\text { Carbon slurry, } \\
\text { etc. }\end{array}$ & $\mathrm{BC}$ & $500 \mathrm{C}$ & $\mathrm{L}$ & $\begin{array}{l}17 \\
50 \\
57 \\
132\end{array}$ & $1^{\text {st }}$ & - & Pore diffusion & Jain et al. 2004 \\
\hline Phenanthrene & $\begin{array}{l}\text { Biochars from } \\
\text { wood }\end{array}$ & $\mathrm{BC}$ & $\begin{array}{l}300 \text { to } \\
820 \mathrm{C}\end{array}$ & $\mathrm{F}$ & $2-30$ & - & - & $\begin{array}{l}\text { Low-affinity isotherms; heating at above } \\
450^{\circ} \mathrm{C} \text { greatly increased uptake. }\end{array}$ & $\begin{array}{l}\text { James et al. } \\
2005\end{array}$ \\
\hline Tetracycline & $\begin{array}{l}\text { Carbon } \\
\text { nanotubes }\end{array}$ & - & - & $\mathrm{F}$ & & - & - & $\begin{array}{l}\text { Humic acids suppressed adsorption of } \\
\text { tetracyclene; } \mathrm{Cu}(\mathrm{II}) \text { increased adsorption. }\end{array}$ & Ji et al. 2010 \\
\hline
\end{tabular}




\begin{tabular}{|c|c|c|c|c|c|c|c|c|c|}
\hline Pollutant & Sorbent & 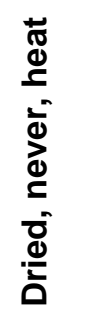 & $\frac{\substack{0 \\
\frac{0}{7}}}{2}$ & 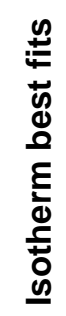 & $\begin{array}{l}\text { Adsorp. } \\
\text { capac. } \\
(\mathrm{mg} / \mathrm{g})\end{array}$ & 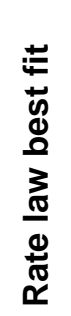 & 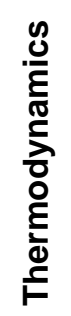 & Key Findings & Author (year) \\
\hline $\begin{array}{l}\text { Phenanthrene, } \\
\text { Anthracene, } \\
\text { Fluoranthrene, } \\
\text { Benz[a]anthracene, } \\
\text { Benzofluoranthene, } \\
\text { Benzo[g,h,i]perylene }\end{array}$ & $\begin{array}{l}\text { Diesel soot } \\
\text { from car } \\
\text { exhaust pipes, } \\
\text { other soots }\end{array}$ & - & - & - & - & - & - & $\begin{array}{l}\text { Adsorption of the aromatic compounds } \\
\text { onto soot was very strong and largely } \\
\text { irreversible, according to isotopic tests; } \\
\text { preferential adsorption of planar } \\
\text { molecules. }\end{array}$ & $\begin{array}{l}\text { Jonker \& } \\
\text { Koelmans } 2002\end{array}$ \\
\hline Lindane & $\begin{array}{l}\text { Gram - bacter } \\
\text { Gram + bacter }\end{array}$ & $\begin{array}{l}\text { Not, } \\
100\end{array}$ & $\begin{array}{l}\text { Live or } \\
\text { dired }\end{array}$ & $\mathrm{F}$ & $0.1-1$ & - & - & $\begin{array}{l}\text { Zeta potential was correlated with } \\
\text { adsorption; Van der Waals interactions. }\end{array}$ & Ju et al. 1997 \\
\hline $\begin{array}{l}\text { Phenol, } \\
\text { 4-Chlorophenol }\end{array}$ & Active carbon & $\begin{array}{l}750- \\
840\end{array}$ & $\begin{array}{l}\text { Steam } \\
\text { active. }\end{array}$ & $\mathrm{L}$ & $\begin{array}{l}240-300 \\
250-400\end{array}$ & - & En & Adsorption in micropores seems likely. & $\begin{array}{l}\text { Juang et al. } \\
2001\end{array}$ \\
\hline $\begin{array}{l}\text { Phenol, } \\
\text { 4-Chlorophenol, } \\
\text { 4-Nitrophenol }\end{array}$ & $\begin{array}{l}\text { Active carbon } \\
\text { fibers }\end{array}$ & $\mathrm{AC}$ & - & $\mathrm{L}$ & $\begin{array}{l}110-140 \\
240-260 \\
230-240\end{array}$ & - & - & $\begin{array}{l}\text { Jossens et al. 3-parameter heterogeneous } \\
\text { thermodynamic isotherm fit best; rate data } \\
\text { fit two-phase model. }\end{array}$ & $\begin{array}{l}\text { Juang et al. } \\
1996 a\end{array}$ \\
\hline $\begin{array}{l}\text { Phenol, } \\
\text { Chlorophenols, } \\
\text { Cresols }\end{array}$ & $\begin{array}{l}\text { Active carbon } \\
\text { fibers }\end{array}$ & $\begin{array}{l}800- \\
1200\end{array}$ & - & - & $\begin{array}{l}150 \\
240-264 \\
199-209\end{array}$ & - & - & $\begin{array}{l}\text { Higher adsorption of chlorinated, } \\
\text { compared to methylated phenols }\end{array}$ & $\begin{array}{l}\text { Juang et al. } \\
1996 b\end{array}$ \\
\hline Phenols & $\begin{array}{l}\text { Active carbon, } \\
\text { plum kernel }\end{array}$ & $\begin{array}{l}750- \\
900\end{array}$ & $\begin{array}{l}\text { Steam } \\
\text { activat. }\end{array}$ & $\mathrm{L}$ & $106-258$ & $\begin{array}{l}2^{\text {nd }} \\
\text { ID }\end{array}$ & - & Intraparticle diffusion, hydrogen bonding & $\begin{array}{l}\text { Juang et al. } \\
2000\end{array}$ \\
\hline $\begin{array}{l}\text { DDT, } \\
\text { DDD, } \\
\text { DDE }\end{array}$ & $\begin{array}{l}\text { Fungal } \\
\text { mycelia }\end{array}$ & - & - & - & - & - & - & $\begin{array}{l}\text { Dichloromethane was used to extract the } \\
\text { chlorinated pesticides from the fungal } \\
\text { mycelia. }\end{array}$ & $\begin{array}{l}\text { Juhasz \& Naidu } \\
\text { 2000b }\end{array}$ \\
\hline$p, p^{\prime}-\mathrm{DDT}$ & $\begin{array}{l}\text { Cladosporium } \\
\text { fungal mycel. }\end{array}$ & no & - & - & $7-17$ & - & - & $\begin{array}{l}\text { Killed biomass adsorbed somewhat more } \\
\text { than living; little effect of } \mathrm{pH} \text {. }\end{array}$ & $\begin{array}{l}\text { Juhasz et al. } \\
2002\end{array}$ \\
\hline $\begin{array}{l}\text { Phenol, } \\
\text { Chlorophenols }\end{array}$ & $\begin{array}{l}\text { Granular act. } \\
\text { carbons }\end{array}$ & $A C$ & - & $F$ & $0.5-10$ & - & - & $\begin{array}{l}\text { Starting bulk concentrations were too low; } \\
\text { dispersion forces proposed important. }\end{array}$ & $\begin{array}{l}\text { Jung et al. } \\
2001\end{array}$ \\
\hline
\end{tabular}




\begin{tabular}{|c|c|c|c|c|c|c|c|c|c|}
\hline Pollutant & Sorbent & 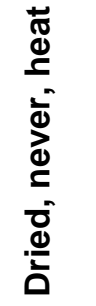 & 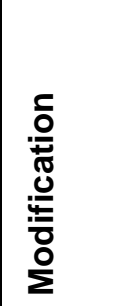 & 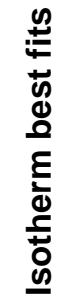 & $\begin{array}{l}\text { Adsorp. } \\
\text { capac. } \\
\text { (mg/g) }\end{array}$ & 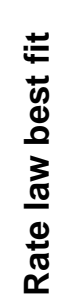 & 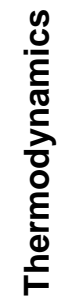 & Key Findings & Author (year) \\
\hline $\begin{array}{l}\text { 2-Chlorophenol, } \\
\text { 2,4-Dichlorophenol }\end{array}$ & $\begin{array}{l}\text { Fly ash from } \\
\text { power plant }\end{array}$ & FA & - & $\mathrm{F}$ & $\begin{array}{l}1.3 \\
2\end{array}$ & - & Ex & $\begin{array}{l}\text { Carbon content and specific surface area } \\
\text { were correlated with uptake; packed bed; } \\
\text { lower adsorption above } \mathrm{pH}=7 \text {. }\end{array}$ & Kao et al. 2000 \\
\hline Phenol & $\begin{array}{l}\text { Hydrogel- } \\
\text { biochar } \\
\text { composites }\end{array}$ & $\mathrm{BC}$ & - & $\mathrm{L}$ & $14-23$ & $1^{\text {st }}$ & - & Increasing salt increased uptake & $\begin{array}{l}\text { Karakoyun et } \\
\text { al. } 2011\end{array}$ \\
\hline Trichloroethylene & Active carbons & $A C$ & - & $\mathrm{F}$ & $1-100$ & - & - & $\begin{array}{l}\text { Many different activated carbons were } \\
\text { compared; } 5 \mathrm{~nm} \text { pore volume is key. }\end{array}$ & $\begin{array}{l}\text { Karanfil \& } \\
\text { Dastgheib } 2004\end{array}$ \\
\hline Trichloroethylene & $\begin{array}{l}\text { Active carbon } \\
\text { fibers }\end{array}$ & $A C$ & - & $\mathrm{F}$ & $1-100$ & - & - & $\begin{array}{l}\text { Natural organic matter can be excluded } \\
\text { with a membrane. }\end{array}$ & $\begin{array}{l}\text { Karanfil et al. } \\
2006\end{array}$ \\
\hline 2-Nitrophenol & Active carbons & $A C$ & - & - & $500-550$ & - & - & $\begin{array}{l}\text { Most of the adsorbed phenol did not come } \\
\text { off when bulk concentration was lowered. }\end{array}$ & $\begin{array}{l}\text { Karimi-J. \& N. } \\
1997\end{array}$ \\
\hline Chlorophenols & $\begin{array}{l}\text { Anaerobic } \\
\text { gran. sludge }\end{array}$ & No. & $\begin{array}{l}\text { Live } \\
\text { sludge }\end{array}$ & $\mathrm{F}$ & $0.1-2$ & - & - & $\begin{array}{l}\text { Linear adsorption isotherms were weakly } \\
\text { correlated to octanol-water partition } \\
\text { coefficients. }\end{array}$ & $\begin{array}{l}\text { Kennedy et al. } \\
1992\end{array}$ \\
\hline Phenol & $\begin{array}{l}\text { Mesoporous } \\
\text { carbon }\end{array}$ & $\begin{array}{l}700- \\
900\end{array}$ & - & $\mathrm{F}$ & 22 & $2^{\text {nd }}$ & Ex & Highest adsorption at low $\mathrm{pH}$. & $\begin{array}{l}\text { Kennedy et al. } \\
2007\end{array}$ \\
\hline $\begin{array}{l}\text { Nefenamic acid } \\
\text { pharmaceutical }\end{array}$ & Active carbon & $A C$ & - & $\bar{L}$ & 100 & - & - & $\begin{array}{l}\text { Activated carbon outperformed membrane } \\
\text { ultrafiltration. }\end{array}$ & $\begin{array}{l}\text { Khalaf et al. } \\
2013\end{array}$ \\
\hline $\begin{array}{l}\text { Phenol, } \\
o \text {-Chlorophenol, } \\
\text { m-Chlorophenol, } \\
\text { p-Chlorophenol, } \\
m \text {-Cresol }\end{array}$ & Active carbon & $A C$ & - & $\mathrm{F}$ & $160-220$ & - & - & $\begin{array}{l}\text { Larger molecules of lower solubility in } \\
\text { water adsorb to a greater degree. }\end{array}$ & $\begin{array}{l}\text { Khan et al. } \\
1997 a\end{array}$ \\
\hline
\end{tabular}




\begin{tabular}{|c|c|c|c|c|c|c|c|c|c|}
\hline Pollutant & Sorbent & 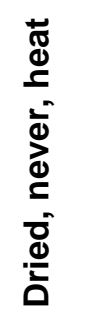 & 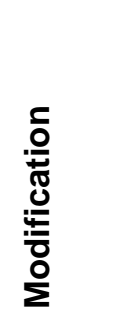 & 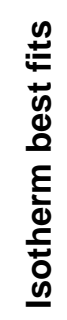 & $\begin{array}{l}\text { Adsorp. } \\
\text { capac. } \\
\text { (mg/g) }\end{array}$ & 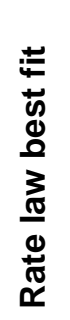 & 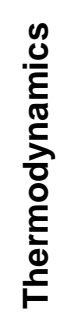 & Key Findings & Author (year) \\
\hline $\begin{array}{l}\text { Toluene, } \\
\text { Acetone, } \\
p \text {-Cresol, } \\
p \text {-Chlorophenol, } \\
\text { Benzene, } \\
n \text {-Pentanol, } \\
4 n \text {-Propylphenol, } \\
p \text {-Methylphenol }\end{array}$ & Active carbon & $\mathrm{AC}$ & - & $\mathrm{L}$ & $\begin{array}{l}260, \\
50, \\
19, \\
260, \\
200, \\
43, \\
200, \\
95\end{array}$ & - & - & & $\begin{array}{l}\text { Khan et al. } \\
1997 b\end{array}$ \\
\hline $\begin{array}{l}\text { Naphthalene, } \\
\text { Acenaphthylene, } \\
\text { Acenaphthene, } \\
\text { Fluorene, } \\
\text { Phenanthrene, } \\
\text { Anthracene, } \\
\text { Fluoranthene }\end{array}$ & $\begin{array}{l}\text { Cat-tail fibers; } \\
\text { Kapok fibers }\end{array}$ & $\begin{array}{l}60 \mathrm{C} \\
24 \mathrm{~h}\end{array}$ & $\begin{array}{l}\text { Cat-tail } \\
\text { was } \\
\text { ground }\end{array}$ & $\mathrm{F}$ & $0.05-0.6$ & - & - & $\begin{array}{l}\text { Cat-tail fibers were more effective than } \\
\text { kapok fibers; low affinity isotherms. }\end{array}$ & $\begin{array}{l}\text { Khan et al. } \\
2007\end{array}$ \\
\hline Dichloromethane & $\begin{array}{l}\text { Commercial G } \\
\text { active carbon }\end{array}$ & $A C$ & - & $\begin{array}{l}\mathrm{F} \\
\mathrm{L}\end{array}$ & 46 & $\begin{array}{l}2^{\text {nd }} \\
1^{\text {st }}\end{array}$ & Ex & $\begin{array}{l}\text { Best pH 6-8; different carbons showed } \\
\text { different fits. }\end{array}$ & $\begin{array}{l}\text { Khan et al. } \\
2010\end{array}$ \\
\hline $\begin{array}{l}16 \text { multi-ringed } \\
\text { compounds }\end{array}$ & $\begin{array}{l}\text { Biochar from } \\
\text { sewag. sludge }\end{array}$ & $\mathrm{BC}$ & $500 \mathrm{C}$ & - & - & - & - & $\begin{array}{l}\text { The biochar reduced bioaccumulation of } \\
\text { polyaromatic hydrocarbons by lettuce. }\end{array}$ & $\begin{array}{l}\text { Khan et al. } \\
2013\end{array}$ \\
\hline $\begin{array}{l}\text { 2,4-Dichlorophen- } \\
\text { oxyacetic acid }\end{array}$ & $\begin{array}{l}\text { Magnetic \& } \\
\text { graphitic C }\end{array}$ & $\mathrm{BC}$ & $\begin{array}{l}\mathrm{Fe}_{3} \mathrm{O}_{4} \\
\mu \text {-wave }\end{array}$ & $\mathrm{L}$ & $33-77$ & $2^{\text {nd }}$ & - & $\begin{array}{l}\text { The magnetic powders are easily } \\
\text { separated. }\end{array}$ & $\begin{array}{l}\text { Khoshnood \& } \\
\text { A. } 2012\end{array}$ \\
\hline Trichloroethylene & $\begin{array}{l}\text { Granular } \\
\text { active carbon }\end{array}$ & $A C$ & - & $\mathrm{F}$ & $1-80$ & - & - & $\begin{array}{l}\text { Preloaded with humic substances; effects } \\
\text { of calcium and salt; low affinity }\end{array}$ & $\begin{array}{l}\text { Kilduff et al. } \\
1998\end{array}$ \\
\hline Phenol & $\begin{array}{l}\text { Active carbon } \\
\text { from tobacco } \\
\text { residues }\end{array}$ & $\mathrm{AC}$ & $\begin{array}{l}\mathrm{K}_{2} \mathrm{CO}_{3}, \\
\mathrm{KOH} \\
700 \mathrm{C}\end{array}$ & $\mathrm{L}$ & 18,46 & $2^{\text {nd }}$ & - & - & Kilic et al. 2011 \\
\hline
\end{tabular}




\begin{tabular}{|c|c|c|c|c|c|c|c|c|c|}
\hline Pollutant & Sorbent & 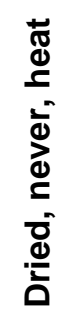 & 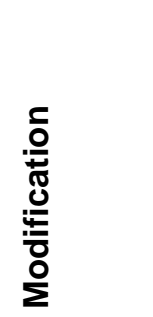 & 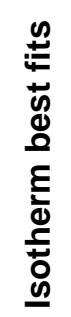 & $\begin{array}{l}\text { Adsorp. } \\
\text { capac. } \\
(\mathrm{mg} / \mathrm{g})\end{array}$ & 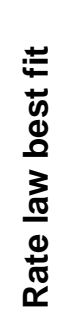 & 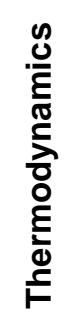 & Key Findings & Author (year) \\
\hline Phenol & $\begin{array}{l}\text { Powder act. } \mathrm{C} \text {, } \\
\text { Alginate bead, } \\
\text { Alginate } \mathrm{C} \text { mix }\end{array}$ & $\mathrm{AC}$ & $\begin{array}{l}\text { As- } \\
\text { received }\end{array}$ & $\mathrm{L}$ & $\begin{array}{l}113 \\
3 \\
75\end{array}$ & - & - & $\begin{array}{l}\text { Ideal adsorbed solution theory was used to } \\
\text { predict the adsorption on beads formed } \\
\text { from alginate and activated carbon. }\end{array}$ & Kim et al. 2011 \\
\hline $\begin{array}{l}\text { Dibromochloro- } \\
\text { propane; } \\
\text { Trichloroethylene }\end{array}$ & $\begin{array}{l}\text { Active carbons } \\
\text { from almond } \\
\text { shells }\end{array}$ & $\mathrm{AC}$ & $\begin{array}{l}850 \mathrm{C} \\
\text { steam }\end{array}$ & - & $100-115$ & - & - & Nut source did not influence the results. & $\begin{array}{l}\text { Klasson et al. } \\
2010\end{array}$ \\
\hline Trichloroethylene & $\begin{array}{l}\text { Active carbons } \\
\text { from flax \& } \\
\text { cotton }\end{array}$ & $\mathrm{AC}$ & $\begin{array}{l}\mathrm{H}_{3} \mathrm{PO}_{4} \\
\text { Steam }\end{array}$ & $\mathrm{L}$ & $64-80$ & - & - & $\begin{array}{l}\text { Also evaluated adsorption from the } \\
\text { gaseous phase. }\end{array}$ & $\begin{array}{l}\text { Klasson et al. } \\
2009\end{array}$ \\
\hline $\begin{array}{l}\text { Phenanthrene, } \\
\text { Naphthalene, } \\
\text { Acenaphthene }\end{array}$ & $\begin{array}{l}\text { Active carbon } \\
\text { from soybean } \\
\text { stalk }\end{array}$ & $\mathrm{AC}$ & $\begin{array}{l}\mathrm{H}_{3} \mathrm{PO}_{4} \\
700 \mathrm{C}\end{array}$ & - & - & - & - & $\begin{array}{l}\text { Uptake increased with carbonation } \\
\text { temperature and carbon content. }\end{array}$ & $\begin{array}{l}\text { Kong et al. } \\
2011 \mathrm{a}\end{array}$ \\
\hline Phenanthrene & $\begin{array}{l}\text { Biochar from } \\
\text { soy stalk }\end{array}$ & $\mathrm{BC}$ & $\begin{array}{l}300- \\
700 \mathrm{C}\end{array}$ & $\mathrm{F}$ & $7-30$ & - & - & $\begin{array}{l}\text { Linear \& Toth adsorption isotherms; found } \\
\text { competition with } \mathrm{Hg}(\mathrm{II}) \text { adsorption. }\end{array}$ & $\begin{array}{l}\text { Kong et al. } \\
2011 \mathrm{~b}\end{array}$ \\
\hline Phenanthrene & $\begin{array}{l}\text { Active carbon, } \\
\text { sesame stalk }\end{array}$ & $\mathrm{AC}$ & $\begin{array}{l}\mathrm{H}_{3} \mathrm{PO}_{4} \\
700 \mathrm{C}\end{array}$ & LF & $10-16$ & - & - & Hydrophobic interactions & $\begin{array}{l}\text { Kong et al. } \\
2012\end{array}$ \\
\hline $\begin{array}{l}\mathrm{N} \text {-nitrosodiethylamine, } \\
\mathrm{N} \text {-methyl-N'-nitro-N- } \\
\text { nitrosoguanidine }\end{array}$ & $\begin{array}{l}\text { Lignin } \\
\text { preparations }\end{array}$ & - & - & - & - & - & - & $\begin{array}{l}\text { Genotoxicants bind to lignin but not to } \\
\text { polysaccharides. }\end{array}$ & $\begin{array}{l}\text { Košíková et al. } \\
2009\end{array}$ \\
\hline$p$-Chlorophenol & $\begin{array}{l}\text { Active carbon } \\
\text { apricot stone }\end{array}$ & $\mathrm{AC}$ & - & - & $20-55$ & ID & - & $\begin{array}{l}\text { Intraparticle diffusion in three phases, was } \\
\text { shown by square-root time dependency. }\end{array}$ & $\begin{array}{l}\text { Koumanova et } \\
\text { al. } 2003\end{array}$ \\
\hline Phenol & $\begin{array}{l}\text { Polymeric } \\
\text { resins }\end{array}$ & - & - & - & - & - & - & $\begin{array}{l}\text { Membranes all were selective for phenol in } \\
\text { mixtures with acetone; } \mathrm{NaOH} \\
\text { regeneration. }\end{array}$ & $\begin{array}{l}\text { Kujawski et al. } \\
2004\end{array}$ \\
\hline $\begin{array}{l}\text { Dibenzothiophenes } \\
\text { (from kerosene) }\end{array}$ & $\begin{array}{l}\text { Active carbon } \\
\text { from rice husk }\end{array}$ & $\mathrm{AC}$ & $\begin{array}{l}850 \mathrm{C} \text { in } \\
\mathrm{CO}_{2}\end{array}$ & & $0.05-0.06$ & - & - & Pore size distribution was the key factor & $\begin{array}{l}\text { Kumagai et al. } \\
2009\end{array}$ \\
\hline
\end{tabular}




\begin{tabular}{|c|c|c|c|c|c|c|c|c|c|}
\hline Pollutant & Sorbent & 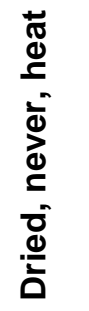 & $\begin{array}{l}\frac{c}{0} \\
\frac{0}{\bar{T}} \\
\frac{0}{\frac{0}{7}} \\
\frac{0}{\Sigma}\end{array}$ & 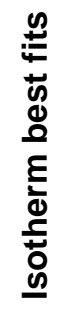 & $\begin{array}{l}\text { Adsorp. } \\
\text { capac. } \\
(\mathrm{mg} / \mathrm{g})\end{array}$ & 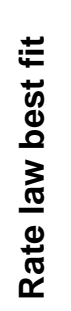 & 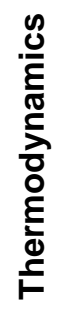 & Key Findings & Author (year) \\
\hline $\begin{array}{l}\text { Phenol, } \\
\text { 4-Nitrophenol }\end{array}$ & $\begin{array}{l}\text { Granular } \\
\text { active carbon }\end{array}$ & $\mathrm{AC}$ & - & $\begin{array}{l}\mathrm{RP} \\
\mathrm{F}\end{array}$ & $\begin{array}{l}166 ; \\
206\end{array}$ & ID & - & Intraparticle diffusion with three phases & $\begin{array}{l}\text { Kumar et al. } \\
2007\end{array}$ \\
\hline $\begin{array}{l}\text { Estriol endocrine } \\
\text { disrupter }\end{array}$ & $\begin{array}{l}\text { Activated } \\
\text { charcoal }\end{array}$ & - & - & $\mathrm{L}$ & 0.003 & $1^{\text {st }}$ & Ex & Film diffusion control of rate & $\begin{array}{l}\text { Kumar et al. } \\
2009 a\end{array}$ \\
\hline Acrylonitrile & $\begin{array}{l}\text { Fly ash from } \\
\text { bagasse }\end{array}$ & $\mathrm{FA}$ & $\begin{array}{l}\text { Sugar } \\
\text { mill }\end{array}$ & & $18-91$ & - & - & Two-step Langmuir adsorption & $\begin{array}{l}\text { Kumar et al. } \\
2008\end{array}$ \\
\hline $\begin{array}{l}\text { Phenol, } \\
\text { 2-Chlorophenol, } \\
\text { 4-Chlorophenol }\end{array}$ & $\begin{array}{l}\text { Trametes } \\
\text { versicolor }\end{array}$ & $70 \mathrm{C}$ & Crushed & $\mathrm{L}$ & $\begin{array}{l}50 \\
86 \\
112\end{array}$ & $1^{\text {st }}$ & - & $\begin{array}{l}\mathrm{NaOH} \text { was used for regeneration; also the } \\
\text { authors did packed bed tests. }\end{array}$ & $\begin{array}{l}\text { Kumar et al. } \\
2009 b\end{array}$ \\
\hline $\begin{array}{l}\text { Phenol, } \\
\text { 2-Chlorophenol, } \\
\text { 4-Chlorophenol }\end{array}$ & $\begin{array}{l}\text { Acacia l. bark } \\
\text { powder }\end{array}$ & $80 \mathrm{C}$ & $\begin{array}{l}0.1 \mathrm{~N} \\
\mathrm{NaOH} \\
\text { acid }\end{array}$ & $\mathrm{L}$ & $\begin{array}{l}94 \\
147 \\
182 \\
\end{array}$ & $1^{\text {st }}$ & - & $\begin{array}{l}\text { Greatest uptake at } \mathrm{pH}=7 \text {, and drop-off at } \\
\text { higher levels }\end{array}$ & $\begin{array}{l}\text { Kumar \& Min } \\
2011 \mathrm{a}\end{array}$ \\
\hline $\begin{array}{l}\text { Phenol, } \\
\text { 2-Chlorophenol, } \\
\text { 4-Chlorophenol }\end{array}$ & $\begin{array}{l}\text { Schizophyllum } \\
\text { commune } \\
\text { fungus }\end{array}$ & $60 \mathrm{C}$ & $\begin{array}{l}\text { Non- } \\
\text { living }\end{array}$ & $\mathrm{L}$ & $\begin{array}{l}120 \\
178 \\
244 \\
\end{array}$ & $2^{\text {nd }}$ & - & $\begin{array}{l}\text { Highest uptake at } \mathrm{pH} 4 \text { to } 7 \text {; regenerate } \\
\text { with } \mathrm{NaOH} \text {. }\end{array}$ & $\begin{array}{l}\text { Kumar \& Min } \\
2011 b\end{array}$ \\
\hline 2,4,6-Triclorophenol & $\begin{array}{l}\text { Acacia l. bark } \\
\text { powder }\end{array}$ & $80 \mathrm{C}$ & $\begin{array}{l}0.1 \mathrm{~N} \\
\mathrm{NaOH} \\
\text { acid }\end{array}$ & $\begin{array}{l}\mathrm{L}, \\
\mathrm{E}\end{array}$ & 256 & $2^{\text {nd }}$ & - & $\begin{array}{l}\text { Highest sorption at } \mathrm{pH}=5 \text {; Langmuir and } \\
\text { Elovich isotherm best fits. }\end{array}$ & $\begin{array}{l}\text { Kumar et al. } \\
2012\end{array}$ \\
\hline $\begin{array}{l}\text { 4-Chlorophenol, } \\
\text { 2,4-Dichlorophenol, } \\
\text { 2,4,6-Trichlorophen. }\end{array}$ & Peat & - & - & $\mathrm{F}$ & - & $2^{\text {nd }}$ & - & $\begin{array}{l}\text { Increasing sorption in the order: } \\
\text { 4-Chlorophenol }<2,4 \text {-Dichlorophenol }< \\
2,4,6 \text {-Trichlorophenol }\end{array}$ & $\begin{array}{l}\text { Kusmierek et } \\
\text { al. } 2013\end{array}$ \\
\hline Nonylphenol & $\begin{array}{l}\text { Rhizopus } \\
\text { arrhizus in } \\
\text { chitosan bead }\end{array}$ & - & $\begin{array}{l}\text { Auto- } \\
\text { claved } \\
125 \mathrm{C} \\
\end{array}$ & $\begin{array}{l}\mathrm{FS} \\
\mathrm{RP}\end{array}$ & $54-74$ & 1st & - & $\begin{array}{l}\text { Shrinking core model; autoclaving } \\
\text { increased uptake; regeneration using } \\
\text { methanol }\end{array}$ & $\begin{array}{l}\text { Lang et al. } \\
2009\end{array}$ \\
\hline $\begin{array}{l}\text { Phenol, } \\
\text { 2,3,4-Trichlorophen. }\end{array}$ & $\begin{array}{l}\text { Activated } \\
\text { carbons }\end{array}$ & $A C$ & - & LF & $\begin{array}{l}95-280 \\
130-680 \\
\end{array}$ & - & - & $\begin{array}{l}\text { Heterogeneity was quantified using the } \\
\text { Langmuir-Freundlich model. }\end{array}$ & $\begin{array}{l}\text { László et al. } \\
2003\end{array}$ \\
\hline Phenol & $\begin{array}{l}\text { Activated } \\
\text { carbons }\end{array}$ & $A C$ & $\begin{array}{l}\text { Nitric ac } \\
900 \mathrm{C}\end{array}$ & LF & $266-279$ & - & - & $\begin{array}{l}\text { Steam activation, Dubinin-Astakhov model } \\
\text { used to model heterogeneous adsorption }\end{array}$ & $\begin{array}{l}\text { László et al. } \\
2006\end{array}$ \\
\hline
\end{tabular}




\begin{tabular}{|c|c|c|c|c|c|c|c|c|c|}
\hline Pollutant & Sorbent & 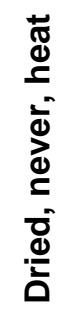 & 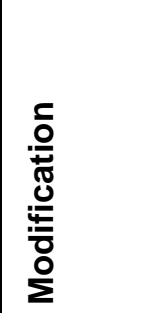 & 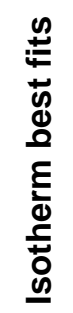 & $\begin{array}{l}\text { Adsorp. } \\
\text { capac. } \\
\text { (mg/g) }\end{array}$ & 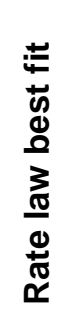 & 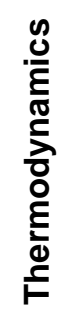 & Key Findings & Author (year) \\
\hline $\begin{array}{l}\text { Phenol, } \\
\text { 2,3,4-Trichlorophen. }\end{array}$ & $\begin{array}{l}\text { Activated } \\
\text { carbons }\end{array}$ & $A C$ & $\begin{array}{l}\text { Steam } \\
900 \mathrm{C}\end{array}$ & $\mathrm{L}$ & $\begin{array}{l}95-280 \\
130-680\end{array}$ & - & - & $\begin{array}{l}\text { Trichlorophenol adsorption was hindered } \\
\text { at high } \mathrm{pH} \text { due to its lower } \mathrm{pK}_{\mathrm{a}} \text {. }\end{array}$ & $\begin{array}{l}\text { László \& Szucs } \\
2001\end{array}$ \\
\hline $\begin{array}{l}\text { Phenol, } \\
\text { Aniline, } \\
\text { Nitrobenzene, } \\
\text { Benzoic acid }\end{array}$ & $\begin{array}{l}\text { Active carbon } \\
\text { with different } \\
\text { O content }\end{array}$ & $A C$ & $\begin{array}{l}350 \mathrm{C} \\
\text { oxygen }\end{array}$ & $\mathrm{F}$ & $\begin{array}{l}100-210 \\
- \\
278-367 \\
30-200\end{array}$ & - & - & Much higher adsorption at $\mathrm{pH} 3$ than 11 & $\begin{array}{l}\text { Leng \& Pinto } \\
1997\end{array}$ \\
\hline Pentachlorophenol & $\begin{array}{l}\text { Granular } \\
\text { active carbon }\end{array}$ & $A C$ & - & PR & $200-340$ & ID & - & $\begin{array}{l}\text { Prausnitz-Radke isotherm model; } \\
\text { intraparticle diffusion }\end{array}$ & $\begin{array}{l}\text { Leyva-Ramos } \\
\text { et al. } 2009 a\end{array}$ \\
\hline Pentachlorophenol & $\begin{array}{l}\text { Active carbon } \\
\text { fibers }\end{array}$ & $A C$ & - & $\bar{L}$ & $230-280$ & ID & - & Hindered diffusion into pores & $\begin{array}{l}\text { Leyva-Ramos } \\
\text { et al. } 2007\end{array}$ \\
\hline $\begin{array}{l}\text { Naphthalene- } \\
\text { sulphonic acid }\end{array}$ & Active carbon & $A C$ & $\begin{array}{l}\text { Ozoniz- } \\
\text { ation }\end{array}$ & $\mathrm{PR}$ & $70-90$ & ID & - & $\begin{array}{l}\text { Prausnitz-Radke isotherm model; excess- } \\
\text { ive ozonation greatly decreases uptake. }\end{array}$ & $\begin{array}{l}\text { Leyva-Ramos } \\
\text { et al. } 2009 \mathrm{~b}\end{array}$ \\
\hline $\begin{array}{l}\text { Methyltertbutyl ether } \\
\text { (MTBE for gasoline) }\end{array}$ & $\begin{array}{l}\text { Biologically } \\
\text { active carbon }\end{array}$ & $A C$ & $\begin{array}{l}\text { Cultured } \\
\text { (inocul.) }\end{array}$ & $F$ & $2-40$ & - & - & $\begin{array}{l}\text { Low affinity isotherms; microbial action } \\
\text { gradually breaks down MTBE. }\end{array}$ & Li et al. 2013c \\
\hline $\begin{array}{l}\text { Porphyrin with long } \\
\text { alkyl tails }\end{array}$ & $\begin{array}{l}\text { Single-wall C } \\
\text { nanotubes }\end{array}$ & - & - & - & - & - & - & $\begin{array}{l}\text { Selectivity was demonstrated, leading to } \\
\text { semi-conductivity. }\end{array}$ & Li et al. 2004 \\
\hline $\begin{array}{l}\text { 2,4-D; } \\
\text { Acetochlor }\end{array}$ & Biochars & $\mathrm{BC}$ & $\begin{array}{l}200 \\
350 \\
500 C\end{array}$ & - & $\begin{array}{l}4-25 \\
4-20\end{array}$ & - & - & $\begin{array}{l}\text { Biochar added to soil slowed the release of } \\
\text { the herbicides; low affinity isotherms. }\end{array}$ & Li et al. 2013a \\
\hline Tetracycline & $\begin{array}{l}\text { Anaerobic } \\
\text { gran. sludge }\end{array}$ & No & $\begin{array}{l}\text { Live } \\
\text { (wet) }\end{array}$ & $\overline{\mathrm{L}}$ & $3-5$ & - & En & Highest adsorption was at $\mathrm{pH}=3$. & Li et al. 2013b \\
\hline$p$-Nitroalinine & $\begin{array}{l}\text { Active carbon } \\
\text { from corn stalk }\end{array}$ & $\mathrm{AC}$ & $\begin{array}{l}\text { Phosph- } \\
\text { ate }\end{array}$ & $\begin{array}{l}\mathrm{RP} \\
\mathrm{L}\end{array}$ & $313-406$ & $2^{\text {nd }}$ & - & Best pH 5-7 & Li et al. 2009 \\
\hline $\begin{array}{l}\text { MTBE; } \\
\text { Trichloroethylene }\end{array}$ & Active carbon & $A C$ & $\begin{array}{l}\text { Three O } \\
\text { levels }\end{array}$ & $\mathrm{F}$ & $\begin{array}{l}0.3-8 \\
4-50\end{array}$ & - & - & $\begin{array}{l}\text { Uptake highly dependent on micropores; } \\
\text { uptake inhibited by natural organics; TCE } \\
\text { adsorption falls with incr. } \mathrm{O}+\mathrm{N} \text { content }\end{array}$ & Li et al. 2002 \\
\hline
\end{tabular}




\begin{tabular}{|c|c|c|c|c|c|c|c|c|c|}
\hline Pollutant & Sorbent & 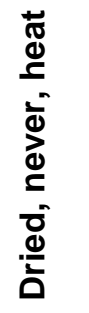 & 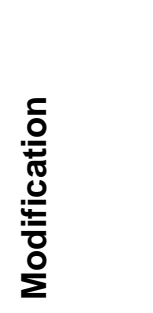 & 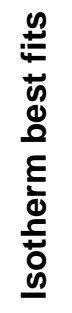 & $\begin{array}{l}\text { Adsorp. } \\
\text { capac. } \\
(\mathrm{mg} / \mathrm{g})\end{array}$ & 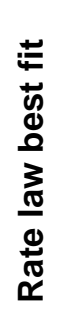 & 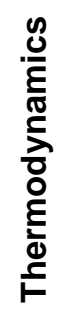 & Key Findings & Author (year) \\
\hline Phenanthrene & $\begin{array}{l}\text { Fruit cuticles; } \\
\text { Potato perid. }\end{array}$ & $60 \mathrm{C}$ & fractions & $\mathrm{F}$ & $1-7$ & - & - & $\begin{array}{l}\text { Cutin and suberin components played big } \\
\text { role in adsorption; low affinity }\end{array}$ & $\begin{array}{l}\text { Li \& Chen } \\
2009\end{array}$ \\
\hline $\begin{array}{l}\text { Phenanthrene; } \\
\text { Pyrene }\end{array}$ & Pine bark & $60 \mathrm{C}$ & $\begin{array}{l}\text { Extract, } \\
\text { Saponif, } \\
\text { Hydrol, } \\
\text { etc. }\end{array}$ & - & $0-6$ & - & - & $\begin{array}{l}\text { Lignin had the largest contribution to } \\
\text { adsorption; bulk concentrations too low; } \\
\text { low affinity isotherms; acid hydrolysis had } \\
\text { good effect by removing polysaccharides. }\end{array}$ & Li et al. 2010a \\
\hline $\begin{array}{l}\text { 4-Chlorophenol, } \\
\text { 2,4-Dichlorophenol, } \\
\text { 2,4,6-Trichlorophen. }\end{array}$ & $\begin{array}{l}\text { Fruit cuticles; } \\
\text { Potato perid. }\end{array}$ & $60 \mathrm{C}$ & fractions & $\mathrm{F}$ & $0-100$ & - & - & $\begin{array}{l}\text { Cutin and suberin components played big } \\
\text { role in adsorption; low affinity. }\end{array}$ & Li et al. 2012 \\
\hline Phenanthrene & $\begin{array}{l}\text { Tea leaf } \\
\text { powder }\end{array}$ & $70 \mathrm{C}$ & Brewed & $\mathrm{F}$ & $0-5$ & - & - & $\begin{array}{l}\text { Low affinity; aliphatic carbons in tea leaves } \\
\text { correlated with uptake. }\end{array}$ & Lin et al. 2007 \\
\hline Organic carbon & Biochars & $\mathrm{BC}$ & - & - & $0.004-0.8$ & - & - & $\begin{array}{l}\text { Hot water extraction of organics already } \\
\text { present in various biochars }\end{array}$ & Lin et al. 2012 \\
\hline $\begin{array}{l}\text { Phenol; } \\
\text { Aniline }\end{array}$ & Active carbon & $A C$ & - & $\mathrm{L}$ & $\begin{array}{l}200-300 \\
200-300\end{array}$ & - & - & $\begin{array}{l}\text { Poor fits to Langmuir model actually; the } \\
\text { ideal adsorbed phase model was used. }\end{array}$ & $\begin{array}{l}\text { Liu \& Pinto } \\
1997\end{array}$ \\
\hline Pentachlorophenol & $\begin{array}{l}\text { Biochar from } \\
\text { rice straw }\end{array}$ & $\mathrm{BC}$ & $\begin{array}{l}\text { Open } \\
\text { burning }\end{array}$ & $\mathrm{F}$ & $30-45$ & - & - & $\begin{array}{l}\text { The biochar benefited germination and } \\
\text { plant growth in-situ. }\end{array}$ & Lou et al. 2011 \\
\hline Trihalomethanes & $\begin{array}{l}\text { Carbon } \\
\text { nanotubes }\end{array}$ & - & - & $\mathrm{L}$ & $1-2.5$ & - & - & Capacity drops off above $\mathrm{pH}=7$ & Lu et al. 2005 \\
\hline Trihalomethanes & $\begin{array}{l}\text { M.-W. carbon } \\
\text { nanotubes }\end{array}$ & - & - & $\mathrm{L}$ & $0.3-3$ & $1^{\text {st }}$ & Ex & Proposed for drinking water treatment. & Lu et al. 2006 \\
\hline $\begin{array}{l}\text { Benzene; } \\
\text { Toluene; } \\
\text { o-Xylene }\end{array}$ & $\begin{array}{l}\text { Wood chips: } \\
\text { fir \& pine }\end{array}$ & - & $\begin{array}{l}\text { Water- } \\
\text { soaked }\end{array}$ & Lin & $0-6$ & - & - & $\begin{array}{l}\text { Fractional lignin content of wood correlated } \\
\text { with the adsorption capacity. }\end{array}$ & $\begin{array}{l}\text { Mackay \& G. } \\
2000\end{array}$ \\
\hline Phenol & Active carbon & $A C$ & $\begin{array}{l}\text { Oxida- } \\
\text { tion }\end{array}$ & $\mathrm{L}$ & $16-20$ & - & - & $\begin{array}{l}\text { Oxidation adversely affected phenol } \\
\text { adsorption. }\end{array}$ & $\begin{array}{l}\text { Mahajan et al. } \\
1980\end{array}$ \\
\hline Phenol & $\begin{array}{l}\text { Rice husk; } \\
\text { Rice husk ash }\end{array}$ & $\begin{array}{l}100 \\
- \\
\end{array}$ & $400 \mathrm{C}$ & $\begin{array}{l}\mathrm{F} \\
\mathrm{L}\end{array}$ & $\begin{array}{l}0.002 \\
0.89 \\
\end{array}$ & $1^{\text {st }}$ & - & Ashing greatly increased adsorption. & $\begin{array}{l}\text { Mahvi et al. } \\
2004\end{array}$ \\
\hline
\end{tabular}




\begin{tabular}{|c|c|c|c|c|c|c|c|c|c|}
\hline Pollutant & Sorbent & 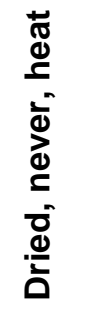 & 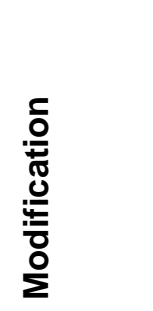 & 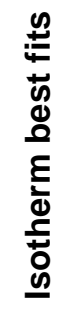 & $\begin{array}{l}\text { Adsorp. } \\
\text { capac. } \\
\text { (mg/g) }\end{array}$ & 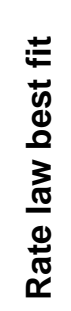 & 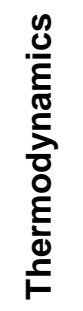 & Key Findings & Author (year) \\
\hline Toluene & $\begin{array}{l}\text { Carbon } \\
\text { aerogels }\end{array}$ & $\mathrm{AC}$ & $\begin{array}{l}900 \mathrm{C} \\
\text { steam }\end{array}$ & - & 1360 & - & - & $\begin{array}{l}\text { Initial carbonation was at } 500 \text { or } 1000 \mathrm{C} \text {; } \\
\text { regenerated at } 400 \mathrm{C} \text {. }\end{array}$ & $\begin{array}{l}\text { Maldonado-H. } \\
\text { et al. } 2007\end{array}$ \\
\hline Atrazine pesticide & $\begin{array}{l}\text { Active C fiber } \\
\text { Gran. act. C }\end{array}$ & $A C$ & $\begin{array}{l}800- \\
1000 C\end{array}$ & - & - & - & - & $\begin{array}{l}\text { Column tests (breakthrough); wide-open } \\
\text { microstructure of carbon highly beneficial. }\end{array}$ & $\begin{array}{l}\text { Martin-G. \& } \\
\text { Font } 2001\end{array}$ \\
\hline Pentachlorophenol & $\begin{array}{l}\text { Aspergillus } \\
\text { niger fungi }\end{array}$ & $60 \mathrm{C}$ & - & $\mathrm{F}$ & 3-10 & $2^{\text {nd }}$ & Ex & $\begin{array}{l}\text { Decreased uptake with increasing } \mathrm{pH} \text {, } \\
\text { except if adsorbent was cationized }\end{array}$ & $\begin{array}{l}\text { Mathialagan \& } \\
\text { V. } 2009\end{array}$ \\
\hline $\begin{array}{l}\text { Phenol, } \\
\text { p-Nitrophenol, } \\
\text { Nitrobenzene }\end{array}$ & $\begin{array}{l}\text { Activated } \\
\text { carbon }\end{array}$ & $A C$ & - & - & $\begin{array}{l}150-260 \\
235-280 \\
230-290 \\
\end{array}$ & - & - & Acid-base interactions proposed & $\begin{array}{l}\text { Mattson et al. } \\
1969\end{array}$ \\
\hline $\begin{array}{l}\text { Phenol, } \\
\text { Resorcinol, } \\
\text { 2-Chlorophenol }\end{array}$ & Rice husk ash & $\mathrm{FA}$ & $\begin{array}{l}\text { Muffle } \\
\text { furnace }\end{array}$ & $\begin{array}{l}\mathrm{L} \\
\mathrm{F}\end{array}$ & $\begin{array}{l}15, \\
8, \\
0.2\end{array}$ & - & - & Maximum adsorption near neutral pH. & $\begin{array}{l}\text { Mbui et al. } \\
2002\end{array}$ \\
\hline $\begin{array}{l}\text { Carbofuran; } \\
\text { Methyl parathion }\end{array}$ & $\begin{array}{l}\text { Chestnut } \\
\text { shells }\end{array}$ & $\begin{array}{l}110 \\
\mathrm{C}\end{array}$ & $\begin{array}{l}\text { Nitric } \\
\text { acid }\end{array}$ & $\mathrm{L}$ & $\begin{array}{l}2.4 \\
6 \\
\end{array}$ & $\begin{array}{l}\text { ID } \\
1 \text { st }\end{array}$ & $\begin{array}{l}\text { En, } \\
\text { Ex }\end{array}$ & & $\begin{array}{l}\text { Memon et al. } \\
2007\end{array}$ \\
\hline Methyl parathion & $\begin{array}{l}\text { Watermelon } \\
\text { peels }\end{array}$ & $\begin{array}{l}110 \\
\mathrm{C}\end{array}$ & $\begin{array}{l}\text { Nitric } \\
\text { acid }\end{array}$ & $\mathrm{L}$ & 7 & $1^{\mathrm{st}}$ & En & Acidic $\mathrm{pH}$ gives higher adsorption. & $\begin{array}{l}\text { Memon et al. } \\
2008\end{array}$ \\
\hline Methyl parathion & Mango kernels & $\begin{array}{l}110 \\
\mathrm{C}\end{array}$ & $\begin{array}{l}\text { Nitric } \\
\text { acid }\end{array}$ & $\mathrm{L}$ & - & $1^{\mathrm{st}}$ & En & & $\begin{array}{l}\text { Memon et al. } \\
2009\end{array}$ \\
\hline $\begin{array}{l}\text { Polychlorinated } \\
\text { piphenyl (PCBs) }\end{array}$ & $\begin{array}{l}\text { Granular } \\
\text { active carbon }\end{array}$ & $\mathrm{AC}$ & - & - & - & - & - & $\begin{array}{l}\text { Biofilm adversely affected adsorption of } \\
\text { PCBs, but not considered significant. }\end{array}$ & $\begin{array}{l}\text { Mercier et al. } \\
2013\end{array}$ \\
\hline Ibuprofin & $\begin{array}{l}\text { Active carbon } \\
\text { fr. cork waste }\end{array}$ & $\mathrm{AC}$ & $\begin{array}{l}\mathrm{K}_{2} \mathrm{CO}_{3} \\
\text { steam }\end{array}$ & $\mathrm{L}$ & $139-417$ & $2^{\text {nd }}$ & nul & $\begin{array}{l}\text { Removal decreases with increasing } \mathrm{pH} ; \\
\text { best with oxidation then steam activation. }\end{array}$ & $\begin{array}{l}\text { Mestre et al. } \\
2007\end{array}$ \\
\hline $\begin{array}{l}\text { Chlorhexidine } \\
\text { diacetate }\end{array}$ & $\begin{array}{l}\text { Flax fibers, } \\
\text { Cotton fibers }\end{array}$ & Yes & $\begin{array}{l}\text { Bleach, } \\
\text { Cottoniz }\end{array}$ & & $\begin{array}{l}0.4 \\
0.2 \\
\end{array}$ & - & - & $\begin{array}{l}\text { The low porosity and high crystallinity of } \\
\text { the cellulose explains the low adsorption. }\end{array}$ & $\begin{array}{l}\text { Mikhalovska et } \\
\text { al. } 2012\end{array}$ \\
\hline Trichloroethyene & $\begin{array}{l}\text { Active carbon } \\
3 \text { commercial }\end{array}$ & $A C$ & - & - & $200-450$ & - & - & Air stripping was reduced by water vapor. & $\begin{array}{l}\text { Miyake et al. } \\
2003\end{array}$ \\
\hline
\end{tabular}




\begin{tabular}{|c|c|c|c|c|c|c|c|c|c|}
\hline Pollutant & Sorbent & 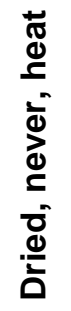 & $\begin{array}{l}\frac{c}{0} \\
\frac{0}{\mathbb{N}} \\
\frac{0}{\frac{7}{0}} \\
\frac{0}{2}\end{array}$ & 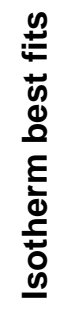 & $\begin{array}{l}\text { Adsorp. } \\
\text { capac. } \\
(\mathrm{mg} / \mathrm{g})\end{array}$ & 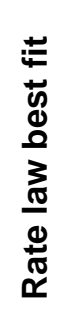 & 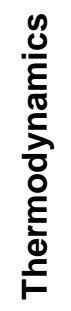 & Key Findings & Author (year) \\
\hline Pyridine & $\begin{array}{l}\text { Active carbons } \\
\text { (coconut) }\end{array}$ & $\mathrm{AC}$ & $\begin{array}{l}\mathrm{H}_{2} \mathrm{SO}_{4} \\
200-800\end{array}$ & $\mathrm{~L}$ & $20-161$ & $1^{\text {st }}$ & En & Best uptake at $\mathrm{pH}>4$; film diffusion & $\begin{array}{l}\text { Mohan et al. } \\
2004\end{array}$ \\
\hline $\begin{array}{l}\text { Alpha-picoline, } \\
\text { Beta-picoline, } \\
\text { Gamma-picline }\end{array}$ & $\begin{array}{l}\text { Active carbons } \\
\text { (coconut) }\end{array}$ & $\mathrm{AC}$ & $\begin{array}{l}\mathrm{H}_{2} \mathrm{SO}_{4} \\
200-800\end{array}$ & $\mathrm{~L}$ & $\begin{array}{l}25-49 \\
42-149 \\
142-400\end{array}$ & $2^{\text {nd }}$ & & $\begin{array}{l}\text { Particle diffusion or film diffusion; } \\
\text { adsorption capacities were inconsistent } \\
\text { relative to temperature of equilibration. }\end{array}$ & $\begin{array}{l}\text { Mohan et al. } \\
2005\end{array}$ \\
\hline Phenol & $\begin{array}{l}\text { Active carbons } \\
\text { (sawdust) }\end{array}$ & $\mathrm{AC}$ & $\begin{array}{l}\mathrm{ZnCl}_{2} \\
300-600\end{array}$ & $\begin{array}{l}\mathrm{L} \\
\mathrm{F}\end{array}$ & 3 & $2^{\text {nd }}$ & - & Highest uptake at $\mathrm{pH}=3.5$ & $\begin{array}{l}\text { Mohanty et al. } \\
2005\end{array}$ \\
\hline Pentachlorophenol & $\begin{array}{l}\text { Granular } \\
\text { active carbon }\end{array}$ & $\mathrm{AC}$ & - & $\begin{array}{l}\mathrm{RP} \\
\mathrm{F}\end{array}$ & 500 & - & Ex & $\begin{array}{l}\text { Radke-Prausnitz modified isotherm } \\
\text { accounts for both } \mathrm{pH} \text { and temperature; } \\
\text { desorbable at high } \mathrm{pH} \text {. }\end{array}$ & $\begin{array}{l}\text { Mollah \& Rob- } \\
\text { inson 1996a }\end{array}$ \\
\hline Pentachlorophenol & $\begin{array}{l}\text { Granular } \\
\text { active carbon }\end{array}$ & $\mathrm{AC}$ & - & - & - & $1^{\text {st }}$ & - & Batch and plug-flow kinetics modeled. & $\begin{array}{l}\text { Mollah \& Rob- } \\
\text { inson 1996b }\end{array}$ \\
\hline $\begin{array}{l}\text { Phenol, } \\
\text { m-Aminophenol, } \\
\text { p-Cresol, } \\
\text { p-Nitrophenol }\end{array}$ & $\begin{array}{l}\text { Active carbon } \\
\text { fr. coal }\end{array}$ & $\mathrm{AC}$ & Steam & - & $\begin{array}{l}167 \\
178 \\
209 \\
196\end{array}$ & - & - & $\begin{array}{l}\text { Thermal regeneration was possible, but } \\
\text { the adsorption capacities gradually } \\
\text { decreased with increasing cycles; some } \\
\text { was physi- and some chemi-sorbed. }\end{array}$ & $\begin{array}{l}\text { Moreno-Castilla } \\
\text { et al. 1995a }\end{array}$ \\
\hline $\begin{array}{l}\text { Phenol, } \\
m \text {-Aminophenol, } \\
p \text {-Cresol, } \\
p \text {-Nitrophenol, } \\
m \text {-Chlorophenol }\end{array}$ & $\begin{array}{l}\text { Active carbon } \\
\text { fr. coal }\end{array}$ & $\mathrm{AC}$ & Steam & $\mathrm{L}$ & $\begin{array}{l}97-152, \\
66-183, \\
99-243, \\
127-232 \\
66-206\end{array}$ & - & - & $\begin{array}{l}\text { Donor-acceptor interactions; adsorption fell } \\
\text { at higher } \mathrm{pH} \text {, depending on adsorbate } \\
\text { details. }\end{array}$ & $\begin{array}{l}\text { Moreno-Castilla } \\
\text { et al. } 1995 \mathrm{~b}\end{array}$ \\
\hline $\begin{array}{l}\text { Phenol, } \\
\text { p--Nitrophenol }\end{array}$ & Active carbon & $\mathrm{AC}$ & $\begin{array}{l}\text { Nitric a., } \\
\mathrm{CO}_{2}\end{array}$ & $\mathrm{~L}$ & $73-238$ & - & - & $\begin{array}{l}\text { The } \mathrm{pH} \text { effects were consistent with charge } \\
\text { interactions. }\end{array}$ & $\begin{array}{l}\text { Mourão et al. } \\
2011\end{array}$ \\
\hline Phenol & $\begin{array}{l}\text { Charred } \\
\text { sawdust }\end{array}$ & $B C$ & $673 C$ & $L$ & 345 & $2^{\text {nd }}$ & - & $\begin{array}{l}\text { Oxygen-containing groups participated in } \\
\text { the adsorption. }\end{array}$ & $\begin{array}{l}\text { Mubarik et al. } \\
2012\end{array}$ \\
\hline $\begin{array}{l}\text { Analine, } \\
\text { Benzoic acid, } \\
\text { p-Nitrophenol }\end{array}$ & $\begin{array}{l}\text { Activated } \\
\text { carbon }\end{array}$ & $A C$ & - & $\mathrm{L}$ & $\begin{array}{l}465-660 \\
866 \\
695-987\end{array}$ & - & - & $\begin{array}{l}\text { Accounting for } \mathrm{pH} \text { effects by means of } \mathrm{pK}_{\mathrm{a}} \\
\text { values and double layer effects }\end{array}$ & $\begin{array}{l}\text { Müller et al. } \\
1985 a\end{array}$ \\
\hline
\end{tabular}




\begin{tabular}{|c|c|c|c|c|c|c|c|c|c|}
\hline Pollutant & Sorbent & 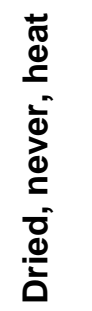 & 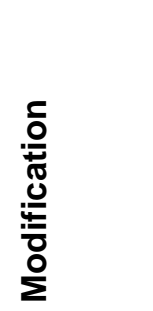 & 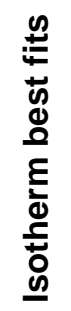 & $\begin{array}{l}\text { Adsorp. } \\
\text { capac. } \\
(\mathbf{m g} / \mathrm{g})\end{array}$ & 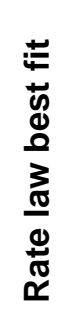 & 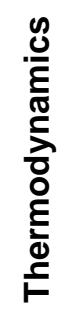 & Key Findings & Author (year) \\
\hline Phenol & $\begin{array}{l}\text { Activated } \\
\text { carbons }\end{array}$ & $A C$ & $\begin{array}{l}\text { Nitric a., } \\
\mathrm{CO}_{2}\end{array}$ & $\mathrm{~F}$ & $45-90$ & - & - & $\begin{array}{l}\text { Reduced adsorption at high pH due to } \\
\text { electrostatics; pi-pi interactions proposed. }\end{array}$ & $\begin{array}{l}\text { Nabais et al. } \\
2009\end{array}$ \\
\hline Phenol & $\begin{array}{l}\text { Pseudomonas } \\
\text { aeruginosa }\end{array}$ & - & $\begin{array}{l}\text { Free or } \\
\text { fixed }\end{array}$ & - & - & - & - & $\begin{array}{l}\text { Fixing of the bacteria onto GAC or on } \\
\text { alginate beads doubles the adsorption. }\end{array}$ & $\begin{array}{l}\text { Namane et al. } \\
2012\end{array}$ \\
\hline 2-Chlorophenol & $\begin{array}{l}\text { Carbon from } \\
\text { coir pith }\end{array}$ & $A C$ & $700 \mathrm{C}$ & $\mathrm{F}$ & 18 & $2^{\text {nd }}$ & & $\begin{array}{l}\text { Acidic } \mathrm{pH} \text { favored adsorption; } \\
\text { chemisorption played major role. }\end{array}$ & $\begin{array}{l}\text { Namasivayam } \\
\text { \& Kavitha } 2003\end{array}$ \\
\hline Phenol & $\begin{array}{l}\text { Carbon from } \\
\text { coir pith }\end{array}$ & $A C$ & $\begin{array}{l}\mathrm{ZnCl} 2 \\
700 \mathrm{C}\end{array}$ & LF & - & - & - & $\begin{array}{l}\text { Rate of adsorption was faster for smaller } \\
\text { particles. }\end{array}$ & $\begin{array}{l}\text { Namasivayam } \\
\text { \& Sangr. } 2006\end{array}$ \\
\hline Paraquat & $\begin{array}{l}\text { Sawdust from } \\
\text { Triplochiton s }\end{array}$ & $\begin{array}{l}\text { Sun } \\
\text { dry }\end{array}$ & Ground & $\mathrm{L}$ & 9.5 & $2^{\text {nd }}$ & Ex & $\begin{array}{l}\text { Uptake increases with increasing } \mathrm{pH} ; \mathrm{NaCl} \\
\text { reduces adsorption capacity. }\end{array}$ & $\begin{array}{l}\text { NanseuNjiki et } \\
\text { al. } 2010\end{array}$ \\
\hline $\begin{array}{l}\text { 2-Nitrophenol, } \\
\text { 2-Chlorophenol }\end{array}$ & $\begin{array}{l}\text { Seaweeds } \\
\text { (algae) }\end{array}$ & $60 \mathrm{C}$ & $\begin{array}{l}\text { Ground } \\
\mathrm{CaCl}_{2}\end{array}$ & $\begin{array}{l}\mathrm{L} \\
\mathrm{F}\end{array}$ & $\begin{array}{l}19-97 \\
10-24\end{array}$ & - & - & $\begin{array}{l}\text { Hydrophobicity (octanol partitioning coef.) } \\
\text { explained the main results. }\end{array}$ & $\begin{array}{l}\text { Navarro et al. } \\
2009\end{array}$ \\
\hline Phenol & $\begin{array}{l}\text { Seaweeds } \\
\text { (algae) }\end{array}$ & $60 \mathrm{C}$ & $\begin{array}{l}\text { Ground } \\
\mathrm{CaCl}_{2}\end{array}$ & - & - & - & - & $\begin{array}{l}\text { Higher uptake at } \mathrm{pH}=10 ; \text { proposes } \\
\text { hydrogen bonding concept. }\end{array}$ & $\begin{array}{l}\text { Navarro et al. } \\
2008\end{array}$ \\
\hline Phenol & $\begin{array}{l}\text { Posidonia } \\
\text { oceanica }\end{array}$ & $40 \mathrm{C}$ & $\begin{array}{l}1-2 \mathrm{~mm} \\
\text { selected }\end{array}$ & $\mathrm{RP}$ & 5 & $2^{\text {nd }}$ & - & Adsorption onto seagrass highest at $\mathrm{pH}=5$. & $\begin{array}{l}\text { Ncibi et al. } \\
2006\end{array}$ \\
\hline $\begin{array}{l}\text { p-Chlorophenol, } \\
\text { 3,4-Dichlorophenol, } \\
\text { 2,4,6-Trichlorophen. }\end{array}$ & $\begin{array}{l}\text { Granular } \\
\text { active carbon }\end{array}$ & $A C$ & - & LF & $\begin{array}{l}2 \\
3 \\
3\end{array}$ & - & Ex & $\begin{array}{l}\text { Particle size affected rate but not capacity; } \\
\text { thermal regeneration was effective; uptake } \\
\text { drops with increasing } \mathrm{pH} \text { above } 7 \text {. }\end{array}$ & $\begin{array}{l}\text { Nelson \& Yang } \\
1995\end{array}$ \\
\hline $\begin{array}{l}\text { Phenol, } \\
\text { Nonylphenol }\end{array}$ & Active carbons & $A C$ & $\begin{array}{l}\mathrm{HNO}_{3} \\
\text { optional }\end{array}$ & - & $\begin{array}{l}150-225 \\
440-620\end{array}$ & - & - & $\begin{array}{l}\text { Oxidation caused 2-step adsorption; } \\
\text { authors proposed hydrogen bonding. }\end{array}$ & $\begin{array}{l}\text { Nevskaia \& G.- } \\
\text { R. } 2001\end{array}$ \\
\hline Nonylphenol & Active carbons & $A C$ & - & - & $260-725$ & - & - & $\begin{array}{l}\text { Two-step isotherms were attributed to } \\
\text { micropores and "surface micelles". }\end{array}$ & $\begin{array}{l}\text { Nevskaia et al. } \\
2001\end{array}$ \\
\hline $\begin{array}{l}\text { 2-Methylisoborneol, } \\
\text { Nat. organic material }\end{array}$ & $\begin{array}{l}\text { Active carbons } \\
\text { (six types) }\end{array}$ & $A C$ & - & - & - & - & - & $\begin{array}{l}\text { Pre-adsorption of 2-methylisoborneol did } \\
\text { not affect NOM subsequent adsorption. }\end{array}$ & $\begin{array}{l}\text { Newcombe et } \\
\text { al. } 2002 a\end{array}$ \\
\hline $\begin{array}{l}\text { 2-Methylisoborneol, } \\
\text { Nat. organic material }\end{array}$ & $\begin{array}{l}\text { Active carbons } \\
\text { (six types) }\end{array}$ & $A C$ & - & & $0.2-10$ & - & - & Pore blockage by NOM & $\begin{array}{l}\text { Newcombe et } \\
\text { al. } 2002 b\end{array}$ \\
\hline
\end{tabular}




\begin{tabular}{|c|c|c|c|c|c|c|c|c|c|}
\hline Pollutant & Sorbent & 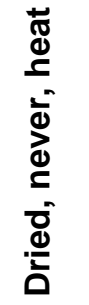 & 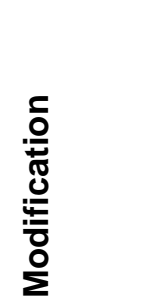 & 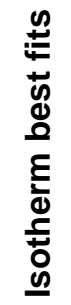 & $\begin{array}{l}\text { Adsorp. } \\
\text { capac. } \\
(\mathbf{m g} / \mathrm{g})\end{array}$ & 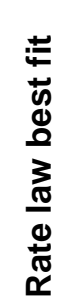 & 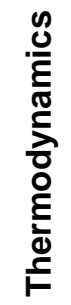 & Key Findings & Author (year) \\
\hline $\begin{array}{l}\text { Trans-1,10-dimethyl- } \\
\text { trans-9-decalol }\end{array}$ & $\begin{array}{l}\text { Active carbons } \\
\text { fr. ag. residue }\end{array}$ & $A C$ & Steam & $\mathrm{F}$ & - & - & - & $\begin{array}{l}\text { Adsorption of "geosim" onto active carbons } \\
\text { from bagasse \& pecan shell }\end{array}$ & $\mathrm{Ng}$ et al. 2000 \\
\hline $\begin{array}{l}\text { Cinnamic acid salt, } \\
\text { Coumaric acid salt }\end{array}$ & $\begin{array}{l}\text { Biochar } \\
\text { (carbon black) }\end{array}$ & $\mathrm{BC}$ & - & $\mathrm{L}$ & $\begin{array}{l}10-23 \\
20\end{array}$ & - & - & $\begin{array}{l}\text { Release of ions upon adsorption implies an } \\
\text { ion exchange mechanism. }\end{array}$ & Ni et al. 2011 \\
\hline $\begin{array}{l}\text { 3-Chlorophenol, } \\
\text { 2,4-Dichlorophenol, } \\
\text { 3,4-Dichlorophenol, } \\
\text { 2,4,6-Trichlorophen., } \\
\text { Pentachlorophenol }\end{array}$ & $\begin{array}{l}\text { Anaerobic } \\
\text { sludge } \\
\text { granules from } \\
\text { a CTMP paper } \\
\text { mill }\end{array}$ & Live & $\begin{array}{l}\text { Acclim- } \\
\text { ation }\end{array}$ & - & - & - & - & $\begin{array}{l}\text { Packed bed experiments; linear adsorption } \\
\text { behavior was observed; biosorption slowed } \\
\text { the elution of the phenols through the } \\
\text { column. }\end{array}$ & Ning et al. 1999 \\
\hline$p$-Nitrophenol & $\begin{array}{l}\text { Activated } \\
\text { carbon }\end{array}$ & $A C$ & $\begin{array}{l}\text { Untreat., } \\
\mathrm{H}_{2} \\
\text { urea, } \\
\mathrm{H}_{2} \mathrm{SO}_{4}\end{array}$ & $\mathrm{~L}$ & $\begin{array}{l}63-210 \\
83-180 \\
63-180 \\
42-250\end{array}$ & - & - & Higher uptake at low pH & $\begin{array}{l}\text { Nouri \& Hagh- } \\
\text { seresht } 2004\end{array}$ \\
\hline $\begin{array}{l}\text { Benzene, } \\
\text { Toluene, } \\
\text { p-Cresol, } \\
\text { Benzoic acid }\end{array}$ & $\begin{array}{l}\text { Activated } \\
\text { carbon }\end{array}$ & $A C$ & - & $\mathrm{L}$ & $\begin{array}{l}275-275 \\
274-278 \\
176-217 \\
29-248\end{array}$ & - & - & $\begin{array}{l}\text { Increased uptake with decreasing } \mathrm{pH} \text { in } \\
\text { cases of benzoic acid and cresol; results } \\
\text { were consistent with } \mathrm{pK}_{\mathrm{a}} \text { values. }\end{array}$ & $\begin{array}{l}\text { Nouri \& Hagh- } \\
\text { seresht } 2005\end{array}$ \\
\hline $\begin{array}{l}p \text {-Cresol, } \\
p \text {-Nitrophenol }\end{array}$ & $\begin{array}{l}\text { Activated } \\
\text { carbon }\end{array}$ & $A C$ & - & $\mathrm{L}$ & $\begin{array}{l}122-174 \\
67-224\end{array}$ & - & - & $\begin{array}{l}\text { Adsorption depended on solubility, which } \\
\text { depended on the } \mathrm{pH} \text { and dissociation. }\end{array}$ & $\begin{array}{l}\text { Nouri et al. } \\
2002 a\end{array}$ \\
\hline $\begin{array}{l}\text { Perfluorinated } \\
\text { surfactants }\end{array}$ & $\begin{array}{l}\text { Active carbon, } \\
\text { Zeolite, } \\
\text { Sludge }\end{array}$ & $\begin{array}{l}\text { AC } \\
- \\
-\end{array}$ & - & $\mathrm{L}$ & $\begin{array}{l}60-250 \\
5-105 \\
2-120\end{array}$ & - & - & $\begin{array}{l}\text { Adsorption capacity increased with length } \\
\text { of the fluorocarbon tail; activated carbon } \\
\text { was most effective. }\end{array}$ & $\begin{array}{l}\text { Ochoa-Herrera } \\
\& \text { S.-A. } 2008\end{array}$ \\
\hline 4-Nitrophenol & $\begin{array}{l}\text { Sawdust from } \\
\text { Mansonia }\end{array}$ & 100 & Ground & $\mathrm{L}$ & 21 & $2^{\text {nd }}$ & - & Three distinct stages of diffusion & Ofomaja 2011 \\
\hline 4-Nitrophenol & $\begin{array}{l}\text { Mansonia } \\
\text { wood sawdust }\end{array}$ & 100 & $\begin{array}{l}\text { Water } \\
\text { wash }\end{array}$ & - & 16 & $\begin{array}{l}2^{\text {nd }} \\
1^{\text {st }}\end{array}$ & - & $\begin{array}{l}\text { Multistage adsorption to reduce aqueous } \\
\text { concentration to a low level; } \mathrm{pH}<6 \text { best }\end{array}$ & $\begin{array}{l}\text { Ofomaja \& U. } \\
2011\end{array}$ \\
\hline 4-Nitrophenol & $\begin{array}{l}\text { Mansonia } \\
\text { wood sawdust }\end{array}$ & 100 & Ground & $\mathrm{L}$ & $150-425$ & $2^{\text {nd }}$ & - & $\begin{array}{l}\text { Time-dependent Langmuir model shows } \\
\text { three stages. }\end{array}$ & $\begin{array}{l}\text { Ofomaja \& U. } \\
2013\end{array}$ \\
\hline
\end{tabular}




\begin{tabular}{|c|c|c|c|c|c|c|c|c|c|}
\hline Pollutant & Sorbent & 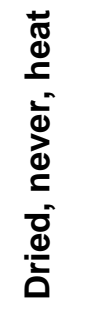 & 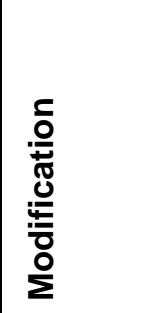 & 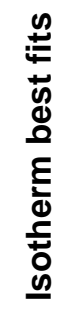 & $\begin{array}{l}\text { Adsorp. } \\
\text { capac. } \\
(\mathrm{mg} / \mathrm{g})\end{array}$ & 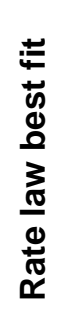 & 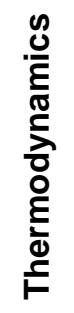 & Key Findings & Author (year) \\
\hline 4-Chlorophenol & $\begin{array}{l}\text { Granular } \\
\text { active carbon }\end{array}$ & $A C$ & Steam & - & $80-200$ & - & - & $\begin{array}{l}\text { Bioregeneration was fitted to a Haldane } \\
\text { kinetic model. }\end{array}$ & Oh et al. 2013 \\
\hline $\begin{array}{l}\text { 4-Chlorophenol, } \\
\text { 2,4-Dichlorophenol }\end{array}$ & $\begin{array}{l}\text { Granular } \\
\text { active carbon }\end{array}$ & $A C$ & Steam & - & $\begin{array}{l}150-280 \\
100-280\end{array}$ & - & - & $\begin{array}{l}\text { The highest biodegradation was when the } \\
\text { concentration was below acclimated level. }\end{array}$ & Oh et al. 2011 \\
\hline Trichloroethylene & $\begin{array}{l}\text { Granular } \\
\text { active carbon }\end{array}$ & $A C$ & - & $\mathrm{F}$ & $1-20$ & - & - & $\begin{array}{l}\text { Wet peroxide oxidation used to regenerate } \\
\text { the adsorbent, low affinity adsorption. }\end{array}$ & $\begin{array}{l}\text { Okawa et al. } \\
2007\end{array}$ \\
\hline Phenanthrene & Cork & - & $\begin{array}{l}\text { Un- } \\
\text { treated }\end{array}$ & - & - & - & - & $\begin{array}{l}\text { Hydrophobic interactions attributed to pi-pi } \\
\text { stacking; negatively charged groups inhibit } \\
\text { adsorption. }\end{array}$ & $\begin{array}{l}\text { Olivella et al. } \\
2013\end{array}$ \\
\hline $\begin{array}{l}2,4-\mathrm{D} \\
2,4-\mathrm{DP} \\
2,4-\mathrm{DB}\end{array}$ & $\begin{array}{l}\text { Anoxybacillus } \\
\text { flavithermus }\end{array}$ & $80 \mathrm{C}$ & Ground & $\begin{array}{ll}\mathrm{L} \\
\mathrm{F}\end{array}$ & $\begin{array}{l}24 \\
14 \\
14\end{array}$ & $1^{\text {st }}$ & - & Optimum $\mathrm{pH}=4$ & $\begin{array}{l}\text { Ozdemir et al. } \\
2012\end{array}$ \\
\hline Phenol & Active carbon & $A C$ & - & $\mathrm{L}$ & 50 & $1^{\text {st }}$ & & $\mathrm{NaOH}$ was used for regeneration. & Özkaya 2006 \\
\hline Phenol & $\begin{array}{l}\text { Active carbon, } \\
\text { Charcoal }\end{array}$ & $\begin{array}{l}\mathrm{AC} \\
\mathrm{BC}\end{array}$ & $\begin{array}{l}- \\
700 \mathrm{C}\end{array}$ & F & $\begin{array}{l}6-18 \\
41-74\end{array}$ & - & - & $\begin{array}{l}\text { The biochars adsorbed more phenol as the } \\
\text { pH was lowered below } 4 \text {. }\end{array}$ & $\begin{array}{l}\text { Pajooheshfar \& } \\
\text { Saeed } 2009\end{array}$ \\
\hline $\begin{array}{l}14 \text { organic chloro } \\
\text { compounds }\end{array}$ & $\begin{array}{l}\text { Active carbon } \\
\text { (5 common) }\end{array}$ & $A C$ & - & $\mathrm{F}$ & $0.03-43$ & - & - & $\begin{array}{l}\text { The authors found no easy way to predict } \\
\text { adsorbed amounts. }\end{array}$ & $\begin{array}{l}\text { Pavoni et al. } \\
2006\end{array}$ \\
\hline 1,2-Dichlorobenzene & $\begin{array}{l}\text { Carbon } \\
\text { nanotubes }\end{array}$ & - & - & - & $28-31$ & - & En & $\begin{array}{l}\text { Good adsorption in range } 3<\mathrm{pH}<10 \text {; falls } \\
\text { off at } \mathrm{pH}=11 \text {. }\end{array}$ & $\begin{array}{l}\text { Peng et al. } \\
2003\end{array}$ \\
\hline Phenol & Active carbons & $A C$ & $\begin{array}{l}\text { Nitric a, } \\
\text { heat }\end{array}$ & $\mathrm{DA}$ & $56-132$ & - & - & $\begin{array}{l}\text { Dubinin-Astakhov isotherm was used to } \\
\text { quantify heterogeneity of adsorption. }\end{array}$ & $\begin{array}{l}\text { Podkościelny et } \\
\text { al. } 2003\end{array}$ \\
\hline Pentachlorophenol & $\begin{array}{l}\text { Granular } \\
\text { active carbon }\end{array}$ & $A C$ & $\begin{array}{l}\text { Plasma } \\
\left(\mathrm{N}_{2}, \mathrm{O}_{2}\right)\end{array}$ & - & $120-150$ & - & - & $\begin{array}{l}\text { Oxygen plasma slightly increase uptake; } \\
\mathrm{N}_{2} \text { plasma caused a decline. }\end{array}$ & Qu et al. 2013 \\
\hline 1,3-Dinitrobenzene, & $\begin{array}{l}\text { Gram+ and } \\
\text { Gram- } \\
\text { bacteria }\end{array}$ & Dry & $\begin{array}{l}\text { Freeze- } \\
\text { dried }\end{array}$ & $\mathrm{L}$ & 17-84, & - & - & $\begin{array}{l}\text { Increased uptake with increasing } \mathrm{pH} \text {; } \\
\text { proposed } \mathrm{n} \text {-pi interactions. }\end{array}$ & Qu et al. 2008 \\
\hline $\begin{array}{l}\text { Meth. tertbutyl ether, } \\
\text { Trichloroethylene }\end{array}$ & $\begin{array}{l}\text { Activated } \\
\text { carbons }\end{array}$ & $A C$ & $\begin{array}{l}\text { Natural } \\
\text { organics }\end{array}$ & & $\begin{array}{l}0.01-0.8 \\
0.3-18\end{array}$ & - & - & $\begin{array}{l}\text { Pores should be } 1.5 \text { times the size of the } \\
\text { target molecules to avoid blockage. }\end{array}$ & $\begin{array}{l}\text { Quinlivan et al. } \\
2005\end{array}$ \\
\hline
\end{tabular}




\begin{tabular}{|c|c|c|c|c|c|c|c|c|c|}
\hline Pollutant & Sorbent & 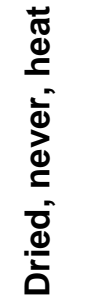 & 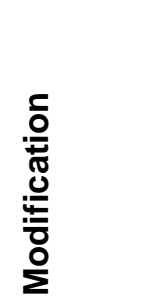 & 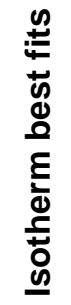 & $\begin{array}{l}\text { Adsorp. } \\
\text { capac. } \\
(\mathrm{mg} / \mathrm{g})\end{array}$ & 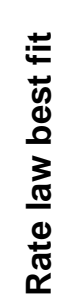 & 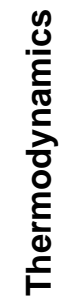 & Key Findings & Author (year) \\
\hline $\begin{array}{l}\text { p-Chlorophenol, } \\
\text { 1,4,6-Trichlorophen. }\end{array}$ & $\begin{array}{l}\text { Activated } \\
\text { carbons }\end{array}$ & $A C$ & $\begin{array}{l}\mathrm{KOH}, \\
\text { etc. }\end{array}$ & $\mathrm{F}$ & $\begin{array}{l}73-134, \\
112-122 \\
\end{array}$ & $2^{\text {nd }}$ & - & $\begin{array}{l}\text { Lower } \mathrm{pH} \text { favored adsorption; only } 10-50 \% \\
\text { desorption, even at } \mathrm{pH}=11 \text {. }\end{array}$ & $\begin{array}{l}\text { Radhika \& Pal- } \\
\text { anivelu } 2006\end{array}$ \\
\hline $\begin{array}{l}\text { Analine, } \\
\text { Nitrobenzene }\end{array}$ & Active carbons & $A C$ & $\begin{array}{l}\text { Oxidiz., } \\
\text { Heated }\end{array}$ & - & $\begin{array}{l}46-186 \\
120-490\end{array}$ & - & - & $\begin{array}{l}\text { Both electrostatic \& dispersive forces are } \\
\text { important; analine uptake enhanced by } \\
\text { oxidation; nitrobenzene by low O content. }\end{array}$ & $\begin{array}{l}\text { Radovic et al. } \\
1997\end{array}$ \\
\hline $\begin{array}{l}\text { Phenanthrene, } \\
\text { Naphthalene, } \\
\text { 1,3,5-Trichlorobenz, } \\
\text { 1,2-Dichlorobenzene }\end{array}$ & $\begin{array}{l}\text { Peats and } \\
\text { humic acids }\end{array}$ & - & - & $\mathrm{F}$ & \begin{tabular}{|l|}
$3-360$ \\
$10-120$ \\
$10-30$ \\
$3-30$ \\
\end{tabular} & - & - & $\begin{array}{l}\text { The substrate surfaces were highly } \\
\text { heterogeneous. }\end{array}$ & Ran et al. 2013 \\
\hline Phenol & $\begin{array}{l}\text { Aspergillus } \\
\text { niger }\end{array}$ & $\begin{array}{l}65- \\
70 C\end{array}$ & $\begin{array}{l}\mathrm{H}_{2} \mathrm{SO}_{4} \\
\text { best }\end{array}$ & $\mathrm{L}$ & 0.3 & - & - & $\begin{array}{l}\text { Best } \mathrm{pH}=5, \mathrm{BET} \text { isotherm, irreversible } \\
\text { uptake }\end{array}$ & $\begin{array}{l}\text { Rao \& Virara- } \\
\text { ghavan } 2002\end{array}$ \\
\hline $\begin{array}{l}\text { Lindane, } \\
\text { Heptachlor }\end{array}$ & Pine bark & $\begin{array}{l}105 \\
\mathrm{C}\end{array}$ & ground & $\mathrm{F}$ & $0.1-200$ & - & - & Low affinity isotherms shown. & $\begin{array}{l}\text { Ratola et al. } \\
2003\end{array}$ \\
\hline $\begin{array}{l}\text { Phenol, } \\
\text { o-Cresol, } \\
m \text {-Cresol, } \\
p \text {-Cresol, } \\
\text { Benzyl alcohol }\end{array}$ & Active carbon & $\mathrm{AC}$ & - & $\mathrm{L}$ & $\begin{array}{l}410-600, \\
420-460, \\
330-370, \\
380-480, \\
340-460\end{array}$ & - & nil & $\begin{array}{l}\text { Irreversibility of adsorption implies changes } \\
\text { in adsorbates upon adsorption. }\end{array}$ & Ravi et al. 1998 \\
\hline Phenol & $\begin{array}{l}\text { Active carbon } \\
\text { fr. palm seed }\end{array}$ & $A C$ & $\begin{array}{l}\mathrm{CO}_{2} \\
850-900\end{array}$ & $\mathrm{~F}$ & $2-20$ & - & - & $\begin{array}{l}\text { Decreased uptake below } \mathrm{pH} 3 \text { and above } \\
\mathrm{pH}=10 \text {, film diffusion rate control }\end{array}$ & $\begin{array}{l}\text { Rengaraj et al. } \\
2002 a\end{array}$ \\
\hline Phenol & $\begin{array}{l}\text { Active carbon } \\
\text { fr. rubber seed }\end{array}$ & $A C$ & $\begin{array}{l}\mathrm{CO}_{2} \\
850-900\end{array}$ & $\mathrm{~F}$ & $10-15$ & $\begin{array}{l}1 \text { st } \\
\text { ID }\end{array}$ & - & $\begin{array}{l}\text { Batch and column; intraparticle diffusion } \\
\text { control }\end{array}$ & $\begin{array}{l}\text { Rengaraj et al. } \\
2002 b\end{array}$ \\
\hline $\begin{array}{l}\text { 2-Chlorophenol, } \\
\text { 3-Chlorophenol }\end{array}$ & $\begin{array}{l}\text { Active carbons } \\
\text { (various) }\end{array}$ & $A C$ & $\overline{840}$ & $\mathrm{~L}$ & $\begin{array}{l}218-401 \\
218-394\end{array}$ & - & - & $\begin{array}{l}\text { Low pH favors adsorption; agricultural- } \\
\text { derived active carbons were highly } \\
\text { effective; uptake related to pore volume. }\end{array}$ & $\begin{array}{l}\text { Rivera-Utrilla et } \\
\text { al. } 1991\end{array}$ \\
\hline Phenol & $\begin{array}{l}\text { Active carbon } \\
\text { fr. avocado }\end{array}$ & $A C$ & $\begin{array}{l}\mathrm{CO}_{2} \\
900 \mathrm{C}\end{array}$ & $\mathrm{L}$ & 87 & $2^{\text {nd }}$ & nil & $\begin{array}{l}\text { Best pH } 4 \text { to } 8.5 \text {, proposes pi-pi } \\
\text { interaction, no easy regeneration found. }\end{array}$ & $\begin{array}{l}\text { Rodrigues et al } \\
2011\end{array}$ \\
\hline
\end{tabular}




\begin{tabular}{|c|c|c|c|c|c|c|c|c|c|}
\hline Pollutant & Sorbent & 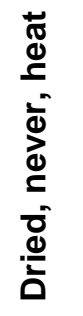 & 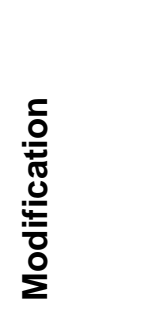 & 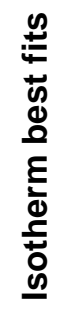 & $\begin{array}{l}\text { Adsorp. } \\
\text { capac. } \\
(\mathbf{m g} / \mathrm{g})\end{array}$ & 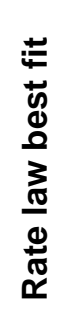 & 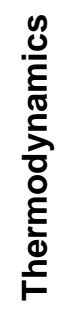 & Key Findings & Author (year) \\
\hline Penol & $\begin{array}{l}\text { Active carbon } \\
\text { fr. macademia }\end{array}$ & $\mathrm{AC}$ & $\begin{array}{l}\mathrm{CO}_{2} \\
850 \mathrm{C}\end{array}$ & $\mathrm{L}$ & 341 & $2^{\text {nd }}$ & Ex & Decreased uptake with increasing $\mathrm{pH}$. & $\begin{array}{l}\text { Rodrigues et al. } \\
2013\end{array}$ \\
\hline $\begin{array}{l}\text { Linuron, } \\
\text { Alachlor, } \\
\text { Metalaxyl, } \\
\text { Chlorpyrifos, } \\
\text { Dicamba, } \\
\text { Paraquat }\end{array}$ & $\begin{array}{l}\text { Nine types of } \\
\text { wood with } \\
\text { lignin } 18 \text { to } \\
27 \% \text { content }\end{array}$ & - & Ground & $\mathrm{F}$ & $\begin{array}{l}>10 \\
>1 \\
>0.2 \\
>3 \\
>5 \\
>30\end{array}$ & - & - & $\begin{array}{l}\text { Strong correlation between uptake and } \\
\text { lignin content; the bulk concentrations } \\
\text { were too low to provide reliable isotherms } \\
\text { and adsorption capacities. }\end{array}$ & $\begin{array}{l}\text { Rodriguez-C. et } \\
\text { al. } 2007\end{array}$ \\
\hline $\begin{array}{l}\text { Imidacloprid } \\
\text { pesticide }\end{array}$ & $\begin{array}{l}\text { Plantago } \\
\text { major L. }\end{array}$ & Dry & As-is & & $\begin{array}{l}0.002- \\
0.037\end{array}$ & - & - & $\begin{array}{l}\text { Phytoremediation; gram-positive bacteria } \\
\text { were able to induce biodegradation. }\end{array}$ & Romeh 2010 \\
\hline Phenol & $\begin{array}{l}\text { Active carbon, } \\
\text { etc. }\end{array}$ & $\mathrm{AC}$ & - & $\begin{array}{l}\mathrm{L} \\
\mathrm{LF}\end{array}$ & $205-310$ & $1^{\text {st }}$ & Ex & $\begin{array}{l}\text { Activated carbon had higher capacity than } \\
\text { silica gel, which had the highest rate; } \\
\text { smaller particles gave faster adsorption. }\end{array}$ & $\begin{array}{l}\text { Roostaei \& } \\
\text { Tezel } 2004\end{array}$ \\
\hline $\begin{array}{l}\text { Meth. tert-butyl ether } \\
\text { (MTBE) }\end{array}$ & $\begin{array}{l}\text { Granular } \\
\text { active carbon } \\
\text { (coconut), etc. }\end{array}$ & $\mathrm{AC}$ & - & $\mathrm{F}$ & $0.1-30$ & - & - & $\begin{array}{l}\text { Surface diffusion was faster for carbon, } \\
\text { compared to other adsorbents; zeolite had } \\
\text { higher capacity \& costs less to regenerate. }\end{array}$ & $\begin{array}{l}\text { Rossner \& } \\
\text { Knappe } 2008\end{array}$ \\
\hline $\begin{array}{l}\text { Endocrine disruptor, } \\
\text { pharmaceuticals }\end{array}$ & $\begin{array}{l}\text { Granular } \\
\text { active carbon } \\
\text { (coconut), etc. }\end{array}$ & $\mathrm{AC}$ & - & - & - & - & - & $\begin{array}{l}\text { Heterogeneity of pore size is essential to } \\
\text { achieve broad-spectrum adsorption; active } \\
\text { carbon removed } 24 \text { of the } 25 \text { chemicals. }\end{array}$ & $\begin{array}{l}\text { Rossner et al. } \\
2009\end{array}$ \\
\hline $\begin{array}{l}\text { Phenol, } \\
\text { 2-Chlorophenol, } \\
\text { 4-Chlorophenol }\end{array}$ & $\begin{array}{l}\text { Sargassum } \\
\text { muticum }\end{array}$ & $60 \mathrm{C}$ & $\begin{array}{l}\mathrm{CaCl}_{2} \\
\text { pretreat }\end{array}$ & $\mathrm{L}$ & $\begin{array}{l}4.6 \\
79 \\
251\end{array}$ & $1^{\text {st }}$ & - & $\begin{array}{l}\text { Uptake correlated with octanol-water } \\
\text { partition coefficients, which suggests the } \\
\text { importance of hydrophobicity. }\end{array}$ & $\begin{array}{l}\text { Rubin et al. } \\
2006\end{array}$ \\
\hline$p$-Nitrophenol & Active carbons & $A C$ & - & $\mathrm{L}$ & $90-185$ & - & - & $\begin{array}{l}\mathrm{CO}_{2} \text { gasification was much more effective } \\
\text { for regeneration than other media. }\end{array}$ & $\begin{array}{l}\text { Sabio et al. } \\
2004\end{array}$ \\
\hline $\begin{array}{l}\text { Trichloroethylene, } \\
\text { Tetrachloroethylene }\end{array}$ & $\begin{array}{l}\text { Active carbon } \\
\text { fibers }\end{array}$ & $\mathrm{AC}$ & - & $\mathrm{L}$ & $\begin{array}{l}52-150 \\
130-390 \\
\end{array}$ & - & - & $\begin{array}{l}\text { Key attributes were micropore content (for } \\
\text { capacity) and length of diffusion path. }\end{array}$ & $\begin{array}{l}\text { Sakoda et al. } \\
1987\end{array}$ \\
\hline
\end{tabular}




\begin{tabular}{|c|c|c|c|c|c|c|c|c|c|}
\hline Pollutant & Sorbent & 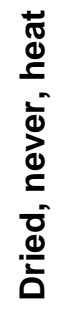 & 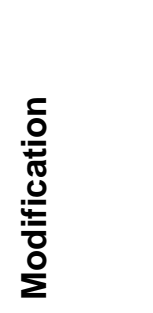 & 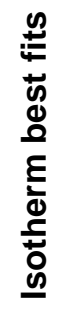 & $\begin{array}{l}\text { Adsorp. } \\
\text { capac. } \\
(\mathrm{mg} / \mathrm{g})\end{array}$ & 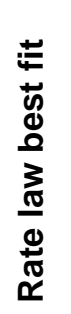 & 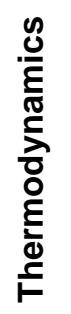 & Key Findings & Author (year) \\
\hline Phenol & $\begin{array}{l}\text { Active carbons } \\
\text { from wood }\end{array}$ & $A C$ & $\begin{array}{l}\mathrm{H}_{3} \mathrm{PO}_{4} \\
627 \mathrm{C} \\
1027 \mathrm{C}\end{array}$ & $\mathrm{F}$ & $50-300$ & - & - & $\begin{array}{l}\text { Phenol uptake depends on both porosity } \\
\text { and chemistry details; esterification with } \\
\text { the surface; } \mathrm{COOH} \text { reduces pi interaction. }\end{array}$ & $\begin{array}{l}\text { Salame \& Ban- } \\
\text { dosz } 2003\end{array}$ \\
\hline Phenanthrene & $\begin{array}{l}\text { Natural } \\
\text { organic matter }\end{array}$ & - & - & $\mathrm{F}$ & $10-20$ & - & - & $\begin{array}{l}\text { Lowest phenanthrene uptake on cellulose; } \\
\text { highest on paraffinic matter }\end{array}$ & $\begin{array}{l}\text { Salloum et al. } \\
2002\end{array}$ \\
\hline 2,4-Dichlorophenol & $\begin{array}{l}\text { Active carbon } \\
\text { from corn cob }\end{array}$ & $A C$ & $700 \mathrm{C}$ & $\mathrm{L}$ & 18 & $2^{\text {nd }}$ & - & $\begin{array}{l}\text { Acidic } \mathrm{pH} \text { favored adsorption; incomplete } \\
\text { desorption indicated chemisorption. }\end{array}$ & $\begin{array}{l}\text { Sathishkumar } \\
\text { et al. } 2009\end{array}$ \\
\hline Carbaryl & $\begin{array}{l}\text { Carbon from } \\
\text { banana pith }\end{array}$ & $A C$ & $\begin{array}{l}\mathrm{ZnCl} 2 \\
110 \mathrm{C}\end{array}$ & $\begin{array}{l}\mathrm{L} \\
\mathrm{F}\end{array}$ & 46 & $\begin{array}{l}1^{\text {st }} \\
2^{\text {nd }}\end{array}$ & - & $\begin{array}{l}\text { Highest uptake at } \mathrm{pH}=11 \text {, desorption } \\
\text { complete with acetone. }\end{array}$ & $\begin{array}{l}\text { Sathishkumar } \\
\text { et al. } 2008\end{array}$ \\
\hline $\begin{array}{l}\text { Phenol, } \\
\text { o-Chlorophenol, } \\
\text { p-Chlorophenol, } \\
\text { 2,4,6-Trichlorophen. }\end{array}$ & $\begin{array}{l}\text { Polyamide } \\
\text { hollow fibers } \\
\text { with reactive } \\
\text { green dye }\end{array}$ & - & - & - & $\begin{array}{l}146 \\
203 \\
194 \\
179\end{array}$ & $2^{\text {nd }}$ & - & $\begin{array}{l}\text { Decreasing sorption with increasing } \mathrm{pH} \\
\text { above 6; chemisorption may be rate- } \\
\text { determining step; regeneration achieved. }\end{array}$ & $\begin{array}{l}\text { Şenel et al. } \\
2006\end{array}$ \\
\hline $\begin{array}{l}\text { Refractory organics } \\
\text { in } 2^{\text {nd }} \text { ary wastewater }\end{array}$ & $\begin{array}{l}\text { Bio-activated } \\
\text { carbon }\end{array}$ & - & Innoc. & $F$ & $9-16$ & - & - & $\begin{array}{l}\text { Biofilm increased sorption capacity by a } \\
\text { factor of four. }\end{array}$ & Seo et al. 1997 \\
\hline Dibenzothiophenes & Active carbons & $A C$ & $800 \mathrm{C}$ & $\mathrm{F}$ & $1-15$ & - & - & $\begin{array}{l}\text { Micropores appeared to be the main site of } \\
\text { adsorption. }\end{array}$ & $\begin{array}{l}\text { Seredych \& } \\
\text { Bandosz } 2010\end{array}$ \\
\hline $\begin{array}{l}\text { Dibenzothiophenes; } \\
\text { 4,6-Dimethyldibenz. }\end{array}$ & Active carbons & $A C$ & $\begin{array}{l}650 \\
800 C\end{array}$ & - & $\begin{array}{l}20 \\
33\end{array}$ & - & - & $\begin{array}{l}\text { Sulfur on the adsorbent promoted uptake } \\
\text { of the sulfur-containing compounds. }\end{array}$ & $\begin{array}{l}\text { Seredych \& } \\
\text { Bandosz } 2011\end{array}$ \\
\hline $\begin{array}{l}\text { 2,4-Dichlorophenol, } \\
\text { 2,4,5-Trichlorophen. }\end{array}$ & $\begin{array}{l}\text { SW kraft fiber, } \\
\text { \& kraft lignin }\end{array}$ & not, & $\kappa=5$ & - & $120-185$ & - & Ex & $\begin{array}{l}\text { Drastic drop in sorption above } \mathrm{pH}=6 \text {; } \\
\text { Lignin is mainly responsible for the } \\
\text { interaction with wood pulp. }\end{array}$ & $\begin{array}{l}\text { Severtson \& } \\
\text { Banerjee } 1996\end{array}$ \\
\hline Dichloroethylene & $\begin{array}{l}\text { Active carbon } \\
\text { fiber }\end{array}$ & $A C$ & $\begin{array}{l}\text { Steam } \\
830 \mathrm{C}\end{array}$ & - & $4-10$ & - & - & $\begin{array}{l}\text { Reduced metal on the carbon enhanced } \\
\text { dichloroethylene uptake. }\end{array}$ & $\begin{array}{l}\text { Shen et al. } \\
2006\end{array}$ \\
\hline $\begin{array}{l}\text { o-Cresol, } \\
p \text {-Nitrophenol }\end{array}$ & Fly ash & FA & $\begin{array}{l}\mathrm{Al}\left(\mathrm{NO}_{3}\right)_{3} \\
\& \mathrm{FeCl}_{3}\end{array}$ & - & $\begin{array}{l}3-5 \\
7-10\end{array}$ & $\begin{array}{l}1^{\text {st }} \\
\text { ID }\end{array}$ & - & $\begin{array}{l}\text { Somewhat faster sorption onto smaller } \\
\text { particles; intraparticle diffusion; trivalent } \\
\text { metal ions became bound to phenolates. }\end{array}$ & $\begin{array}{l}\text { Singh \& Rawat } \\
1994 \mathrm{a}\end{array}$ \\
\hline
\end{tabular}




\begin{tabular}{|c|c|c|c|c|c|c|c|c|c|}
\hline Pollutant & Sorbent & 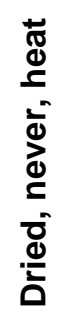 & 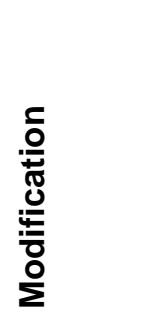 & 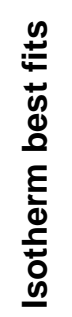 & $\begin{array}{l}\text { Adsorp. } \\
\text { capac. } \\
(\mathrm{mg} / \mathrm{g})\end{array}$ & 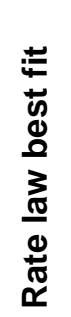 & 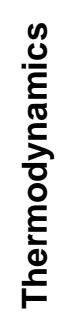 & Key Findings & Author (year) \\
\hline $\begin{array}{l}\text { Phenol, } \\
\text { o-Cresol, } \\
\text { m-Cresol, } \\
\text { p-Cresol, } \\
\text { o-Nitrophenol, } \\
\text { m-Nitrophenol, } \\
\text { p-Nitrophenol }\end{array}$ & Fly ash & FA & $\begin{array}{l}\mathrm{Al}\left(\mathrm{NO}_{3}\right)_{3} \\
\& \mathrm{FeCl}_{3}\end{array}$ & $\begin{array}{l}\mathrm{L} \\
\mathrm{F}\end{array}$ & $\begin{array}{l}4-7 \\
3-5 \\
4-6, \\
5-7 \\
6-7 \\
7-8 \\
8-10\end{array}$ & - & - & $\begin{array}{l}\text { Higher capacity with decreasing particle } \\
\text { size; trivalent metal species boosted } \\
\text { adsorption by about } 20 \% \text {. }\end{array}$ & $\begin{array}{l}\text { Singh \& Rawat } \\
1994 b\end{array}$ \\
\hline $\begin{array}{l}\text { Phenol, } \\
\text { 2,4-Dichlorophenol }\end{array}$ & $\begin{array}{l}\text { Active carbons } \\
\text { from coconut }\end{array}$ & $\mathrm{AC}$ & $\begin{array}{l}\mathrm{H}_{2} \mathrm{SO}_{4} \\
200-800\end{array}$ & $\begin{array}{l}\mathrm{L} \\
\mathrm{F}\end{array}$ & $\begin{array}{l}300-490 \\
310-650\end{array}$ & $2^{\text {nd }}$ & En & $\begin{array}{l}\text { Sulfuric acid activation enhanced } \\
\text { adsorption. }\end{array}$ & $\begin{array}{l}\text { Singh et al. } \\
2008\end{array}$ \\
\hline Pentachlorophenol & Active carbon & $\mathrm{AC}$ & - & $\mathrm{F}$ & - & - & - & Fixed beds, surface diffusion model & $\begin{array}{l}\text { Slaney \& Bha- } \\
\text { midim. } 1998\end{array}$ \\
\hline $\begin{array}{l}\text { Phenol, } \\
\text { p-Nitrophenol }\end{array}$ & Active carbon & $\mathrm{AC}$ & - & $\mathrm{F}$ & $180-380$ & & nil & $\begin{array}{l}\text { Adsorption heterogeneity and hysteresis } \\
\text { observed, intermediate } \mathrm{pH} \text { is favored. }\end{array}$ & $\begin{array}{l}\text { Snoeyink et al. } \\
1969\end{array}$ \\
\hline Phenol & $\begin{array}{l}\text { Cotton with } \\
\text { acrylate graft }\end{array}$ & - & - & - & - & - & - & $\begin{array}{l}\text { Sulfonic acid modification of the grafted } \\
\text { cotton gave high adsorption of phenol. }\end{array}$ & $\begin{array}{l}\text { Sokker et al. } \\
2009\end{array}$ \\
\hline Ethylene & $\begin{array}{l}\text { Active carbon } \\
\text { in paper }\end{array}$ & $\mathrm{AC}$ & $\begin{array}{l}10-30 \% \\
\text { content }\end{array}$ & - & $\begin{array}{l}0.0004- \\
0.0008\end{array}$ & - & - & $\begin{array}{l}\text { Glucomannan did not affect ethylene } \\
\text { uptake. }\end{array}$ & $\begin{array}{l}\text { Sothornvit \& S. } \\
2012\end{array}$ \\
\hline $\begin{array}{l}\text { 2,4,6-Trinitrophenol, } \\
\text { 4-Nitrophenol, } \\
\text { 4-Chlorophenol, } \\
\text { 1,3-Dihydroxybenze. }\end{array}$ & $\begin{array}{l}\text { Active carbon } \\
\text { fr. fertilizer }\end{array}$ & $\mathrm{AC}$ & 450 & $\mathrm{~L}$ & $\begin{array}{l}183 \\
74 \\
59 \\
37\end{array}$ & - & - & Competitive adsorption was significant. & $\begin{array}{l}\text { Srivastava \& } \\
\text { Tyagi 1995a }\end{array}$ \\
\hline of 2,4-Dinitrophenol & $\begin{array}{l}\text { Active carbons } \\
\text { fr. fertilizer }\end{array}$ & $\mathrm{AC}$ & $\begin{array}{l}450 \mathrm{C} \\
\mathrm{HCl}\end{array}$ & $\mathrm{L}$ & $114-129$ & - & - & $\begin{array}{l}\text { Optimum } \mathrm{pH}=4 \text {; salt increased uptake; } \\
\text { complete desorption with } \mathrm{NaOH} \text {; } \\
\text { regeneration with } \mathrm{HNO}_{3} \text {. }\end{array}$ & $\begin{array}{l}\text { Srivastaya et } \\
\text { al. } 1997\end{array}$ \\
\hline Phenol & $\begin{array}{l}\text { Fly ash, } \\
\text { Active carbons }\end{array}$ & FA & - & $\mathrm{RP}$ & $\begin{array}{l}24 \\
25-30\end{array}$ & $2^{\text {nd }}$ & En & Best results at $\mathrm{pH}=6.5$ & $\begin{array}{l}\text { Srivastava et } \\
\text { al. } 2006\end{array}$ \\
\hline
\end{tabular}




\begin{tabular}{|c|c|c|c|c|c|c|c|c|c|}
\hline Pollutant & Sorbent & 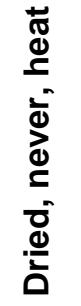 & 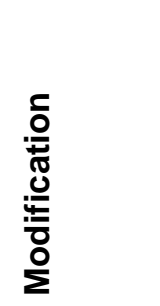 & 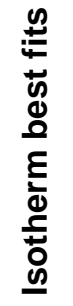 & $\begin{array}{l}\text { Adsorp. } \\
\text { capac. } \\
\text { (mg/g) }\end{array}$ & 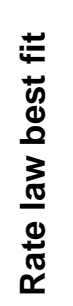 & 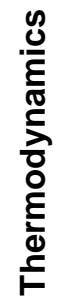 & Key Findings & Author (year) \\
\hline $\begin{array}{l}\text { Phenol, } \\
\text { p-Nitrophenol }\end{array}$ & Olive pomace & Dry & $\begin{array}{l}\text { Dried, } \\
\text { Extract. }\end{array}$ & $\begin{array}{l}\mathrm{L} \\
\mathrm{F}\end{array}$ & $5-11$ & $2^{\text {nd }}$ & - & Uptake increased with increasing $\mathrm{pH}$. & $\begin{array}{l}\text { Stasinakis et al. } \\
2008\end{array}$ \\
\hline Phenol & Active carbons & $A C$ & $\begin{array}{l}\mathrm{O}_{2} \\
\mathrm{HNO}_{3} \\
\text { Urea }\end{array}$ & $\mathrm{F}$ & $50-440$ & & & $\begin{array}{l}\text { Nitrogen groups from urea favored } \\
\text { adsorption of phenol; oxygen groups } \\
\text { reduced uptake. }\end{array}$ & $\begin{array}{l}\text { Stavropoulos et } \\
\text { al. } 2008\end{array}$ \\
\hline $\begin{array}{l}\text { Pyrene, } \\
\text { Phenanthrene }\end{array}$ & \begin{tabular}{|l|} 
Mixed \\
microbes \\
\end{tabular} & - & - & - & - & - & - & $\begin{array}{l}\text { Partition coefficients octanol/water } \\
\text { predicted uptake. }\end{array}$ & $\begin{array}{l}\text { Steen \& Karick- } \\
\text { hoff } 1981\end{array}$ \\
\hline $\begin{array}{l}\text { Phenol, } \\
\text { 3-Chlorophenol }\end{array}$ & Active carbon & $\mathrm{AC}$ & - & $\begin{array}{l}\text { DRK } \\
\text { L }\end{array}$ & $\begin{array}{l}120-350 \\
75-450\end{array}$ & - & - & $\begin{array}{l}\text { Monolayer adsorption; the Dubinin- } \\
\text { Radushkevich-Kaganer (DRK) equation is } \\
\text { based on BET surface area \& energy term. }\end{array}$ & $\begin{array}{l}\text { Stoecklli et al. } \\
2001\end{array}$ \\
\hline $\begin{array}{l}\text { Phenol, } \\
p \text {-Chlorophenol }\end{array}$ & $\begin{array}{l}\text { Active carbon } \\
\text { fr. straw, etc. }\end{array}$ & $\mathrm{AC}$ & $\begin{array}{l}\text { Steam } \\
800-900\end{array}$ & $F$ & $\begin{array}{l}113-193 \\
116-335\end{array}$ & - & - & $\begin{array}{l}\text { Results were as good as commercial } \\
\text { activated carbon products. }\end{array}$ & $\begin{array}{l}\text { Streat et al. } \\
1995\end{array}$ \\
\hline Phenanthrene & $\begin{array}{l}\text { Bacterial } \\
\text { biomass }\end{array}$ & no & $\begin{array}{l}\mathrm{CH}_{2} \mathrm{O} \text { to } \\
\text { kill cells }\end{array}$ & - & 3 & - & - & $\begin{array}{l}\text { Nocardioform bacteria exhibited the } \\
\text { highest adsorption. }\end{array}$ & $\begin{array}{l}\text { Stringfellow \& } \\
\text { Alvarez-C } 1999\end{array}$ \\
\hline Phenol & $\begin{array}{l}\text { Active carbon } \\
\text { fr. coir pith }\end{array}$ & $\mathrm{AC}$ & $\begin{array}{l}\mathrm{ZnCl}_{2} \\
700 \mathrm{C}\end{array}$ & $\mathrm{L}$ & 93 & $2^{\text {nd }}$ & nil & Desorption increased with increasing $\mathrm{pH}$. & $\begin{array}{l}\text { Subha \& Nam- } \\
\text { asivayam } 2009\end{array}$ \\
\hline 2-Chlorophenol & $\begin{array}{l}\text { Active carbon } \\
\text { fr. coir pith }\end{array}$ & AC & $\begin{array}{l}\mathrm{ZnCl} 2 \\
700 \mathrm{C}\end{array}$ & $\bar{L}$ & 149 & $2^{\text {nd }}$ & nil & $\begin{array}{l}\text { Only partial desorption took place, even at } \\
\text { the very highest } \mathrm{pH} \text { of } 14 \text {. }\end{array}$ & $\begin{array}{l}\text { Subha \& Nam- } \\
\text { asivayam } 2010\end{array}$ \\
\hline Phenol & $\begin{array}{l}\text { Granular } \\
\text { active carbon }\end{array}$ & $A C$ & - & $\mathrm{L}$ & 67 & - & - & $\begin{array}{l}\text { Packed bed and competitive adsorption } \\
\text { with lead }\end{array}$ & $\begin{array}{l}\text { Sulaymon et al. } \\
2012\end{array}$ \\
\hline Phenol & $\begin{array}{l}\text { Active carbon, } \\
\text { Anaer. sludge }\end{array}$ & $\begin{array}{l}\mathrm{AC} \\
-\end{array}$ & Dried & $\bar{L}$ & $\begin{array}{l}67 \\
70\end{array}$ & - & - & $\begin{array}{l}\text { Competition was observed between phenol } \\
\text { and lead. }\end{array}$ & $\begin{array}{l}\text { Sulaymon et al. } \\
2013\end{array}$ \\
\hline $\begin{array}{l}\text { Fluridone pesticide, } \\
\text { Norflurizon pesticide }\end{array}$ & $\begin{array}{l}\text { Biochar, } \\
\text { Soil organics }\end{array}$ & $\begin{array}{ll}\mathrm{BC} \\
-\end{array}$ & $\begin{array}{l}250-400 \\
\mathrm{HCl}\end{array}$ & $\mathrm{F}$ & $\begin{array}{l}5 \\
5\end{array}$ & - & - & $\begin{array}{l}\text { Aliphatic and aromatic components and } \\
\text { nitrogen were important for adsorption. }\end{array}$ & $\begin{array}{l}\text { Sun et al. } \\
2012 a\end{array}$ \\
\hline $\begin{array}{l}\text { Di-ethyl phthalate, } \\
\text { Di-butyl phthalate, } \\
\text { Butylbenzyl phthal. }\end{array}$ & Biochars & $\mathrm{BC}$ & $300-400$ & $\mathrm{~F}$ & $\begin{array}{l}1-60 \\
1-50 \\
2-60\end{array}$ & - & - & $\begin{array}{l}\text { Uptake correlated to hydrophobicity of the } \\
\text { sorbate }\end{array}$ & $\begin{array}{l}\text { Sun et al. } \\
2012 b\end{array}$ \\
\hline
\end{tabular}




\begin{tabular}{|c|c|c|c|c|c|c|c|c|c|}
\hline Pollutant & Sorbent & 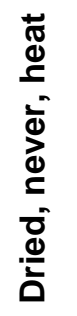 & 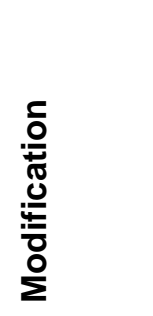 & 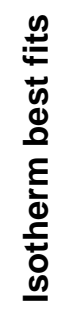 & $\begin{array}{l}\text { Adsorp. } \\
\text { capac. } \\
(\mathrm{mg} / \mathrm{g})\end{array}$ & 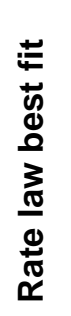 & 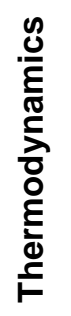 & Key Findings & Author (year) \\
\hline $\begin{array}{l}\text { Fluridone pesticide, } \\
\text { Norflurizon pesticide }\end{array}$ & Biochars & $\mathrm{BC}$ & $200-600$ & $\mathrm{~F}$ & $\begin{array}{l}1-60 \\
1-80\end{array}$ & - & - & $\begin{array}{l}\text { Lower-temperature treatment yielded (400) } \\
\text { higher sorption; aromatic content was key. }\end{array}$ & $\begin{array}{l}\text { Sun et al. } \\
2011 \mathrm{a}\end{array}$ \\
\hline $\begin{array}{l}\text { Bisphenol } \mathrm{A}, \\
17 \alpha \text { Ethinylestradiol, } \\
\text { Phenanthrene }\end{array}$ & Biochars & $\mathrm{BC}$ & $\begin{array}{l}\text { Therml, } \\
\text { Hydroth. } \\
250 ; 400\end{array}$ & $\mathrm{~F}$ & $\begin{array}{l}0.1-20 \\
0.1-8 \\
0.2-20\end{array}$ & - & - & $\begin{array}{l}\text { Hydrothermal chars are more amorphous, } \\
\text { giving wider spectrum of adsorption; low } \\
\text { affinity results. }\end{array}$ & $\begin{array}{l}\text { Sun et al. } \\
2011 b\end{array}$ \\
\hline 2,4,6-Trichlorophen. & $\begin{array}{l}\text { Active carbon } \\
\text { fr. corn husk }\end{array}$ & $A C$ & $\begin{array}{l}\mathrm{KOH} \\
\mathrm{CO}_{2} 750\end{array}$ & $\mathrm{~F}$ & 192 & - & - & $\begin{array}{l}\text { Large-well-developed pores resulted from } \\
\text { the optimized activation. }\end{array}$ & Tan et al. 2008 \\
\hline 2,4,6-Trichlorophen. & $\begin{array}{l}\text { Active carbon } \\
\text { from palm }\end{array}$ & $\mathrm{AC}$ & $\begin{array}{l}\mathrm{KOH} \\
\mathrm{CO}_{2} 750\end{array}$ & - & $5-9$ & - & - & $\begin{array}{l}\text { Column experiments, breakthrough; } \\
\text { ethanol was effective for regeneration. }\end{array}$ & $\begin{array}{l}\text { Tan et al. } \\
2009 a\end{array}$ \\
\hline 2,4,6-Trichlorophen. & $\begin{array}{l}\text { Active carbon } \\
\text { from palm }\end{array}$ & $\mathrm{AC}$ & $\begin{array}{l}\mathrm{KOH} \\
\mathrm{CO}_{2} 700\end{array}$ & $\begin{array}{l}\mathrm{F} \\
\mathrm{L}\end{array}$ & $500-588$ & $2^{\text {nd }}$ & En & $\begin{array}{l}\text { Lower } \mathrm{pH} \text { favored, intraparticle diffusion } \\
\text { was rate-controlling. }\end{array}$ & $\begin{array}{l}\text { Tan et al. } \\
2009 b\end{array}$ \\
\hline Phenol & $\begin{array}{l}\text { Active carbons } \\
\text { from wood }\end{array}$ & $A C$ & 500 & $\begin{array}{l}\mathrm{L} \\
\mathrm{F}\end{array}$ & $46-148$ & - & - & $\begin{array}{l}\text { Preferential sorption observed onto carbon } \\
\text { element, not on the clay binder used. }\end{array}$ & $\begin{array}{l}\text { Tancredi et al. } \\
2004\end{array}$ \\
\hline$p$-Nitrophenol & $\begin{array}{l}\text { Active carbon } \\
\text { fiber }\end{array}$ & $\mathrm{AC}$ & - & $\mathrm{F}$ & $357-385$ & $2^{\text {nd }}$ & En & $\begin{array}{l}\text { Adsorption dropped at } \mathrm{pH} \text { above } 6 ; \mathrm{NaOH} \\
\text { desorbed only } 60 \% \text {, regardless or conc. }\end{array}$ & $\begin{array}{l}\text { Tang et al. } \\
2007\end{array}$ \\
\hline Phenol & Active carbons & $A C$ & $\mathrm{CO}_{2}$ & $\begin{array}{l}\mathrm{L} \\
\mathrm{F}\end{array}$ & $73-138$ & - & Ex & $\begin{array}{l}\text { Uptake correlated to surface area, but } \\
\text { negatively affected by oxygen content. }\end{array}$ & $\begin{array}{l}\text { Teng \& Hseih } \\
1999\end{array}$ \\
\hline Phenol & $\begin{array}{l}\text { Microporous } \\
\text { carbons }\end{array}$ & $A C$ & $\begin{array}{l}\text { Molec. } \\
\text { dynamic }\end{array}$ & - & - & - & - & $\begin{array}{l}\text { Pore of about } 0.6 \mathrm{~nm} \text { are optimal; surface } \\
\text { oxygen tends to block such pores. }\end{array}$ & $\begin{array}{l}\text { Terzyk et al. } \\
2010\end{array}$ \\
\hline $\begin{array}{l}\text { o-Cresol, } \\
\text { o-Chlorophenol }\end{array}$ & Active carbons & $A C$ & Outgas & $\mathrm{F}$ & $90-300$ & - & - & $\begin{array}{l}\text { Oxygen-containing surface groups } \\
\text { promote irreversible adsorption. }\end{array}$ & $\begin{array}{l}\text { Tessmer et al. } \\
1997\end{array}$ \\
\hline Phenol & $\begin{array}{l}\text { Sewage } \\
\text { sludge }\end{array}$ & - & Dried & - & 94 & - & - & Maximum removal was at $\mathrm{pH} 6$ to 8 . & $\begin{array}{l}\text { Thawornchaisit } \\
\text { \& P. } 2007\end{array}$ \\
\hline $\begin{array}{l}\text { Dieldrin pesticide, } \\
\text { Chlorpyrifos }\end{array}$ & Active carbons & $\mathrm{AC}$ & $\begin{array}{l}\text { Steam } \\
800+\end{array}$ & $\mathrm{F}$ & $\begin{array}{l}544-910 \\
500-873\end{array}$ & - & - & $\begin{array}{l}\text { Favorable pore size distribution was } \\
\text { achieved. }\end{array}$ & $\begin{array}{l}\text { Thuy et al. } \\
2012\end{array}$ \\
\hline Phenol & $\begin{array}{l}\text { Active carbons } \\
\text { from oak cup }\end{array}$ & $\mathrm{AC}$ & $\begin{array}{l}\mathrm{H}_{3} \mathrm{PO}_{4} \\
\mathrm{ZnCl}_{2}\end{array}$ & $\mathrm{~L}$ & $\begin{array}{l}62 \\
75\end{array}$ & - & - & $\begin{array}{l}\text { Adsorption mainly was related to } \\
\text { micropores. }\end{array}$ & $\begin{array}{l}\text { Timur et al. } \\
2010\end{array}$ \\
\hline
\end{tabular}




\begin{tabular}{|c|c|c|c|c|c|c|c|c|c|}
\hline Pollutant & Sorbent & 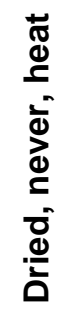 & 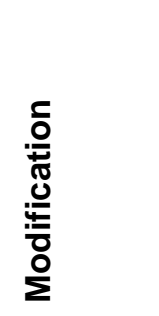 & 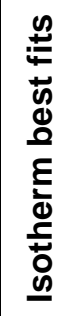 & $\begin{array}{l}\text { Adsorp. } \\
\text { capac. } \\
(\mathrm{mg} / \mathrm{g})\end{array}$ & 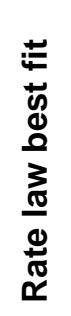 & 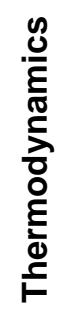 & Key Findings & Author (year) \\
\hline $\begin{array}{l}\text { Phenol, } \\
\text { o-Cresol }\end{array}$ & $\begin{array}{l}\text { Granular } \\
\text { active carbon }\end{array}$ & $\mathrm{AC}$ & Steam & - & $\begin{array}{l}150-170 \\
210-225\end{array}$ & - & - & Bioregeneration was shown to be effective. & Toh et al. 2013 \\
\hline $\begin{array}{l}\text { Benzene, toluene, } \\
\text { acetone, etc. mix }\end{array}$ & $\begin{array}{l}\text { Granular } \\
\text { active carbon }\end{array}$ & $\mathrm{AC}$ & $\begin{array}{l}\mathrm{H}_{3} \mathrm{PO}_{4} \\
\mathrm{CO}_{2}\end{array}$ & - & $30-50$ & - & - & $\begin{array}{l}\text { Activation conditions affected uptake of } \\
\text { polar and nonpolar adsorbates. }\end{array}$ & $\begin{array}{l}\text { Toles et al. } \\
1997\end{array}$ \\
\hline $\begin{array}{l}\text { Benzene, toluene, } \\
\text { acetone, etc. mix }\end{array}$ & $\begin{array}{l}\text { Granular } \\
\text { active carbon }\end{array}$ & $\mathrm{AC}$ & $\mathrm{H}_{3} \mathrm{PO}_{4}$ & - & $25-40$ & - & - & $\begin{array}{l}\text { Air oxidation could be used in place of } \\
\text { conventional oxidation. }\end{array}$ & $\begin{array}{l}\text { Toles et al. } \\
1998\end{array}$ \\
\hline Phenol, & $\begin{array}{l}\text { Active carbons } \\
\text { from pine }\end{array}$ & $\mathrm{AC}$ & $\begin{array}{l}\text { Steam } \\
900\end{array}$ & $\mathrm{~F}$ & $120-170$ & $2^{\text {nd }}$ & - & $\begin{array}{l}\text { The Elovich equation could fit the kinetic } \\
\text { data best. }\end{array}$ & $\begin{array}{l}\text { Tseng et al. } \\
2003\end{array}$ \\
\hline $\begin{array}{l}\text { Phenol, } \\
\text { 4-Chlorophenol, } \\
\text { 2,4-Dichlorophenol }\end{array}$ & Active carbons & $\mathrm{AC}$ & $\begin{array}{l}450 \mathrm{C} \\
\mathrm{NaOH}\end{array}$ & $\mathrm{L}$ & $\begin{array}{l}214-284 \\
308-426 \\
438-613\end{array}$ & - & - & $\begin{array}{l}\text { The process could be divided into fast and } \\
\text { moderately fast segments. }\end{array}$ & $\begin{array}{l}\text { Tseng et al. } \\
2010\end{array}$ \\
\hline 2,4-Dichlorophenol & Active carbons & $\mathrm{AC}$ & $\begin{array}{l}\mathrm{NaOH} \\
780\end{array}$ & $\mathrm{~L}$ & 719 & $2^{\text {nd }}$ & - & $\begin{array}{l}\text { Half-life and half-capacity values were } \\
\text { shown to be useful. }\end{array}$ & $\begin{array}{l}\text { Tseng et al. } \\
2011\end{array}$ \\
\hline $\begin{array}{l}\text { Lindane, } \\
\text { Pentachlorophenol }\end{array}$ & $\begin{array}{l}\text { Activated } \\
\text { sludge }\end{array}$ & - & Live & $\mathrm{F}$ & - & - & - & Biosorption played a significant role. & $\begin{array}{l}\text { Tsezos \& Bell } \\
1988\end{array}$ \\
\hline $\begin{array}{l}\text { Lindane, } \\
\text { Diazinon, } \\
\text { Pentachlorophenol, } \\
\text { 2-Chlorobiphenyl }\end{array}$ & $\begin{array}{l}\text { Rhiazopus } \\
\text { arrhizus }\end{array}$ & Dry & $\begin{array}{l}\text { Live and } \\
\text { dead }\end{array}$ & $\mathrm{F}$ & $0.8-1$ & - & - & $\begin{array}{l}\text { Results consistent with octanol/water } \\
\text { partition coefficients; drying of the biomass } \\
\text { increased uptake by a factor of about } 3 .\end{array}$ & $\begin{array}{l}\text { Tsezos \& Bell } \\
1989\end{array}$ \\
\hline Malathion & $\begin{array}{l}\text { R. arrhizus, } \\
\text { Active sludge }\end{array}$ & No & $\begin{array}{l}\text { Live and } \\
\text { dead }\end{array}$ & $\mathrm{F}$ & 30 & - & - & $\begin{array}{l}\text { Either living or dead cells were able to } \\
\text { biosorb the pollutant; reversible sorption. }\end{array}$ & $\begin{array}{l}\text { Tsezos \& Bell } \\
1991\end{array}$ \\
\hline $\begin{array}{l}\text { Lindane, } \\
\text { Diazinon, } \\
\text { 2-Chlorobiphenyl }\end{array}$ & $\begin{array}{l}\text { R. arrhizus, } \\
\text { Active sludge }\end{array}$ & $\begin{array}{l}115 \\
\mathrm{C}\end{array}$ & - & - & - & $2^{\text {nd }}$ & - & Reversibility shown & $\begin{array}{l}\text { Tsezos \& } \\
\text { Wang 1991b }\end{array}$ \\
\hline
\end{tabular}




\begin{tabular}{|c|c|c|c|c|c|c|c|c|c|}
\hline Pollutant & Sorbent & 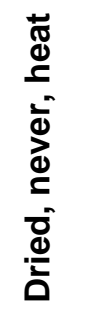 & 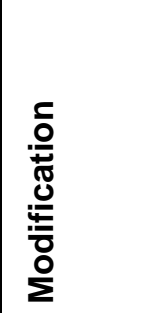 & 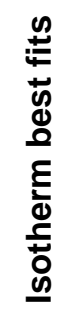 & $\begin{array}{l}\text { Adsorp. } \\
\text { capac. } \\
\text { (mg/g) }\end{array}$ & 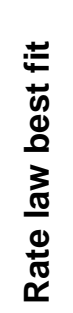 & 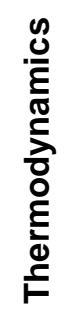 & Key Findings & Author (year) \\
\hline $\begin{array}{l}\text { Tetrachloroethylene, } \\
\text { Trichloroethylene, } \\
\text { 1,2-Dichloroethylen, } \\
\text { 1,1-Dichloroethane, } \\
\text { Carbontetrachloride, } \\
\text { Trichloroethane, } \\
\text { Chloroform }\end{array}$ & $\begin{array}{l}\text { Granular } \\
\text { active carbons }\end{array}$ & $A C$ & - & $F$ & $1-100$ & - & - & $\begin{array}{l}\text { Pores smaller than } 2 \mathrm{~nm} \text { had a dominant } \\
\text { effect; humic substances decreased } \\
\text { sorption by about } 10-20 \% \text {. }\end{array}$ & $\begin{array}{l}\text { Urano et al } \\
1991\end{array}$ \\
\hline 2-Methylpehnol, & Active carbons & $A C$ & $\begin{array}{l}\text { Anoxic, } \\
\text { Oxidiz. }\end{array}$ & - & $\begin{array}{l}79-142 \\
105-288\end{array}$ & - & - & $\begin{array}{l}\text { Irreversible adsorption (up to } 288 \mathrm{mg} / \mathrm{g} \text { ) } \\
\text { was proportional to surface area. }\end{array}$ & $\begin{array}{l}\text { Uranowski et } \\
\text { al. } 1998\end{array}$ \\
\hline Phenols mixture & $\begin{array}{l}\text { Granular } \\
\text { active carbon }\end{array}$ & $A C$ & - & $\begin{array}{l}\mathrm{L} \\
\mathrm{F}\end{array}$ & 1.5 & $1^{\text {st }}$ & - & Column experiments & $\begin{array}{l}\text { Vázquez et al. } \\
2007\end{array}$ \\
\hline $\begin{array}{l}\text { 2-Methylphenol, } \\
\text { 2-Chlorophenol, } \\
\text { 2-Ethylphenol }\end{array}$ & $\begin{array}{l}\text { Granular } \\
\text { active carbon }\end{array}$ & $A C$ & $\begin{array}{l}\text { Anoxic, } \\
\text { Oxidiz. }\end{array}$ & $\mathrm{F}$ & $\begin{array}{l}100-300 \\
250-400\end{array}$ & - & - & $\begin{array}{l}\text { Oxygenation increased the adsorption } \\
\text { capacity. }\end{array}$ & $\begin{array}{l}\text { Vidic et al. } \\
1994\end{array}$ \\
\hline $\begin{array}{l}\text { Phenol, } \\
\text { Analine, } \\
\text { Nitrobenzene }\end{array}$ & Active carbons & $A C$ & $\begin{array}{l}\mathrm{HNO}_{3} \\
\mathrm{H}_{2}\end{array}$ & $\mathrm{~L}$ & $\begin{array}{l}103-179 \\
105-214 \\
197-406\end{array}$ & - & - & $\begin{array}{l}\text { The aminated carbon exhibited the highest } \\
\text { sorption capacity. }\end{array}$ & $\begin{array}{l}\text { Villacanas et al. } \\
2006\end{array}$ \\
\hline Phenol & $\begin{array}{l}\text { Peat, } \\
\text { Fly ash, } \\
\text { Bentonite }\end{array}$ & $\begin{array}{l}103, \\
- \\
-\end{array}$ & - & $\mathrm{F}$ & $\begin{array}{l}0.2 \\
40\end{array}$ & - & - & Optimum pH 3 to 5. & $\begin{array}{l}\text { Viraraghavan \& } \\
\text { Alfaro } 1998\end{array}$ \\
\hline $\begin{array}{l}\text { 2,4,6-Trinitrophenol, } \\
\text { 4-Nitrophenol, } \\
\text { 2,4-Dinitrophenol, }\end{array}$ & $\begin{array}{l}\text { Acrylate-graft } \\
\text { cotton }\end{array}$ & - & \begin{tabular}{|l|} 
Glycicyl \\
meth- \\
acrylate \\
\end{tabular} & $\begin{array}{ll}L \\
F\end{array}$ & \begin{tabular}{|l|}
$56-116$ \\
$31-65$ \\
$56-108$ \\
\end{tabular} & $2^{\text {nd }}$ & - & $\begin{array}{l}\text { Poor adsorption at pH } 2.3 \text { in most cases; } \\
\text { most data are for } \mathrm{pH} 11 ; \text { glycidic groups } \\
\text { favored uptake of hydrophobic compound. }\end{array}$ & $\begin{array}{l}\text { Vismara et al. } \\
2009\end{array}$ \\
\hline
\end{tabular}




\begin{tabular}{|c|c|c|c|c|c|c|c|c|c|}
\hline Pollutant & Sorbent & 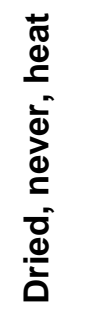 & 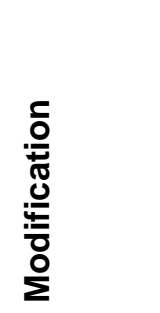 & 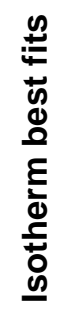 & $\begin{array}{l}\text { Adsorp. } \\
\text { capac. } \\
\text { (mg/g) }\end{array}$ & 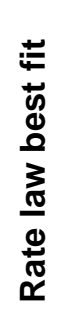 & 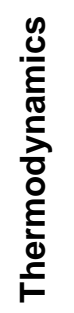 & Key Findings & Author (year) \\
\hline 2,4-Dichlorophenol & $\begin{array}{l}\text { Active carbon } \\
\text { fibers }\end{array}$ & $\mathrm{AC}$ & $\begin{array}{l}\text { StaticAir } \\
\text { 900C }\end{array}$ & $\begin{array}{l}\mathrm{L} \\
\mathrm{RP}\end{array}$ & $396-400$ & - & - & $\begin{array}{l}\text { Lower } \mathrm{pH} \text { is favorable, pi-pi interactions \& } \\
\text { electrostatics; use } \mathrm{NaOH} \text { to regenerate. }\end{array}$ & $\begin{array}{l}\text { Wang et al. } \\
2007 a\end{array}$ \\
\hline 2,4-Dichlorophenol & $\begin{array}{l}\text { Active carbon } \\
\text { fibers }\end{array}$ & $A C$ & $\begin{array}{l}\text { StaticAir } \\
\text { 900C }\end{array}$ & L & $342-372$ & $2^{\text {nd }}$ & Ex & $\begin{array}{l}\text { Air activation was judged to be an efficient } \\
\text { approach. }\end{array}$ & $\begin{array}{l}\text { Wang et al. } \\
2007 \mathrm{~b}\end{array}$ \\
\hline Di-n-butyl phthalate & $\begin{array}{l}\text { Pseudomonas } \\
\text { fluorescens }\end{array}$ & $\begin{array}{l}\text { Auto } \\
\text { clav }\end{array}$ & $\begin{array}{l}\text { Live vs. } \\
\text { dead }\end{array}$ & $\mathrm{F}$ & $\begin{array}{l}1.7 \\
2.5\end{array}$ & - & - & Dead biomass had a higher affinity. & $\begin{array}{l}\text { Wang \& Grady } \\
1994\end{array}$ \\
\hline $\begin{array}{l}\text { Perchloroethylene, } \\
\text { Trichloroethylene, } \\
\text { Trans-dichloroethyl., } \\
\text { Cis-dichloroethylene }\end{array}$ & \begin{tabular}{|l} 
Pine mulch, \\
Hardwood m., \\
Cypress \\
mulch \\
\end{tabular} & $60 \mathrm{C}$ & $\begin{array}{l}\text { Wash, } \\
\text { auto- } \\
\text { clave }\end{array}$ & $\begin{array}{l}L \\
F\end{array}$ & $\begin{array}{l}92-320 \\
162-315 \\
94-102 \\
88-150\end{array}$ & & & Pine mulch was most effective. & $\begin{array}{l}\text { Wei \& Seo } \\
2010\end{array}$ \\
\hline$p$-Nitrophenol & Active carbon & $\mathrm{AC}$ & - & - & - & - & - & Fixed bed breakthrough curves & Wolborka 1989 \\
\hline $\begin{array}{l}\text { Phenol, } \\
p \text {-Cresol, } \\
p \text {-Chlorophenol, } \\
p \text {-Nitrophenol }\end{array}$ & $\begin{array}{l}\text { Active carbon } \\
\text { fr. fir wood }\end{array}$ & $\mathrm{AC}$ & $\begin{array}{l}\mathrm{KOH} \\
\mathrm{CO}_{2} 780\end{array}$ & $\mathrm{~L}$ & $\begin{array}{l}220-275 \\
254-333 \\
355-418 \\
377-542\end{array}$ & $\begin{array}{l}\text { Elo } \\
\text { vic. }\end{array}$ & - & $\begin{array}{l}\mathrm{CO}_{2} \text { played a critical role in activation after } \\
\text { the } \mathrm{KOH} \text { treatment. }\end{array}$ & $\begin{array}{l}\text { Wu \& Tseng } \\
2006\end{array}$ \\
\hline Phenol & $\begin{array}{l}\text { Active carbon } \\
\text { from bamboo }\end{array}$ & $\mathrm{AC}$ & $700-880$ & L & $223-231$ & - & - & Activation conditions were optimized. & Wu et al. 1999 \\
\hline $\begin{array}{l}\text { 2,4-Dichlorophenol, } \\
\text { 4-Chlorophenol, } \\
\text { p-Cresol, } \\
\text { Phenol }\end{array}$ & $\begin{array}{l}\text { Active carbon } \\
\text { from fir wood }\end{array}$ & $\mathrm{AC}$ & $\begin{array}{l}\mathrm{KOH} \\
\text { Steam }\end{array}$ & - & $\begin{array}{l}244-570 \\
194-452 \\
108-324 \\
94-207\end{array}$ & - & - & & Wu et al. 2005 \\
\hline 4-Chlorophenol & $\begin{array}{l}\text { Active carbon } \\
\text { fr. corn hull }\end{array}$ & $\mathrm{AC}$ & $\begin{array}{l}\mathrm{H}_{2} \mathrm{SO}_{4} \\
\mathrm{KOH} 780\end{array}$ & $\mathrm{~L}$ & 520 & $\begin{array}{l}\text { Elo } \\
\text { vic. }\end{array}$ & - & $\begin{array}{l}\text { Rapid adsorption was attributed to the thin } \\
\text { nature of the material. }\end{array}$ & Wu et al. 2011 \\
\hline $\begin{array}{l}\text { Phenol, } \\
\text { 2-Chlorophenol, } \\
\text { 4-Chlorophenol, } \\
\text { 2,4-Dichlorophenol }\end{array}$ & $\begin{array}{l}\text { Phanerochaet. } \\
\text { chrysosporium } \\
\text { fungal mycelia }\end{array}$ & $\begin{array}{l}\text { Auto } \\
\text { clav. }\end{array}$ & Pellets & $\mathrm{F}$ & $\begin{array}{l}1, \\
1.6, \\
1.7 \\
3.7\end{array}$ & - & - & $\begin{array}{l}\text { Results were consistent with octanol-water } \\
\text { partitioning coefficients. }\end{array}$ & Wu \& Yu 2006a \\
\hline
\end{tabular}




\begin{tabular}{|c|c|c|c|c|c|c|c|c|c|}
\hline Pollutant & Sorbent & 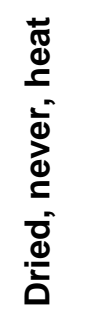 & 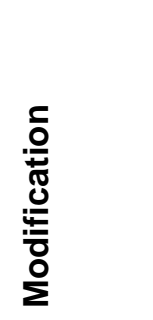 & 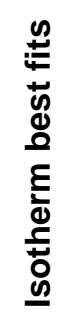 & $\begin{array}{l}\text { Adsorp. } \\
\text { capac. } \\
(\mathrm{mg} / \mathrm{g})\end{array}$ & 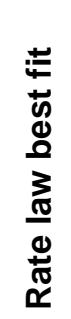 & 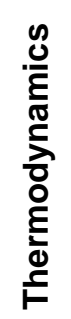 & Key Findings & Author (year) \\
\hline 2,4-Dichlorophenol & $\begin{array}{l}\text { Phanerochaet. } \\
\text { chrysosporium } \\
\text { fungal mycelia }\end{array}$ & $\begin{array}{l}\text { Auto } \\
\text { clav. }\end{array}$ & Pellets & $\begin{array}{l}\mathrm{F} \\
\mathrm{L}\end{array}$ & 4.1 & $\begin{array}{l}2^{\text {nd }} \\
\text { ID }\end{array}$ & Ex & Best $\mathrm{pH}=5$, intraparticle diffusion & Wu \& Yu 2006b \\
\hline 2,4-Dichlorophenol & $\begin{array}{l}\text { Phanerochaet. } \\
\text { chrysosporium } \\
\text { fungal mycelia }\end{array}$ & $\begin{array}{l}\text { Auto } \\
\text { clav. }\end{array}$ & $\begin{array}{l}\text { Immob- } \\
\text { ilized }\end{array}$ & $\begin{array}{l}\mathrm{L} \\
\mathrm{F}\end{array}$ & $4-7$ & - & - & Reversible with distilled water & Wu et al. 2007 \\
\hline 2,4-Dichlorophenol & $\begin{array}{l}\text { Phanerochaet. } \\
\text { chrysosporium } \\
\text { fungal mycelia }\end{array}$ & $\begin{array}{l}\text { Auto } \\
\text { clav. }\end{array}$ & $\begin{array}{l}\text { Immob- } \\
\text { ilized }\end{array}$ & - & $5-12$ & - & - & $\begin{array}{l}\text { Fixed bed, breakthrough models, the bed } \\
\text { could be reused five times with up to } 68 \% \\
\text { desorption. }\end{array}$ & Wu \& Yu 2008 \\
\hline 1-Naphthol & $\begin{array}{l}\text { MW carbon } \\
\text { nanotubes }\end{array}$ & - & $\begin{array}{l}\mathrm{KMnO}_{4} \\
\mathrm{NaOH} \\
\mathrm{H}_{2} \mathrm{SO}_{4} \\
\end{array}$ & - & $20-1200$ & - & - & $\begin{array}{l}\text { Oxidative polymerization of the adsorbate; } \\
\text { surface oxygen groups covalently bond; } \\
\text { adsorption increased up to } \mathrm{pH}=7 \text {, then fell. }\end{array}$ & Wu et al. 2012a \\
\hline Phenol & $\begin{array}{l}\text { Active carbon } \\
\text { (N-enriched) }\end{array}$ & $A C$ & $\begin{array}{l}\mathrm{KOH} \\
850 \mathrm{C}\end{array}$ & $\mathrm{L}$ & 207 & $2^{\text {nd }}$ & - & $\begin{array}{l}\text { Nitrogen-enriched activated carbon was } \\
\text { effective for adsorption of phenol. }\end{array}$ & Wu et al. 2012b \\
\hline $\begin{array}{l}\text { Phenol, } \\
\text { 2-Chlorophenol, } \\
\text { 4-Chlorophenol, } \\
\text { 2-4-Dichlorophenol }\end{array}$ & $\begin{array}{l}\text { MW caron } \\
\text { nanotubes }\end{array}$ & - & $\begin{array}{l}\text { Zero- } \\
\text { valent } \\
\text { Fe }\end{array}$ & $\mathrm{L}$ & \begin{tabular}{|l}
4 \\
14 \\
14 \\
20 \\
\end{tabular} & - & - & $\begin{array}{l}\text { Chlorine atoms on nanotubes increase } \\
\text { adsorption capacity. }\end{array}$ & Xu et al. 2012 \\
\hline $\begin{array}{l}\text { Organochlorines in } \\
\text { pulp bleach effluent }\end{array}$ & $\begin{array}{l}\text { Sewage } \\
\text { sludge }\end{array}$ & $\begin{array}{l}\text { Auto } \\
\text { clav. }\end{array}$ & - & $\mathrm{L}$ & 7.5 as $\mathrm{Cl}$ & - & - & $\begin{array}{l}\text { Adsorption was not dependent on cell } \\
\text { viability. }\end{array}$ & $\begin{array}{l}\text { Yan \& Allen } \\
1994\end{array}$ \\
\hline $\begin{array}{l}\text { Naphthalene, } \\
\text { Phenanthrene, } \\
\text { Pyrene }\end{array}$ & $\begin{array}{l}\text { Fullerenes, } \\
\text { SW C nanotu., } \\
\text { MW C nanot. }\end{array}$ & - & - & $\mathrm{F}$ & $\begin{array}{l}1-50 \\
10-40 \\
10-45 \\
\end{array}$ & - & - & $\begin{array}{l}\text { Polanyi model was used to fit the } \\
\text { isotherms. }\end{array}$ & $\begin{array}{l}\text { Yang et al. } \\
2006\end{array}$ \\
\hline Triphenyltin & $\begin{array}{l}\text { Brevibacillus } \\
\text { brevis }\end{array}$ & live & Cultured & - & - & - & - & $\begin{array}{l}\text { Endocrine disruptor was biodegraded to } \\
\text { certain byproducts; minor } \mathrm{pH} \text { effects. }\end{array}$ & Ye et al. 2013 \\
\hline
\end{tabular}




\begin{tabular}{|c|c|c|c|c|c|c|c|c|c|}
\hline Pollutant & Sorbent & 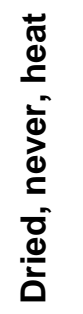 & 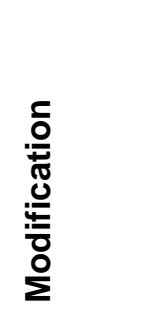 & 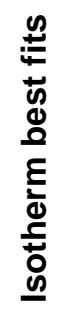 & $\begin{array}{l}\text { Adsorp. } \\
\text { capac. } \\
(\mathbf{m g} / \mathrm{g})\end{array}$ & 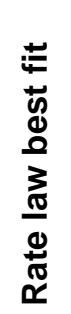 & 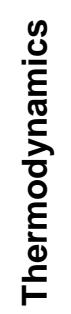 & Key Findings & Author (year) \\
\hline $\begin{array}{l}\text { Trichloroethene, } \\
\text { Tetrachloroethene, } \\
\text { Trichloroethane, } \\
\text { I,I-Dichloroethene }\end{array}$ & $\begin{array}{l}\text { Active carbon } \\
\text { fiber }\end{array}$ & $\mathrm{AC}$ & - & - & $\begin{array}{l}20-43 \\
38-88 \\
4-28 \\
6-19\end{array}$ & - & - & $\begin{array}{l}\text { Groundwater purification (closed vinyl } \\
\text { chloride plant) was achieved by passing } \\
\text { through stirred vessels. }\end{array}$ & $\begin{array}{l}\text { Yu \& Chou } \\
2000\end{array}$ \\
\hline $\begin{array}{l}\text { Perfluorooctane } \\
\text { sulfonate \& P. } \\
\text { octanoate }\end{array}$ & $\begin{array}{l}\text { Activated } \\
\text { carbon, } \\
\text { Act. sludge }\end{array}$ & AC & - & $\begin{array}{l}\mathrm{F} \\
\mathrm{F}\end{array}$ & $\begin{array}{r}150-250 \\
150-250 \\
\end{array}$ & - & - & $\begin{array}{l}\text { The adsorbed amount fell by half in the } \\
\text { presence of effluent organic matter. }\end{array}$ & Yu \& Hu 2011 \\
\hline $\begin{array}{l}\text { Methylcyclohexane, } \\
\text { Toluene, } \\
\text { Isobut.-meth. ketone }\end{array}$ & Active carbon & $\mathrm{AC}$ & - & $\mathrm{L}$ & $\begin{array}{l}205 \\
190 \\
258\end{array}$ & - & - & Various isotherms compared. & $\begin{array}{l}\text { Yu \& Neret- } \\
\text { nieks } 1990\end{array}$ \\
\hline $\begin{array}{l}\text { Perfluorooctane } \mathrm{SO}_{4} \\
\text { Perfluorooctanoate }\end{array}$ & Active carbons & $\mathrm{AC}$ & - & $\mathrm{L}$ & $\begin{array}{l}185-520 \\
161-1209 \\
\end{array}$ & $2^{\text {nd }}$ & - & Ion exchange and hydrophobic interactions & Yu et al. 2009 \\
\hline $\begin{array}{l}\text { Napoxen, } \\
\text { Carbamazepine, } \\
\text { Nonylphenol }\end{array}$ & Active carbon & $\mathrm{AC}$ & - & $\mathrm{F}$ & $0.2-1$ & - & - & $\begin{array}{l}\text { Affinities did not match hydrophobicities or } \\
\text { capacities; natural organic matter (NOM) } \\
\text { suppressed adsorption. }\end{array}$ & Yu et al. 2008 \\
\hline $\begin{array}{l}\text { Phenol (DMSO \& } \\
\text { acrylonitrile-aq. sys.) }\end{array}$ & Cellulose & - & $\begin{array}{l}\mathrm{H}_{2} \mathrm{O}- \\
\text { organics }\end{array}$ & - & $1-35$ & - & - & $\begin{array}{l}\text { Adsorption on cellulose was affected by } \\
\text { adsorbate-solvent interactions; low affinity } \\
\text { with evidence of self-association (admic- } \\
\text { elles) at high bulk concentration of phenol. }\end{array}$ & $\begin{array}{l}\text { Zakharov et al. } \\
2010\end{array}$ \\
\hline $\begin{array}{l}\text { Toluene, } \\
\text { Dichloromethane }\end{array}$ & $\begin{array}{l}\text { Granular } \\
\text { active carbon }\end{array}$ & $A C$ & - & $\mathrm{L}$ & $\begin{array}{l}4-9 \\
340\end{array}$ & - & En & $\begin{array}{l}\text { A Langmuir-BET model best fit with data } \\
\text { for toluene; breakthrough predicted. }\end{array}$ & $\begin{array}{l}\text { Zeinali et al. } \\
2012\end{array}$ \\
\hline Phenanthrene & $\begin{array}{l}\text { Pure algae, } \\
\text { Field plankton } \\
\text { Market algae }\end{array}$ & dry & $\begin{array}{l}\text { Freeze- } \\
\text { dried }\end{array}$ & $\mathrm{F}$ & $1-10$ & - & - & $\begin{array}{l}\text { Alkyl and nonhydrolyzable components } \\
\text { accounted for uptake. }\end{array}$ & $\begin{array}{l}\text { Zhang et al. } \\
2013\end{array}$ \\
\hline Simazine herbicide & $\begin{array}{l}\text { Biochars from } \\
\text { corn straw }\end{array}$ & $\mathrm{BC}$ & $100-600$ & $\mathrm{~F}$ & $0.1-5$ & - & - & $\begin{array}{l}\text { Aromatic function and pi-pi interactions } \\
\text { were important; increased carbonation } \\
\text { beneficial; pore-filling mechanism. }\end{array}$ & $\begin{array}{l}\text { Zhang et al. } \\
\text { 2011a }\end{array}$ \\
\hline
\end{tabular}




\begin{tabular}{|c|c|c|c|c|c|c|c|c|c|}
\hline Pollutant & Sorbent & 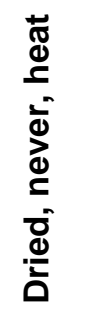 & 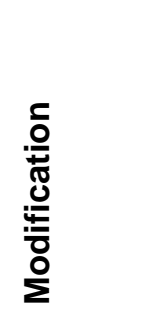 & 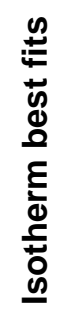 & $\begin{array}{l}\text { Adsorp. } \\
\text { capac. } \\
\text { (mg/g) }\end{array}$ & 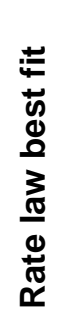 & 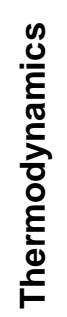 & Key Findings & Author (year) \\
\hline $\begin{array}{l}\text { Olaquindox (animal } \\
\text { growth promoter) }\end{array}$ & $\begin{array}{l}\text { MW carbon } \\
\text { nanotubes }\end{array}$ & - & - & $\mathrm{L}$ & 133 & $\begin{array}{l}2^{\text {nd }} \\
\text { ID }\end{array}$ & Ex & Pi-pi interactions; intraparticle diffusion & $\begin{array}{l}\text { Zhang et al. } \\
2011 \mathrm{~b}\end{array}$ \\
\hline $\begin{array}{l}\text { Naphthylamine, } \\
\text { Naphthol, } \\
\text { Benzoic acid, } \\
p \text {-Toluidine, } \\
p \text {-Cresol, } \\
\text {-Toluic acid, } \\
\text { Phenol, } \\
p \text {-Toluenesulfonic ac }\end{array}$ & $\begin{array}{l}\text { Penicillium } \\
\text { oxalicum }\end{array}$ & $\begin{array}{l}\text { Auto } \\
\text { clav }\end{array}$ & Cultured & $\begin{array}{l}L \\
F\end{array}$ & $\begin{array}{l}21, \\
8, \\
- \\
3.5, \\
2.4, \\
-, \\
0.9, \\
0.8\end{array}$ & - & - & $\begin{array}{l}\text { Adsorption was favored by low pH; four } \\
\text { key binding sites were identified as } \\
\text { carboxyl, phosphoric, amine, and hydroxyl } \\
\text { groups; low ionization degree and } \\
\text { hydrophobicity favored adsorption. }\end{array}$ & $\begin{array}{l}\text { Zhang et al. } \\
2011 \mathrm{c}\end{array}$ \\
\hline $\begin{array}{l}\text { Sulfamethoxazole } \\
\text { antibiotic }\end{array}$ & Biochars & $\mathrm{BC}$ & $300-600$ & $\mathrm{~F}$ & $1-4$ & $\begin{array}{l}\mathrm{F} \\
\mathrm{DA}\end{array}$ & - & $\begin{array}{l}\text { Increasing char temp increased uptake; } \\
\text { Freundlich/Dubin-Ashtakhov hybrid model; } \\
\text { charge-assisted hydrogen bonding can be } \\
\text { significant at higher pH values. }\end{array}$ & $\begin{array}{l}\text { Zheng et al. } \\
2013\end{array}$ \\
\hline $\begin{array}{l}\text { Atrazine pesticide, } \\
\text { Simazine pesticide }\end{array}$ & $\begin{array}{l}\text { Biochar from } \\
\text { greenwaste }\end{array}$ & $\mathrm{BC}$ & $450 \mathrm{C}$ & $\mathrm{F}$ & $\begin{array}{l}0.4-1.2 \\
0.2-1.1\end{array}$ & - & - & Competitive adsorption effects observed. & $\begin{array}{l}\text { Zheng et al. } \\
2010\end{array}$ \\
\hline Phenol & $\begin{array}{l}\text { Active carbon } \\
\text { fr. vinegar lees }\end{array}$ & $A C$ & $\begin{array}{l}\mathrm{CO}_{2} \\
875\end{array}$ & $\mathrm{~L}$ & $92-127$ & - & - & $\begin{array}{l}\text { The temperature of activation was } \\
\text { optimized. }\end{array}$ & $\begin{array}{l}\text { Zhong et al. } \\
2012\end{array}$ \\
\hline
\end{tabular}

(See notes for Table A on the following page.) 


\section{NOTES FOR TABLE A}

\section{Dried, Never, Heat}

$A C=$ Activated carbon (drying is implied in the manner of preparation)

$\mathrm{BC}=$ Biochar (drying is implied in the manner of preparation)

$\mathrm{C}=$ Degrees Celsius (even if no " $\mathrm{C}$ " is shown due to lack of space

Dry = Dried by some means, temperature not specified

$\mathrm{FA}=\mathrm{Fly}$ ash, which often is dominated by mineral components after incineration of biomass

$\mathrm{FD}=$ Freeze-dried using vacuum

No $=$ Not dried

\section{Isotherm best fits}

$\mathrm{F}=$ Freundlich isotherm gave a good fit to the data.

$\mathrm{L}=$ Langmuir isotherm gave a good fit to the data .

$\mathrm{RP}=$ Redlich-Peterson isotherm game a good fit to the data.

$\mathrm{T}=$ Temkin isotherm game a good fit to the data.

\section{Rate law best fit}

$1^{\text {st }}=$ Lagergren's pseudo-first order rate model

$2^{\text {nd }}=\mathrm{Ho}$ and McKay's pseudo-second order model

ID = Intraparticle diffusion

UT = Urano-Tachikawa model

\section{Thermodynamics}

$\mathrm{En}=$ Endothermic

Ex $=$ Exothermic

nil. $=$ No clear thermal trend 